\title{
Lumbar spinal fusion
}

Citation for published version (APA):

Loenen, A. C. Y. (2022). Lumbar spinal fusion: a biomechanical and biological perspective on early fusion. [Doctoral Thesis, Maastricht University]. Gildeprint Drukkerijen. https://doi.org/10.26481/dis.20220317al

\section{Document status and date:}

Published: 01/01/2022

DOI:

10.26481/dis.20220317al

Document Version:

Publisher's PDF, also known as Version of record

\section{Please check the document version of this publication:}

- A submitted manuscript is the version of the article upon submission and before peer-review. There can be important differences between the submitted version and the official published version of record.

People interested in the research are advised to contact the author for the final version of the publication, or visit the DOI to the publisher's website.

- The final author version and the galley proof are versions of the publication after peer review.

- The final published version features the final layout of the paper including the volume, issue and page numbers.

Link to publication

\footnotetext{
General rights rights.

- You may freely distribute the URL identifying the publication in the public portal. please follow below link for the End User Agreement:

www.umlib.nl/taverne-license

Take down policy

If you believe that this document breaches copyright please contact us at:

repository@maastrichtuniversity.nl

providing details and we will investigate your claim.
}

Copyright and moral rights for the publications made accessible in the public portal are retained by the authors and/or other copyright owners and it is a condition of accessing publications that users recognise and abide by the legal requirements associated with these

- Users may download and print one copy of any publication from the public portal for the purpose of private study or research.

- You may not further distribute the material or use it for any profit-making activity or commercial gain

If the publication is distributed under the terms of Article $25 \mathrm{fa}$ of the Dutch Copyright Act, indicated by the "Taverne" license above, 


\section{Lumbar Spinal Fusion}

a biomechanical and biological perspective on early fusion

Arjan Cornelius Yvar Loenen 
ISBN

978-94-6423-654-5

Cover design Arjan Loenen

Layout Arjan Loenen

Printing Gildeprint

\section{Financial support}

The research presented in this thesis was financially supported by the prosperos (printing personalized orthopaedic implants) project, funded by the Interreg VA, Belgium - the Netherlands program, CCI grant number 2014TC16RFCB046. Financial support for the publication of this thesis was provided by Maastricht University, 4WEB EU B.V., Cerapedics Inc, Neo Medical SA, and Anna Fonds | NOREF.

\section{Copyright $@$ C A.C.Y. Loenen, 2022}

All rights reserved. For all articles published, the copyright has been transferred to the respective publisher. No part of this thesis may be reproduced, stored in a database or retrieval system, or published, in any form or in any way, electronically, mechanically, by print, photo print, microfilm, or any other means without prior written permission from the author or, when appropriate, from the publisher. 


\section{Lumbar Spinal Fusion}

a biomechanical and biological perspective on early fusion

\section{PROEFSCHRIFT}

ter verkrijging van de graad van doctor aan de Universiteit Maastricht, op gezag van de Rector Magnificus, Prof. dr. Pamela Habibović, volgens het besluit van het College van

Decanen, in het openbaar te verdedigen op donderdag 17 maart 2022 om 13:00 uur

$$
\text { door }
$$

Arjan Cornelius Yvar Loenen

Geboren op 11 Juni 1992 te Vierlingsbeek 


\section{Promotoren}

Dr. J.J. Arts

Prof. dr. L.W. van Rhijn

\section{Copromotor}

Dr. ir. B. van Rietbergen (Technische Universiteit Eindhoven)

\section{Beoordelingscommissie}

Prof. dr. M. van Griensven (Voorzitter)

Prof. dr. L. Moroni

Prof. dr. H. van Santbrink

Prof. dr. ir. G.J. Verkerke (Universiteit Twente)

Prof. dr. A.A. Zadpoor (Technische Universiteit Delft) 


\section{Content}

$\begin{array}{ll}\text { Nederlandse Samenvatting } & 7\end{array}$

English summary

Chapter 1 General introduction

Chapter 2 The progression of bony bridging early after lumbar fusion surgery: a systematic review of the literature

Chapter 3 Misaligned spinal rods can induce high internal forces consistent with those observed to cause screw pullout and disc degeneration

Chapter 4 Patient-specific variations in local strain patterns on the surface of a trussed titanium interbody cage

Chapter 5 Early bone ingrowth and segmental stability of a trussed titanium cage versus a polyether ether ketone cage in an ovine lumbar interbody fusion model

Chapter 6 Peptide enhanced bone graft substitute presents improved short-term increase in bone volume and construct stiffness compared to iliac crest autologous bone in an ovine lumbar interbody fusion model

Chapter 7 Local bone metabolism during the consolidation process of spinal interbody fusion

Chapter 8 General discussion

Societal impact 



\section{Nederlandse Samenvatting}

Van de wereldwijde populatie ervaart $80 \%$ ooit lage rugpijn in zijn of haar leven. Lage rugpijn is dan ook de voornaamste oorzaak dat mensen een fysieke beperking ervaren in hun leven. Omdat lage rugpijn ook een grote sociale en economische impact heeft, wordt het beschouwd als een van de belangrijkste volksgezondheidsproblemen wereldwijd. Wanneer conservatieve behandelmethodes zoals fysiotherapie, het dragen van een brace, en pijnmedicatie de symptomen van lage rugpijn niet kunnen verhelpen, kan een operatieve ingreep genaamd 'spinale fusie' uitkomst bieden. Het doel van de spinale fusie is om de wervels in de pijnregio aan elkaar vast te zetten (te fuseren) om zo de wervelkolom te stabiliseren.

Het fuseren van twee wervels kan via de wervellichamen (interbody fusie), of via een instrumentatie raamwerk. Implantaten (genaamd kooien) gevuld met stukjes bottransplantaat worden in de tussenwervelschijfruimte geplaatst om een interbody fusie te stimuleren, terwijl een pedikel schroef-staaf constructie vaak wordt gebruikt voor de fusie van twee wervels via een instrumentatie raamwerk. Tijdens een posterieure lumbale interbody fusie (PLIF) worden deze twee normaliter gecombineerd. Voor succes op de lange termijn is het belangrijk dat er nieuw bot wordt gevormd, door en rondom de kooi, zodat de twee aangrenzende wervels aan elkaar vastgroeien (een fusie). Tot $20 \%$ van de lumbale interbody fusie (LIF) operaties resulteren echter niet in een daadwerkelijke fusie. De afwezigheid van een fusie zorgt niet per definitie voor problemen maar verkleint de kans op een goed klinisch resultaat.

Dit proefschrift beschreef de biomechanische en biologische gevolgen van fusieoperaties en behandelde verschillende disciplines die kunnen worden toegepast om de klinische betekenis van bestaande en nieuwe technologieën te evalueren. Omdat de verwachting was dat de nieuwe technologieën voornamelijk vroeg na de operatie een belangrijk effect zouden kunnen bewerkstelligen, richtte dit proefschrift zich vooral op de periode kort na de fusieoperatie.

Na een inleiding (Chapter 1) over de basisprincipes van de wervelkolom, de klinische achtergrond van fusieoperaties, en verschillende materialen die gebruikt worden bij fusieoperaties, werden de resultaten van een systematisch literatuuronderzoek gepresenteerd in Chapter 2. Hierin werd gevonden dat vroeg na de fusieoperatie er een grote spreiding zit in het percentage patiënten dat een succesvolle fusie bereikt. Dit toonde aan dat er grote voordelen behaald kunnen worden door de vroege fusiecondities te verbeteren. Tevens werd gesuggereerd dat de kans op complicaties verminderd kan worden wanneer de tijd tussen operatie en het bereiken van de fusie ingekort kan worden.

Wanneer meerdere spinale segmenten gefuseerd worden met pedikel schroef-staaf constructies kunnen er aanzienlijke afwijkingen ontstaan tussen staaf en schroefhoofd, zelfs na handmatige correcties van de staaf. In Chapter 3 werd door middel van een patiënt specifiek eindige elementen model voorspeld wat de consequentie is van het corrigeren van 
deze afwijking door schroefhoofd en staaf naar elkaar toe te trekken. We concludeerden dat een correctie van een dergelijke afwijking kan resulteren in hoge krachten op de schroeven die tot uittrekking van de schroef zouden kunnen leiden. Daarnaast kan de correctie leiden tot hoge weefselrekken in het geopereerde segment en in aangrenzende segmenten.

Snelle ontwikkelingen in het 3D printen van metalen hebben de productie van poreuze titanium fusiekooien mogelijk gemaakt. Deze poreuze titanium fusiekooien kunnen biomechanisch geoptimaliseerd zijn zoals bijvoorbeeld de 'trussed' titanium kooien. Door gebruik te maken van vier patiënt specifieke eindige elementen modellen in Chapter 4, hebben we de grootte en verdeling van lokale rekpatronen op de oppervlakte van deze 'trussed' titanium kooien kunnen voorspellen onder fysiologische belastingcondities en hebben we bepaald hoe deze rekpatronen afhingen van patiënt specifieke factoren. Er werd aangetoond dat de rekpatronen op de oppervlakte van de kooi erg vergelijkbaar waren tussen de verschillende patiënten, wat suggereert dat het ontwerp van de 'trussed' titanium kooi vrij robuust is vanuit mechanobiologisch perspectief. De rekken op de oppervlakte van de kooi, onder fysiologische belastingcondities, bleken een grootte te hebben die gerelateerd is met het onderhouden van bothomeostase en het stimuleren van botformatie.

De in vivo performance van de 'trussed' titanium kooien werd geanalyseerd in Chapter 5. De vroege bot ingroei en segmentale stabiliteit tijdens consolidatie van LIF werd gekwantificeerd voor 'trussed' titanium kooien en vergeleken met die voor polyether ether ketone (PEEK) kooien. Tussen de twee kooi types werd een ander mechanisme van bot ingroei en aanhechting gevonden. Op basis van de verschillen in ontwikkeling van fusie, veronderstellen we dat de 'trussed' titanium kooien verhoogde vroege segmentale stabiliteit kunnen faciliteren door directe integratie van bot en kooi op de wervel-kooi interface zonder dat er een volledige bot brug door de kooi heen aanwezig hoeft te zijn. Wanneer een verhoogde stabilisatie van het segment inderdaad bereikt kan worden zonder dat er een complete bot brug gevormd dient te worden, kan het tijdsvenster dat een segment kwetsbaar is voor instabiliteit-gerelateerde complicaties verkort worden.

Chapter 6 was opgezet om de in vivo effectiviteit en veiligheid van een synthetische bottransplantaatvervanger $(\mathrm{P}-15 \mathrm{~L})$ te beoordelen en om de prestaties van $\mathrm{P}-15 \mathrm{~L}$ te vergelijken met het autologe iliac crest bottransplantaat voor LIF. P-15L bleek effectief en vellig te zijn voor LIF. In vergelijking met het autologe iliac crest bottransplantaat, leek P$15 \mathrm{~L}$ de botvorming en modellering te versnellen maar op de lange termijn waren de fusieresultaten vergelijkbaar. Introductie van P-15L in de kliniek als vervanger voor autologe iliac crest bottransplantaten kan besparing van de iliac crest mogelijk maken waardoor de patiënt een pijnlijke ingreep bespaard blijft bespaard blijft.

Om een beter inzicht te krijgen in het consolidatieproces van LIF, kwantificeerde we in Chapter 7 de veranderingen in het lokale botmetabolisme vroeg na een LIF operatie met behulp van ${ }^{18} \mathrm{~F}$ natrium fluoride $\left({ }^{18} \mathrm{~F}-\mathrm{NaF}\right)$ positron emissie tomografie/computer tomografie (PET/CT) in een schapenmodel. Na een LIF operatie bleek er eerst een snelle toename van het botmetabolisme te zijn in de vertebrale eindplaten die zich naar het midden van de 
interbody ruimte ontwikkelde. $\mathrm{Nu}$ het lokale botmetabolisme tijdens gezonde consolidatie van spinale fusie bekend is, kan in de toekomst de identificatie van verminderde fusievorming vroeg na de LIF operatie wellicht mogelijk zijn met behulp van ${ }^{18} \mathrm{~F}-\mathrm{NaF}$ PET/CT scanning.

Chapter 8 gaf een overzicht van de belangrijkste bevindingen en implicaties, toekomstperspectieven, en conclusies van dit proefschrift.

Concluderend presenteerde dit proefschrift nieuwe inzichten over het belang van de progressie van fusie vroeg na de operatie en werd gesuggereerd hoe deze vroege fusie resultaten verbeterd zouden kunnen worden met biomechanisch geoptimaliseerde kooien en synthetische bottransplantaatvervangers. Of het gebruik van deze nieuwe technologieën inderdaad zal resulteren in verbeterede vroege fusie met succesvollere klinische resultaten en minder complicaties, vereist verder klinisch onderzoek. 


\section{English summary}

With an extreme high lifetime prevalence of $80 \%$, low back pain (LBP) is globally the primary cause of years lived with disability. LBP has been suggested as one of the leading global public health problems as LBP is not only a healthcare but also a major social and economic problem. When conservative treatments like physiotherapy, bracing, and pain medication cannot resolve LBP symptoms, spinal fusion surgery can be applied as operative treatment for a broad range of spinal disorders. This surgery aims to stabilize the spinal column by fixing vertebrae in the affected region together.

Fusion of two vertebrae might be performed via their vertebral bodies (interbody fusion), or via an instrumentation framework. Cages impacted with bone graft material are routinely inserted into the intervertebral space to induce interbody fusion, whereas pedicle screw-rod constructs are often used for fusion via an instrumentation framework. With posterior lumbar interbody fusion (PLIF) these two are combined. For long-term success, PLIF treatments rely on new bone formation that unites the adjacent vertebrae through the interbody cage. However, up to $20 \%$ of the lumbar interbody fusion (LIF) surgeries do not result in a bony union. Non-unions are not symptomatic by definition but are generally associated with inferior clinical outcome.

This thesis addressed biomechanical and biological consequences of fusion surgery and demonstrated several disciplines that can be utilized for evaluating the clinical significance of existing and novel technologies. The impact of these technologies, on spinal fusion treatment, was hypothesized to be most pronounced early after surgery. Therefore, this thesis mainly focused on the period early after fusion surgery.

After an introduction (Chapter 1) about the basics of the spine, clinical background of fusion surgeries, and different devices used in fusion surgeries, the results of a systematic literature review were presented in Chapter 2. It was demonstrated that early after fusion surgery there was a large variation in fusion rates, which highlighted that major advantages might be gained by enhancing short-term fusion conditions. By shortening the time window from surgery to stable union of the vertebrae, non-union related complications were suggested to be reduced.

When fusing multiple spinal segments by means of pedicle screw and rod constructs, significant residual mismatches between rod and screw head may exist, even after manual contouring. In Chapter 3 the consequence of forcefully reducing such mismatches was predicted using a patient-specific finite element (FE) model. We concluded that correction of misalignments could result in high forces at the screws consistent with those reported to cause screw pullout, and may cause high tissue strains in adjacent and downstream spinal segments.

Rapid evolvements in metal additive manufacturing techniques have enabled production of highly porous titanium interbody fusion cages that are biomechanically optimized, e.g. trussed titanium cages. Using four patient-specific FE models in Chapter 4, we evaluated 
the size and distribution of local strain patterns on the surface of trussed titanium cages under physiological loading conditions and determined how these strain patterns depended on patient-specific factors. It was demonstrated that the surface strains were very similar for the different models in the selected patient group, suggesting that the cage design is rather robust from a mechanobiological perspective. The strain magnitudes at the implant surface, under physiological loading conditions, were found in a range consistent with those reported to preserve bone homeostasis and stimulate bone formation.

The in vivo performance of the trussed titanium cage was analyzed in Chapter $\mathbf{5}$, i.e. the early bone ingrowth and segmental stability during consolidation of LIF was quantified for trussed titanium cages and compared to those for polyether ether ketone (PEEK) cages. A different mechanism of bone ingrowth and attachment was found between the two cages. Based on the differences in development of bony fusion, we hypothesized that trussed titanium cages might facilitate increased early segmental stability by direct osseointegration of the cage at the vertebral endplates without requiring complete bone bridging through the cage. When increased stabilization of the interbody segment can indeed be attained before achieving full consolidation of fusion, the time window that a segment is vulnerable to instability related complications might be shortened

Chapter 6 was set out to assess the in vivo efficacy and safety of the P-15L synthetic bone graft substitute and to compare its performance to autologous iliac crest bone graft (ICBG) for LIF indications. P-15L was demonstrated to be effective and safe for LIF. Compared to autologous ICBG, P-15L seemed to expedite bone formation and remodeling but in the longer term fusion results were similar. Introduction of $\mathrm{P}-15 \mathrm{~L}$ into the clinic as stand-alone alternative for autologous ICBG might thus obviate the necessity for harvesting ICBG reducing donor-site morbidities.

To get better insight in the consolidation process of LIF, Chapter 7 quantified the changes in local bone metabolism early after LIF surgery using ${ }^{18} \mathrm{~F}$ sodium fluoride $\left({ }^{18} \mathrm{~F}-\mathrm{NaF}\right)$ positron emission tomography/computed tomography (PET/CT) in an ovine model. After LIF surgery, there was shown to be a rapid increase in bone metabolism at the vertebral endplates that develops towards the center of the interbody region. Knowing the local bone metabolism during uncompromised consolidation of spinal fusion might enable identification of impaired bone formation early after LIF surgery using ${ }^{18} \mathrm{~F}-\mathrm{NaF}$ PET/CT scanning.

Chapter 8 provided an overview of the main findings and implications, future perspectives, and conclusion of this thesis.

In conclusion, this thesis presented new insights into the importance of the progression of fusion early after surgery and how these early fusion rates might be improved with biomechanically optimized cages and biomimetic bone graft products. Whether the use of these new technologies will indeed result in higher early fusion rates with improved clinical results and lower complications, warrants further dedicated clinical trial. 



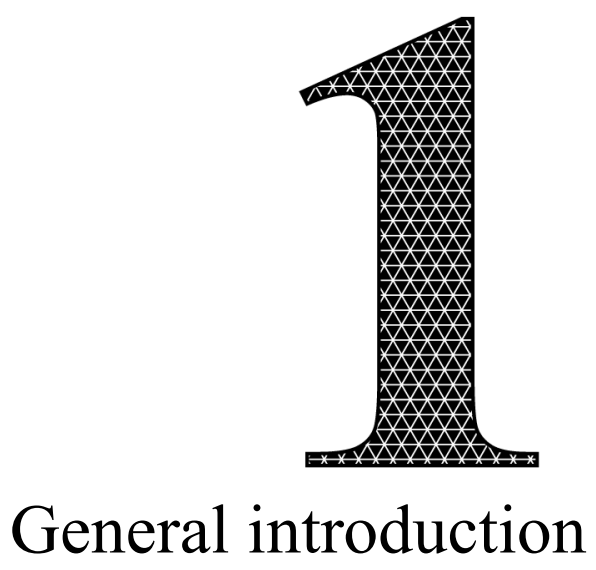



As biomedical engineer I want to contribute to improved healthcare by evaluating current clinical practice and developing new medical innovations. In this thesis, several aspects related to spinal fusion surgery were analyzed and novel spinal products were evaluated. This provided insight in the scope for improvement and the potential role of technological innovations in spinal healthcare.

\section{THE SPINE}

The spine, also called the backbone, is often used in metaphorical expressions to emphasize the presence or absence of mental strength, e.g. "show some backbone" or "you wouldn't have your peers walk over you like that if you had any spine". These metaphors are not merely a figure of speech as the spine indeed plays an important physical role in supporting and stabilizing the human body. Besides bearing the load of the human body, the spine facilitates movement of the back and simultaneously protects the neural tissue running from the brain, via the back, towards all peripheries of the body.

Although the name 'backbone' is a generally accepted term in daily language, the spine surely exists of more tissue types than bone only. The main substructures of the spine are the vertebrae, facet joints, intervertebral discs (IVDs), spinal cord and nerve roots, ligaments, tendons, and muscles [1]. The vertebrae are the bony structures of the spine. Humans generally have seven cervical (neck region), twelve thoracic (chest region), and five lumbar (low back region) vertebrae.

Two adjacent vertebrae are the main building blocks of a functional spinal unit (FSU), also known as spinal motion segment. Figure 1 provides a schematic overview of the structures composing one FSU with several anatomical parts highlighted. In addition, the anatomical parts of a single vertebra are described. Muscles, tendons, and other surrounding soft tissues are omitted for visualization purposes. Two adjacent vertebrae are separated by an IVD which consists of a central nucleus pulposus (NP) that is surrounded by an annulus fibrosis (AF). The NP is a gel-like substance with high water content while the AF consists of concentric rings (lamellae) of collagen [2]. Together, the NP and AF are responsible for the shock absorbing behavior of the IVD and the allowance for physiological motions within the FSU. Cartilaginous endplates form the connection between IVD and the bony endplates of the adjacent vertebrae. As these layers are semi-permeable, nutrient and waste transport between bone and IVD is continuously taking place [3]. The superior and inferior articular processes of two adjacent vertebrae constitute the facet joints and provide stability while allowing motion. The orientation of the articulating surfaces differs with the region in the 

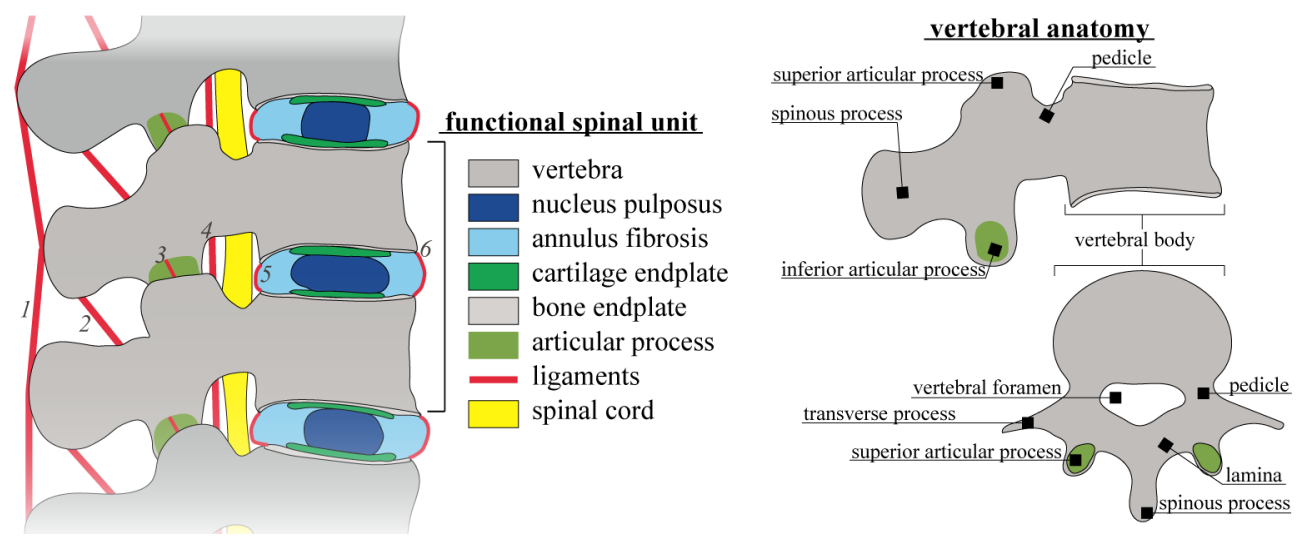

Figure 1. Schematic sagittal view of the spine in which several anatomical parts are highlighted (left). Two adjacent vertebrae, the intervertebral disc (IVD) in between, and all connecting ligaments form a functional spinal unit (FSU). Six of the seven major ligament groups per FSU are numbered in the overview, the seventh ligament (the intertransverse) is out of plane and thus not visible; (1) supraspinous (2) interspinous (3) capsular (4) flavum (5) posterior longitudinal (6) anterior longitudinal. For visualization purposes, the ligament groups are all shown as a single line while all groups in fact comprehend a collection of multiple fibers connecting bone to bone. For the general vertebral anatomy, substructures are indicated on a sagittal (top right) and top axial (bottom right) view of a single vertebra.

spine thereby explaining the differences in range of motion for the different regions of the spine. Ligaments are direct bone-to-bone fibers that link vertebrae together, stabilize the spinal column, and protect structures like the IVD and neural tissue. Additionally, ligaments prevent excessive movement of the spine as they give resistance when being elongated. The spinal cord passes through the vertebral foramen of the vertebral bodies, where it is surrounded by bone and thus protected, from the neck towards the first or second lumbar vertebra. Here, the spinal cord terminates (conus medullaris), and several separate nerve roots (known as cauda equina) continue to descend. At every lumbar level specific nerves branch out from the vertebral foramen [4].

\section{LOW BACK PAIN}

Spine related disorders are globally one of the most commonly observed clinical problems. As the lower segments of the spine are subjected to higher loads during daily activities, disorders are most abundant in the lumbar region of the spine [5]. Disorders in the lumbar spine may consist of a variety of degenerative changes. IVD degeneration may lead to a decrease in IVD height, bulging of the IVD, and reduction of the shock absorbing capacity of the IVD. Facet joints may degenerate over time and lose their ability to regulate intersegmental motion appropriately. Facet and/or IVD degeneration or a fracture of the pars interarticularis, which is the bony bridge connecting the inferior and superior articular process, may even result in slippage of one vertebra with respect to an adjacent vertebra, also called 'spondylolisthesis'. IVD degeneration, facet joint degeneration, spondylolisthesis, or a combination of these spinal alterations may lead to direct bone to bone contact, 
destabilization of the spinal column, tissue inflammation, and compression of neural structures, thereby generating low back pain (LBP) and/or leg pain symptoms. With a lifetime prevalence up to $80 \%[6,7]$, LBP is at the moment the primary cause of years lived with disability globally [8]. As LBP is the main cause for work absenteeism or disablement, it is not only a personal or a healthcare problem, but also a major social and economic problem [9]. LBP has therefore been recognized as one of the leading global public health problems.

Patients with LBP are initially treated with conservative therapies like physiotherapy, bracing, and pain medication. When being refractory to conservative treatments, spinal fusion surgery can be used as operative treatment for a wide range of spinal disorders [10]. Spinal fusion surgery (also known as spondylodesis) aims to stabilize the spinal column by fixing the vertebrae of the affected FSUs together, to indirectly reduce compression of neural tissue, and to restore initial IVD heights. As the fusion surgery relies on stabilization of the painful motion segments, it is suggested to be most effective for indications with a dynamic symptomatology [11]. An example of an indication with a dynamic symptomatology is a spondylolisthesis which causes segmental instability.

\section{SPINAL FUSION}

\section{Surgical technique}

Spinal fusion techniques started to emerge from the late $19^{\text {th }}$ century. The American surgeon W.F. Wilkins was the first in 1887 to describe an internal fixation of the spine to immobilize a dislocated fracture in a newborn [12]. This was quickly followed by the American surgeon B.E. Hadra who implemented steel wires to stabilize the cervical spine [13]. Also, the German surgeon F. Lange pioneered in the early $20^{\text {th }}$ century with internal steel bars to stabilize the spine of patients suffering from Pott's disease (spinal tuberculosis) [14]. In parallel, the American surgeons R.A. Hibbs and F.H. Albee explored and laid the groundwork for spinal fusion techniques without instrumentation, i.e. achieving spinal fusion by placing autologous pieces of bone, which promote bone development, at the desired fusion site $[15,16]$. In 1944, H. Briggs and P.R. Milligan described a posterior approach of the intervertebral disc space to place bone chips locally in order to promote solid fusion between two adjacent vertebrae via their vertebral bodies [17]. This procedure can be regarded as the first posterior lumbar interbody fusion (PLIF) surgery performed. As surgeons realized that immediate postoperative stabilization of the treated segment was imperative for achieving a successful spinal fusion, several internal spinal fixators were developed. The pedicle screw fixation as introduced by R. Roy-Camille in 1970 formed the basis of the pedicle screw and rod constructs as commonly used in current spinal fusion treatments [18].

With a pedicle screw and rod construct, metal screws are inserted bilaterally in the pedicles of the vertebrae of interest and are longitudinally connected to each other with rods. In this way, one or multiple FSUs can be posteriorly fused in order to stabilize the spine or to correct deformities. This procedure is also called a posterior spinal fusion. With multiple 


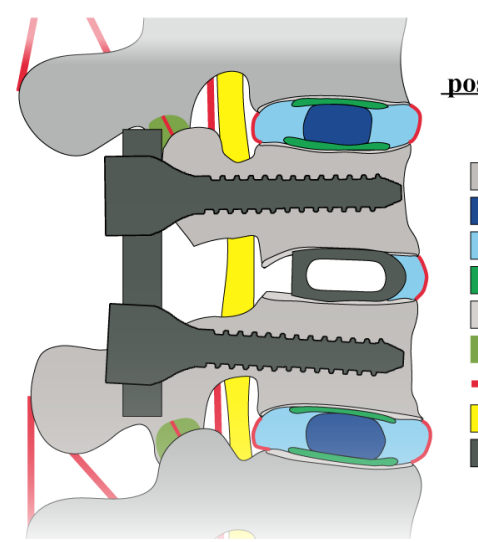

posterior lumbar interbody fusion (PLIF)
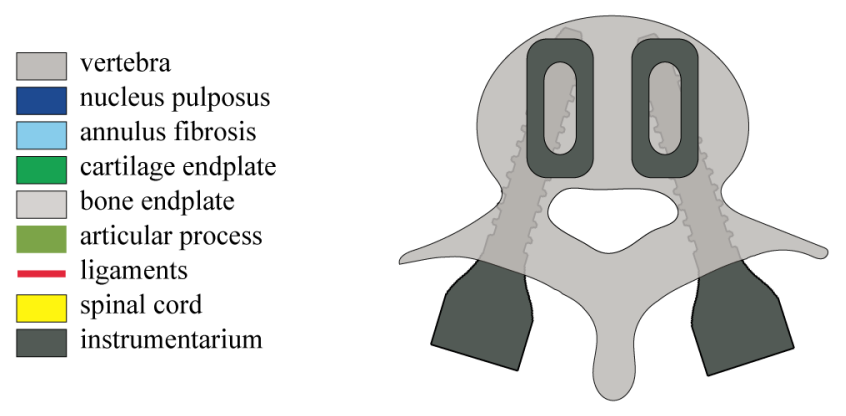

Figure 2. Schematic sagittal view of the spine after a combination of a one level posterior and interbody fusion via the posterior approach (left). For visualization purposes, the ligament groups are all shown as a single line while all groups in fact comprehend a collection of multiple fibers connecting bone to bone. A laminectomy is performed at the upper vertebra involved, which results in removal of the spinous process and all connecting ligaments. Also, the facet joints at the level of interest are usually removed to provide access to the intervertebral disc (IVD) space. Apart from the anterior part of the IVD, the complete IVD is resected, and two spacers are inserted between the vertebral bodies. A pedicle screw and rod construct is implemented to provide immediate stabilization to the treated segment. A top axial view of the lower vertebra involved displays the configuration of the pedicle screws and interbody spacers with respect to the vertebra (right).

spinal levels involved, proper alignment of the screws and rods is crucial to retain acceptable biomechanical forces [19]. In case of a segmental instability that originates from a degenerated disc, combined interbody and posterior fusion is suggested to be more effective than posterior fusion alone [20]. A posterior approach of the spine allows to instrument the spine both at the pedicles and at the intervertebral space via the same incision. Therefore, PLIF surgeries routinely consist of a combination of a pedicle screw and rod construct and an interbody fusion. Figure 2 provides a schematic overview of the structures in the spine after a PLIF surgery. Lumbar interbody fusion (LIF) surgery can also be performed via a transforaminal, (extreme) lateral, oblique, or anterior approach [21]. In general, every approach of interbody fusion is combined with some additional spinal fixator to provide initial stability.

\section{Interbody cages}

With PLIF, the pedicle screw and rod construct immediately stabilizes the spine posteriorly. Anteriorly, following retraction of the spinal cord and exiting nerve roots, the IVD is (partly) resected to enable insertion of a spacer between the vertebral bodies. This spacer is inserted to provide immediate mechanical stability and to facilitate bony bridging on the longer term. Conventionally, an iliac crest autologous bone (autograft) block was used as interbody spacer because it met the required criteria for an interbody spacer, i.e. it has the capacity to directly form bone (osteogenic); it triggers primitive cells to differentiate into bone-forming cells (osteoinductive); it facilitates bone ongrowth (osteoconductive); and it 

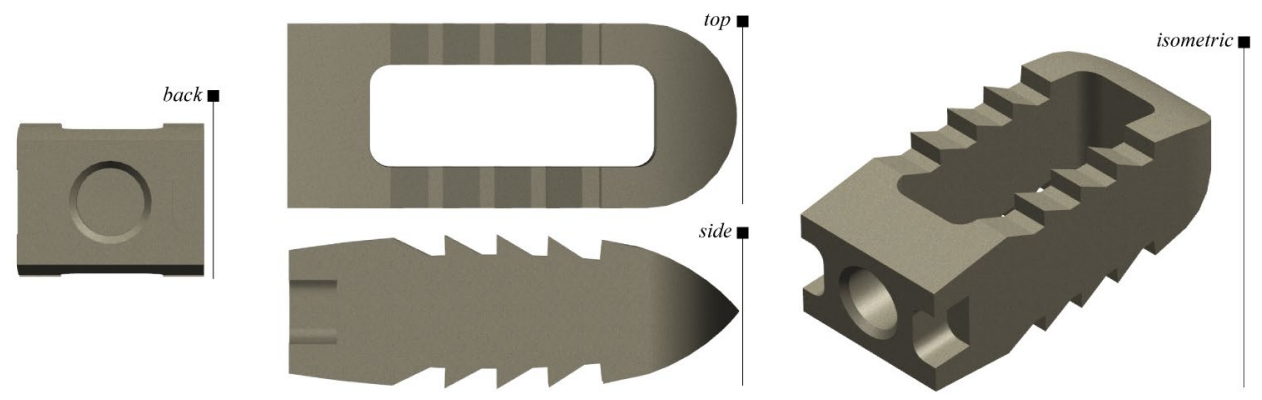

Figure 3. Back, top, side, and isometric view of a typical posterior lumbar interbody fusion (PLIF) cage design. These cage designs are mostly manufactured in polyether ether ketone (PEEK) and titanium. On the back, the cage contains a screw hole such that the cage can be screwed onto an insertion device. The front of the cage is bullet-shaped to facilitate gradual insertion. The top and bottom interface of the cage have teeth to reduce the risk on cage expulsion. Centrally, there is a window that can be packed with graft material.

provides sufficient mechanical strength [22]. However, due to comorbidities related to harvesting procedures and the limited availability of autograft, various alternative spacer materials have been investigated and used as interbody implants. These interbody implants are often called interbody cages. Polyether ether ketone (PEEK) and titanium are two wellaccepted types of interbody cages. Figure 3 shows a typical design of a PLIF cage. With a posterior approach of the spine, the spinal cord hinders full access to the dorsal side of the operated segment. Two cages are therefore used in PLIF surgery, one is inserted via the left and on via the right side of the spinal cord, respectively.

Both PEEK and titanium cages are considered suboptimal. PEEK cages do not facilitate bone ongrowth due to their biological inertness but have a stiffness matching the stiffness of native bone. In contrary, titanium cages facilitate bone ongrowth excellently but may induce adverse effects due to their high stiffness compared to the stiffness of native bone [23]. PEEK is radiolucent and thus allows assessment of bone growth by means of computed tomography (CT) excellently, whereas titanium generates significant CT artifacts impeding accurate evaluation of bone growth. Because of the limitations of both cage types, new cages are still being developed and introduced into the clinic. One specific technique used to manufacture a new generation of interbody cages is titanium additive manufacturing, commonly known as three-dimensional (3D) printing [24]. It builds an object layer-by-layer by selectively melting titanium powder together where needed, thus enabling production of porous titanium cages with an overall stiffness matching that of native bone. Examples of such 3D printed titanium cages are the trussed titanium interbody cages. The trussed titanium interbody cage will be further introduced and investigated in the current thesis. 


\section{Product introduction: 3D printed trussed titanium interbody cage}

$3 \mathrm{D}$ printing requires the design of a $3 \mathrm{D}$ geometry which is usually designed in dedicated computer aided design (CAD) software. Preprocessing software of the printer subsequently slices this geometry into layers producing spatial information about the model per layer. In the printer, a thin layer of titanium powder is spread on a building plate. Based on the geometrical information per layer, the powder is selectively fused together using a highintensity focused laser or electron beam. After one layer is finished, the building plate lowers with the distance of one layer thickness, and a new layer of powder is deposited such that the next layer can be processed. This process is repeated until the full product is fabricated. Since the titanium powder is only fused selectively, localized solidifications will form the desired product while surrounding, non-fused powder will remain untouched. The trussed titanium cages described here are 3D printed using electron beam melting (EBM). These systems fuse the metal powder together by means of an electron beam in a high vacuum environment. Because of the EBM printing technique, the implants contain a relatively roughened surface topography.

Figure 4 shows the as-manufactured geometry of a 3D printed trussed titanium PLIF cage. The trussed cages encompass a network of linear beam elements (struts) that join at several intersections within the design. The characteristics of trussed titanium implants have recently been summarized [25]. In brief, the trussed structure produces some struts to be in compressive and other struts to be in tensile strain under physiological loading. These strains are in a range that can provide a mechanobiological cue to the adjacent cells and thereby stimulating bone growth throughout the cage. The roughened surface topography at the struts is thought to improve the cage functionality. It has been extensively demonstrated before that roughened titanium accelerates bone formation and bone bonding as compared to smooth titanium. Besides, this roughness results in a larger coefficient of friction between the cage
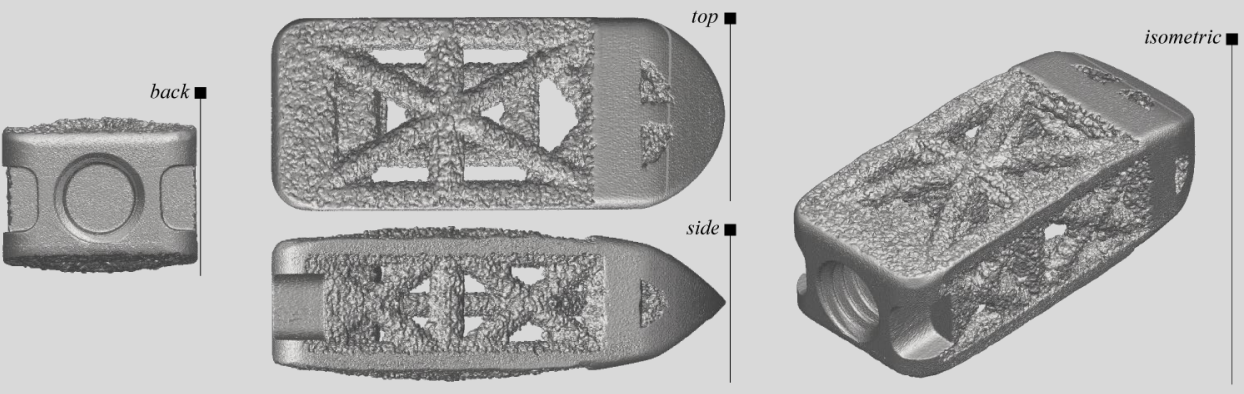

Figure 4. Back, top, side, and isometric view of the as-manufactured geometry of a 3D printed trussed titanium posterior lumbar interbody fusion (PLIF) cage. On the back, the cage contains a screw hole such that the cage can be screwed onto an insertion device. The front of the cage is bullet-shaped to facilitate gradual insertion. The rough surface at the struts provides resistance against cage expulsion. Graft material can be packed in the open spaces of the trussed structure. 
and the vertebral endplate, which improves the initial fixation and reduces the chances on migration. Another advantage of the trussed structure is the footprint of the cage that is in direct contact with the vertebral endplate. Because of its web-like design, it is claimed to distribute the load on the endplate more evenly and reduces the risk on cage subsidence.

\section{Cage grafting}

As interbody cages do typically not possess osteogenic or osteoinductive properties, cages are generally packed with graft material to stimulate bony fusion. For spinal interbody fusion, local bone graft from the resected lamina and/or autologous iliac crest bone graft (ICBG) still remain the gold standard of graft materials to be inserted [26]. However, the amount of local bone graft from the resected lamina may be insufficient, especially in case of earlier decompression surgery, and harvesting ICBG is associated with donor-site morbidity [27]. Therefore, several biological and synthetic graft substitutes have been proposed and investigated. Campana et al. provided an excellent overview of the available bone substitutes for orthopedic surgery in general [28]. Also, bone graft substitutes specifically used in spinal fusion surgery have been extensively reviewed recently [29-33]. For this reason, only a brief recapitulation of the most relevant bone graft substitutes is given here.

Osteoconductive synthetic ceramic materials as calcium-phosphate based granules or cements allow bone ongrowth excellently but do not promote bone formation and are therefore mainly effective as autograft extender but not as substitute. Allogenic bone (allograft) is one of the most often used alternatives for autografts. Allografts are obtained from a bone bank in which bone material from cadaveric and living donors (mainly from joint replacement surgeries) is stored. As sterilization of allografts is required to minimize the risks for contamination and infections, allografts do not contain viable cells and thus lack osteogenic properties. Additionally, allografts are lyophilized or frozen to be stored which destroys proteins and thus minimizes their osteoinductive capacity. As a consequence, allografts mainly serve as an autograft extender and inherently always bear some risk of viral or bacterial transmission. Demineralized bone matrices (DBMs) are allografts processed with acid extraction, which removes the mineralized portion of the structure. As a result, the osteoconductivity of the material is reduced. The remaining DBM consists of the collagen matrix of bone, growth factors and various proteins among which bone morphogenic protein (BMP). Because of the presence of these growth factors and proteins, DBMs have some osteoinductive properties. The exact osteoinductivity and osteoconductivity of the DBM depends on the manufacturers protocol and the carrier that is used for delivery of the composite to the surgical site. Moreover, the level of osteoinductive agents can vary within product batches. DBMs are successful autograft extenders, whereas clinical data demonstrating their efficacy as stand-alone autograft substitute for LIF indications is lacking. Development in recombinant gene technology has allowed production of synthetically 
engineered BMPs (rhBMPs) for clinical applications on large scale. As BMP is known to regulate and induce the entire formation process of new bone, rhBMP products are osteoinductive per definition. To enhance the osteoconductive capacity of the product, rhBMPs are usually added onto a collagen or ceramic carrier. Although rhBMP products have been demonstrated to be effective as stand-alone autograft substitute for LIF indications, several potential complications have been linked with the use of these products, i.e. increased risk of cancer, ectopic bone formation, cage migration and subsidence as a consequence of vertebral osteolysis, radiculitis, and inflammatory reactions. Because of these concerns, the search for ideal stand-alone bone graft substitutes still continues. A new approach is the development of biomimetic products that resemble the natural elements responsible for evoking bone formation. An example of such a biomimetic product is $\mathrm{P}-15 \mathrm{~L}$ (brand name iFACTOR+Matrix) as introduced below. This $\mathrm{P}-15 \mathrm{~L}$ is further investigated in current thesis.

\section{Product introduction: peptide enhanced bone graft substitute P-15L}

Proteins are large molecules, which are continuously synthesized in the human body, and are regarded as the workhorses of the cells. Amongst others, proteins catalyze chemical reactions, transport substances within the body, recognize signaling molecules, and defend organisms from infections. Proteins are made of a long chain of building blocks called amino acids. A short chain of these amino acids is called a polypeptide. In general, proteins thus consist out of multiple polypeptides, each having their own biological function within the complete protein. A biological function of a polypeptide within a protein might be to form a binding site for specific factors or even other proteins. With current technological advancements it has become possible to unravel the amino acid sequence of a protein and to synthetically reproduce specific polypeptides from the protein. The polypeptide enhanced bone graft substitute described over here consists of such a synthetically produced polypeptide.

Type-I collagen is the most abundantly present protein in bone, which increases the strength and toughness of the bone. During bone formation, osteoblasts first secrete an unmineralized organic matrix (osteoid) which consists mainly (90\%) of type-I collagen [34]. Subsequently, osteoblasts mineralize the osteoid which provides strength and rigidity to the bone. Collagen type-I is also responsible for initiating a cascade of cell bonding, migration, proliferation, and differentiation, eventually leading to osteogenesis. Type-I collagen thus plays a pivotal role in new bone formation.

The P-15L bone graft substitute contains synthetically produced 15-amino acid long polypeptides (P-15), which replicate the cell-binding domain of type-I collagen (see Figure 5). As cells get attracted and attached to this polypeptide, the cascade of orchestrating cell proliferation, differentiation, and osteogenesis will be activated [35-38]. To provide a 3D osteoconductive scaffold for bone deposition, the P-15 polypeptides are chemically bound to anorganic bone mineral (ABM) particles. To provide proper handling properties, specifically 


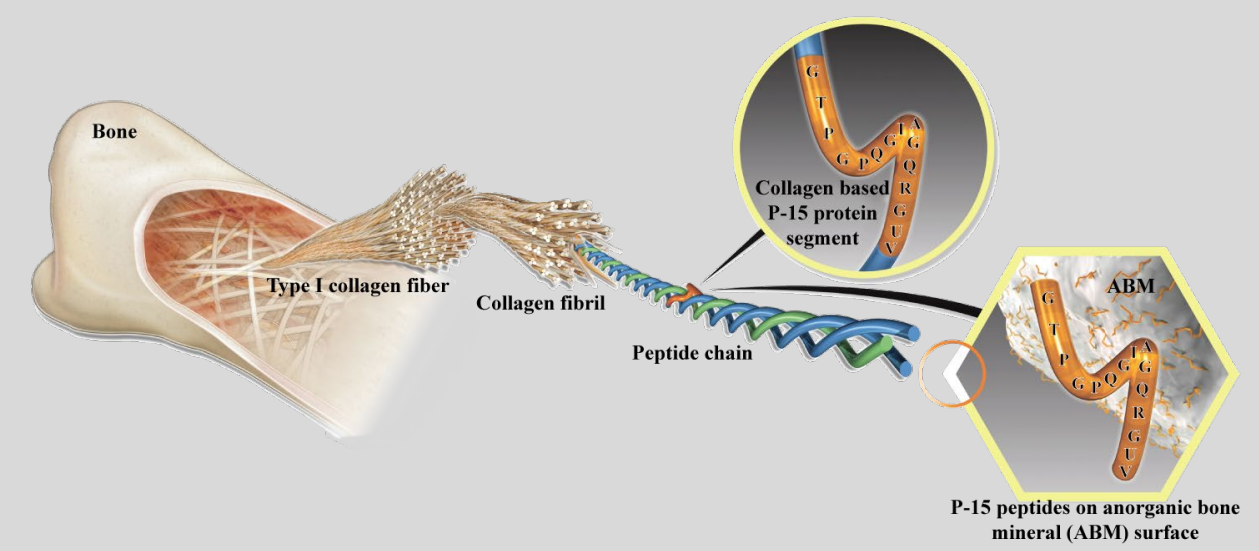

Figure 5. Schematic overview of the collagen fibers in the human bone. These type-I collagen fibers consist of fibrils, which are formed by a triple helix of polypeptide chains. Within these polypeptide chains, the amino acid sequence of P-15 can be found. This specific segment was found to have strong biological activities on osteogenic cells. P-15 polypeptides are synthetically produced and chemically bound to osteoconductive anorganic bone mineral (ABM) particles. P-15 coated ABM particles within a collagen carrier form the P-15L peptide enhanced bone graft substitute (image used with permission from Cerapedics Inc., Westminster, CO).

for lumbar fusion indications, the P-15 coated ABM particles are incorporated within a collagen carrier forming the $\mathrm{P}-15 \mathrm{~L}$ product. Just before usage, the product is required to be hydrated with saline.

\section{Postoperative course}

Following PLIF surgery, the spine is initially stabilized by means of the inserted interbody cages and the supplemental pedicle screw and rod construct. For long-term success, the treatment relies on bony union of the two adjacent vertebrae through and around the interbody cage [39]. Directly after surgery, there is an early inflammatory response in which granulation tissue is formed and vascularized. Then, ossification of the intervertebral space can proceed with a process termed creeping substitution [40]. During this process, bone progenitor cells, which reside in the bone marrow and enter the intervertebral space via the endplates, differentiate and start to actively resorb and replace the graft material by new bone. This substitution process commences at both endplates and gradually develops towards the center of the intervertebral space. The newly formed osseous structure will remodel for multiple years after surgery to adapt to the mechanical loads experienced by the tissue [41]. This is how bony fusion is progressing in an uncompromised situation. However, up to $20 \%$ of the LIFs do not result in a bony union [42]. Non-unions are not symptomatic by definition but are generally associated with inferior clinical outcome. Symptoms originating from a non-union may result in revision surgery up to 10 years after the initial treatment [43]. For this reason, patients are monitored postoperatively to detect potential abnormalities as soon 
as possible. In clinical practice, patients are routinely monitored using plain radiography and CT following LIF surgery. ${ }^{18} \mathrm{~F}$ sodium fluoride $\left({ }^{18} \mathrm{~F}-\mathrm{NaF}\right)$ positron emission tomography (PET) may additionally be used as a research tool to investigate the progression of fusion. The current thesis mainly focused on the imaging modalities CT and ${ }^{18} \mathrm{~F}-\mathrm{NaF}$ PET.

CT scanners make use of a rotating x-ray tube in order to generate radiographic projections of the patient under different angles. The collection of projections is then processed by an algorithm to reconstruct a $3 \mathrm{D}$ representation of the human body. This $3 \mathrm{D}$ representation consists of voxels that all have a gray value ranging from black to white. The exact gray value of every voxel depends on the tissue composition at that specific location. $\mathrm{X}$-rays penetrate easily through air whereas X-rays are more attenuated by mineralized bone tissue, which leads to relatively black and white CT voxel values for the lungs and bones, respectively (Figure 6, left). Following LIF surgery, CT is the most reliable non-invasive modality to assess to what extent new bone is formed between the two vertebral bodies [44]. In addition, $\mathrm{CT}$ can be used to detect hardware related complications such as cage subsidence or migration, or failure of the pedicle screw and rod construct.

Although the CT data provide a detailed static overview of the bone anatomy at the moment of scanning, it does not reveal any information on the bone formation process that might be ongoing. To get more insight into the ongoing bone metabolism at the moment of evaluation, nuclear medicine techniques can be deployed. These techniques rely on administration of a radioactive tracer that will accumulate at tissues that actively use this tracer. The amount of tracer that is accumulated after a certain time can be quantified based on the measured radioactivity. In case of PET imaging, the administered tracer should emit positrons $\left(\mathrm{e}^{+}\right)$upon decay. The emitted positrons annihilate with electrons $\left(\mathrm{e}^{-}\right)$, which are abundantly present in human tissue, within $2 \mathrm{~mm}$ distance [45]. Upon annihilation, two antiparallel photons $(\gamma)$ will be emitted with a specific energy of $511 \mathrm{keV}$. The PET system detects these $511 \mathrm{keV}$ photons and uses the given fact that, per event, two photons were emitted with an angular spread of $180^{\circ}$. With this info, the raw data of radioactive counts can be reconstructed into 3D image data which describes the amount of tracer accumulated per voxel. For orthopedic applications of PET imaging, ${ }^{18} \mathrm{~F}-\mathrm{NaF}$ is a well-appreciated radioactive tracer. Because of an excess of protons, ${ }^{18} \mathrm{~F}$ is unstable and emits positrons upon decay with a half-life of 109.7 minutes. ${ }^{18} \mathrm{~F}$ is known to accumulate at locations with a high bone metabolism where it integrates into the bone converting hydroxyapatite to fluorapatite. PET images thus enable evaluation of the metabolic activity of bone tissue. PET data is often combined with CT data to allow for attenuation correction of the PET images and to couple the anatomical data from the $\mathrm{CT}$ with the metabolic data from the PET scan (Figure 6, right). ${ }^{18} \mathrm{~F}-\mathrm{NaF}$ PET/CT potentially provides prognostic information on the ongoing bone formation after LIF surgery and might predict whether uncompromised progression of fusion is expected [46]. 

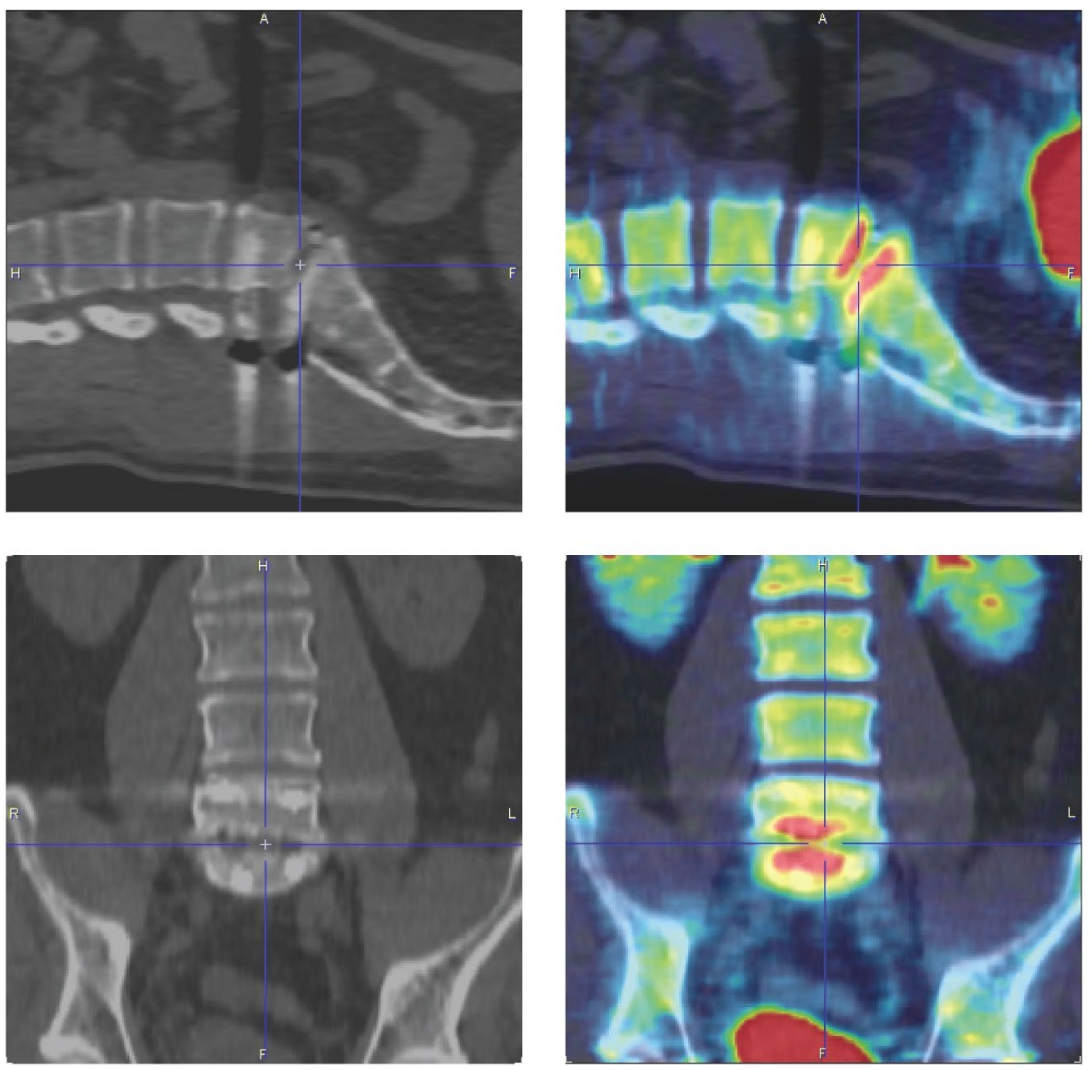

Figure 6. Sagittal (top row) and coronal (bottom row) images of the lumbar spine six weeks after posterior lumbar interbody fusion (PLIF) surgery. Computed tomography (CT) images (left) and ${ }^{18} \mathrm{~F}$ sodium fluoride $\left({ }^{18} \mathrm{~F}-\mathrm{NaF}\right)$ positron emission tomography (PET) images on top of the CT images (right). Red colors in the PET images represent areas with a high ${ }^{18} \mathrm{~F}$ uptake and can be found at the operated region as well as in the kidneys and the bladder. In general, all skeletal tissues show some ${ }^{18} \mathrm{~F}$ uptake whereas the soft tissues do not show any ${ }^{18} \mathrm{~F}$ uptake.

\section{OBJECTIVES AND THESIS OUTLINE}

Spinal fusion remains a well-acknowledged treatment for a wide range of spinal disorders when conservative treatment has failed [10]. Because of an aging population and the increasing effectiveness of spinal fusion for a variety of clinical indications, the amount of fusion procedures has increased over the past decades [47]. Due to the multifactorial nature of the interbody fusion process [41], a large array of novel technologies is continuously in development aiming to optimize the surgical technique, the device and graft material, and the postoperative monitoring of the patient. This thesis addresses biomechanical and biological aspects of fusion surgery and demonstrates several research methods that can be utilized for evaluating the clinical significance of existing and novel technologies. The impact of these technologies on the process of spinal fusion was hypothesized to be most pronounced early after surgery. Therefore, this thesis mainly focuses on the period early after fusion surgery. 
In the current chapter (Chapter 1), the clinical background, different products to be investigated in this thesis, and the outline of this thesis were introduced.

Chapter 2 continues the introduction by outlining the current status of interbody fusion in terms of progression of bony bridging over time. A systematic review approach was adopted to entail all relevant clinical studies on LIF outcomes. Main objective of this study was to quantify the fusion rate over time following LIF treatment. A secondary aim was to explore the potential relationship between early postoperative fusion rate and complication rate.

Subsequently, patient-specific finite element (FE) models were used to assess clinically relevant situations following fusion surgery from a biomechanical perspective. FE analysis allows for multistep procedures, provides parameters impossible to acquire experimentally or clinically, and has previously proven its value in exploring spinal care interventions [48, 49].

Spinal fusion surgery often includes pedicle screw and rod constructs in order to provide initial stabilization to the operated segment. When fusing multiple segments posteriorly, manual contouring of the spinal rod is commonly required to realize proper alignment of the rods within the screw heads [50]. However, even after contouring, significant residual mismatches between rod and screw head may exist [51]. Chapter 3 describes the consequences of forcefully reducing such a mismatch using a patient-specific FE model of the operated lumbar spine. In this research, it was aimed to predict whether the reduction might result in clinical complications directly after reduction and during a subsequent physiological flexion movement.

The rapid developments in additive manufacturing techniques have enabled the production of highly porous titanium interbody fusion cages like the previously introduced trussed titanium cages. These highly porous cages provide an open architecture to accommodate bone ingrowth and may, under physiological loading, deliver bone stimulating mechanobiological strains to the cells attached to the strut surfaces $[52,53]$. The exact in vivo strains, however, may depend on patient-specific factors such as weight, bone density, degenerative state of the spine, spinal curvature, and the loads applied. Chapter 4 presents FE models of a small population of patients eligible for LIF treatment. The FE models were adjusted to represent a PLIF surgery using two trussed titanium interbody cages. The purpose of this study was to determine the patient-specific variations in local strain patterns on the surface of the trussed titanium interbody cages under physiological loading conditions.

Next, preclinical models were used to investigate novel cage and graft products, and to monitor the bone metabolism during the consolidation process of LIF. The preclinical models used in this thesis were ovine LIF models. Although several animal models exist for preclinical spinal research, the ovine model is most often used because of its similarities in anatomy and biomechanics with the human spine [54-56]. 
As described before, LIF is an effective treatment for unstable spinal segments causing back and/or leg pain. However, the time required to establish a solid bony interbody fusion between the two vertebrae might be longer than twelve months after surgery [57]. During this time window, the instrumented spinal segment is assumed to be at increased risk for instability related complications such as cage migration or subsidence $[58,59]$. It is hypothesized that porous trussed titanium interbody cages, as previously introduced, enable direct osseointegration of the cage at the vertebral endplates, without requiring full bony fusion between the two vertebral endplates. Consequently, these cages might shorten the time window that the instrumented spinal segment is susceptible to failure. Chapter $\mathbf{5}$ presents the bone ingrowth and segmental stability during consolidation of fusion following LIF surgery using a trussed titanium cage compared to a conventional boxed PEEK cage.

To provide a biologically favorable environment for facilitating spinal interbody fusion, cages are generally packed with graft material. Autologous ICBG still remains the gold standard graft material in LIF surgery because of its osteogenic, osteoconductive, and osteoinductive properties [22]. However, as mentioned before, harvesting ICBG is associated with significant donor-site morbidity [27]. The bone graft substitute P-15L, as introduced previously, has been optimized for LIF indications and might be a stand-alone alternative graft material, which could obviate the necessity for ICBG harvesting. Chapter 6 assesses the in vivo efficacy and safety of the $\mathrm{P}-15 \mathrm{~L}$ bone graft substitute and compares its performance to ICBG for LIF indications using an ovine model.

Following LIF surgery, CT can identify the presence of eventual bony bridges but does not provide information on the ongoing formation process of new bony structures. ${ }^{18} \mathrm{~F}-\mathrm{NaF}$ PET could be used as complementary modality to add information on the local bone metabolism at the fusion site. However, it remains unknown how bone metabolism in the operated segment changes early after LIF surgery in uncompromised situations. Chapter 7 quantifies the changes in local bone metabolism during the consolidation process of LIF in an ovine model.

To finalize, Chapter 8 discusses the main findings and implications, future perspectives, and conclusions of this thesis.

\section{REFERENCES}

1. Biomechanics of Spine Stabilization. Stuttgart: Georg Thieme Verlag; 2015. Available from: http://www.thieme-connect.de/products/ebooks/book/10.1055/b-003-106374.

2. Roughley PJ, Melching LI, Heathfield TF, Pearce RH, Mort JS. The structure and degradation of aggrecan in human intervertebral disc. European Spine Journal. 2006;15(3):326-32.

3. Urban JP, Smith S, Fairbank JC. Nutrition of the intervertebral disc. Spine. 2004;29(23):2700-9. 
4. Cramer GD. Chapter 7 - The Lumbar Region. In: Cramer GD, Darby SA, eds. Clinical Anatomy of the Spine, Spinal Cord, and Ans (Third Edition). Saint Louis: Mosby; 2014. p. 246-311.

5. Morishita Y, Buser Z, D'Oro A, Shiba K, Wang JC. Clinical Relationship of Degenerative Changes between the Cervical and Lumbar Spine. Asian Spine J. 2018;12(2):343-8.

6. Walker BF. The prevalence of low back pain: a systematic review of the literature from 1966 to 1998. J Spinal Disord. 2000;13(3):205-17.

7. Hoy D, Bain C, Williams G, March L, Brooks P, Blyth F, . . ., Buchbinder R. A systematic review of the global prevalence of low back pain. Arthritis and rheumatism. 2012;64(6):2028-37.

8. Wu A, March L, Zheng X, Huang J, Wang X, Zhao J, ..., Hoy D. Global low back pain prevalence and years lived with disability from 1990 to 2017: estimates from the Global Burden of Disease Study 2017. Ann Transl Med. 2020;8(6):299-.

9. Lambeek LC, van Tulder MW, Swinkels ICS, Koppes LLJ, Anema JR, van Mechelen W. The Trend in Total Cost of Back Pain in the Netherlands in the Period 2002 to 2007. Spine. 2011;36(13):1050-8.

10. Mobbs RJ, Phan K, Malham G, Seex K, Rao PJ. Lumbar interbody fusion: techniques, indications and comparison of interbody fusion options including PLIF, TLIF, MI-TLIF, OLIF/ATP, LLIF and ALIF. Journal of Spine Surgery. 2015;1(1):2-18.

11. Bhalla A, Schoenfeld AJ, George J, Moghimi M, Bono CM. The influence of subgroup diagnosis on radiographic and clinical outcomes after lumbar fusion for degenerative disc disorders revisited: a systematic review of the literature. The spine journal : official journal of the North American Spine Society. 2017;17(1):143-9.

12. Wilkins WF. Separation of vertebrae with protrusion of hernia between same-operation cure. St Louis Med Surg J. 1888;54:340-1.

13. Hadra BE. Wiring the spinous processes in Pott's disease. Trans Am Orthop Assoc. 1891;4:206-10.

14. Lange F. Support for the spondylitic spine by means of buried steel bars, attached to the vertebrae. Am J Orthop Surg. 1910;8:334-61.

15. Hibbs RA. An operation for progressiv spinal deformities. NY Med J. 1911;93:1013.

16. Albee FH. Transplantation of a portion of the tibia into the spine for Pott's disease. Jama. 1911;57:885.

17. Briggs H, Milligan PR. Chip fusion of the low back following exploration of the spinal canal. Journal of Bone and Joint Surgery. 1944;26:125-30.

18. Roy-Camille R, Roy-Camille M, Demeulenaere C. [Osteosynthesis of dorsal, lumbar, and lumbosacral spine with metallic plates screwed into vertebral pedicles and articular apophyses]. La Presse medicale. 1970;78(32):1447-8.

19. Kang DG, Lehman RA, Jr., Wagner SC, Bevevino AJ, Tracey RW, Gaume RE, Dmitriev AE. Effects of rod reduction on pedicle screw fixation strength in the setting of Ponte osteotomies. The Spine Journal. 2015;15(1):146-52.

20. Videbaek TS, Christensen FB, Soegaard R, Hansen ES, Høy K, Helmig P, . . , Bünger CE. Circumferential fusion improves outcome in comparison with instrumented posterolateral fusion: long-term results of a randomized clinical trial. Spine. 2006;31(25):2875-80.

21. Phan K, Maharaj M, Assem Y, Mobbs RJ. Review of early clinical results and complications associated with oblique lumbar interbody fusion (OLIF). Journal of Clinical Neuroscience. 2016;31:23-9. 
22. Laurencin C, Khan Y, El-Amin SF. Bone graft substitutes. Expert review of medical devices. 2006;3(1):49-57.

23. Seaman S, Kerezoudis P, Bydon M, Torner JC, Hitchon PW. Titanium vs. polyetheretherketone (PEEK) interbody fusion: Meta-analysis and review of the literature. Journal of clinical neuroscience : official journal of the Neurosurgical Society of Australasia. 2017;44:23-9.

24. Arts M, Torensma B, Wolfs J. Porous titanium cervical interbody fusion device in the treatment of degenerative cervical radiculopathy; 1-year results of a prospective controlled trial. The Spine Journal. 2020;20(7):1065-72.

25. Hunt JP, Begley MR, Block JE. Truss implant technology ${ }^{\mathrm{TM}}$ for interbody fusion in spinal degenerative disorders: profile of advanced structural design, mechanobiologic and performance characteristics. Expert review of medical devices. 2021:1-9.

26. Dimar JR, Glassman SD, Burkus JK, Pryor PW, Hardacker JW, Carreon LY. Two-year fusion and clinical outcomes in 224 patients treated with a single-level instrumented posterolateral fusion with iliac crest bone graft. The Spine Journal. 2009;9(11):880-5.

27. Summers BN, Eisenstein SM. Donor site pain from the ilium. A complication of lumbar spine fusion. The Journal of bone and joint surgery British volume. 1989;71(4):677-80.

28. Campana V, Milano G, Pagano E, Barba M, Cicione C, Salonna G, . . , Logroscino G. Bone substitutes in orthopaedic surgery: from basic science to clinical practice. Journal of materials science Materials in medicine. 2014;25(10):2445-61.

29. Gupta A, Kukkar N, Sharif K, Main BJ, Albers CE, El-Amin Iii SF. Bone graft substitutes for spine fusion: A brief review. World J Orthop. 2015;6(6):449-56.

30. Abjornson C, Brecevich A, Callanan T, Dowe C, Cammisa FP, Lorio MP. ISASS Recommendations and Coverage Criteria for Bone Graft Substitutes used in Spinal Surgery. International journal of spine surgery. 2018;12(6):757-71.

31. Smith KA, Russo GS, Vaccaro AR, Arnold PM. Scientific, Clinical, Regulatory, and Economic Aspects of Choosing Bone Graft/Biological Options in Spine Surgery. Neurosurgery. 2018;84(4):827-35.

32. Duarte RM, Varanda P, Reis RL, Duarte ARC, Correia-Pinto J. Biomaterials and Bioactive Agents in Spinal Fusion. Tissue engineering Part B, Reviews. 2017;23(6):54051.

33. D'Souza M, Macdonald NA, Gendreau JL, Duddleston PJ, Feng AY, Ho AL. Graft Materials and Biologics for Spinal Interbody Fusion. Biomedicines. 2019;7(4):75.

34. Kalfas IH. Principles of bone healing. Neurosurgical focus. 2001;10(4):E1.

35. Qian JJ, Bhatnagar RS. Enhanced cell attachment to anorganic bone mineral in the presence of a synthetic peptide related to collagen. Journal of biomedical materials research. 1996;31(4):545-54.

36. Kübler A, Neugebauer J, Oh JH, Scheer M, Zöller JE. Growth and proliferation of human osteoblasts on different bone graft substitutes: an in vitro study. Implant dentistry. 2004;13(2):171-9.

37. Yang XB, Bhatnagar RS, Li S, Oreffo RO. Biomimetic collagen scaffolds for human bone cell growth and differentiation. Tissue engineering. 2004;10(7-8):1148-59.

38. Gomar F, Orozco R, Villar JL, Arrizabalaga F. P-15 small peptide bone graft substitute in the treatment of non-unions and delayed union. A pilot clinical trial. Int Orthop. 2007;31(1):93-9.

39. Raizman NM, O'Brien JR, Poehling-Monaghan KL, Yu WD. Pseudarthrosis of the spine. The Journal of the American Academy of Orthopaedic Surgeons. 2009;17(8):494503. 
40. Burchardt $\mathrm{H}$. The biology of bone graft repair. Clinical orthopaedics and related research. 1983;(174):28-42.

41. Smit TH, Muller R, van Dijk M, Wuisman PI. Changes in bone architecture during spinal fusion: three years follow-up and the role of cage stiffness. Spine. 2003;28(16):1802-8; discussion 9.

42. Meng B, Bunch J, Burton D, Wang J. Lumbar interbody fusion: recent advances in surgical techniques and bone healing strategies. European Spine Journal. 2021;30(1):2233.

43. Kornblum MB, Fischgrund JS, Herkowitz HN, Abraham DA, Berkower DL, Ditkoff JS. Degenerative lumbar spondylolisthesis with spinal stenosis: a prospective long-term study comparing fusion and pseudarthrosis. Spine. 2004;29(7):726-33; discussion 33-4.

44. Peters MJM, Bastiaenen CHG, Brans BT, Weijers RE, Willems PC. The diagnostic accuracy of imaging modalities to detect pseudarthrosis after spinal fusion-a systematic review and meta-analysis of the literature. Skeletal Radiol. 2019;48(10):1499-510.

45. Bridges RL, Wiley CR, Christian JC, Strohm AP. An introduction to Na(18)F bone scintigraphy: basic principles, advanced imaging concepts, and case examples. Journal of nuclear medicine technology. 2007;35(2):64-76; quiz 8-9.

46. Peters MJM. The diagnostic potential of 18F-Fluoride PET/CT in lumbar spinal fusion patients - early detection of pseudarthrosis and identification of pain generators after surgery [Doctoral Thesis]. Maastricht: Maastricht University; 2019.

47. Reisener MJ, Pumberger M, Shue J, Girardi FP, Hughes AP. Trends in lumbar spinal fusion-a literature review. Journal of spine surgery (Hong Kong). 2020;6(4):752-61.

48. Fagan MJ, Julian S, Mohsen AM. Finite element analysis in spine research. Proceedings of the Institution of Mechanical Engineers, Part H: Journal of Engineering in Medicine. 2002;216(5):281-98.

49. Noailly J, Lacroix D. 5 - Finite element modelling of the spine. In: Ambrosio L, Tanner E, eds. Biomaterials for Spinal Surgery: Woodhead Publishing; 2012. p. 144-234e.

50. Wanivenhaus F, Neuhaus C, Liebmann F, Roner S, Spirig JM, Farshad M. Augmented reality-assisted rod bending in spinal surgery. The spine journal : official journal of the North American Spine Society. 2019;19(10):1687-9.

51. Fiere V, Armoiry X, Vital JM, Lafage V, Berthiller J, Barrey C. Preoperative Planning and Patient-Specific Rods for Surgical Treatment of Thoracolumbar Sagittal Imbalance. In: van de Kelft E, ed. Surgery of the Spine and Spinal Cord: A Neurosurgical Approach. Cham: Springer International Publishing; 2016. p. 645-62.

52. Caffrey JP, Cory E, Wong VW, Masuda K, Chen AC, Hunt JP, ..., Sah RL. Ex vivo loading of trussed implants for spine fusion induces heterogeneous strains consistent with homeostatic bone mechanobiology. J Biomech. 2016;49(16):4090-7.

53. Caffrey JP, Alonso E, Masuda K, Hunt JP, Carmody CN, Ganey TM, Sah RL. Strains in trussed spine interbody fusion implants are modulated by load and design. Journal of the mechanical behavior of biomedical materials. 2018;80:203-8.

54. Wilke HJ, Kettler A, Wenger KH, Claes LE. Anatomy of the sheep spine and its comparison to the human spine. The Anatomical record. 1997;247(4):542-55.

55. Wilke HJ, Kettler A, Claes LE. Are sheep spines a valid biomechanical model for human spines? Spine. 1997;22(20):2365-74

56. Pearce AI, Richards RG, Milz S, Schneider E, Pearce SG. Animal models for implant biomaterial research in bone: a review. European cells \& materials. 2007;13:1-10. 
57. Schiffman M, Brau SA, Henderson R, Gimmestad G. Bilateral implantation of lowprofile interbody fusion cages: subsidence, lordosis, and fusion analysis. The spine journal : official journal of the North American Spine Society. 2003;3(5):377-87.

58. Vaidya R, Sethi A, Bartol S, Jacobson M, Coe C, Craig JG. Complications in the Use of rhBMP-2 in PEEK Cages for Interbody Spinal Fusions. Clinical Spine Surgery. 2008;21(8):557-62.

59. Lee JH, Jeon D-W, Lee S-J, Chang B-S, Lee C-K. Fusion Rates and Subsidence of Morselized Local Bone Grafted in Titanium Cages in Posterior Lumbar Interbody Fusion Using Quantitative Three-Dimensional Computed Tomography Scans. Spine. 2010;35(15):1460-5. 



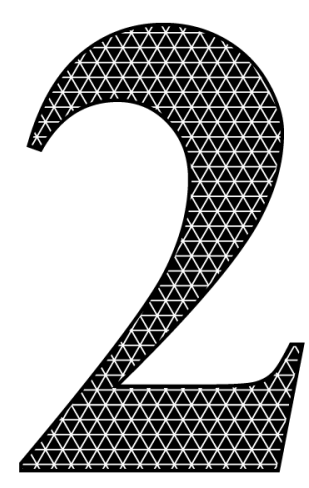

The progression of bony bridging early after lumbar fusion surgery: a systematic review of the literature

ACY Loenen

SMJ van Kuijk

J Howick

K McDermott

S Johnson

PC Willems

JJ Arts

In preparation 



\section{INTRODUCTION}

Lumbar interbody fusion (LIF) surgery is widely applied to treat a range of spinal disorders refractory to conservative treatment [1]. During LIF surgery, the intervertebral disc of the affected segment is resected followed by insertion of an interbody spacer. Biological interbody spacers (e.g. autologous and allogenic bone constructs), synthetic spacers (e.g. polyether ether ketone (PEEK) and titanium cages), or a combination of these (e.g. synthetic cages packed with bone graft) are commonly used in clinical practice [2]. Immediately postoperative, the role of these spacers or cages is to restore the initial disc height and to provide mechanical stability to the spinal column. As time progresses, the two adjacent vertebrae should fuse together within and around the cage by bony union in order to achieve long-term clinical success [3]. This is because delayed unions can result in adverse effects as progressive deformity, instrument failure, symptomatic micromotion of the cage, and mechanical failure of the fusion construct. These adverse effects may ultimately lead to revision surgery up to 10 years after the initial treatment [4].

Despite the current technological advancements for LIF surgery, non-union still remains a major complication following fusion treatment affecting between 7 and $20 \%$ of patients [5]. While it is clear that non-union is a problem, attempts to estimate the progression of fusion precisely are plagued by numerous problems including the application of different modalities to monitor the fusion, the use of different assessment criteria to declare a segment fused, and the use of different (predominantly long) postoperative time periods at which the status of fusion is reported during follow-up [6].

Moreover, the progression of fusion is known to be affected by a multitude of factors amongst which patient demographics, surgical approach, and the inserted graft and cage materials [7-9]. In order to get more insight in the early postoperative progression of fusion, i.e. bony bridging over time following LIF surgery, we systematically reviewed any study that assessed the fusion rate within one year by means of the gold standard of computed tomography (CT) in patients with persistent severe low back pain undergoing LIF surgery. A secondary aim was to explore the potential relationship between early postoperative fusion rate and complication rate.

\section{MATERIALS AND METHODS}

A systematic review of studies describing the fusion rate after LIF surgery was performed as described in a predefined protocol. The preferred reporting items for systematic reviews and meta-analyses (PRISMA) guidelines were followed to build a database that enables investigation of several research questions regarding LIF surgery [10].

\section{Search strategy and eligibility criteria}

Searches were developed specifically for each of the following electronic databases: MEDLINE (Ovid), EMBASE (Ovid), Cochrane database of systematic reviews (Wiley), 
Cochrane central register of controlled trials (Wiley), and KSR evidence (see Supplementary material 1 for the full search strategy). Bibliographies of identified articles were also checked for relevant studies. Searches were conducted on January 25, 2021 and were not limited by date, language, or publication status. A study was considered eligible for review if it reported a fusion rate following LIF surgery for a population of minimally 15 patients on at least one (un)specific time point. Studies were excluded when they solely focused on revision surgery, animal research, cadaver research, computational modelling, tumor cases, scoliosis and other spinal deformity cases, high grade ( $>$ II) spondylolisthesis, long-segment $(>3)$ fusions, infection cases, thoracic or cervical spinal region, adjacent segment disease, corpectomy, or posterolateral fusions. In addition, methodological papers, commentary articles, economic data, guideline updates, description of fusion criteria, and review articles were excluded from the analysis. Other reasons for exclusion were vertebroplasty, vertebral fracture cases, osteoporotic patient populations, osteophyte analyses, or rheumatic cases, as well as research in the form of a published abstract or poster without an available full paper.

\section{Study selection}

Duplicated records were removed as well as all publications with a date before January 1, 2001. Title and abstracts were screened by two independent reviewers, with discrepancies resolved by discussion. In case of disagreement a third reviewer was consulted. Exclusion of studies based on full paper screening was performed in two steps. First, the papers that did not meet the initial inclusion criteria based on full-text review were removed and the reason for exclusion was indicated. Second, for each paper it was checked whether the fusion rates were assessed by means of CT data, and whether there was at least one assessment of fusion within one year after surgery. Studies that did not meet these two criteria were excluded from full data extraction as well.

\section{Data extraction and quality assessment}

Data extraction into a predefined extraction sheet was performed by one reviewer and checked by a second reviewer. Any discrepancies were resolved by discussion between two reviewers, or with a third reviewer when necessary. Various details were extracted from each of the eligible studies, including the article information, patient group descriptors, information on surgical procedure and materials used, the way fusion was assessed, fusion rates at (un)specific time point(s), clinical outcome scores, and complications.

Appropriate risk of bias (RoB) tools were used for different study designs. For randomized trials, the Cochrane RoB tool was used [11]. For cohort, case control, and case series study designs, the appropriate appraisal tools of the Joanna Briggs Institute (JBI) were used [12]. RoB was performed by one reviewer and checked by a second reviewer. Any discrepancy was resolved by discussion between the two reviewers, or if necessary with a third reviewer. 


\section{Data analysis}

Patient groups for which the fusion rate was reported at specific time points $(3,6,9,12$, 18 , and 24 months postoperatively) were eventually included in the data overview. Per postoperative time point, the weighted mean fusion rate across all patient groups including the weighted standard deviation was calculated. The size of patient group was used for weighing. Additionally, the minimum and maximum reported fusion rate per time point were determined. This data was also visualized by plotting every patient group on a postoperative time point versus fusion rate graph.

Patient groups for which the fusion rate was reported 3 or 24 months postoperatively, as well as the complication rate of instrument migration, instrument subsidence, instrument failure, or the rate of reoperations following initial surgery, were included to plot the complication rate versus fusion rate. Weighted linear regressions were performed per complication rate as a function of the fusion rate 3 and 24 months postoperatively. Patient group sizes were used for weighing, i.e. the patient group size of each single data point was used to determine the relative influence of each data point in the least squares regression.

\section{RESULTS}

In total, 20,956 records were retrieved by the database searches (Figure 1). After the removal of 5,643 duplicate records and the removal of 1,328 records because of the 2001 publication date limit, a total of 13,985 records remained available for title and abstract screening. As 13,329 were excluded based on title and abstract screening, 656 studies were identified as potentially eligible and full texts were sought. Of these, 64 turned out to be conference reports, and 12 studies could not be obtained, leaving 580 papers for initial full paper screening. In the first step, 126 studies did not meet the initial inclusion criteria and were removed. In the second step, an additional 366 studies were excluded because they did not meet the additional criteria (assessment by means of CT data and at least one assessment of fusion within one year after surgery). This left a total of 88 studies for complete data extraction (24 randomized trials, 30 cohort studies, and 34 case series). Of all included studies, 7, 66, and 15 studies were assessed to have a low, high, and unclear RoB, respectively.

Figure 2 shows a graphical overview of the reported fusion rate per patient group over time and an overview of the descriptive statistics per postoperative time point. Two years postoperatively, fusion rates were generally high with a relatively narrow variation (range of $76-100 \%$ with a weighted mean of $92 \%$ over all patient groups). Early after surgery, large variations were found in fusion rates. In fact, within six months after surgery, fusion rates vary within the whole spectrum from $0-100 \%$. The number of patient groups that reported fusion rates at 9 and 18 months after surgery were low ( $n=3$ and $n=7$ respectively), while the most reported fusion rates were found at 6 and 12 months after surgery. The overall fusion rate seems to reach its maximum 1.5-2 years after surgery. 

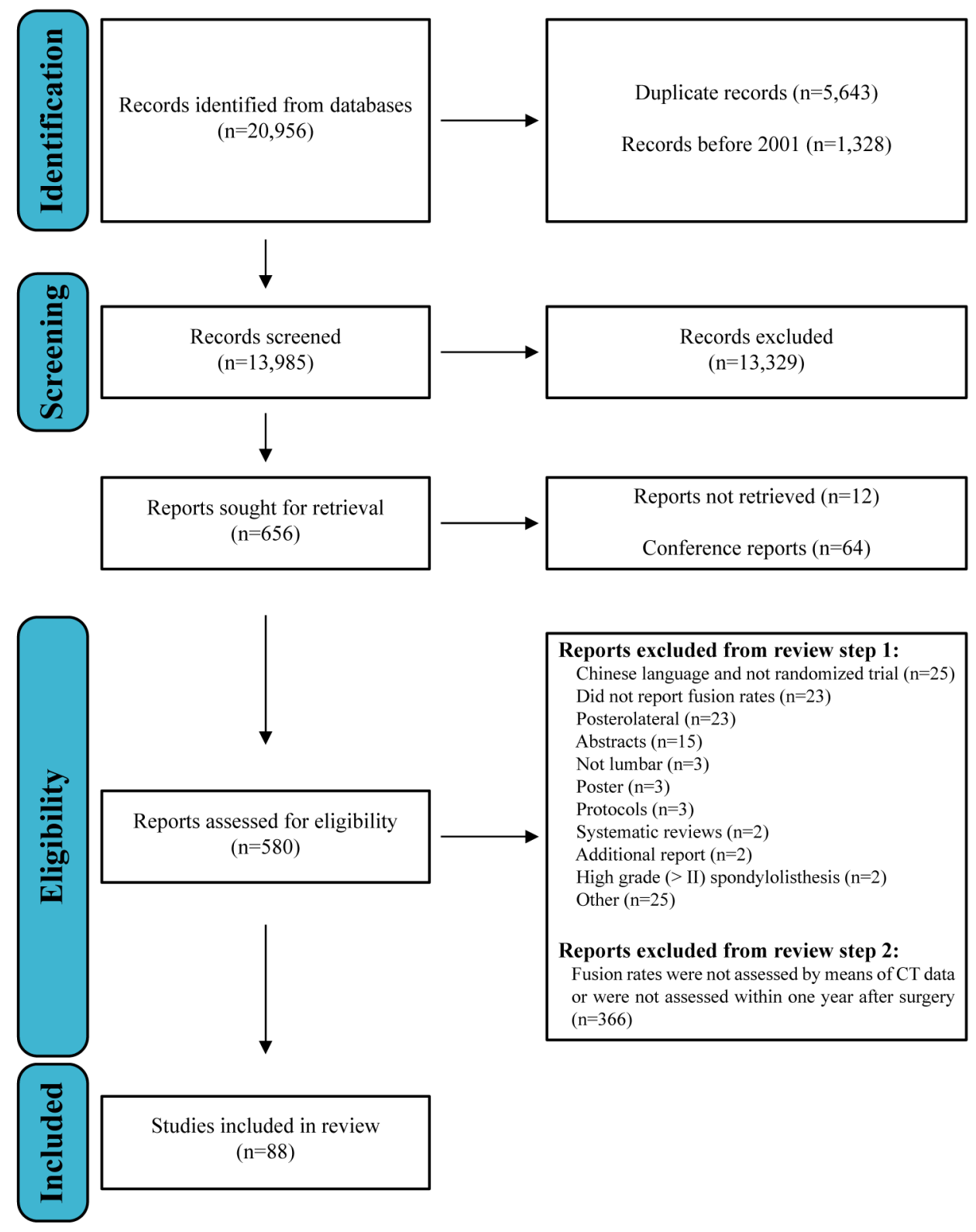

Reports excluded from review step 1:

Did not report fusion rates $(\mathrm{n}=23$ )

olateral $(n=23)$

Not lumbar $(\mathrm{n}=3)$

Poster $(\mathrm{n}=3)$

High grade $(>\mathrm{II})$ spondylolisthesis $(\mathrm{n}=2$

Reports excluded from review step 2 :

Fusion rates were not assessed by means of CT data

Figure 1. Overview of the identification, screening, and selection of articles for inclusion in the systematic review. 


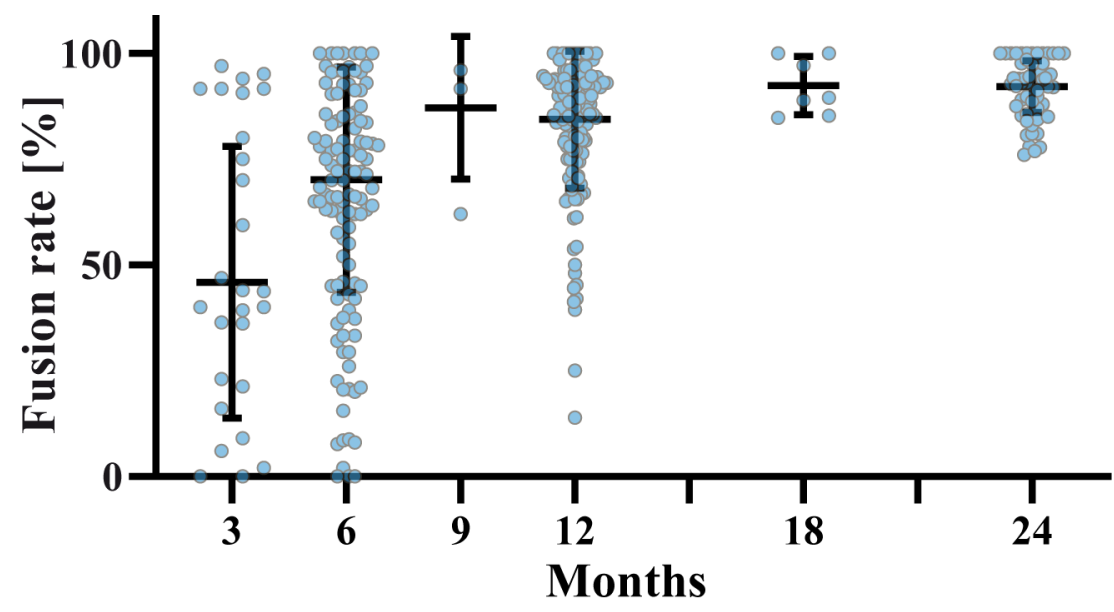

\begin{tabular}{cccccccc}
\hline & Months & $\mathbf{3}$ & $\mathbf{6}$ & $\mathbf{9}$ & $\mathbf{1 2}$ & $\mathbf{1 8}$ & $\mathbf{2 4}$ \\
\hline Fusion & mean & 46 & 70 & 87 & 84 & 92 & 92 \\
rate $[\%]$ & stdev & 32 & 27 & 17 & 16 & 7 & 6 \\
& min & 0 & 0 & 62 & 14 & 85 & 76 \\
& max & 97 & 100 & 96 & 100 & 100 & 100 \\
\multicolumn{2}{c}{ patient groups } & 27 & 115 & 3 & 132 & 7 & 57
\end{tabular}

Figure 2. Graphical overview of the fusion rates over time. Each data point originates from a patient group for which the fusion rate was reported at that postoperative time point, lines represent the weighted mean and weighted standard deviation. The size of patient group was used for weighing. In addition, the descriptive statistics are shown per time point in the table below the graph.

Instrument migration rate was only reported for one patient group for which a fusion rate was reported 3 months postoperatively (fusion rate of $2 \%$ and instrument migration rate of $3 \%$ ). There was also only one patient group for which instrument migration rate and the 24 months postoperative fusion rate was reported (fusion rate of $100 \%$ and instrument migration rate of $4 \%$ ). Linear regressions could thus not be performed for the instrument migration rate as a function of fusion rates. Figure 3 provides an overview of the complication rates versus fusion rate including R-squared values of the weighted linear regressions. For instrument subsidence and failure there seems to be a negative relation between fusion rate 3 months postoperatively and the occurrence of complication (R-squared of 0.61 and 0.98 respectively), whereas this relation is absent between fusion rate 24 months postoperatively and complication rate (R-squared of 0.01 and 0.10 respectively). Besides, there seems to be a negative relation between fusion rate 24 months postoperatively and the rate of reoperations (R-squared of 0.45). 

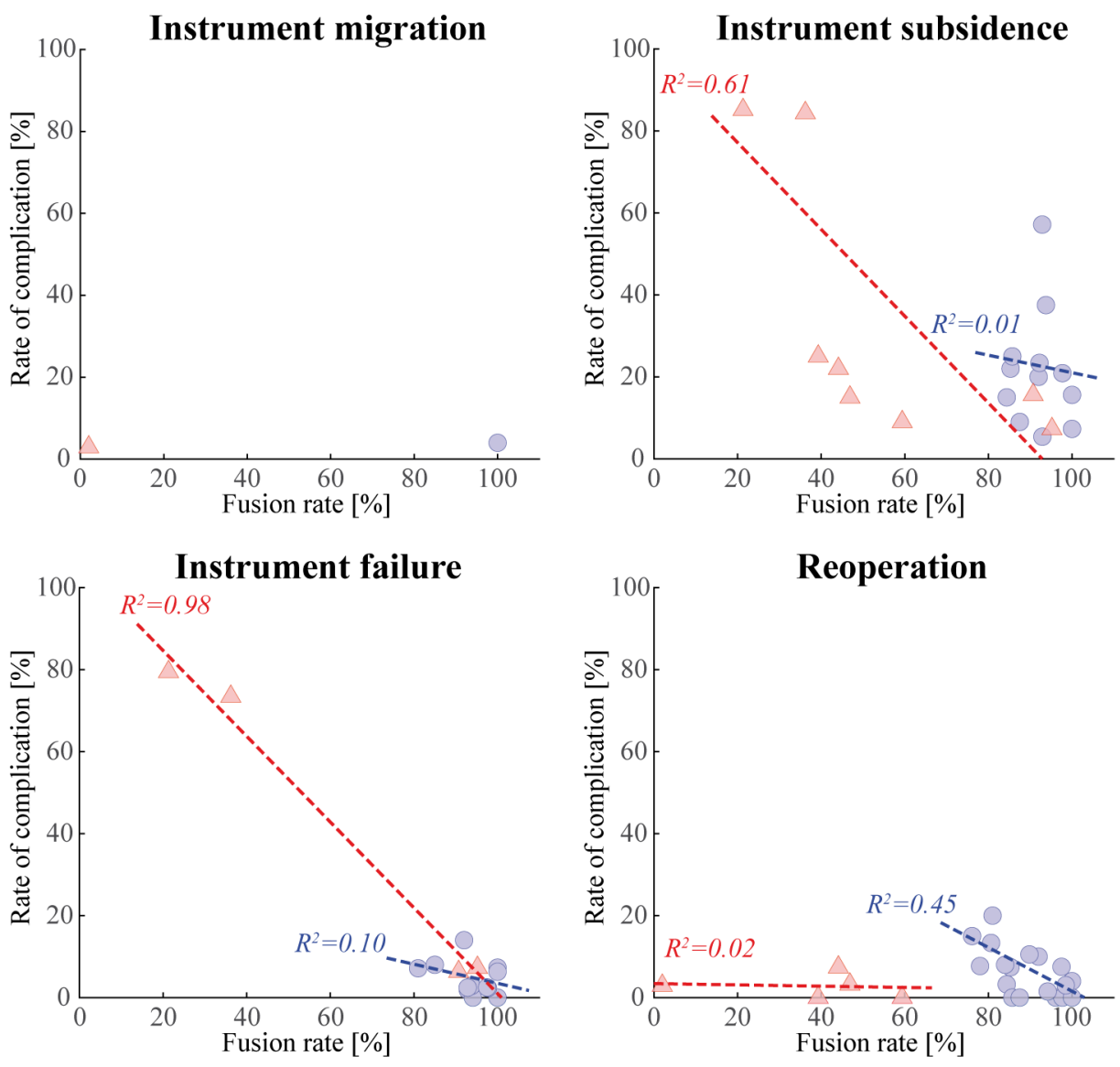

\section{Months postoperatively 24 Months postoperatively}

Figure 3. Relations between complication rate and fusion rate 3 and 12 months postoperatively. Lines represent the result of the weighted linear regression with corresponding R-squared values.

\section{DISCUSSION}

This systematic review was set out to analyze the early postoperative progression of fusion over time following LIF surgery. Current analysis of the overall fusion rates demonstrated that early after LIF surgery there is a large variation in fusion rates, whereas on longer term ( 2 years) fusion rates are relatively equal across patient groups. This suggests that major advantages might be gained by revealing the conditions that result in high shortterm fusion rates and by the development of new devices that focus on standardizing and improving short-term fusion rates.

As this literature review aimed to focus on the period early after LIF surgery, a second step was performed during study selection based on full paper screening. As a consequence, studies were only included when a fusion rate was reported at least once within one year after 
surgery. Studies that mentioned the fusion rate only one year postoperatively (and/or later) were thus excluded from our overview. Nevertheless, the long-term fusion rates of included studies were in line with previous literature [5]. Studies that did meet all inclusion criteria except for reporting a fusion rate within one year after surgery, were additionally saved for potential future analysis (this would add another 189 reports to the included data).

Immediately after surgery (time point of 0 months), there is of course a fusion rate of $0 \%$ as there is no direct bony union with the surgery. As bone growth takes time, there will be a time-dependent development of fusion. The question, however, remains how long it generally takes and at which time point a clinician may recognize a non-union that is not expected to unite anymore. Generally, a non-union is referred to as a failed union that is confirmed by CT (potentially combined with dynamic radiographs) one year postoperatively $[3,13]$. It has, however, been shown that bony fusion may still develop longer than one year following surgery [14]. Our review data confirms that the status of fusion is not per se definite one year postoperatively, as the data shows an increase in mean fusion rate together with a reduction in range and standard deviation of the fusion rate more than one year after surgery. However, it should be acknowledged that the change in fusion rates from one to two years postoperatively is presumably affected by follow-up bias. For example, several studies excluded patients who underwent revision surgery from the fusion rate calculations at later follow-up periods, which unjustly leads to higher fusion rates.

Interestingly, there were several patient groups for which a high fusion rate $(>90 \%)$ was reported at 3 months after surgery. In-depth analysis of each individual patient group should be performed to explore the exact details of the original clinical study in which these patient groups were reported. A crucial question is whether these high fusion rates early after surgery originate from very potent cage and graft material combinations, or from questionable assessment criteria to declare a segment fused. If the latter holds true, the concerned fusion rates should be adjusted or even removed from the analysis. However, when decent fusion criteria were applied, the exact surgical details of the original study will be of major interest.

It has been proposed before that by minimizing the time window from surgery to stable union of the vertebrae, the susceptibility to non-union related complications is to be reduced $[15,16]$. Current data analysis explored the relation between complication rates and the fusion rate at 3 and 24 months postoperatively. The complications included in this analysis were instrument migration, instrument subsidence, instrument failure, and reoperation. These specific categories were selected as they are believed to be mainly associated with inadequate device implementation and bone healing. Although the regression analyses revealed a negative relation between instrument subsidence and fusion rate 3 months postoperatively, as well as between instrument failure rate and fusion rate 3 months postoperatively, these trends should be interpreted with care. First, there was only a small amount of patient groups for which both the early postoperative fusion and eventual complication rates were explicitly reported. Second, the postoperative time points at which the complications were evaluated were not fully taken into account with data extraction. Third, the complications were not 
reported in a standardized fashion (e.g. the threshold for a sinking cage to be considered as subsided differed across studies). The studies included in the meta-analysis should thus be analyzed in more depth in order to determine to what extend numbers can be compared across studies, and how to take into account potential methodological discrepancies between articles. Specifically, the negative relation between instrument subsidence, instrument failure, and fusion rate 3 months postoperatively is dictated by two patient groups with a high complication rate and a low fusion rate. If these patient groups originate from a report with a controversial methodology, caution is warranted with the interpretation of the regression values.

The negative relation between fusion rate at 24 months after surgery and the need for reoperations complies with previous research which demonstrates that a substantial part of reoperations is performed because of non-unions [17]. Because several other factors also affect the need for a reoperation, fusion rate alone is not a direct predictor for the rate of reoperations.

Various previous studies have shown that fusion rates may depend on cage and graft material used in surgery [18-24]. However, it has already been highlighted before that for nearly every fusion technique and material combination one can extract favorable or unfavorable outcomes from existing studies [25]. The heterogeneity in data is caused by several bias factors such as patient selection bias, surgical performance bias, and assessment bias [26]. Ideally, current literature review would provide a data platform that enables identification of certain combinations of graft and cage materials as well as fusion techniques guaranteeing high early fusion rates. The poor quality of reporting of studies along with considerable variation in study designs, reporting, outcomes, and measures, however, may present an inherent limitation to synthesizing statistical evidence in this area. The vast majority of the included studies indeed was associated with a high risk of bias, which will also impede the identification of trends. The observations presented in this paper should thus be interpreted with care as the certainty of evidence is considered limited. Therefore, the generated database should be further extended and continuously updated with ongoing clinical trials in order to improve the certainty of evidence and to draw more solid conclusions.

In summary, current analysis mapped the overall development of fusion following LIF surgery and raised further research questions that require more rigorous analysis of the underlying data. It was demonstrated that early after fusion surgery there was a large variation in fusion rates, which highlighted that major advantages might be gained by enhancing shortterm fusion conditions. Additionally, low fusion rates early after surgery seem to be related to increased complications rates. Whether improved short-term fusion conditions indeed result in less complications and ultimately result in better clinical outcomes, remains to be further investigated. 


\section{REFERENCES}

1. Fritzell P, Hägg O, Wessberg P, Nordwall A. 2001 Volvo Award Winner in Clinical Studies: Lumbar fusion versus nonsurgical treatment for chronic low back pain: a multicenter randomized controlled trial from the Swedish Lumbar Spine Study Group. Spine. 2001;26(23):2521-32; discussion 32-4.

2. Duarte RM, Varanda P, Reis RL, Duarte ARC, Correia-Pinto J. Biomaterials and Bioactive Agents in Spinal Fusion. Tissue engineering Part B, Reviews. 2017;23(6):54051.

3. Raizman NM, O'Brien JR, Poehling-Monaghan KL, Yu WD. Pseudarthrosis of the spine. The Journal of the American Academy of Orthopaedic Surgeons. 2009;17(8):494503.

4. Kornblum MB, Fischgrund JS, Herkowitz HN, Abraham DA, Berkower DL, Ditkoff JS. Degenerative lumbar spondylolisthesis with spinal stenosis: a prospective long-term study comparing fusion and pseudarthrosis. Spine. 2004;29(7):726-33; discussion 33-4.

5. Meng B, Bunch J, Burton D, Wang J. Lumbar interbody fusion: recent advances in surgical techniques and bone healing strategies. European Spine Journal. 2021;30(1):2233.

6. Choudhri TF, Mummaneni PV, Dhall SS, Eck JC, Groff MW, Ghogawala Z, ..., Kaiser MG. Guideline update for the performance of fusion procedures for degenerative disease of the lumbar spine. Part 4: radiographic assessment of fusion status. Journal of neurosurgery Spine. 2014;21(1):23-30.

7. Glassman SD, Anagnost SC, Parker A, Burke D, Johnson JR, Dimar JR. The effect of cigarette smoking and smoking cessation on spinal fusion. Spine. 2000;25(20):2608-15.

8. Makanji H, Schoenfeld AJ, Bhalla A, Bono CM. Critical analysis of trends in lumbar fusion for degenerative disorders revisited: influence of technique on fusion rate and clinical outcomes. European Spine Journal. 2018;27(8):1868-76.

9. Gao Y, Li J, Cui H, Zhang F, Sun Y, Li Z, ..., Zhang W. Comparison of intervertebral fusion rates of different bone graft materials in extreme lateral interbody fusion. Medicine. 2019;98(44).

10. Moher D, Liberati A, Tetzlaff J, Altman DG. Preferred reporting items for systematic reviews and meta-analyses: The PRISMA statement. International Journal of Surgery. 2010;8(5):336-41.

11. Higgins JPT, Altman DG, Gøtzsche PC, Jüni P, Moher D, Oxman AD, . ., Sterne JAC. The Cochrane Collaboration's tool for assessing risk of bias in randomised trials. BMJ (Clinical research ed). 2011;343:d5928.

12. Joanna Briggs Institute. Critical Appraisal Tools [Internet]. Adelaide: The University of Adelaide, 2020 [accessed 16.8.21]; Available from: https://jbi.global/critical-appraisaltools.

13. Larsen JM, Capen DA. Pseudarthrosis of the Lumbar Spine. The Journal of the American Academy of Orthopaedic Surgeons. 1997;5(3):153-62.

14. Pimenta L, Marchi L, Oliveira L, Coutinho E, Amaral R. A Prospective, Randomized, Controlled Trial Comparing Radiographic and Clinical Outcomes between Stand-Alone Lateral Interbody Lumbar Fusion with either Silicate Calcium Phosphate or rh-BMP2. J Neurol Surg A Cent Eur Neurosurg. 2013;74(06):343-50.

15. Vaidya R, Sethi A, Bartol S, Jacobson M, Coe C, Craig JG. Complications in the Use of rhBMP-2 in PEEK Cages for Interbody Spinal Fusions. Clinical Spine Surgery. 2008;21(8):557-62. 
16. Lee JH, Jeon D-W, Lee S-J, Chang B-S, Lee C-K. Fusion Rates and Subsidence of Morselized Local Bone Grafted in Titanium Cages in Posterior Lumbar Interbody Fusion Using Quantitative Three-Dimensional Computed Tomography Scans. Spine. 2010;35(15):1460-5.

17. Martin BI, Mirza SK, Comstock BA, Gray DT, Kreuter W, Deyo RA. Reoperation rates following lumbar spine surgery and the influence of spinal fusion procedures. Spine. 2007;32(3):382-7.

18. Sasso RC, Kitchel SH, Dawson EG. A prospective, randomized controlled clinical trial of anterior lumbar interbody fusion using a titanium cylindrical threaded fusion device. Spine. 2004;29(2):113-22; discussion 21-2.

19. Slosar PJ, Josey R, Reynolds J. Accelerating lumbar fusions by combining rhBMP-2 with allograft bone: a prospective analysis of interbody fusion rates and clinical outcomes. The spine journal : official journal of the North American Spine Society. 2007;7(3):301-7.

20. Chou YC, Chen DC, Hsieh WA, Chen WF, Yen PS, Harnod T, ..., Chen SY. Efficacy of anterior cervical fusion: comparison of titanium cages, polyetheretherketone (PEEK) cages and autogenous bone grafts. Journal of clinical neuroscience : official journal of the Neurosurgical Society of Australasia. 2008;15(11):1240-5.

21. Burkus JK, Sandhu HS, Gornet MF. Influence of rhBMP-2 on the Healing Patterns Associated With Allograft Interbody Constructs in Comparison With Autograft. Spine. 2006;31(7):775-81.

22. Roh JS, Yeung CA, Field JS, McClellan RT. Allogeneic morphogenetic protein vs. recombinant human bone morphogenetic protein-2 in lumbar interbody fusion procedures: a radiographic and economic analysis. Journal of orthopaedic surgery and research. 2013;8:49.

23. Cuzzocrea F, Ivone A, Jannelli E, Fioruzzi A, Ferranti E, Vanelli R, Benazzo F. PEEK versus metal cages in posterior lumbar interbody fusion: a clinical and radiological comparative study. Musculoskeletal surgery. 2019;103(3):237-41.

24. Nemoto O, Asazuma T, Yato Y, Imabayashi H, Yasuoka H, Fujikawa A. Comparison of fusion rates following transforaminal lumbar interbody fusion using polyetheretherketone cages or titanium cages with transpedicular instrumentation. European Spine Journal. 2014;23(10):2150-5.

25. Boos N, Webb JK. Pedicle screw fixation in spinal disorders: a European view. European spine journal : official publication of the European Spine Society, the European Spinal Deformity Society, and the European Section of the Cervical Spine Research Society. 1997;6(1):2-18.

26. Burkus JK, Foley K, Haid RW, LeHuec JC. Surgical Interbody Research Group-radiographic assessment of interbody fusion devices: fusion criteria for anterior lumbar interbody surgery. Neurosurgical focus. 2001;10(4):E11. 
Supplementary material 1 . Search strategy.

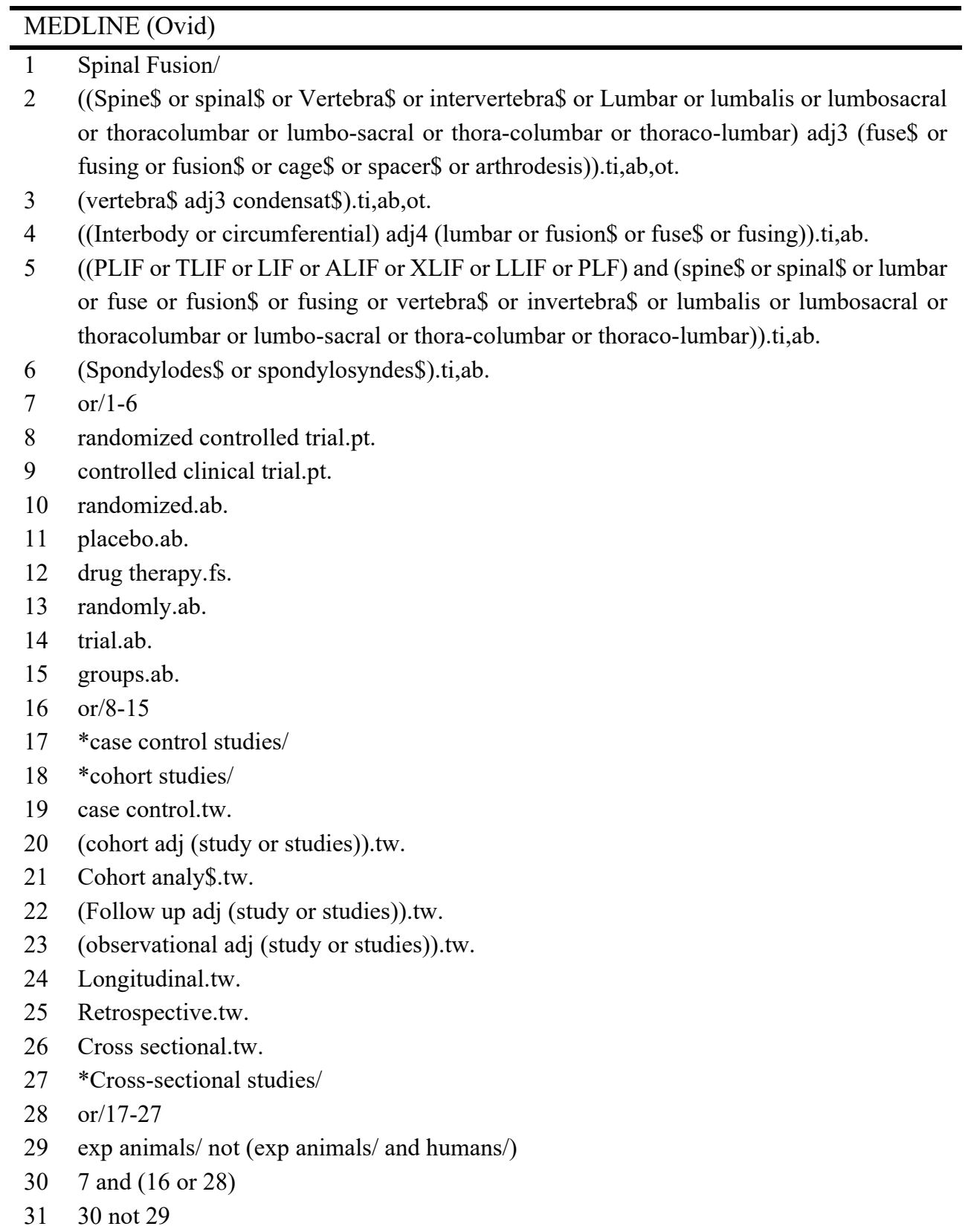


EMBASE (Ovid)

1 ((Spine\$ or spinal\$ or Vertebra $\$$ or intervertebra $\$$ or Lumbar or lumbalis or lumbosacral or thoracolumbar or lumbo-sacral or thora-columbar or thoraco-lumbar) adj3 (fuse $\$$ or fusing or fusion\$ or cage $\$$ or spacer\$ or arthrodesis)).ti,ab,ot.

2 exp spine fusion/

3 (vertebra $\$$ adj3 condensat\$).ti,ab,ot.

4 ((Interbody or circumferential) adj4 (lumbar or fusion\$ or fuse $\$$ or fusing)).ti,ab.

5 ((PLIF or TLIF or LIF or ALIF or XLIF or LLIF or PLF) and (spine\$ or spinal\$ or lumbar or fuse or fusion $\$$ or fusing or vertebra $\$$ or invertebra $\$$ or lumbalis or lumbosacral or thoracolumbar or lumbo-sacral or thora-columbar or thoraco-lumbar)).ti,ab.

6 (Spondylodes $\$$ or spondylosyndes\$).ti,ab.

7 or/ $1-6$

8 crossover-procedure/ or double-blind procedure/ or randomized controlled trial/ or singleblind procedure/

9 (random\$ or factorial\$ or crossover $\$$ or cross over $\$$ or cross-over $\$$ or placebo $\$$ or (doubl\$ adj blind\$) or (singl\$ adj blind\$) or assign\$ or allocat\$ or volunteer\$).ti,ab,ot.

10 or/8-9

$11 *$ Clinical study/ or *Case control study/ or *Family study/ or *Longitudinal study/ or *Retrospective study/

12 *Prospective study/

13 Randomized controlled trial/

1412 not 13

$15 *$ Cohort analysis/

16 (Cohort adj (study or studies)).mp.

17 (Case control adj (study or studies)).tw.

18 (follow up adj (study or studies)).tw.

19 (observational adj (study or studies)).tw.

20 (cross sectional adj (study or studies)).tw.

21 or/ $11,14-20$

22 animal/ or animal experiment/

23 (rat or rats or mouse or mice or murine or rodent or rodents or hamster or hamsters or pig or pigs or porcine or rabbit or rabbits or animal or animals or dogs or dog or cats or cow or bovine or sheep or ovine or monkey or monkeys).ti,ab,ot,hw.

24 or $/ 22-23$

25 exp human/ or human experiment/

$26 \quad 24 \operatorname{not} 25$

$27 \quad 7$ and (10 or 21$)$

$28 \quad 27$ not 26 


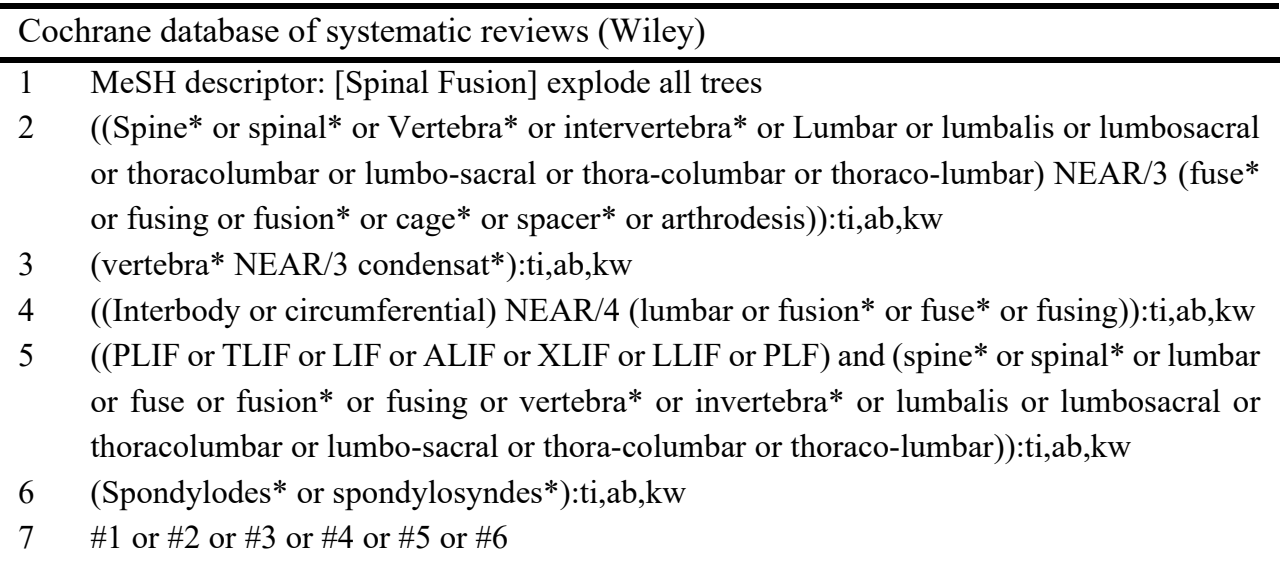

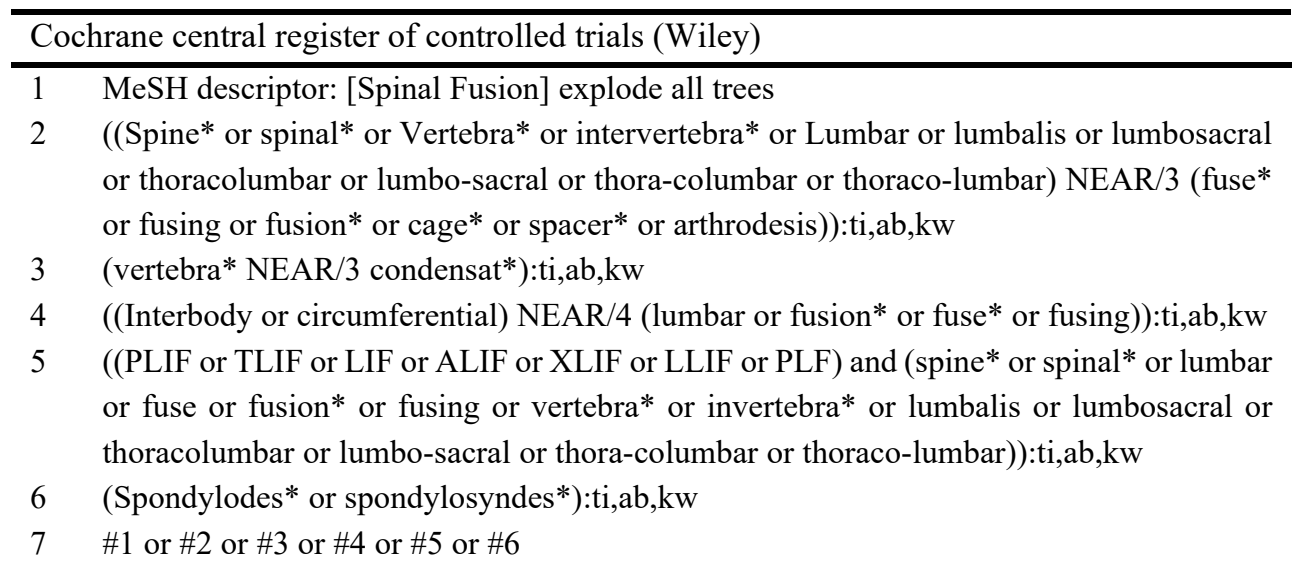

\footnotetext{
KSR Evidence

1 (Spine* or spinal* or Vertebra* or intervertebra* or Lumbar or lumbalis or lumbosacral or thoracolumbar or "lumbo-sacral" or "thora-columbar" or "thoraco-lumbar") and (fuse* or fusing or fusion* or cage* or spacer* or arthrodesis) in Title or Abstract

2 vertebra* and condensat* in Title or Abstract

3 (Interbody or circumferential) and (lumbar or fusion* or fuse* or fusing) in Title or Abstract

4 (PLIF or TLIF or LIF or ALIF or XLIF or LLIF or PLF) and (spine* or spinal* or lumbar or fuse or fusion* or fusing or vertebra* or invertebra* or lumbalis or lumbosacral or thoracolumbar or "lumbo-sacral" or "thora-columbar" or "thoraco-lumbar") in Title or Abstract

5 Spondylodes* or spondylosyndes* in Title or Abstract

$6 \# 1$ or $\# 2$ or \#3 or \#4 or \#5 in Title or Abstract
} 



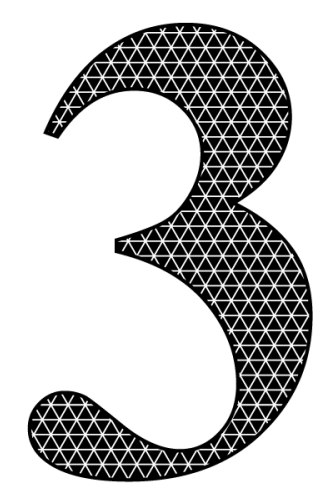

Misaligned spinal rods can induce high internal forces consistent with those observed to cause screw pullout and disc degeneration

\author{
ACY Loenen \\ DC Noriega \\ C Ruiz Wills \\ J Noailly \\ PD Nunley \\ R Kirchner \\ K Ito \\ $B$ van Rietbergen
}

The Spine Journal 2021; 21(3):528-537

https://doi.org/10.1016/j.spinee.2020.09.010 


\begin{abstract}
BACKGROUND CONTEXT: Manual contouring of spinal rods is often required intraoperatively for proper alignment of the rods within the pedicle screw heads. Residual misalignments are frequently reduced by using dedicated reduction devices. The forces exerted by these devices, however, are uncontrolled and may lead to excessive reaction forces. As a consequence, screw pullout might be provoked and surrounding tissue may experience unfavorable biomechanical loads. The corresponding loads and induced tissue deformations are however not well identified. Additionally, whether the forced reduction alters the biomechanical behavior of the lumbar spine during physiological movements postoperatively, remains unexplored.
\end{abstract}

PURPOSE: To predict whether the reduction of misaligned posterior instrumentation might result in clinical complications directly after reduction and during a subsequent physiological flexion movement.

STUDY DESIGN: Finite element analysis.

METHODS: A patient-specific, total lumbar (L1-S1) spine finite element model was available from previous research. The model consists of poro-elastic intervertebral discs with Pfirrmann grade-dependent material parameters, with linear elastic bone tissue with stiffness values related to the local bone density, and with the seven major ligaments per spinal motion segment described as nonlinear materials. Titanium instrumentation was implemented in this model to simulate a L4, L5, and S1 posterolateral fusion. Next, coronal and sagittal misalignments of 6 millimeters each were introduced between the rod and the screw head at L4. These misalignments were computationally reduced and a physiological flexion movement of $15^{\circ}$ was prescribed. Non-instrumented and well-aligned instrumented models were used as control groups.

RESULTS: Pulling forces up to $1.0 \mathrm{kN}$ were required to correct the induced misalignments of 6 millimeters. These forces affected the posture of the total lumbar spine, as motion segments were predicted to rotate up to 3 degrees and rotations propagated proximally to and even affect the L1-2 level. The facet contact pressures in the corrected misaligned models were asymmetrical suggesting non-physiological joint loading in the misaligned models. In addition, the discs and vertebrae experienced abnormally high forces as a result of the correction procedure. These effects were more pronounced after a $15^{\circ}$ flexion movement following forced reduction.

CONCLUSIONS: The results of this study indicate that the correction of misaligned posterior instrumentation can result in high forces at the screws consistent with those reported to cause screw pullout, and may cause high tissue strains in adjacent and downstream spinal segments.

CLINICAL SIGNIFICANCE: Proper alignment of spinal posterior instrumentation may reduce clinical complications secondary to unfavorable biomechanics. 


\section{INTRODUCTION}

Pedicle screw and rod constructs are commonly used to provide posterior spine stabilization in a wide variety of spinal disorders [1]. Such constructs can involve the fixation of one spinal motion segment or more. With more segments involved, manual contouring of the spinal rod is commonly necessary to obtain proper alignment of the screw heads and the rod [2]. However, residual mismatches are expected, even after contouring [3]. The relevance of such mismatches has long been dismissed as dedicated reduction devices are typically available to assist the surgeon in assembling the construct. These devices mechanically force the spinal rod into the head of the screw but don't control the exerted forces, which may lead to excessive reaction forces that may result in clinical complications [4].

Previous ex vivo biomechanical research revealed that the correction of clinically relevant residual mismatches by a reduction device may decrease screw pullout strength, or even provoke instantaneous screw pullout [5-7]. Even if screw pullout does not occur, it is possible that the reduction of residual mismatches can have undesirable effects, i.e. increased facet joint and intra-vertebra forces, and increased intervertebral disc deformations [8]. The corresponding mechanical loads and induced tissue deformations are however not well identified. Additionally, whether the forced correction of the mismatch alters the mechanical behavior of the lumbar spine during postoperative physiological movements, is unexplored.

Finite Element (FE) analysis of the spine enables quantification of biomechanical parameters impossible to acquire experimentally, allows for multi-step procedures, and has previously been acknowledged as valuable tool to address clinically relevant problems [9, 10]. Therefore, we used FE analysis in this study to reveal both the direct and the indirect consequences of the correction of the mismatch. Using this approach, a posterolaterally fused lumbar spine was modeled, introducing perfectly fitting rods or clinically relevant mismatches. The first aim was to analyze the mechanical loads and deformations both in the instrumentation and surrounding tissue when performing the mismatch correction procedure. The second aim was to analyze the biomechanical loads in the corrected, posterolaterally fused, lumbar spine during a physiological flexion movement. Two different scenarios were employed by inducing a mismatch between rod and screw head, in the coronal and in the sagittal plane, respectively. Finally, the presence of a fixed contralateral construct was varied to evaluate the impact of different surgical situations.

\section{MATERIALS AND METHODS}

\section{FE models of the intact lumbar spine}

An FE model that includes the vertebrae L1-L5 and the discs L1-2 to L5-S1 was used in this study. It originated from the EU-funded MySpine project (EU FP7-ICT 269909) that included low back pain patients and was approved by the Scientific Research Ethics Committee of the Medical Research Council (751/PI/2010) of the National Center for Spinal 
Disorders, Budapest, Hungary. Details of the patients and models can be found elsewhere and are only summarized here $[11,12]$. Computed tomography (CT) and magnetic resonance imaging (MRI) scans were used to segment the vertebrae and intervertebral discs (IVDs), respectively $[13,14]$. MRI scans enabled identification of the nucleus pulposus (NP) and annulus fibrosis (AF) regions of each IVD. Both segmentations were performed with a trained algorithm following the active shape modelling (ASM) framework as introduced by Cootes et al. [15]. The mesh of a generic FE model was morphed to the patient, based on anatomical landmarks as described in Castro-Mateos et al. [16]. The model used in this study was based on data of a 55 year-old female patient with a weight of 74 kilograms, height of 167 centimeters, and Pfirrmann grades of III, III, III, IV, and III for disc L1-2 to L5-S1. This patient was selected from the database since she represented a typical patient case of the degenerative spine eligible for spinal fusion surgery [17].

The bony posterior elements, facets and bony endplates were modelled as isotropic linear elastic materials. For the vertebral bodies, patient-specific trabecular bone densities were integrated in the model by relating the transversely isotropic, linear elastic material properties of the elements to the mean $\mathrm{CT}$ gray value calculated within the representative volume of each element [18]. The sacrum and cortical bone were modeled as orthotropic linear elastic. Facet joint articulation was modelled by surface-to-surface frictionless contact resolved through a penalty algorithm with a penalty normal stiffness of $200 \mathrm{~N} / \mathrm{mm}$ [19]. The cartilage endplates were modelled as isotropic poro-elastic [20]. The NP and AF were both modelled by a poro-hyperelastic material model, assuming a Neo-Hookean material to determine the strain energy density for the isotropic solid matrix. For the AF, an additional anisotropic term was added to the strain energy density function representing the contribution of the cross-ply collagen fibers during positive strain of the AF [21]. The total stress resulting from the external load was defined as the superposition of the porous solid stress and the fluid pore pressure. The strain energy density function and Darcy's law were used to derive the porous solid stress and fluid pore pressure, respectively. For the NP, a swelling pressure related term was introduced in order to describe proteoglycan-induced NP swelling [11]. For each poro-(hyper)elastic material model, a strain-dependent permeability was included and updated during the simulations. All IVDs were previously graded by an experienced radiologist based on the Pfirrmann classification [22]. Depending on the Pfirrmann grade, different material parameters were adjusted for the NP and AF based on Malandrino et al. [11]. Ligaments were included in the model and described as hypo-elastic unidirectional materials. The stress-strain relationship was described by an initial non-linear toe region, modelled by a fitted power law, followed by a simple linear function. Fiber stiffness parameters were defined per ligament type and disc level [23], and were further optimized to reproduce the ex vivo experimental data of full L1-S1 specimens from Malandrino et al. [11].

The FE model as described above is referred to as the control or intact model (Figure 1). The calculation outputs of this model served as reference values for the physiological flexion movement analysis. The simulations started with a pre-conditioning step of eight 
hours that allowed for pre-swelling of the poro-(hyper)elastic IVDs. During this initial step, the caudal end of the spine was completely constrained while the cranial end was allowed to translate as consequence of changing disc height. Subsequently, a flexion rotation of $15^{\circ}$ applied in five seconds was prescribed as physiological movement of the lumbar spine.

\section{FE model of the posterolaterally fused lumbar spine}

Titanium (Ti-6Al-4V) pedicle screw and rod instrumentation was implemented into the intact model based on anatomical landmarks. Polyaxial screw heads without any rotational restrictions were assumed in the model. In this study, an L4-S1 bi-segmental posterolateral fusion was simulated assuming L5-S1 instrumentation was already tightened. This assumption allows for replacement of the disc of segment L5-S1 and its corresponding posterior instrumentation by constraining boundary conditions. Each screw was fixed in the corresponding vertebra by embedding constraints. The titanium rods could be embedded in the screw heads under every angle provided that previously specified caudal and cranial element areas were located within the screw head. In this way, polyaxial screw heads could be modelled without requiring geometrical rearrangement of the mesh of the screw heads (Figure 1).

This model represents an L4-S1 posterolateral fusion without any mismatch between screw heads and fixation rod (well-aligned PLF control). Similar to the non-instrumented
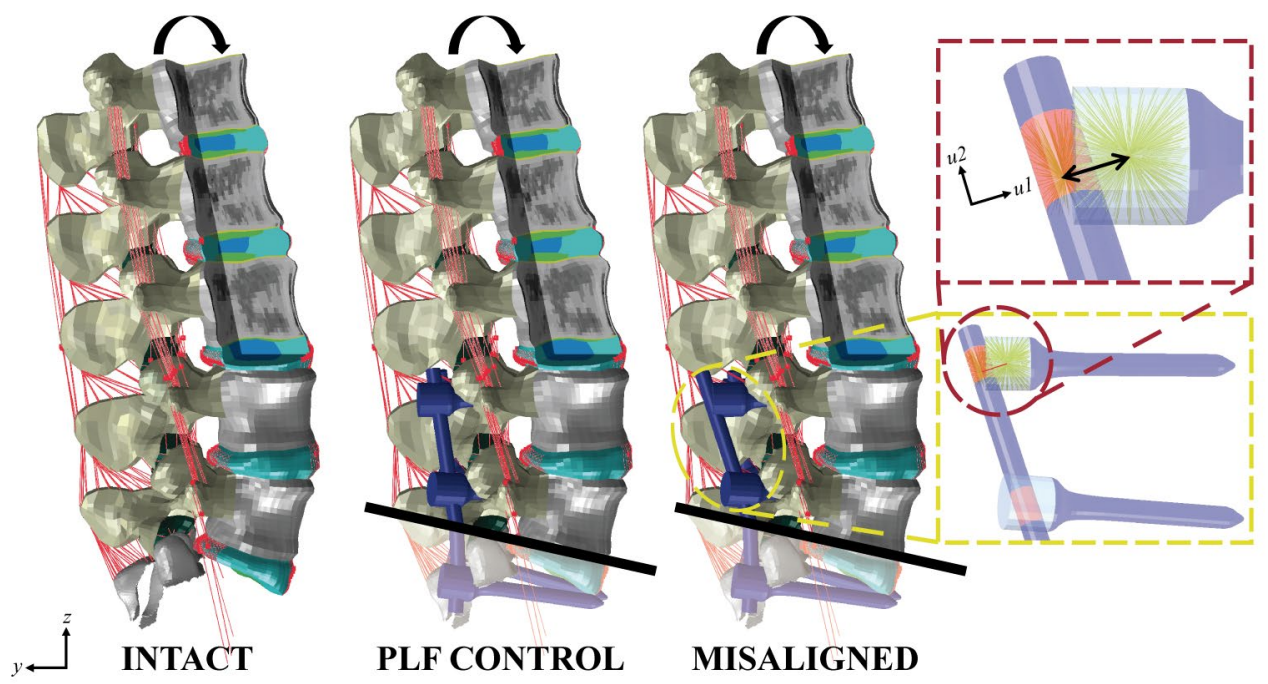

Figure 1. Overview of the intact control, posterolaterally fused control, and sagittally misaligned model. Different colors represent different material properties for ligaments, bony posterior ends, facets, sacrum, cortical bone, trabecular bone with density dependent stiffness, annulus fibrosis, nucleus pulposus, cartilage endplates, bony endplates, and titanium. On the right, the element set (in red) that is required to be located in the screw head (lucent blue). A connector element (black double arrow) was defined between the central point of the rod and screw head elements respectively. $U$ is the local coordinate system of the connector element with $\mathrm{u} 1$ along the direction of the connector element and $\mathrm{u} 2$ along the longitudinal axis of the spinal rod. 
control model, this model starts with a pre-conditioning period of eight hours. The posterior instrumentation was implemented right after the pre-conditioning step, just before the flexion rotation of fifteen degrees was prescribed. The output data of this model provided reference values for the physiological flexion movement of a well-instrumented posterolaterally fused (L4-S1) spine.

\section{FE model of the misaligned posterolateral instrumentation in the lumbar spine}

The PLF control model was altered to induce a misalignment of six millimeters between the right rod and the right screw head of L4. The orientation of the rod was manipulated such that a misfit was introduced in either the coronal or sagittal plane while retaining the fit between the right rod and the screw head of L5. For the coronal respectively sagittal misalignment, the rod was positioned six millimeters medially and posteriorly with respect to the right screw head of L4. The nodes constituting the head of the right screw of L4 were all rigidly coupled to their central location. Also the nodes in the region of the rod that is designated for fixation in the screw head (depicted in red in Figure 1) were all coupled to their central location. Then, a 3D connector element that can be reduced in length was implemented between these two points. The direction of this connector element was used to specify the pulling (reduction) direction i.e. mediolateral and anteroposterior for the coronal and sagittal misalignment, respectively (u1-axis in Figure 1). During pulling, movement along the longitudinal axis of the spinal rod was allowed (u2-axis in Figure 1).

Again, the model starts with an initial pre-conditioning period of eight hours without instrumentation being present. After the pre-conditioning step, the misaligned posterior instrumentation was implemented and a five-second correction procedure was simulated by contraction of the connector element while vertebra L1 was constrained at its post-swelling position. For both misaligned configurations, two different surgical situations considering the presence of a contralateral construct at segment L4-5 were analyzed. Situation I assumed that the contralateral side, on the left, was fixed without misalignment prior to the correction procedure. On the contrary, situation II assumed that the contralateral side was not stabilized yet during the correction procedure. Following the correction, the rod and screw head on the right were fastened and a well-aligned contralateral rod was introduced and fastened on the left. Then, the flexion rotation of $15^{\circ}$ was prescribed.

\section{Output analysis}

The FE solver ABAQUS/Standard (Simulia, Inc., Providence, RI, USA) version 2018 was used for solving the described models. The force that was required for pulling rod and screw towards each other was determined post-correction. In addition, the relative rotation for each of the vertebrae was calculated post-correction and post-flexion. A Matlab script, based on Horn's quaternion-based method [24], was used to determine the rotation matrix that best maps the original position of the nodes of the vertebra's corpus on their updated position after correction and flexion respectively. For each vertebra, the rotation matrix 
relative to its caudal neighbor was derived as described by Kingma et al. [25]. Then, the relative rotation matrix was decomposed using Tait-Bryan chained rotations. The adopted order of axis was horizontal, anteroposterior, and longitudinal axis providing angular motions in the sagittal, coronal, and axial plane respectively. Also, the maximum contact pressures per facet joint were estimated post-correction and post-flexion. Besides, the reaction moment at the cranial end of vertebra L1 was monitored after realizing the flexion movement. Both post-correction and post-flexion, the volume of tissue that is at risk for damage was quantified in the bony structures and IVDs. A bone element was considered vulnerable for local damage when its absolute maximum principal strain value exceeded 1\% [26]. For IVD elements, a threshold value of $20 \%$ major principal strain was considered to promote biological responses associated with disc degeneration [27].

\section{RESULTS}

\section{Post-correction analysis}

The pulling forces required to reduce the rod completely into the screw head were 0.9 and $1.0 \mathrm{kN}$ for the coronal and sagittal misalignment, respectively, assuming the contralateral side was already rigidly fixed (situation I). When the contralateral side was not fixed yet (situation II), the required pulling forces decreased to $0.7 \mathrm{kN}$ for the correction of both the coronal and sagittal misalignments.

The induced angular motions of the functional spinal units (FSUs) were predominantly in the plane in which the misalignment was initially introduced. Rotations were smaller when the contralateral rod was already tightly fixed during the correction. FSUs L2-3 and L3-4

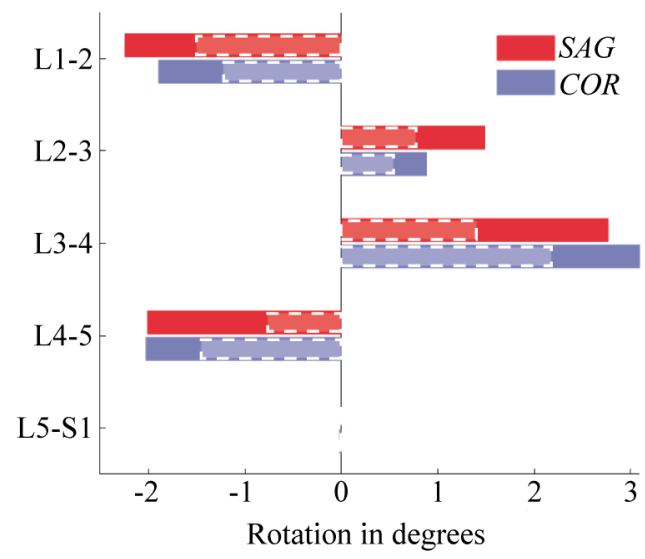

Figure 2. Main angular motion per FSU after correction of the misalignment. For both misalignments, the main angular motion was found in its corresponding anatomical plane. Therefore, values represent rotation in the coronal (blue) and sagittal (red) plane as result of correcting the coronal and sagittal misalignment respectively. Negative/positive rotation means left/right bending in the coronal plane and extension/flexion in the sagittal plane. Dashed insets: situation I. Solid bars: situation II. 
Table 1. The maximum facet contact pressure [MPa] found at the left and right joint after performing the correction procedure for the coronal (COR) and sagittal (SAG) misalignment in situation I and II respectively.

\begin{tabular}{ccccccccc}
\hline & L1-2 left & L1-2 $2_{\text {right }}$ & L2-3 left & L2-3 right $_{\text {L }}$ L-4 left & L3-4 $4_{\text {right }}$ & L4-5 left & L4-5 right \\
\hline COR I & - & 4.0 & - & 2.8 & - & 3.9 & 3.2 & - \\
COR II & - & 6.3 & - & 3.9 & - & 5.1 & 9.0 & - \\
SAG I & - & 2.0 & - & 2.1 & - & 3.3 & - & - \\
SAG II & - & 1.3 & - & 1.0 & 0.6 & 4.1 & - & -
\end{tabular}

Table 2. Tissue volume at risk in the vertebrae and intervertebral discs $\left[\mathrm{mm}^{3}\right]$ for the misaligned and control models after simulation of the correction and the flexion motion. Post-correction and postflexion values are shown for the coronal (COR) and sagittal (SAG) with (I) and without (II) having fixed the contralateral rod before the correction. Additionally, the results for the intact and well-aligned posterolateral fusion control (PLF) are shown.

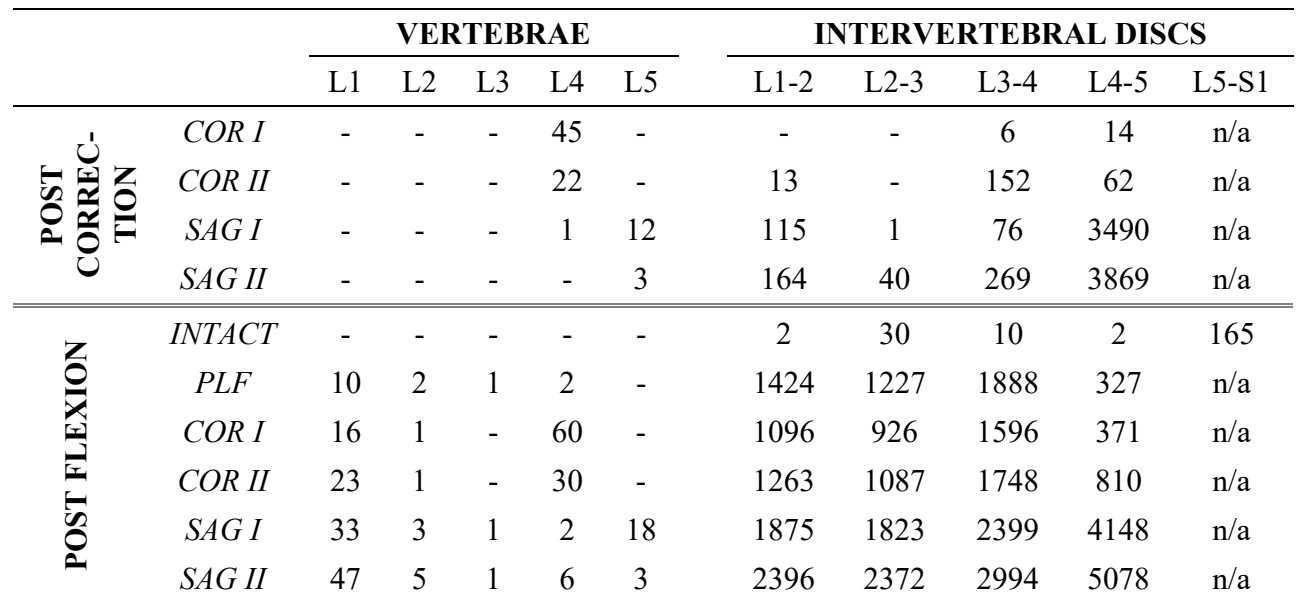

consistently showed opposite rotations compared to L1-2 and L4-5. Overall, rotations up to three degrees were induced during correction (Figure 2).

Table 1 gives an overview of the maximum contact pressure in the facet joints for the different models. Especially for the coronal misalignment, the maximum facet pressure was $40-180 \%$ larger when the contralateral rod was not implemented yet (situation II). Asymmetrical increased facet contact pressures of up to $6 \mathrm{MPa}$ were found cranial to L4-5 after correction of the misalignment.

The tissue volumes at risk after the correction procedure are presented in Table 2. In general, the correction of the coronal misalignment induced larger tissue volumes at risk in the bone, whereas the correction of the sagittal misalignment induced larger tissue volumes at risk in the IVDs. Having the contralateral rod already rigidly fixed (situation I) generated higher tissue volumes at risk in the bone and lower tissue volumes at risk in the IVD compared to the situation in which the correction was performed while the contralateral rod was not fixed (situation II). 


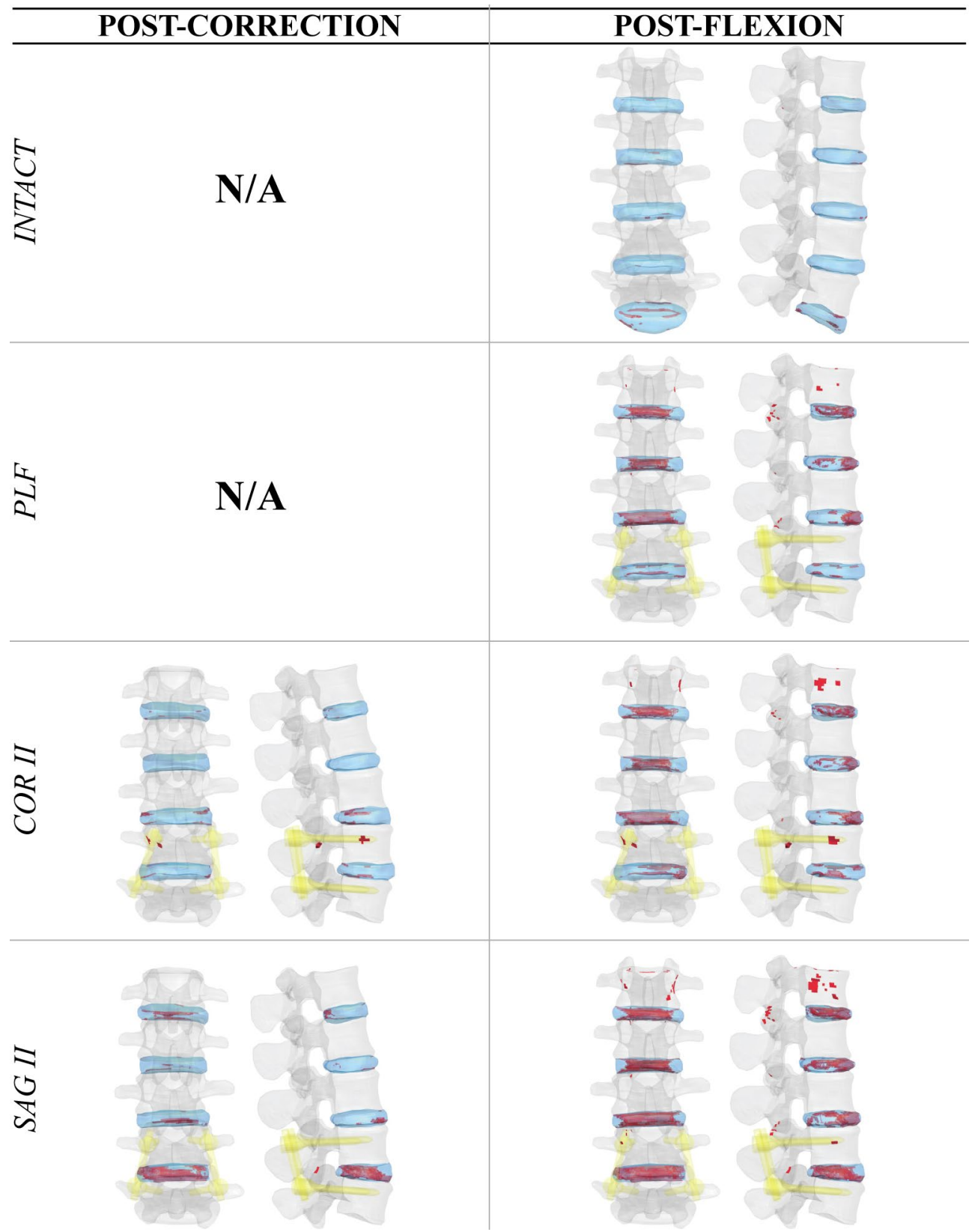

Figure 3. Graphical representation indicating the tissue volumes being at risk after correction and flexion (grey, vertebrae; blue, IVDs; yellow, instrumentation; red, tissue at risk). The intact control showed hardly any tissue being at risk while the well-aligned posterolaterally fused control shows substantial volume at risk post-flexion. Correcting the coronal (COR) and sagittal (SAG) misalignment in which the contralateral rod was not implemented yet during correction (situation II) showed to induce adverse tissue deformations. These volumes increase during flexion following the correction procedure. 


\section{Post-flexion analysis}

For the intact control spine, the angular motion in the sagittal plane was on average three degrees for each of the five FSUs. For the PLF control and misaligned models, the rotation in the sagittal plane increased up to six degrees at L1-2, L2-3, and L3-4, while the rotations decreased down to zero degrees at the fixed discs L4-5 and L5-S1.

The maximum contact pressure in the facet joints in the corrected misaligned models generally decreased as result of the flexion movement (data not shown). The reaction moment in a fifteen degrees flexion configuration was $8 \mathrm{Nm}$ for the intact control spine. The instrumented spine models required significantly higher moments to achieve this configuration; 26, 22, 23, 31 and $37 \mathrm{Nm}$ for PLF control, coronal misalignment situations I, II, and sagittal misalignment situations I, II, respectively.

The tissue volumes at risk after having simulated the flexion movement are summarized for the different models in Table 2 and graphically displayed in Figure 3. Comparing the post-flexion with the post-correction values for the misaligned situations, the tissue volume being at risk increased within the IVDs. Additionally, new bone tissue volume at risk was introduced as consequence of the flexion movement. The PLF control model shows the same trends while the intact control model shows only IVD tissue at risk during the physiological flexion movement.

\section{DISCUSSION}

The purpose of this study was to predict the loads and deformations associated with the correction of a misalignment between the spinal rod and the pedicle screw heads, directly after having simulated the operation and a subsequent postoperative physiological flexion movement. Results demonstrate that the correction of small $(6 \mathrm{~mm})$ residual mismatches between spinal rod and pedicle screw head may induce forces and deformations that potentially lead to clinical complications.

Independent of the direction of misalignment and presence of the contralateral rod, excessive forces (0.7-1.0 kN) were required to correct a small misalignment of six millimeters. Lumbar pedicle screw pullout has been reported to occur at mean forces of 0.3 $1.4 \mathrm{kN}$ [28-30], depending on bone mineral density, screw type, use of cement, and insertion torque. Our results indicate, therefore, that there might be a considerable risk for screw pullout intraoperatively or postoperatively because of misalignment. For the correction of the sagittal misalignment, a direct comparison between reported pullout forces and predicted pulling forces is relevant as the applied force during rod-screw reduction was mainly oriented along the longitudinal axis of the pedicle screw. For the correction of the coronal misalignment, predicted force values are, however, not directly comparable to reported pullout forces, since the force exerted during correction was oriented perpendicular to the longitudinal screw axis. In order to preclude these excessive forces from being applied, it 
would be recommended to implement an overload protection for reduction devices utilized in surgery.

The excessive correction forces were found to affect the posture of the total lumbar spine as motion segments were observed to rotate and rotations propagated up to L1-2 included. Compared to a rotation per FSU of 1-10 degrees during different physiological movements of the lumbar spine [31], the extra rotations induced by the correction only (up to 3 degrees) are considered substantial. It is hypothesized that these additional segmental rotations may induce clinical implications on the longer term as segmental imbalances will chronically change the local load distribution and increase the risk for developing not only adjacent segment disease [32, 33] but also downstream segment disease i.e. the onset of tissue deterioration at multiple levels distance of the operated segments. Segment L2-3 and L3-4 were oppositely angulated to L4-5 to compensate for the induced movement at the level of misalignment. This was due to the assumption that the cranial end of L1 was completely constrained at its post-swelling position, to ensure normal posture. Although some rotation at the T12-L1 level may occur in reality, thus leading to slightly different spinal deformation curves, this is not expected to affect the main results with regard to the forces in the lumbar spine.

The maximum facet joint contact pressure at L4-5 strongly increased on the left side during correction of the coronal misalignment, which occurred because the misalignment was introduced by placing the rod medially with respect to the upper right screw in L4. Consequently, L4 should translate towards the left, generating a movement analogue to a left lateral bending in order to correct the misalignment. Following this movement, the right facet joint will open while the left one will close. Because of the opposite angulation at higher levels, increased pressures were found on the right side in facet joints cranial to L4-5. As for correction of sagittal misalignment, there was no increase in maximum facet contact pressure at L4-5. Since an extension rotation of L4-5 was induced during correction, the decreasing lumbar lordosis angle closed mainly the right fact joints (since the correction was also applied on the right). In general, the maximum facet contact pressures cranial to the corrected segment range up to $6 \mathrm{MPa}$. Because compressive load of the spine was not modeled and lumbar facet joints open in a flexed posture [34], the intact models did not provide reference values for physiological facet contact pressures to which the values in the other situations could be compared. Consulting previous literature, El-Bohy et al. reveal physiological facet contact pressures of 0.1-0.3 MPa under body weight combined with a $15 \mathrm{Nm}$ flexion moment in their ex vivo experiments [35]. Additionally, Du et al. predict mean and maximum facet contact pressures up to 5 and $9 \mathrm{MPa}$ respectively in their in silico approach considering every basic spine movement under $\pm 7.5 \mathrm{Nm}$, combined with a follower preload varying from 0 $1200 \mathrm{~N}$ [36]. Comparing these values with the predicted maximum facet contact pressures in this research, it can be concluded that the deformations, induced by correction of the misalignment, cause relatively large, asymmetric facet joint pressures in the joints adjacent 
to the initially misaligned segment. Although there is no particular damage threshold for facet pressure, overloading is generally suggested to accelerate degeneration of the joint [37].

Correction of a six millimeter misalignment made the bone and IVD tissues to be at risk of damage. To correct the coronal misalignment, a medial-lateral repositioning is required. As consequence, the closing facet joints on one side restricts further segmental movement. Hence, the correction of the coronal misalignment results mainly in overloaded bone tissue. The amount of IVD tissue being at risk after correction of the coronal misalignment seems to be limited. It should however be emphasized that the IVD tissue will experience the induced deformation uninterruptedly as the spine is fixed in this deformed configuration. While appropriate dynamic loading of the IVD promotes the anabolic response of the disc, static loading favors the catabolic response suggesting a negative impact of these deformations on the longer term [38]. Besides, due to slow turnover of the IVD [39], possible disturbance of the natural balance of matrix synthesis and degradation may be clinically expressed long after surgery. The correction of the sagittal misalignment requires an anteriorposterior repositioning, which the anatomical configuration of the facet joints allows through an extension rotation of the FSU. As a result, deformations are mainly induced in the IVD instead of in the bony structures. The correction of the sagittal misalignment thus mainly translates into tissue volume at risk within the IVD. Obviously, many combined misalignments of various magnitudes can exist, e.g. a screw head that is misaligned both anteroposteriorly and mediolaterally. Investigating such combinations was outside the scope of this publication, but potentially could introduce even higher forces and deformations with downstream deleterious consequences.

The presence of the contralateral rod during correction had a significant influence on the consequences of the correction procedure. Generally, the situation in which the rod was already tightened (situation I) allowed less segmental motion since the segment is partly immobilized before performing the correction procedure. Therefore, higher pulling forces were required while the induced segmental rotations were smaller. This caused higher internal stresses in the bone, generating more bone tissue volume being at risk. Additionally, higher pulling forces increase the risk for intraoperative screw pullout undoubtedly. In contrast, situation II resulted in slightly higher contact pressures in the facet joints and more IVD tissue volume being at risk because of the larger segmental motions induced by the correction. It should be noted that with a circumferential fusion operation, the disc is removed and replaced by an interbody fusion cage, and the increased loading calculated here for the disc may not be representative for the loading the cage is subjected to. An extension of the model with a cage would be needed to investigate if similar conclusions hold in case of using interbody fusion cages.

In a flexion posture of fifteen degrees, the intact control model shows no bone tissue at risk but does show a relatively small volume of IVD tissue at risk. This might indicate that the damage threshold for the IVD tissue was chosen somewhat too low. However, most of this volume was found at the edge of the IVD suggesting this could also result from mesh 
imperfections secondary to morphing the generic FE mesh on the patient-specific geometry without additional re-meshing [40]. Nevertheless, all the instrumented models show substantially more bone and IVD tissue being at risk compared to the intact control model. This originates from the fact that segments L5-S1 and L4-5 are stabilized with posterior instrumentation. As a consequence, the other segments will be more severely deformed in order to allow the spine model to meet the prescribed flexion movement. The adjacent segments are thus at increased risk for degeneration, a phenomenon known as adjacent segment disease [41-43]. For the corrected coronal misaligned spine in flexion, there are minor differences with respect to the well-aligned instrumented spine in flexion as the correction of the coronal misalignment had little influence on the sagittal posture of the spine. The IVD volume at risk is slightly lower while the bone volume at risk is higher in the corrected coronal misaligned spine in flexion. Moreover, the large bone volume at risk as result from the correction procedure remains present in vertebra L4 during flexion. Compared to the well-aligned instrumented spine in flexion, the corrected sagittal misaligned spine showed a larger amount of bone and IVD tissue being at risk in flexion. This can be explained by the fact that the misalignment was introduced by misaligning the rod posteriorly with respect to the upper right screw of L4. As a consequence, the correction procedure induced an extension movement of segment L4-5 before the flexion movement was prescribed, explaining a larger moment and tissue volume at risk in the subsequent flexion than in the other instrumented cases. This is consistent with previous literature that reveals sagittal imbalance as one of the risk factors for developing degeneration at levels adjacent to the fused segment $[43,44]$. In agreement with clinical observations, this phenomenon is in all models most expressed in the segment immediately adjacent to the fusion, i.e. segment L34. Interestingly, the bone tissue at risk is highest for L1 during flexion in all but the intact model. It should be noted, however, that the calculated risk depends on several factors, including the size and anatomical shape of the vertebrae, the load distribution between facet joints and discs, and the bone density distribution, and thus can be different for different patients.

The influence of the presence of the contralateral rod could be clearly observed in the post-correction configuration. These effects continue to exist in the flexion posture at the operated FSU, i.e. in presence of the contralateral rod (situation I) more bone tissue is at risk than in absence of the contralateral rod (situation II) at L4-5. Additionally, it was rationalized that situation II allowed for larger segmental motions during the correction procedure affecting the natural posture of the spine more rigorously. As a consequence, larger tissue deformations are subsequently found for all the discs and the vertebrae proximal to the operated FSU in situation II when prescribing fifteen degrees flexion without allowing any off-plane rotations. In general, the maximum contact pressures in the facet joints decrease in all models in flexion posture since the contact layers are moving away from each other during forward bending. 
Although the presented FE models analyzed the biomechanical consequences of screwrod reduction quantitatively, output data should be carefully interpreted. For example, the adopted thresholds for considering bone respectively IVD tissue being at risk follow different principles. On the one hand, the bone damage threshold predicts a direct initiation of local damage, clinically presented as immediate posterior pain due to trabecular damage. On other hand, the adopted threshold for IVD tissue is expected to induce effects on the longer term when being experienced cyclically, clinically presented as the development of degeneration. Although it is premature to interpret the exact quantity of the tissue volume at risk, the relative changes between different situations and load-steps indicate a relative risk of that particular configuration. To get a more extensive validation of the tissue being at risk, we need to implement non-linear material behavior for the bone, including elastic-plastic-damage behavior, and to implement a tissue degeneration model for the disc [12]. This would involve the introduction of many new parameters and require further experimental validation of the model which is outside the scope of this publication.

Limitations of the current models can be found in several assumptions that were made. First, as explained before, it is assumed that the cranial end of L1 is unaltered by the correction procedure. This was assumed since it is known that patients will try to retain their original upright posture postoperatively but it is possible as well that part of this adaptation is in the thoracic spine. Second, the replacement of posteriorly fixed segment L5-S1 by constraining the caudal end of L5 might have resulted in overestimation of the correction effects. Since the segment was only posteriorly fixed, limited motion of the FSU might be expected $[45,46]$. This may explain the relatively high moments that were found for the instrumented cases. Third, plasticity was not included in the material model of the titanium instrumentation. Since the von Mises stress of some of the elements in the right rod exceeded the yield stress during correction, plastic deformation will be expected, leading to lower forces than predicted here. Fourth, only one specific patient was analyzed in this research. Nevertheless, the same reduction is expected to generate similar forces in other patients, as long as rods and vertebrae are similar in size. The predicted bone tissue volume at risk, on the other hand, will also depend on the bone density distribution since the tissue at risk is based on a strain limit. Finally, our results are valid only for the situation during and directly after the surgery. After progression of bony fusion, the loads on the instrumentation as well as on the adjacent levels may change.

Because both sagittal and coronal misalignment, as well as different clinical situations considering the presence of the contralateral rod were established, only one basic spine movement was modelled in this study. It may be appreciated that the exact output depends on both the direction and size of the misalignment, and the direction and size of the considered movement. Therefore, it is recommended to include several phenotypes of misalignments and different physiological movements in future work in order to analyze the consequences of the correction procedure in greater detail. Additionally, the induced misalignment of six millimeters was chosen based on the rod size and recommendation from 
clinicians, who indicated that deviations in the order of the diameter of the rod were realistic to occur. This value complies with other values tested in ex vivo experiments [5]. Moreover, it is expected that this deviation between rod and screw head will only increase when the amount of included spinal segments increases.

In conclusion, the FE analysis in this study demonstrates the importance to minimize the residual mismatch between spinal rod and pedicle screw head during posterolateral fusion surgery in the lumbar spine. Avoiding the need for reduction procedures may reduce the loads both on the posterior construct and on adjacent hard and soft tissues. We postulate that clinical complications secondary to unfavorable biomechanics could be reduced by ensuring proper screw rod construct alignment such that minimal external and unintended forces are required for connecting the spinal rods to the heads of the pedicle screws.

\section{REFERENCES}

1. Haschtmann D, Ferguson SJ. Spinal Instrumentation. In: Boos N, Aebi M, eds. Spinal Disorders: Fundamentals of Diagnosis and Treatment. Berlin, Heidelberg: Springer Berlin Heidelberg; 2008. p. 67-90.

2. Wanivenhaus F, Neuhaus C, Liebmann F, Roner S, Spirig JM, Farshad M. Augmented reality-assisted rod bending in spinal surgery. The spine journal : official journal of the North American Spine Society. 2019;19(10):1687-9.

3. Fiere V, Armoiry X, Vital JM, Lafage V, Berthiller J, Barrey C. Preoperative Planning and Patient-Specific Rods for Surgical Treatment of Thoracolumbar Sagittal Imbalance. In: van de Kelft E, ed. Surgery of the Spine and Spinal Cord: A Neurosurgical Approach. Cham: Springer International Publishing; 2016. p. 645-62.

4. Tohmeh A, Isaacs RE, Dooley ZA, Turner AW. Long Construct Pedicle Screw Reduction and Residual Forces are Decreased Using a Computer-Assisted Spinal Rod Bending System. The Spine Journal. 2014;14(11):S143-S4.

5. Paik H, Kang DG, Lehman RA, Jr., Gaume RE, Ambati DV, Dmitriev AE. The biomechanical consequences of rod reduction on pedicle screws: should it be avoided? The spine journal : official journal of the North American Spine Society. 2013;13(11):1617-26.

6. Kang DG, Lehman RA, Jr., Wagner SC, Bevevino AJ, Tracey RW, Gaume RE, Dmitriev AE. Effects of rod reduction on pedicle screw fixation strength in the setting of Ponte osteotomies. The Spine Journal. 2015;15(1):146-52.

7. Ohba T, Ebata S, Oba H, Koyama K, Haro H. Risk Factors for Clinically Relevant Loosening of Percutaneous Pedicle Screws. Spine Surg Relat Res. 2018;3(1):79-85.

8. Umehara S, Zindrick MR, Patwardhan AG, Havey RM, Vrbos LA, Knight GW, . . . , Lorenz MA. The biomechanical effect of postoperative hypolordosis in instrumented lumbar fusion on instrumented and adjacent spinal segments. Spine. 2000;25(13):161724.

9. Fagan MJ, Julian S, Mohsen AM. Finite element analysis in spine research. Proceedings of the Institution of Mechanical Engineers, Part H: Journal of Engineering in Medicine. 2002;216(5):281-98

10. Noailly J, Lacroix D. 5 - Finite element modelling of the spine. In: Ambrosio L, Tanner E, eds. Biomaterials for Spinal Surgery: Woodhead Publishing; 2012. p. 144-234e. 
11. Malandrino A, Pozo JM, Castro-Mateos I, Frangi AF, van Rijsbergen MM, Ito K, ..., Noailly J. On the relative relevance of subject-specific geometries and degenerationspecific mechanical properties for the study of cell death in human intervertebral disk models. Frontiers in bioengineering and biotechnology. 2015;3:5.

12. Rijsbergen MV, van Rietbergen B, Barthelemy V, Eltes P, Lazary A, Lacroix D, . . , Ito K. Comparison of patient-specific computational models vs. clinical follow-up, for adjacent segment disc degeneration and bone remodelling after spinal fusion. PLoS One. 2018;13(8):e0200899.

13. Castro-Mateos I, Pozo JM, Lazary A, Frangi A. 3D Vertebra Segmentation by Feature Selection Active Shape Model. In: Yao J, Glocker B, Klinder T, Li S, eds. Recent Advances in Computational Methods and Clinical Applications for Spine Imaging. Cham: Springer International Publishing; 2015. p. 241-5.

14. Castro-Mateos I, Pozo JM, Eltes PE, Rio LD, Lazary A, Frangi AF. 3D segmentation of annulus fibrosus and nucleus pulposus from T2-weighted magnetic resonance images. Physics in medicine and biology. 2014;59(24):7847-64.

15. Cootes TF, Taylor CJ, Cooper DH, Graham J. Active Shape Models-Their Training and Application. Computer Vision and Image Understanding. 1995;61(1):38-59.

16. Castro-Mateos; I, Pozo; JM, Lazary; A, Frangi AF. Automatic construction of patientspecific finite-element mesh of the spine from IVDs and vertebra segmentations. Proceedings Volume 9788, Medical Imaging 2016: Biomedical Applications in Molecular, Structural, and Functional Imaging;. 2016;(-):- 97881U.

17. Horváth G, Koroknai G, Acs B, Than P, Illés T. Prevalence of low back pain and lumbar spine degenerative disorders. Questionnaire survey and clinical-radiological analysis of a representative Hungarian population. Int Orthop. 2010;34(8):1245-9.

18. Blanchard R, Morin C, Malandrino A, Vella A, Sant Z, Hellmich C. Patient-specific fracture risk assessment of vertebrae: A multiscale approach coupling X-ray physics and continuum micromechanics. Int J Numer Method Biomed Eng. 2016;32(9).

19. Schmidt H, Midderhoff S, Adkins K, Wilke H-J. The effect of different design concepts in lumbar total disc arthroplasty on the range of motion, facet joint forces and instantaneous center of rotation of a L4-5 segment. European Spine Journal. 2009;18(11):1695-705.

20. Malandrino A, Lacroix D, Hellmich C, Ito K, Ferguson SJ, Noailly J. The role of endplate poromechanical properties on the nutrient availability in the intervertebral disc. Osteoarthritis and cartilage. 2014;22(7):1053-60.

21. Malandrino A, Noailly J, Lacroix D. Regional annulus fibre orientations used as a tool for the calibration of lumbar intervertebral disc finite element models. Computer methods in biomechanics and biomedical engineering. 2013;16(9):923-8.

22. Pfirrmann CW, Metzdorf A, Zanetti M, Hodler J, Boos N. Magnetic resonance classification of lumbar intervertebral disc degeneration. Spine. 2001;26(17):1873-8.

23. Noailly J, Ambrosio L, Elizabeth Tanner K, Planell JA, Lacroix D. In silico evaluation of a new composite disc substitute with a L3-L5 lumbar spine finite element model. European spine journal : official publication of the European Spine Society, the European Spinal Deformity Society, and the European Section of the Cervical Spine Research Society. 2012;21 Suppl 5:S675-87.

24. Horn BKP. Closed-form solution of absolute orientation using unit quaternions. J Opt Soc Am A. 1987;4(4):629-42. 
25. Kingma I, Busscher I, van der Veen AJ, Verkerke GJ, Veldhuizen AG, Homminga J, van Dieën JH. Coupled motions in human and porcine thoracic and lumbar spines. Journal of Biomechanics. 2018;70:51-8.

26. Kopperdahl DL, Keaveny TM. Yield strain behavior of trabecular bone. Journal of Biomechanics. 1998;31(7):601-8.

27. Gawri R, Rosenzweig DH, Krock E, Ouellet JA, Stone LS, Quinn TM, Haglund L. High mechanical strain of primary intervertebral disc cells promotes secretion of inflammatory factors associated with disc degeneration and pain. Arthritis Res Ther. 2014;16(1):R21-R.

28. Qian L, Jiang C, Sun P, Xu D, Wang Y, Fu M, . . , Ouyang J. A comparison of the biomechanical stability of pedicle-lengthening screws and traditional pedicle screws. The Bone \& Joint Journal. 2018;100-B(4):516-21.

29. Lorenz A, Leichtle CI, Frantz S, Bumann M, Tsiflikas I, Shiozawa T, Leichtle UG. Pull out Strength of Dual Outer Diameter Pedicle Screws Compared to Uncemented and Cemented Standard Pedicle Screws: A Biomechanical in vitro Study. Orthopaedic Surgery. 2017;9(2):229-36.

30. Kwok AW, Finkelstein JA, Woodside T, Hearn TC, Hu RW. Insertional torque and pullout strengths of conical and cylindrical pedicle screws in cadaveric bone. Spine. 1996;21(21):2429-34.

31. Panjabi MM, Oxland TR, Yamamoto I, Crisco JJ. Mechanical behavior of the human lumbar and lumbosacral spine as shown by three-dimensional load-displacement curves. The Journal of bone and joint surgery American volume. 1994;76(3):413-24.

32. Oda I, Cunningham BW, Buckley RA, Goebel MJ, Haggerty CJ, Orbegoso CM, McAfee PC. Does spinal kyphotic deformity influence the biomechanical characteristics of the adjacent motion segments? An in vivo animal model. Spine. 1999;24(20):2139-46.

33. Heo Y, Park JH, Seong HY, Lee YS, Jeon SR, Rhim SC, Roh SW. Symptomatic adjacent segment degeneration at the L3-4 level after fusion surgery at the L4-5 level: evaluation of the risk factors and 10-year incidence. European spine journal : official publication of the European Spine Society, the European Spinal Deformity Society, and the European Section of the Cervical Spine Research Society. 2015;24(11):2474-80.

34. Levangie PK, Norkin CC. Joint structure and function : a comprehensive analysis. Philadelphia, PA: F.A. Davis Co.; 2005.

35. El-Bohy AA, Yang K-H, King AI. Experimental verification of facet load transmission by direct measurement of facet lamina contact pressure. Journal of Biomechanics. 1989;22(8):931-41.

36. Du C-F, Yang N, Guo J-C, Huang Y-P, Zhang C. Biomechanical response of lumbar facet joints under follower preload: a finite element study. BMC Musculoskeletal Disorders. 2016;17(1):126.

37. Jaumard NV, Welch WC, Winkelstein BA. Spinal facet joint biomechanics and mechanotransduction in normal, injury and degenerative conditions. Journal of biomechanical engineering. 2011;133(7):071010-.

38. Wang DL, Jiang SD, Dai LY. Biologic response of the intervertebral disc to static and dynamic compression in vitro. Spine. 2007;32(23):2521-8.

39. Pattappa G, Li Z, Peroglio M, Wismer N, Alini M, Grad S. Diversity of intervertebral disc cells: phenotype and function. Journal of anatomy. 2012;221(6):480-96.

40. Hadagali P, Peters JR, Balasubramanian S. Morphing the feature-based multi-blocks of normative/healthy vertebral geometries to scoliosis vertebral geometries: development 
of personalized finite element models. Computer methods in biomechanics and biomedical engineering. 2018;21(4):297-324.

41. Kumar MN, Jacquot F, Hall H. Long-term follow-up of functional outcomes and radiographic changes at adjacent levels following lumbar spine fusion for degenerative disc disease. European spine journal : official publication of the European Spine Society, the European Spinal Deformity Society, and the European Section of the Cervical Spine Research Society. 2001;10(4):309-13.

42. Ghiselli G, Wang JC, Bhatia NN, Hsu WK, Dawson EG. Adjacent segment degeneration in the lumbar spine. The Journal of bone and joint surgery American volume. 2004;86(7):1497-503.

43. Park P, Garton HJ, Gala VC, Hoff JT, McGillicuddy JE. Adjacent segment disease after lumbar or lumbosacral fusion: review of the literature. Spine. 2004;29(17):1938-44.

44. Radcliff KE, Kepler CK, Jakoi A, Sidhu GS, Rihn J, Vaccaro AR, . . , Hilibrand AS. Adjacent segment disease in the lumbar spine following different treatment interventions. The Spine Journal. 2013;13(10):1339-49.

45. Perez-Orribo L, Zucherman JF, Hsu KY, Reyes PM, Rodriguez-Martinez NG, Crawford NR. Biomechanics of a Posterior Lumbar Motion Stabilizing Device: In Vitro: Comparison to Intact and Fused Conditions. Spine. 2016;41(2):E55-E63.

46. Hegewald AA, Hartmann S, Keiler A, Scheufler KM, Thomé C, Schmoelz W. Biomechanical investigation of lumbar hybrid stabilization in two-level posterior instrumentation. European Spine Journal. 2018;27(8):1887-94. 




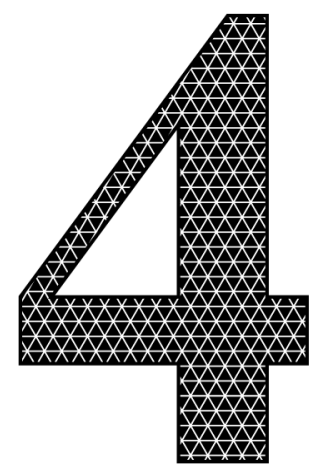

\title{
Patient-specific variations in local strain patterns on the surface of a trussed titanium interbody cage
}

\author{
ACY Loenen \\ J Noailly \\ $\mathrm{K}$ Ito \\ PC Willems \\ JJ Arts \\ $B$ van Rietbergen
}

Frontiers in Bioengineering and Biotechnology 2022; 9(750246) https://doi.org/10.3389/fbioe.2021.750246 


\begin{abstract}
INTRODUCTION: 3D printed trussed titanium interbody cages may deliver bone stimulating mechanobiological strains to cells attached at their surface. The exact size and distribution of these strains may depend on patient-specific factors, but the influence of these factors remains unknown. Therefore, this study aimed to determine patient-specific variations in local strain patterns on the surface of a trussed titanium interbody fusion cage.

MATERIALS AND METHODS: Four patients eligible for spinal fusion surgery with the same cage size were selected from a larger database. For these cases, patient-specific finite element models of the lumbar spine including the same trussed titanium cage were made. Functional dynamics of the non-operated lumbar spinal segments, as well as local cage strains and caudal endplate stresses at the operated segment, were evaluated under physiological extension/flexion movement of the lumbar spine.

RESULTS: All patient-specific models revealed physiologically realistic functional dynamics of the operated spine. In all patients, approximately $30 \%$ of the total cage surface experienced strain values relevant for preserving bone homeostasis and stimulating bone formation. Mean caudal endplate contact pressures varied up to $10 \mathrm{MPa}$. Both surface strains and endplate contact pressures varied more between loading conditions than between patients.
\end{abstract}

CONCLUSIONS: This study demonstrates the applicability of patient-specific finite element models to quantify the impact of patient-specific factors such as bone density, degenerative state of the spine, and spinal curvature on interbody cage loading. In the future, the same framework might be further developed in order to establish a pipeline for interbody cage design optimizations. 


\section{INTRODUCTION}

Lumbar interbody fusion (LIF) is a well-accepted treatment for low back pain symptoms that emerge from segmental mechanical instability [1, 2]. During LIF surgery, the intervertebral disc (IVD) of the affected segment is replaced by an interbody fusion cage. Interbody cages provide immediate mechanical support and serve as scaffold to facilitate bone growth in the intervertebral space and fuse the two adjacent vertebrae [3]. Although cages are usually enriched with bone graft (substitute) to foster bone formation [4], both material and design of the inserted cage dominate the mechanical interplay and define the initial interface between host tissue and cage. Current interbody fusion cages still render suboptimal fusion rates following LIF treatment [5]. For this reason, novel interbody cages are still being developed and introduced into the clinic.

One specific technique utilized to manufacture a new generation of interbody cages is metal additive manufacturing [6], commonly known as 3D printing. It builds an object layerby-layer by selectively adding material where needed, thus enabling production of tailored porous implant designs that are biomechanically optimized [7, 8]. Examples of such novel 3D printed metal interbody cages are trussed titanium interbody fusion cages [9]. Trussed cages encompass a network of linear beam elements (struts) that join at several intersections within the design. These highly porous cages provide an open architecture to accommodate bone ingrowth and may deliver bone stimulating mechanobiological strains to the cells attached to the strut surfaces.

Previous ex vivo research quantified the strain in all the struts of a trussed cage under moderate $(1,000 \mathrm{~N})$ and strenuous $(2,000 \mathrm{~N})$ axial compressive loads, by using high resolution micro computed tomography (CT) imaging [10]. Assuming that strain amplitudes over $200 \mu \varepsilon$ (microstrain, 10-6 strain) are relevant to both preserve bone homeostasis and stimulate bone formation [11], it was concluded that physiological loading of the cages induced strut strains consistent with those reported to maintain bone balance. Accordingly, it was demonstrated that cage design (e.g. diameter of struts) could be adjusted in order to tailor the strains induced by physiological mechanical loads [12].

Although the aforementioned ex vivo investigations provide valuable insights into the size and distribution of strut strains under physiological loading conditions and allow to explore design modifications, the experimental set-up entailed several limitations. Firstly, loading protocols were limited to static axial compression to allow for microCT image analysis. Secondly, strain magnitudes were quantified per strut, based on the change in total strut length, disregarding local strains within the struts that potentially arise from bending behavior. Thirdly, the actual in vivo strain regimes may depend on many additional factors, including cage placement and patient-specific factors such as weight, bone density, degenerative state of the spine, and spinal curvature [13-16]. The influence of patient-specific variations on local strain regimes thus remains unknown.

Therefore, this study aimed to determine patient-specific variations in local strain patterns on the surface of a trussed titanium interbody fusion cage. Finite element (FE) 
modeling enables simulation of several physiological loading conditions and quantification of local strain values within spinal (sub)structures as well as within the cages $[17,18]$. Additionally, the effect of patient-specific factors can be examined by studying the variation between different patient-specific models. Patient-specific FE models of four patients eligible for spinal fusion surgery were modified to simulate a posterior lumbar interbody fusion (PLIF) treatment with trussed titanium cages. Functional dynamics of the non-operated lumbar spinal segments, and the local cage strains and endplate stresses at the operated segment, were evaluated under physiological extension/flexion movement of the lumbar spine.

\section{MATERIALS AND METHODS}

\section{Patient-specific FE models of the intact lumbar spine}

Four patients were selected from a database of patients eligible for a spinal fusion operation as available from the earlier EU-funded MySpine project (EU FP7-ICT 269909). These patients were selected because they had similar vertebral sizes, such that the same cage design and size could be used in all patients, thereby excluding variation in the results due to differences in cage size. For all four patients, patient-specific FE models of the lumbar spine were available. The FE models were composed of the lumbar vertebrae (L1-L5), the IVDs (L1-2 to L5-S1), and the major ligaments per spinal motion segment. Detailed descriptions of patient data, model generation, and underlying material models can be found elsewhere $[19,20]$ and are only described briefly here. Based on segmentations of vertebral structures via CT data and segmentations of IVD structures via magnetic resonance imaging (MRI) data, a generic FE model was morphed to patient-specific spinal geometries [21-23].

Patient-specific trabecular bone densities were integrated in the models by defining transversely isotropic linear elastic material properties for each element, based on the mean CT gray value calculated within the representative volume of each element [24]. Bony posterior elements, facets, and bony endplates were modeled as isotropic linear elastic materials, whereas the sacrum and cortical bone were modeled as orthotropic linear elastic materials. Surface articulation in the facet joints was assumed to be frictionless and resolved with a penalty normal stiffness of $200 \mathrm{~N} / \mathrm{mm}$ [25]. Cartilage endplates were modeled as isotropic poro-elastic materials, whereas the nucleus pulposus (NP) and annulus fibrosis (AF) were both modelled as poro-hyperelastic materials [26]. The role of cross-ply collagen fibers present in the AF was implemented by adding an additional anisotropic term to the strain energy density function [27]. Darcy's law was used to determine the fluid pore pressure. The total stress in the poro-(hyper)elastic elements was defined as the sum of the fluid pore pressure and the porous solid stress as derived from the strain energy density function. An additional swelling pressure-related term was introduced for the NP to model proteoglycaninduced swelling of the IVD. Strain-dependent permeability was implemented and updated during the simulations for each poro-(hyper)elastic material model [19]. Exact material 
parameters of the IVD substructures depended on the degenerative state of the IVD, which was previously determined by an experienced radiologist using the MRI data and the Pfirrmann grading system [28]. The included ligaments were described as hypoelastic unidirectional materials of which the parameters differed per ligament type and disc level [29]. Pfirrmann grade-dependent material parameters for IVD substructures were optimized based on ex vivo creep tests of monosegments, and independent validation was achieved for the full L1-S1 patient-specific model thanks to ex vivo kinematic measurements [19]. Supplementary material 1 provides a summary of the materials used within the FE models.

\section{Patient-specific FE models of the operated lumbar spine}

Each of the four patient-specific FE models was modified to represent a situation directly after L4-5 PLIF surgery. A complete laminectomy was simulated which resulted in the removal of the elements of the spinous process and of all connecting ligaments at L4. In addition, the facet joints between L4 and L5, and the L4-5 IVD were virtually resected by eliminating the corresponding elements (Figure 1, top left).

In order to build the cage model to be implanted in each patient-specific model, a prototype trussed titanium PLIF cage was scanned at a 37 micrometer isotropic resolution in a microCT 100 system (SCANCO Medical AG, Brüttisellen, Switzerland) to retrieve the asmanufactured geometry of the cage. Scan data was imported into image processing software for design and modeling (Mimics Innovation Suite, Materialise, Leuven, Belgium). Following segmentation of the cage, a FE mesh was generated that consisted of 97,186 quadratic tetrahedral elements with a target triangle edge length of $0.30 \mathrm{~mm}$ to describe submillimeter details. Supplementary material 2 shows the geometry of the cage and how the meshing procedure affected the level of detail in surface features that was retained in the eventual cage models.

In order to accommodate interactive placement of the cages into the intervertebral disc space, without the need for laborious remeshing of the adjacent vertebrae, contact layers were introduced. Contact layers conforming to the top and bottom curvature of the cage were designed by using a computer aided design software (NX 12, Siemens PLM software, Plano TX, USA). These layers were $2.0 \mathrm{~mm}$ thick. They were imported in ABAQUS/Standard (Simulia, Inc., Providence, RI, USA) version 2018 and meshed, leading to approximately 25,000 linear brick elements per contact layer with a target triangle edge length of $0.33 \mathrm{~mm}$. These layers, representing the cage endplate interface, were modeled as an isotropic linear elastic material with a Young's modulus of 1,000 MPa and a Poisson's ratio of 0.30 [30]. Although this stiffness value is believed to resemble the cage endplate interface appropriately, the exact stiffness depends on endplate preparation technique and might vary from the stiffness of cancellous up to cortical bone (100-10,000 MPa). To investigate the effect of these variations, a side study was performed (see Supplementary material 3). 

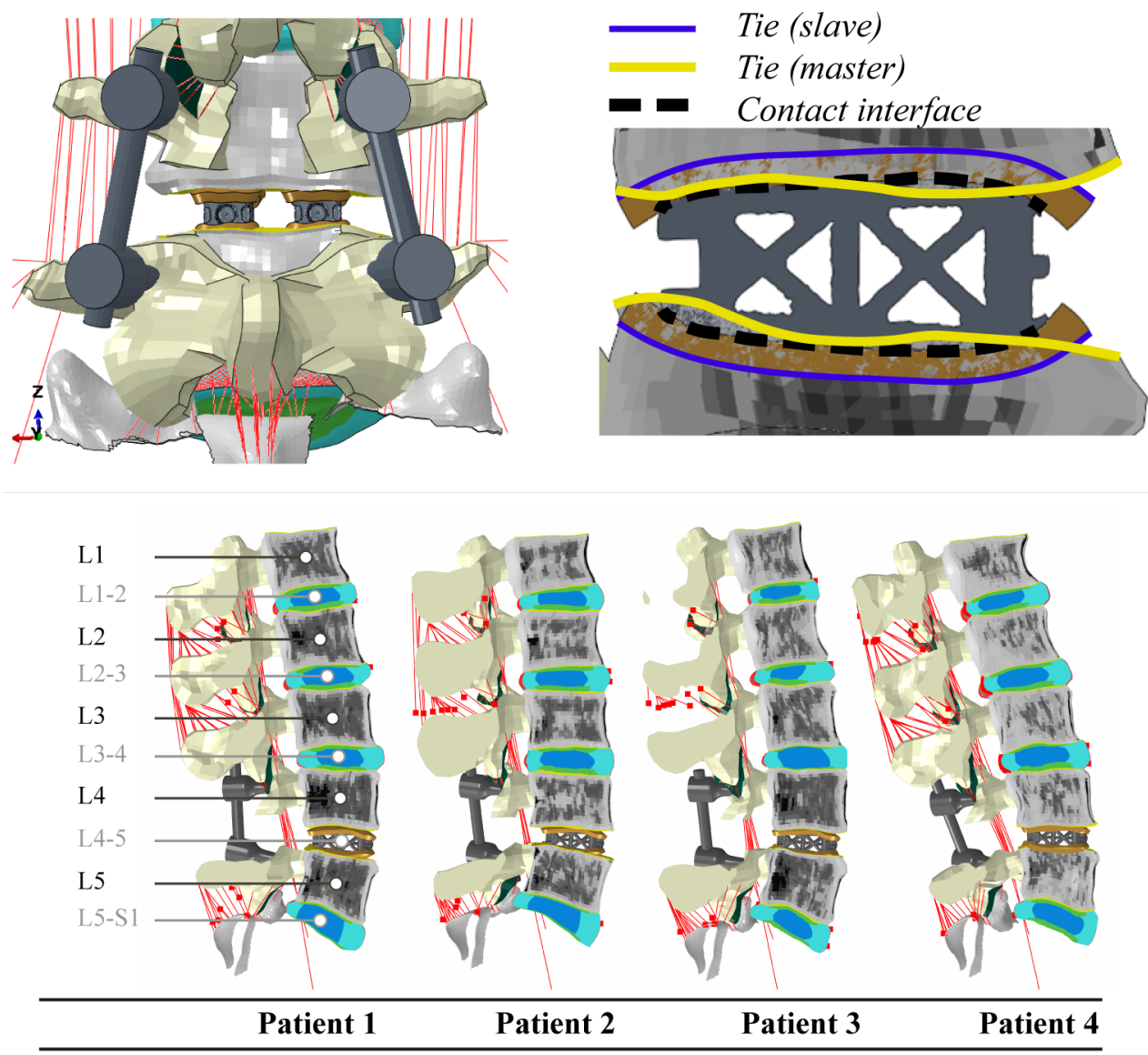

\section{Patient 2}

\begin{tabular}{cc} 
Patient 3 & Patient $\mathbf{4}$ \\
\hline Female & Female \\
55 & 34 \\
74 & 70 \\
167 & 164 \\
36 & 29
\end{tabular}

\begin{tabular}{cc}
\hline Gender & Fema \\
Age [year] & 41 \\
Weight [kg] & 60 \\
Length [cm] & 168 \\
Lordosis [ ${ }^{\circ}$ ] & 40 \\
Pfirrmann grade & \\
L1-2 & II \\
L2-3 & II \\
L3-4 & II \\
L5-S1 & IV
\end{tabular}

Figure 1. Top left: posterior view of segment L4-5 following PLIF surgery. A complete laminectomy was performed and two interbody cages were inserted. Top right: graphical overview of the interaction properties prescribed for cage vertebra interaction. The outer surface of the contact layer (purple) is rigidly tied to the associated bony endplate surface (yellow). Hard normal contact and a coefficient of friction of 0.20 were used to describe the contact between the cage and the inner surface of the contact layer (dashed black line). Bottom: a midsagittal cut of each of the four operated patient-specific models with corresponding demographic data. The different colors in the models represent different material properties. 
To match the shape of the contact layers with the exterior struts of the cage, a deformable contact simulation was performed. Interaction between the inner surface of the contact layer and the interbody cage was modelled as hard normal contact with a coefficient of friction of 0.20 [31]. Then, the contact layers were moved $0.30 \mathrm{~mm}$ towards the cage and were allowed to deform, as the contact with the cage, modelled as a rigid body, was detected. The resulting deformed mesh of the contact layers was saved in its stress-free state, and the meshes of two interbody cages (one left and one right) and the corresponding contact layers were manually positioned within each patient-specific lumbar FE model to simulate an L4-5 interbody fusion. The outer surfaces of the contact layers were then rigidly tied to the bony endplate surface of the associated vertebra (Figure 1, top right). Because cage positioning is a manual procedure both in our models and in the clinic, the exact cage position can vary. To investigate the effect of these variations, a side study was performed (see Supplementary material 3).

Interbody cages were modelled as isotropic linear elastic titanium (Ti-6Al-4V, Young's modulus of $116 \mathrm{GPa}$, Poisson's ratio of 0.32). Finally, titanium (Ti-6Al-4V) pedicle screw and rod instrumentations were implemented in the models, based on anatomical landmarks of the spine. Pedicle screws ( $32 \mathrm{~mm}$ shaft length, $5 \mathrm{~mm}$ diameter) were fixed in the vertebrae and spinal rods ( $5 \mathrm{~mm}$ diameter) were fixed in the screw heads by embedding constraints. Figure 1 shows segment L4-5 following PLIF surgery and visualizes the imposed interaction properties between cage, contact layer, and vertebrae. In addition, the four operated models are visualized in this figure.

\section{Boundary and loading conditions}

The caudal end of each lumbar spine model was completely constrained in all modeling steps. In the first step ( 8 hours), the cranial end remained unconstrained allowing pre-swelling of the poro-(hyper)elastic IVD elements. In the second step (5 seconds), a patient-specific compressive load was applied to the spine by means of the follower load technique [32]. Two node connector elements were placed bilaterally through the vertebral centers in the sagittal plane in order to apply a compressive load that is oriented tangent to the spinal curvature. Patient-specific magnitudes of the follower load (range 368 to $454 \mathrm{~N}$ ) were based on previous literature [33]. In the third step ( 5 seconds), an extension or flexion movement was simulated. A total deflection of 20 degrees was imposed at the cranial end of L1 while constraining all off-axis rotations. Simultaneously, the patient-specific follower load was set to increase during extension (range 748 to $888 \mathrm{~N}$ ) and flexion (range 976 to $1,148 \mathrm{~N}$ ). The patientspecific magnitudes of the follower load per loading condition were derived from the data of Han et al. by interpolating the literature values of the resultant force at spinal level L1 to the patient-specific weight and length characteristics of the patients included in this study [33]. 


\section{Output analysis}

ABAQUS/Standard (Simulia, Inc., Providence, RI, USA) version 2018 was used to solve extension and flexion simulations for each of the four patient-specific models. Loaddeflection curves were determined for the complete lumbar spine and per non-operated functional spinal unit (FSU) as described before [34]. In addition, the intradiscal pressure (IDP) was quantified in the NP of the IVDs. It was defined as the superposition of the average pore pressure and the average axial component of the solid matrix stress. The absolute maximum principal strain values in the spinal cages were visualized and the percentage of surface nodes that exceeded an absolute strain value of $200 \mu \varepsilon$ was quantified for each loading condition. Additionally, the normal contact pressures at the caudal cage-contact layer interface were visualized and the mean caudal contact pressure was quantified for each loading condition.

\section{RESULTS}

Figure 1 provides an overview of the demographic data of the four patients included in this study (one male and three female). As patients were selected to fit the same cage size, the population comprised a relatively narrow weight and length range (60 to $74 \mathrm{~kg}$ and 164 to $172 \mathrm{~cm}$ ). Lumbar lordotic angles ranged from 29 to 40 degrees while degenerative state of the non-operated discs varied from Pfirrmann grade II to IV. Different gray value intensities and distributions in the trabecular bone regions indicate the differences in bone density between vertebrae and patients.

Figure 2 displays the total lumbar spine motion, the angular motion per FSU, and the IDP per IVD during extension/flexion movement. The four S1-L1 patient-specific models showed comparable asymmetrical extension/flexion flexibility profiles but differed in terms of reaction moment magnitudes at 20 degrees, in both extension (range -9.9 to $-7.7 \mathrm{Nm}$ ) and flexion (range 17.3 to $25.8 \mathrm{Nm}$ ). These patient-specific differences were also reflected in the angular motion per FSU, especially in flexion at L5-S1. L5-S1 was also the disc with most patient-to-patient variability in terms of degenerative state (Figure 1). The IDP over all discs in neutral position, under follower load compression, ranged from 0.4 to $0.8 \mathrm{MPa}$. In general, it increased more in flexion (range 1.3 to $2.7 \mathrm{MPa}$ ) than in extension (range 0.6 to $1.1 \mathrm{MPa}$ ). Again, patient-specific variations were most pronounced in flexion at the L5-S1 level. The Pfirrmann grade III L3-4 IVD model (patient 3) led to clearly lower IDP values than the grade II L3-4 IVD models of the other patients, during the flexion movement.

Since the two inserted PLIF cages (left, right) demonstrated similar deformations within one patient for each of the loading conditions, Figure 3 illustrates only the calculation outcomes in the right cage of patient 1 . In neutral position, only small strain values $(<200$ $\mu \varepsilon)$ were calculated in the cage. In extension, strains shifted to the posterior side of the cage and values increased up to approximately $300 \mu \varepsilon$. In flexion, strains shifted to the anterior side of the cage and locally, values exceeded $500 \mu \varepsilon$. For all loading conditions, both 
compressive (negative) and tensile (positive) strains were present at the struts. In the enlarged inset, struts show compressive strain on the one side and tensile strain on the other side, indicating inwards bending of the struts during flexion. The bar chart demonstrates that the relative amount of surface exceeding $200 \mu \varepsilon$ varied more between loading conditions than between patients, whereas the coefficient of variation in flexion was $8.3 \%$. The peak von Mises stresses within the PLIF cages ranged from 248 to $304 \mathrm{MPa}$ over the different patients, which is far below the yield stress of 3D printed titanium.
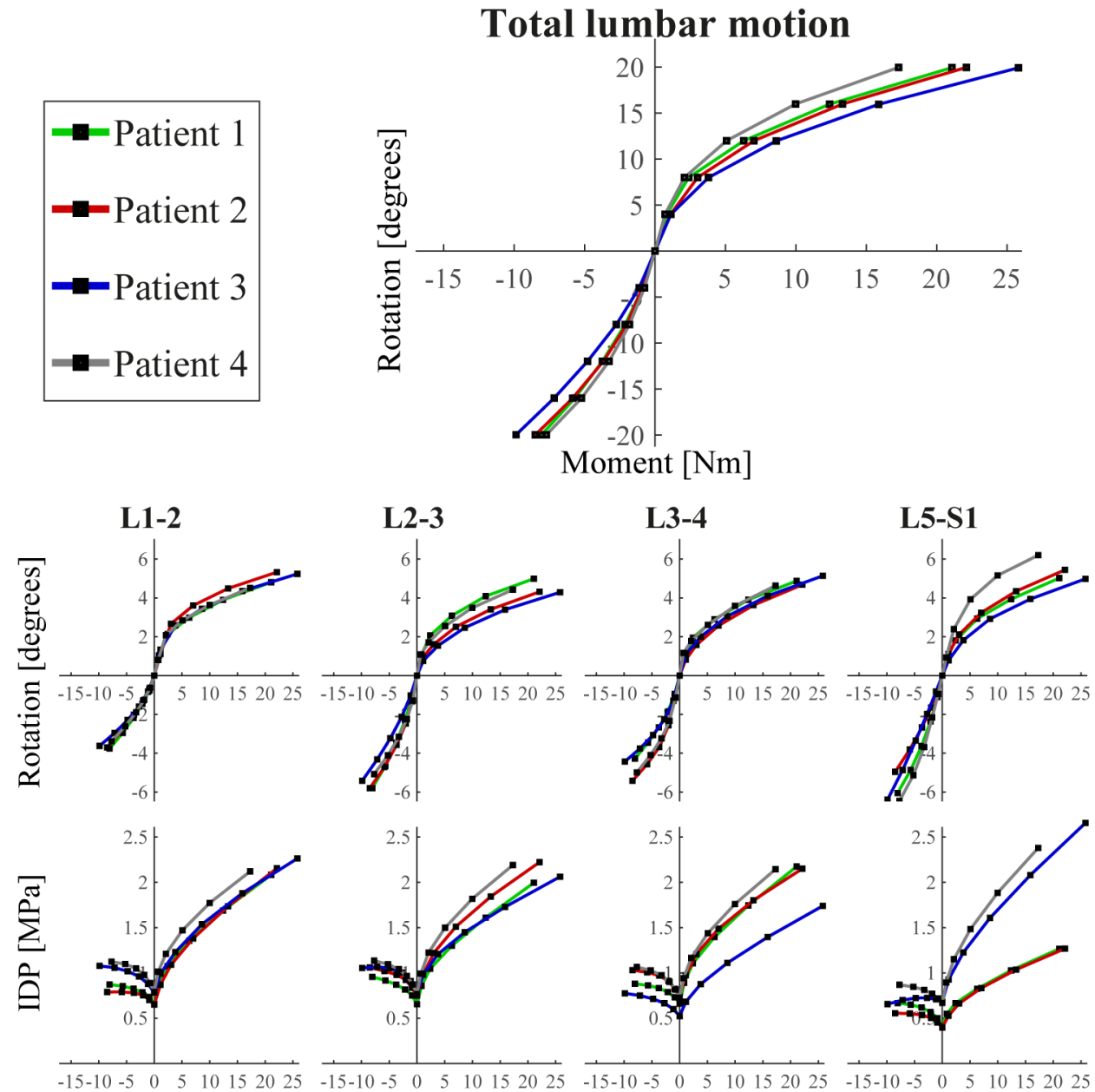

Figure 2. Top: Load-deflection curve of the total lumbar spine for the four patient-specific models. Rotation represents rotation of the cranial endplate of $\mathrm{L} 1$ in the sagittal plane and moment is the reaction moment required to obtain these rotation values. Bottom: angular motion per functional spinal unit (FSU) and intradiscal pressure (IDP) per intervertebral disc (IVD) of the unoperated levels of each of the four patients. For all (sub)figures, negative and positive moments/rotations describe extension and flexion, respectively. 

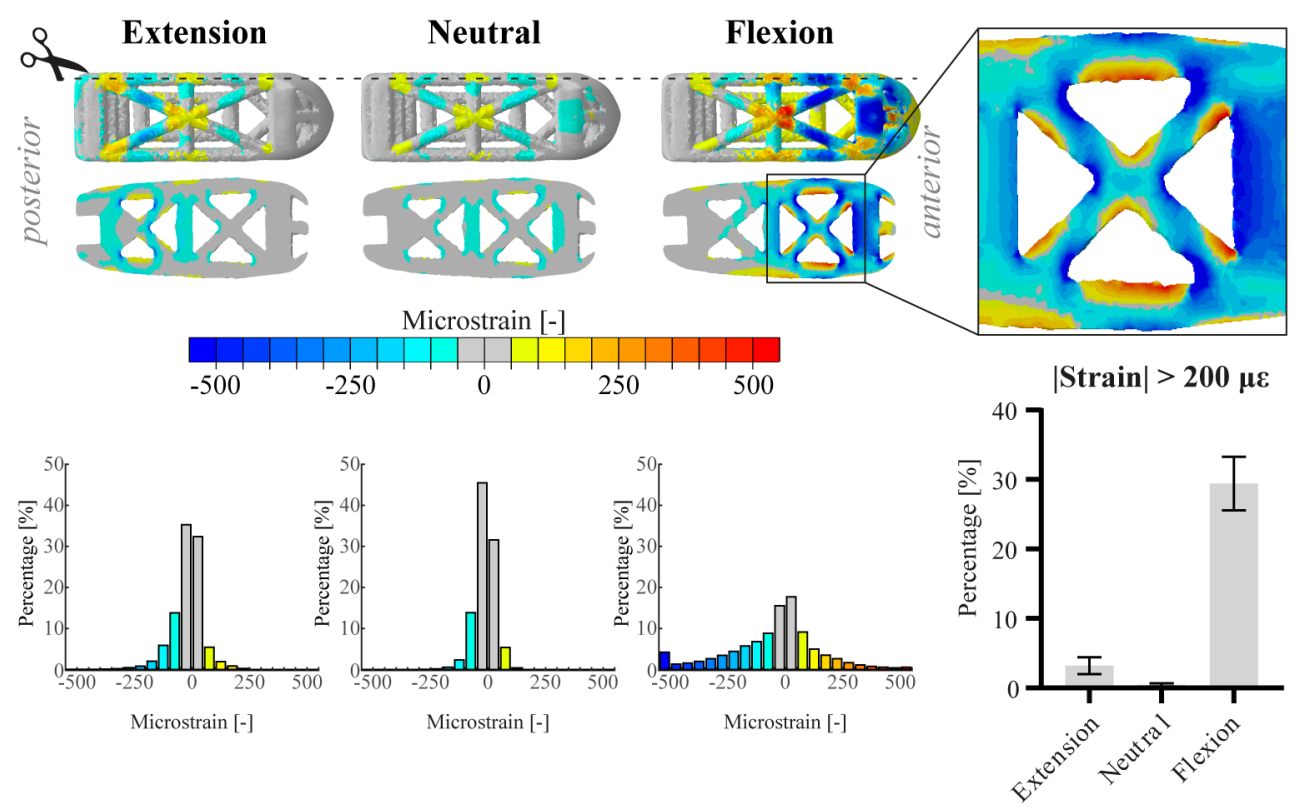

Figure 3. Top part of the figure shows the absolute maximum principal strain values (top view and sagittal cut, respectively) on the right cage of patient 1 in extension, neutral, and flexion position. Additionally, an enlarged view of the anterior part of the cage in flexion is displayed. The three histograms correspond to the images above and represent the relative amount of surface nodes [\%] for different strain ranges. For the bar chart, data of both cages within one patient were amalgamated. The bar chart displays the relative amount of surface nodes [\%] exceeding an absolute strain value of 200 $\mu \varepsilon$ for the different loading conditions. Bars represent the mean and $95 \%$ confidence interval of the patient population $(n=4)$.

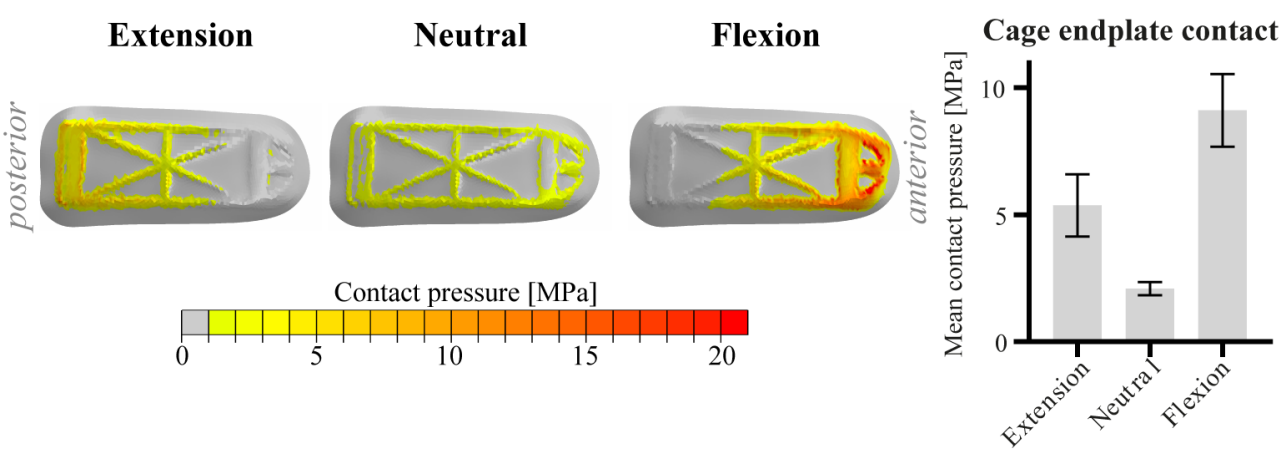

Figure 4. Visualization of the contact pressure of the right cage of patient 1 on the caudal contact layer in extension, neutral and flexion position. For the bar chart, data of the two caudal contact layers within one patient were amalgamated. The bar chart displays the mean caudal contact pressure for the different loading conditions. Bars represent the mean and $95 \%$ confidence interval of the patient population $(n=4)$. 
Since the two caudal contact layers (left, right) within one patient showed similar behavior for each of the loading conditions, Figure 4 shows only the graphical output at the right caudal contact layer of patient 1 . Comparable to the strain distribution in the cages, the caudal contact pressure shifts posteriorly and anteriorly in extension and flexion, respectively. Highest caudal contact pressures were observed anteriorly in the flexion configuration. Like the relative amount of surface exceeding $200 \mu \varepsilon$, the mean caudal contact pressure varied more between loading conditions than between patients (see bar chart). The coefficient of variation of the mean caudal contact pressure in flexion was $9.9 \%$ between patients.

\section{DISCUSSION}

The main purpose of this study was to determine patient-specific variations in local strain patterns on the surface of trussed titanium interbody fusion cages. These variations were analyzed in a specific subgroup allowing for implementation of one specific PLIF cage size for all included patients. The results demonstrate that within this specific subgroup patient-specific factors such as weight, bone density, degenerative state of the spine, and spinal curvature did affect local strain regimes; however, loading conditions in this group had a much more prominent impact on both size and distribution of the strains. The same trend was observed for the mean contact pressure of the cages at the caudal vertebral endplates. It should however be emphasized that the patient dataset in current research did not include any patients with comorbidities like previous lumbar surgery, heavy smoking, drug use or other conditions affecting bone or disc metabolism, osteoporosis, obesity, or scoliosis. Therefore, this patient cohort does not reflect the broad patient population undergoing spinal fusion surgery. Inclusion of patients with these comorbidities could provide additional insight as to what patient-specific constraints need to be taken into consideration and how to optimize implant design to address these conditions.

Although the lumbar spine models used in this research were validated in earlier studies, further validation would be warranted, particularly because the earlier studies did not include the instrumentation modeled in this research. A logical next step would be to validate the predicted strains within the cages using ex vivo spine testing of operated spines such that the FE results can be verified against the ex vivo observations. Subsequently, a patient study in which strain results, obtained from patient-specific models, are correlated with the postoperative progression of bone growth would provide further clinical evidence.

The operated patient-specific lumbar spine models in this study are somewhat stiff in flexion and somewhat compliant in extension [35,36]. This behavior might be caused by the surgical modifications to the intact models, as spinal fusion surgery generally increases the stiffness of the spine more in flexion than in extension movement [37]. Since the rotational contribution of FSU L4-5 is known to be proportionally larger in flexion compared to extension [38], this effect might have been enhanced as all patients were scheduled for L4-5 
interbody fusion. Additionally, the implementation of the follower load might have had a minor effect on angular motion per FSU [39]. The differences observed between patients on total lumbar motion level mainly emerged from FSU L5-S1, whose degenerative state varied most substantially between patients (range II to IV on the Pfirrmann grading system). Because the reduced disc height of a degenerated disc presumably increases the stiffness of the FSU [40], different load-deflection curves between segments could be expected. Mean IDP values in neutral position were consistent with in vivo data and increased, in accordance with previous literature, more substantially in flexion than in extension [41]. As IDP is known to increase more significantly in flexion in the fused spine compared to the native spine [42], IDP values were found to be in the high-end regime. The differences in IDP observed for disc L3-4 and L5-S1 in flexion correspond with loss of water in the more degenerated discs, inducing lower IDP values [43]. Overall, all patient-specific models revealed physiologically realistic functional dynamics of the operated spine.

The percentage of the cage that experienced strains consistent with those reported to maintain bone balance under physiological loading in the current study were slightly less than those found in the aforementioned study that investigated a different trussed titanium cage under moderate $(1,000 \mathrm{~N})$ axial compression [10], i.e. up to $50 \%$ of the free struts was loaded beyond $200 \mu \varepsilon$ in the ex vivo study versus up to $30 \%$ of the total surface in current in silico approach. These differences, however, might be explained by the fact that in the ex vivo study a larger cage was used, which has a relatively smaller screw insertion block. In the prototype PLIF cage of the current study the screw insertion block carries a relatively large part of the load, thereby reducing the load on the struts. Therefore, it can be expected that for a similar cage design the actual strain values would compare well to those reported in the earlier study.

In current research, a value of $200 \mu \varepsilon$ was adopted in order to quantify the percentage of surface that experienced a strain value relevant for preserving bone homeostasis and stimulating bone formation. It has however been described before that the exact strain threshold for maintaining bone mass is a nonlinear function of the daily loading cycle number [44]. Stimuli with magnitudes of $200 \mu \varepsilon$ are estimated to require approximately 35,000 loading cycles per day (once every 2 to 3 seconds) to maintain bone mass, whereas for mechanical stimuli with a frequency in the order of $10^{6}$ to $10^{7}$ per day (10 to 100 cycles per second) even strain values lower than $10 \mu \varepsilon$ are suggested to be capable of stimulating bone formation [45]. Patient-specific spinal motion profiles may therefore be required to interpret the strain values more appropriately. Moreover, it is worthwhile to emphasize that these reference strain values originate from bone remodeling research and it is unknown to what extent these values can be directly translated towards a former intervertebral disc, i.e. a cartilaginous environment. Once interbody fusion has progressed between the vertebrae, these values would be directly applicable. This would, however, require extension of the FE models to include the formation of bone within the cages and was outside the scope of this research. 
Although the FE models were intended to predict strain values at the surface of trussed cages on submillimeter scale, they do not provide a full characterization of the mechanical stimuli the attached cells might perceive in an in vivo situation. This is because the exact micro- to nanoscale surface features at the struts, the way cells could be attached to the struts (bridged versus non-bridged), and other mechanical stimuli like fluid flow and hydrostatic pressure in the cages were not involved in current FE models [46-48]. Also, the trussed titanium cage model did not take surface micro- to nanostructure and strut composition in consideration. This simplified cage model therefore provides only a limited representation of the cage properties regarding its in vivo mechanobiological response. In order to accurately represent this response, multi-scale modelling will be required including microstructural features that include cell-strut interaction and fluid flow within the cage.

Since the posterior side of the PLIF cage is shielded more by the pedicle screw and rod instrumentation than the anterior side, higher strains could be found in the anterior part of the cage under extension/flexion movement. Assuming the higher strains will indeed accelerate bone formation at the anterior side of the cage, this would be favorable from a biomechanical point of view as PLIF segments that are partially fused anteriorly are found to be more stable than those partially fused posteriorly [49].

Current research used a subset of patient-specific FE models to predict the impact of patient-specific factors on cage level. The same framework could also serve as a platform to evaluate several design modifications of the interbody cages iteratively. Design modifications might be considered in order to target higher surface strains or to distribute the strains more homogenously across the whole cage. However, the ultimate strength of the proposed design modifications should also be continuously monitored as interbody cages should also withstand high peak forces in the lumbar spine [50]. Additionally, modified designs could change the amount of direct cage to endplate contact thus affecting the stresses on the endplate and the risk for cage subsidence [51]. Cage design optimization algorithms would therefore require a cost function that assesses a combination of several output metrics. In the future, development of such algorithms may facilitate interbody cage design optimizations.

It should be noted that the current study analyzed the behavior of one specific trussed titanium cage geometry used for LIF treatment with a posterior approach (PLIF cage) and that results might be different for other cage geometries. In fact, the choice for another surgical approach, like anterior lumbar interbody fusion (ALIF), would affect the output on the cage level by multiple means. ALIF surgery requires only one large cage as the anterior approach provides full access to the ventral side of the operated spinal segment [52]. Since each single cage contains a screw anchoring point to enable cage insertion during surgery, one trussed ALIF cage contains relatively more struts than two trussed PLIF cages. Additionally, one ALIF cage generally comprehends a larger footprint on the vertebral endplate than two PLIF cages do. Moreover, ALIF surgery can be performed as stand-alone procedure, which generally means there is some additional fixation that can be instrumented 
anteriorly directly after cage placement (e.g. an anterior fixating plate), but there is no pedicle screw and rod instrumentation or other supplemental posterior fixation involved [53]. The different types of additional fixation in PLIF and ALIF surgery obviously result in different loading patterns on the interbody fusion construct [54].

In conclusion, this study demonstrates the applicability of patient-specific FE models to quantify the impact of patient-specific factors as weight, bone density, degenerative state of the spine, and spinal curvature on interbody cage loading. As the resulting surface strains were very similar for the different patient-specific models in the selected patient group, it can be concluded that the trussed design is rather robust from a mechanobiological perspective. In the future, the same framework might be further developed in order to establish a pipeline for interbody cage design optimizations.

\section{REFERENCES}

1. Fritzell P, Hägg O, Wessberg P, Nordwall A. 2001 Volvo Award Winner in Clinical Studies: Lumbar fusion versus nonsurgical treatment for chronic low back pain: a multicenter randomized controlled trial from the Swedish Lumbar Spine Study Group. Spine. 2001;26(23):2521-32; discussion 32-4.

2. Bhalla A, Schoenfeld AJ, George J, Moghimi M, Bono CM. The influence of subgroup diagnosis on radiographic and clinical outcomes after lumbar fusion for degenerative disc disorders revisited: a systematic review of the literature. The spine journal : official journal of the North American Spine Society. 2017;17(1):143-9.

3. Bagby GW. Arthrodesis by the distraction-compression method using a stainless steel implant. Orthopedics. 1988;11(6):931-4.

4. Duarte RM, Varanda P, Reis RL, Duarte ARC, Correia-Pinto J. Biomaterials and Bioactive Agents in Spinal Fusion. Tissue engineering Part B, Reviews. 2017;23(6):54051 .

5. Meng B, Bunch J, Burton D, Wang J. Lumbar interbody fusion: recent advances in surgical techniques and bone healing strategies. European Spine Journal. 2021;30(1):2233.

6. Arts M, Torensma B, Wolfs J. Porous titanium cervical interbody fusion device in the treatment of degenerative cervical radiculopathy; 1-year results of a prospective controlled trial. The Spine Journal. 2020;20(7):1065-72.

7. Tan XP, Tan YJ, Chow CSL, Tor SB, Yeong WY. Metallic powder-bed based 3D printing of cellular scaffolds for orthopaedic implants: A state-of-the-art review on manufacturing, topological design, mechanical properties and biocompatibility. Materials science \& engineering C, Materials for biological applications. 2017;76:132843.

8. Pobloth A-M, Checa S, Razi H, Petersen A, Weaver JC, Schmidt-Bleek K, ..., Schwabe P. Mechanobiologically optimized 3D titanium-mesh scaffolds enhance bone regeneration in critical segmental defects in sheep. Science Translational Medicine. 2018;10(423).

9. Hunt JP, Begley MR, Block JE. Truss implant technology ${ }^{\mathrm{TM}}$ for interbody fusion in spinal degenerative disorders: profile of advanced structural design, mechanobiologic and performance characteristics. Expert review of medical devices. 2021:1-9. 
10. Caffrey JP, Cory E, Wong VW, Masuda K, Chen AC, Hunt JP, . . , Sah RL. Ex vivo loading of trussed implants for spine fusion induces heterogeneous strains consistent with homeostatic bone mechanobiology. J Biomech. 2016;49(16):4090-7.

11. Duncan RL, Turner $\mathrm{CH}$. Mechanotransduction and the functional response of bone to mechanical strain. Calcified tissue international. 1995;57(5):344-58.

12. Caffrey JP, Alonso E, Masuda K, Hunt JP, Carmody CN, Ganey TM, Sah RL. Strains in trussed spine interbody fusion implants are modulated by load and design. Journal of the mechanical behavior of biomedical materials. 2018;80:203-8.

13. Abbushi A, Čabraja M, Thomale U-W, Woiciechowsky C, Kroppenstedt SN. The influence of cage positioning and cage type on cage migration and fusion rates in patients with monosegmental posterior lumbar interbody fusion and posterior fixation. European Spine Journal. 2009;18(11):1621.

14. Polikeit A, Ferguson SJ, Nolte LP, Orr TE. Factors influencing stresses in the lumbar spine after the insertion of intervertebral cages: finite element analysis. European spine journal : official publication of the European Spine Society, the European Spinal Deformity Society, and the European Section of the Cervical Spine Research Society. 2003;12(4):413-20.

15. Naserkhaki S, Jaremko JL, El-Rich M. Effects of inter-individual lumbar spine geometry variation on load-sharing: Geometrically personalized Finite Element study. Journal of Biomechanics. 2016;49(13):2909-17.

16. Galbusera F, Niemeyer F, Tao Y, Cina A, Sconfienza LM, Kienle A, Wilke HJ. ISSLS Prize in Bioengineering Science 2021: in vivo sagittal motion of the lumbar spine in low back pain patients-a radiological big data study. European spine journal : official publication of the European Spine Society, the European Spinal Deformity Society, and the European Section of the Cervical Spine Research Society. 2021.

17. Goel VK, Panjabi MM, Patwardhan AG, Dooris AP, Serhan H. Test protocols for evaluation of spinal implants. The Journal of bone and joint surgery American volume. 2006;88 Suppl 2:103-9.

18. Gustafson HM, Cripton PA, Ferguson SJ, Helgason B. Comparison of specimen-specific vertebral body finite element models with experimental digital image correlation measurements. Journal of the mechanical behavior of biomedical materials. 2017;65:801-7.

19. Malandrino A, Pozo JM, Castro-Mateos I, Frangi AF, van Rijsbergen MM, Ito K, ... , Noailly J. On the relative relevance of subject-specific geometries and degenerationspecific mechanical properties for the study of cell death in human intervertebral disk models. Frontiers in bioengineering and biotechnology. 2015;3:5.

20. Rijsbergen MV, van Rietbergen B, Barthelemy V, Eltes P, Lazary A, Lacroix D, ... , Ito K. Comparison of patient-specific computational models vs. clinical follow-up, for adjacent segment disc degeneration and bone remodelling after spinal fusion. PLoS One. 2018;13(8):e0200899.

21. Castro-Mateos I, Pozo JM, Lazary A, Frangi A. 3D Vertebra Segmentation by Feature Selection Active Shape Model. In: Yao J, Glocker B, Klinder T, Li S, eds. Recent Advances in Computational Methods and Clinical Applications for Spine Imaging. Cham: Springer International Publishing; 2015. p. 241-5.

22. Castro-Mateos I, Pozo JM, Eltes PE, Rio LD, Lazary A, Frangi AF. 3D segmentation of annulus fibrosus and nucleus pulposus from T2-weighted magnetic resonance images. Physics in medicine and biology. 2014;59(24):7847-64. 
23. Castro-Mateos; I, Pozo; JM, Lazary; A, Frangi AF. Automatic construction of patientspecific finite-element mesh of the spine from IVDs and vertebra segmentations. Proceedings Volume 9788, Medical Imaging 2016: Biomedical Applications in Molecular, Structural, and Functional Imaging;. 2016;(-):- 97881U.

24. Blanchard R, Morin C, Malandrino A, Vella A, Sant Z, Hellmich C. Patient-specific fracture risk assessment of vertebrae: A multiscale approach coupling X-ray physics and continuum micromechanics. Int J Numer Method Biomed Eng. 2016;32(9).

25. Schmidt H, Heuer F, Drumm J, Klezl Z, Claes L, Wilke HJ. Application of a calibration method provides more realistic results for a finite element model of a lumbar spinal segment. Clinical biomechanics (Bristol, Avon). 2007;22(4):377-84.

26. Malandrino A, Lacroix D, Hellmich C, Ito K, Ferguson SJ, Noailly J. The role of endplate poromechanical properties on the nutrient availability in the intervertebral disc. Osteoarthritis and cartilage. 2014;22(7):1053-60.

27. Malandrino A, Noailly J, Lacroix D. Regional annulus fibre orientations used as a tool for the calibration of lumbar intervertebral disc finite element models. Computer methods in biomechanics and biomedical engineering. 2013;16(9):923-8.

28. Pfirrmann CW, Metzdorf A, Zanetti M, Hodler J, Boos N. Magnetic resonance classification of lumbar intervertebral disc degeneration. Spine. 2001;26(17):1873-8.

29. Noailly J, Ambrosio L, Elizabeth Tanner K, Planell JA, Lacroix D. In silico evaluation of a new composite disc substitute with a L3-L5 lumbar spine finite element model. European spine journal : official publication of the European Spine Society, the European Spinal Deformity Society, and the European Section of the Cervical Spine Research Society. 2012;21 Suppl 5:S675-87.

30. Polikeit A, Ferguson SJ, Nolte LP, Orr TE. The importance of the endplate for interbody cages in the lumbar spine. European spine journal : official publication of the European Spine Society, the European Spinal Deformity Society, and the European Section of the Cervical Spine Research Society. 2003;12(6):556-61.

31. Vadapalli S, Sairyo K, Goel VK, Robon M, Biyani A, Khandha A, Ebraheim NA. Biomechanical rationale for using polyetheretherketone (PEEK) spacers for lumbar interbody fusion-A finite element study. Spine. 2006;31(26):E992-8.

32. Renner SM, Natarajan RN, Patwardhan AG, Havey RM, Voronov LI, Guo BY, ..., An HS. Novel model to analyze the effect of a large compressive follower pre-load on range of motions in a lumbar spine. Journal of Biomechanics. 2007;40(6):1326-32.

33. Han K-S, Rohlmann A, Zander T, Taylor WR. Lumbar spinal loads vary with body height and weight. Medical Engineering \& Physics. 2013;35(7):969-77.

34. Loenen ACY, Noriega DC, Ruiz Wills C, Noailly J, Nunley PD, Kirchner R, ..., van Rietbergen B. Misaligned spinal rods can induce high internal forces consistent with those observed to cause screw pullout and disc degeneration. The Spine Journal. 2021;21(3):528-37.

35. Panjabi MM, Oxland TR, Yamamoto I, Crisco JJ. Mechanical behavior of the human lumbar and lumbosacral spine as shown by three-dimensional load-displacement curves. The Journal of bone and joint surgery American volume. 1994;76(3):413-24.

36. Dreischarf M, Zander T, Shirazi-Adl A, Puttlitz CM, Adam CJ, Chen CS, ... , Schmidt H. Comparison of eight published static finite element models of the intact lumbar spine: predictive power of models improves when combined together. J Biomech. 2014;47(8):1757-66. 
37. Molz FJ, Partin JI, Kirkpatrick JS. The Acute Effects of Posterior Fusion Instrumentation on Kinematics and Intradiscal Pressure of the Human Lumbar Spine. Clinical Spine Surgery. 2003;16(2):171-9.

38. Pearcy M, Portek I, Shepherd J. Three-Dimensional X-ray Analysis of Normal Movement in the Lumbar Spine. Spine. 1984;9(3):294-7.

39. Rohlmann A, Neller S, Claes L, Bergmann G, Wilke H-J. Influence of a Follower Load on Intradiscal Pressure and Intersegmental Rotation of the Lumbar Spine. Spine. 2001;26(24):E557-E61.

40. Muriuki MG, Havey RM, Voronov LI, Carandang G, Zindrick MR, Lorenz MA, . . , Patwardhan AG. Effects of motion segment level, Pfirrmann intervertebral disc degeneration grade and gender on lumbar spine kinematics. Journal of Orthopaedic Research. 2016;34(8):1389-98.

41. Wilke H-J, Neef P, Hinz B, Seidel H, Claes L. Intradiscal pressure together with anthropometric data - a data set for the validation of models. Clinical Biomechanics. 2001;16:S111-S26.

42. Weinhoffer SL, Guyer RD, Herbert M, Griffith SL. Intradiscal pressure measurements above an instrumented fusion. A cadaveric study. Spine. 1995;20(5):526-31.

43. Sato K, Kikuchi S, Yonezawa T. In Vivo Intradiscal Pressure Measurement in Healthy Individuals and in Patients With Ongoing Back Problems. Spine. 1999;24(23).

44. Rubin CT, Sommerfeldt DW, Judex S, Qin Y. Inhibition of osteopenia by low magnitude, high-frequency mechanical stimuli. Drug discovery today. 2001;6(16):84858.

45. Qin YX, Rubin CT, McLeod KJ. Nonlinear dependence of loading intensity and cycle number in the maintenance of bone mass and morphology. Journal of orthopaedic research : official publication of the Orthopaedic Research Society. 1998;16(4):482-9.

46. Hasegawa M, Saruta J, Hirota M, Taniyama T, Sugita Y, Kubo K, . . . , Ogawa T. A Newly Created Meso-, Micro-, and Nano-Scale Rough Titanium Surface Promotes Bone-Implant Integration. Int J Mol Sci. 2020;21(3):783.

47. Zhao F, Vaughan TJ, McNamara LM. Multiscale fluid-structure interaction modelling to determine the mechanical stimulation of bone cells in a tissue engineered scaffold. Biomechanics and Modeling in Mechanobiology. 2015;14(2):231-43.

48. Kapur S, Baylink DJ, Lau KH. Fluid flow shear stress stimulates human osteoblast proliferation and differentiation through multiple interacting and competing signal transduction pathways. Bone. 2003;32(3):241-51.

49. Bono CM, Khandha A, Vadapalli S, Holekamp S, Goel VK, Garfin SR. Residual sagittal motion after lumbar fusion: a finite element analysis with implications on radiographic flexion-extension criteria. Spine. 2007;32(4):417-22.

50. Ledet EH, Liddle B, Kradinova K, Harper S. Smart implants in orthopedic surgery, improving patient outcomes: a review. Innovation and entrepreneurship in health. 2018;5:41-51.

51. Steffen T, Tsantrizos A, Aebi M. Effect of implant design and endplate preparation on the compressive strength of interbody fusion constructs. Spine. 2000;25(9):1077-84.

52. Mobbs RJ, Phan K, Malham G, Seex K, Rao PJ. Lumbar interbody fusion: techniques, indications and comparison of interbody fusion options including PLIF, TLIF, MI-TLIF, OLIF/ATP, LLIF and ALIF. Journal of Spine Surgery. 2015;1(1):2-18.

53. Manzur M, Virk SS, Jivanelli B, Vaishnav AS, McAnany SJ, Albert TJ, ..., Qureshi S. The rate of fusion for stand-alone anterior lumbar interbody fusion: a systematic review. 
The spine journal : official journal of the North American Spine Society. 2019;19(7):1294-301.

54. Choi K-C, Ryu K-S, Lee S-H, Kim YH, Lee SJ, Park C-K. Biomechanical comparison of anterior lumbar interbody fusion: stand-alone interbody cage versus interbody cage with pedicle screw fixation - a finite element analysis. BMC Musculoskeletal Disorders. 2013;14(1):220. 
Supplementary material 1 . Summary of the materials used within the models.

\begin{tabular}{|c|c|c|c|}
\hline Component & $\begin{array}{l}\text { Element } \\
\text { type }\end{array}$ & Constitutive law & Parameters \\
\hline Trabecular bone & C3D8 & $\begin{array}{l}\text { Transversely isotropic linear } \\
\text { elastic }\end{array}$ & $\begin{array}{l}\text { Young's moduli and Poisson's ratios based } \\
\text { on mean CT gray value calculated within the } \\
\text { representative volume of each element }\end{array}$ \\
\hline Cortical bone & C3D8 & Orthotropic linear elastic & $\begin{array}{l}\mathrm{E}_{1}=8,000 \mathrm{MPa} \\
\mathrm{E}_{2}=8,000 \mathrm{MPa} \\
\mathrm{E}_{3}=12,000 \mathrm{MPa} \\
v_{12}=0.4 \\
v_{13}=0.35 \\
v_{23}=0.3 \\
\mathrm{G}_{12}=2,000 \mathrm{MPa} \\
\mathrm{G}_{13}=2,400 \mathrm{MPa} \\
\mathrm{G}_{23}=2,400 \mathrm{MPa}\end{array}$ \\
\hline $\begin{array}{l}\text { Bony posterior } \\
\text { elements }\end{array}$ & C3D8 & Isotropic linear elastic & $\begin{array}{l}\mathrm{E}=3,500 \mathrm{MPa} \\
v=0.3\end{array}$ \\
\hline Facet cartilage & C3D8 & Isotropic linear elastic & $\begin{array}{l}\mathrm{E}=20 \mathrm{MPa} \\
v=0.4\end{array}$ \\
\hline Bony endplate & C3D8 & Isotropic linear elastic & $\begin{array}{l}\mathrm{E}=1000 \mathrm{MPa} \\
v=0.3\end{array}$ \\
\hline $\begin{array}{l}\text { Cartilage } \\
\text { endplate }\end{array}$ & C3D8P & $\begin{array}{l}\text { Poro-elastic: } \\
\text { - } \quad \begin{array}{l}\text { Isotropic linear elastic } \\
\text { solid }\end{array} \\
\text { - } \begin{array}{l}\text { Fluid pore pressure } \\
\text { derived from Darcy's } \\
\text { law }\end{array}\end{array}$ & $\begin{array}{ll}\text { - } & \mathrm{E}=20 \mathrm{MPa} \\
& \mathrm{v}=0.17 \\
\text { - } & \begin{array}{l}\text { Strain dependent porosity and } \\
\text { permeability }\end{array}\end{array}$ \\
\hline $\begin{array}{l}\text { Annulus } \\
\text { fibrosis }\end{array}$ & C3D8P & $\begin{array}{l}\text { Poro-hyperelastic } \\
\text { - } \quad \begin{array}{l}\text { Isotropic hyperelastic } \\
\text { solid including } \\
\text { anisotropic fibers }\end{array} \\
\text { - } \quad \begin{array}{l}\text { Fluid pore pressure } \\
\text { derived from Darcy's } \\
\text { law }\end{array}\end{array}$ & $\begin{array}{l}\text { - Shear and bulk modulus, as well as } \\
\text { fiber organization depend on the } \\
\text { Pfirrmann grade } \\
\text { - Strain-dependent porosity and } \\
\text { permeability. Initial porosity and } \\
\text { permeability values depend on the } \\
\text { Pfirrmann grade }\end{array}$ \\
\hline $\begin{array}{l}\text { Nucleus } \\
\text { pulposus }\end{array}$ & C3D8P & $\begin{array}{l}\text { Poro-hyperelastic: } \\
\text { - } \quad \begin{array}{l}\text { Isotropic hyperelastic } \\
\text { solid }\end{array} \\
\text { - } \quad \begin{array}{l}\text { Fluid pore pressure } \\
\text { derived from Darcy's } \\
\text { law, assuming constant } \\
\text { presence of a swelling } \\
\text { pressure related term }\end{array}\end{array}$ & $\begin{array}{l}\text { - Shear and bulk modulus depend on the } \\
\text { Pfirrmann grade } \\
\text { - Strain-dependent porosity and } \\
\text { permeability. Initial porosity and } \\
\text { permeability, as well as the swelling } \\
\text { pressure related term value depend on } \\
\text { the Pfirrmann grade }\end{array}$ \\
\hline Ligaments & $\mathrm{T} 3 \mathrm{D} 2$ & Unidirectional hypo-elastic & $\begin{array}{l}\text { Parameters differ per ligament type and } \\
\text { spinal motion segment }\end{array}$ \\
\hline Titanium & C3D8 & Isotropic linear elastic & $\begin{array}{l}\mathrm{E}=116,000 \mathrm{MPa} \\
v=0.3\end{array}$ \\
\hline
\end{tabular}


Mesh 1

$2,057,481$ nodes

$1,159,781$ elements
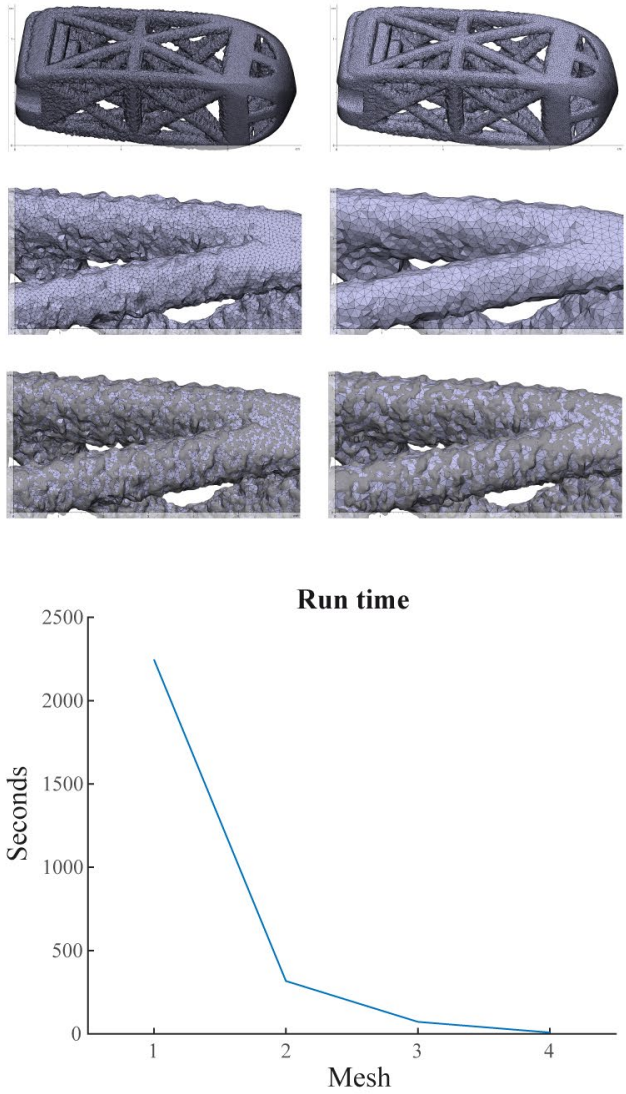

Mesh 3

181,539 nodes

97,186 elements
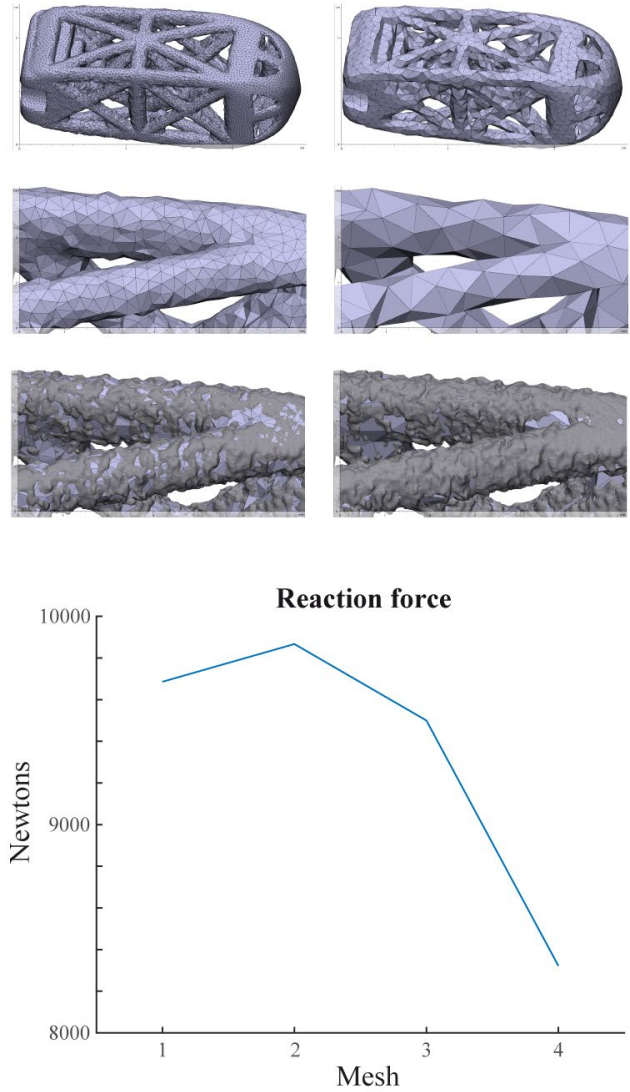

Supplementary material 2. Mesh refinements of the prototype trussed titanium PLIF cage that was used in the current study. For each mesh, the mesh of the whole cage (first row) as well as a zoomed in area (second row) is shown. In the third row, the geometry of the cage as derived by segmentation of the 37 micrometer isotropic resolution micro computed tomography scan is added to indicate the level of detail that was retained in each of the meshes of the cage. The graphs below the meshes show the run time and total reaction force across the cage meshes for a $0.1 \%$ compression analysis. Based on this output, the third mesh was eventually used in the patient-specific models. 


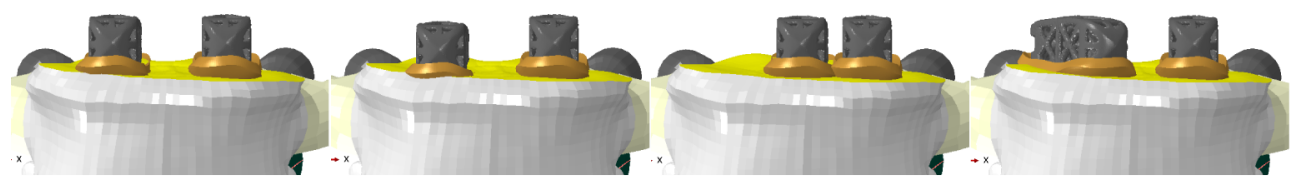

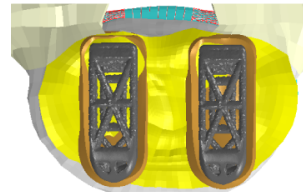

DEFAULT

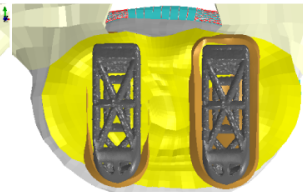

Position A

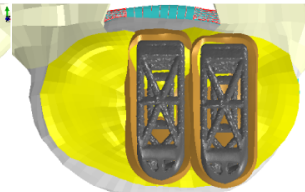

Position B

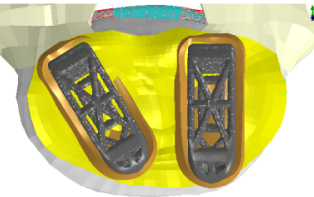

Position C
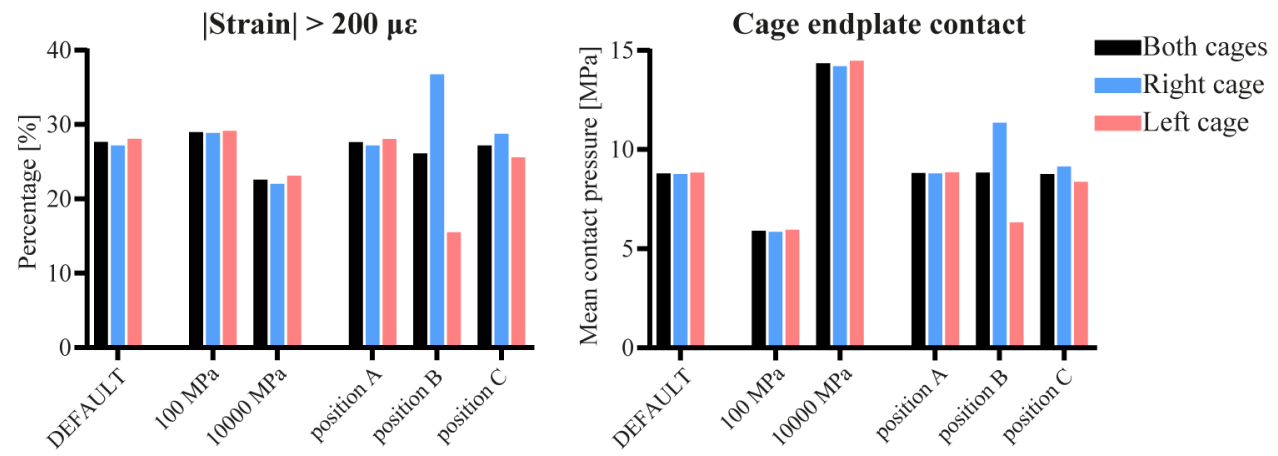

Supplementary material 3. Overview of the side study about the effect of variation in contact layer stiffness and cage positioning. At the top of the image, the default and three alternative cage positions are graphically shown. In position A, the right cage is translated $1.2 \mathrm{~mm}$ caudally. In position $\mathrm{B}$, the right cage is translated $8.6 \mathrm{~mm}$ medially. In position $\mathrm{C}$, the right cage is rotated 30 degrees in the axial plane. For all positions, the left cage remained at the default position. The stiffness and positioning variations were implemented for patient 1 and strains and stresses were evaluated in flexion movement only. The left bar chart shows the percentage of surface nodes that exceeded an absolute strain value of $200 \mu \varepsilon$ and the right bar chart shows the mean contact pressure at the caudal cage-contact layer interface. For both charts, data is presented for the left and right cage separately, as well as combined. Changing the stiffness of the contact layers did not induce different strain or stress output between the left and right cage but did result in different absolute values. These differences can be mainly found for the mean contact pressure. A stiffer contact layer is less forgiving and thus results in local peak forces without further distribution of the loads. Consequently, the contact pressure increases and less surface nodes experience a strain above the $200 \mu \varepsilon$. The maximum strain experienced by surface nodes, however, does increase as result of these high local forces. Variation in cage positioning could induce differences between the left and right cage while the combined output remained unchanged. Unsymmetric positioning may lead to unsymmetric loading of the cages explaining the variations in strain and stress output are most pronounced for position B. 


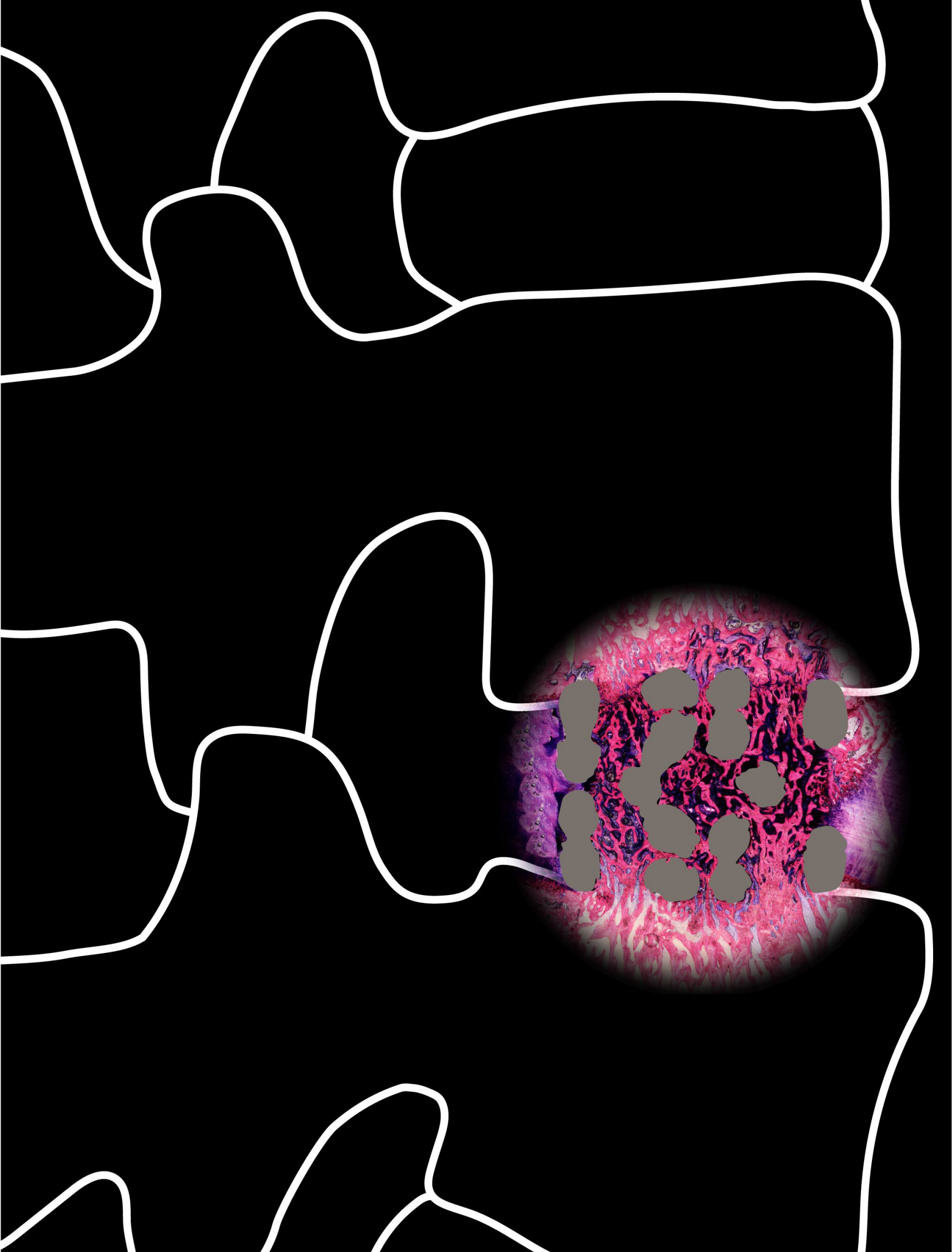


Early bone ingrowth and segmental stability of a trussed titanium cage versus a polyether ether ketone cage in an ovine lumbar interbody fusion model

\author{
ACY Loenen \\ MJM Peters \\ RTJ Bevers \\ C Schaffrath \\ E van Haver \\ VMJI Cuijpers \\ T Rademakers \\ $B$ van Rietbergen \\ PC Willems \\ JJ Arts
}

The Spine Journal 2022; 22(1):174-182 https://doi.org/10.1016/j.spinee.2021.07.011 


\begin{abstract}
BACKGROUND CONTEXT: Lumbar interbody fusion is an effective treatment for unstable spinal segments. However, the time needed to establish a solid bony interbody fusion between the two vertebrae may be longer than twelve months after surgery. During this time window, the instrumented spinal segment is assumed to be at increased risk for instability related complications such as cage migration or subsidence. It is hypothesized that the design of new interbody cages that enable direct osseointegration of the cage at the vertebral endplates, without requiring full bony fusion between the two vertebral endplates, might shorten the time window that the instrumented spinal segment is susceptible to failure. PURPOSE: To quantify the bone ingrowth and resulting segmental stability during consolidation of lumbar interbody fusion using two different cage types.

STUDY DESIGN: Preclinical ovine model.

METHODS: Seven skeletally mature sheep underwent bi-segmental lumbar interbody fusion surgery with one conventional polyether ether ketone (PEEK) cage, and one newly developed trussed titanium (TT) cage. After a postoperative time period of 13 weeks, nondestructive range of motion testing and histological analysis were performed. Additionally, sample specific finite element (FE) analysis was performed to predict the stability of the interbody fusion region alone.
\end{abstract}

RESULTS: Physiological movement of complete spinal motion segments did not reveal significant differences between the segments operated with PEEK and TT cages. The onset of creeping substitution within the cage seemed to be sooner for PEEK cages, which led to significantly higher bone volume over total volume (BV/TV) compared to the TT cages. TT cages showed significantly more direct bone to implant contact (BIC). Although the mean stability of the interbody fusion region alone was not statistically different between the PEEK and TT cages, the variation within the cage types illustrated an all-or-nothing response for the PEEK cages while a more gradual increase in stability was found for the TT cages.

CONCLUSIONS: Spinal segments operated with conventional PEEK cages were not different from those operated with newly developed TT cages in terms of segmental stability but did show a different mechanism of bone ingrowth and attachment. Based on the differences in development of bony fusion, we hypothesize that TT cages might facilitate increased early segmental stability by direct osseointegration of the cage at the vertebral endplates without requiring complete bony bridging through the cage.

CLINICAL SIGNIFICANCE: Interbody cage type affects the consolidation process of spinal interbody fusion. Whether different consolidation processes of spinal interbody fusion result in clinically significant differences requires further investigation. 


\section{INTRODUCTION}

Lumbar interbody fusion is an effective treatment for unstable spinal segments [1]. This surgery relies on restoring the segmental stability by implanting a cage into the intervertebral disc space which facilitates bony union of the two adjacent vertebrae. Polyether ether ketone (PEEK) and titanium remain the most commonly used cage materials with both materials having their own strengths and shortcomings [2]. PEEK approaches the stiffness of native bone closely, but does not promote osseointegration because of its hydrophobicity [3]. Titanium is significantly stiffer than native bone, but it promotes osseointegration excellently [4]. Since bone can only adhere to the implant surface and cannot grow into non-porous materials, both PEEK and titanium cages typically contain a central cavity to enable graft placement and to facilitate bony bridging between vertebral endplates through the cage [5].

In the human clinic, the time to establish bony bridging through the cage may be six to twelve months or even more [6]. During this healing period, the interbody cage is not yet physically constrained by new bony tissue. It has been suggested before that, during this time window, the instrumented spinal segment is at increased risk for complications such as migration or subsidence of the cage $[7,8]$. The usage of supplemental osteobiologics, like bone morphogenetic proteins (BMPs), has previously been evaluated for their ability to shorten this vulnerable healing period $[9,10]$. Although BMPs accelerate bone formation, BMPs also demonstrate an initial resorptive response, which may actually lead to an increased incidence of cage migration and subsidence [11-13]. Another strategy to shorten the time window that a cage is susceptible for migration and subsidence would be the design of new interbody cages that enable quick osseointegration at the vertebral endplates without requiring full consolidation of fusion through the cage.

The emergence of titanium three dimensional (3D) printing has enabled the production of novel, complex implant geometries, which reduce the apparent stiffness of the total construct and simultaneously provide an open architecture for bone ingrowth $[14,15]$. Using 3D printing to manufacture newly designed titanium interbody cages, the osteoconductive material property of titanium can be retained, while eliminating the mismatch in apparent stiffness between cage and native bone. One such novel cage is the trussed titanium (TT) interbody fusion cage (4WEB Medical, Frisco, TX, USA). This design is tailored to distribute the load more evenly throughout the implant and to accommodate ample space for bone ingrowth [16, 17]. Compared to conventional, non-porous, ringed and boxed cages, the TT open cage architecture is hypothesized to facilitate increased early segmental stability during consolidation of fusion, as new bony structures emerging from the vertebral endplates can directly integrate with the interbody cage to establish early osseointegration of the cage at the endplates.

The aim of this study was to quantify the bone ingrowth and segmental stability during consolidation of fusion following lumbar interbody fusion surgery using a novel TT cage compared to a conventional boxed PEEK cage. An ovine lumbar interbody fusion model with a short postoperative time period was used to monitor the development of bone ingrowth 
histologically and biomechanically before full consolidation of fusion was achieved. Nondestructive range of motion testing was used to evaluate the segmental stability of the complete spinal motion segment and segment specific finite element (FE) analysis was conducted to predict the stability of the interbody fusion region only.

\section{MATERIALS AND METHODS}

\section{Cage types}

The TT cage used in this research originates from the Posterior Spine Truss System (PSTS) portfolio of interbody fusion devices (4WEB Medical, Frisco, TX, USA). Based on cadaver analysis, the $22 \times 9 \times 6 \mathrm{~mm}$ cage without lordosis angle (PSTS-SM0006-22-SP) was selected to be implemented in this ovine study. The open space available for bone graft throughout this TT cage is approximately $0.5 \mathrm{~mL}$. Custom-made, boxed, PEEK cages with the same outer dimensions and a central graft window of about $0.5 \mathrm{~mL}$ were designed and manufactured (Instrument Development, Engineering and Evaluation, Maastricht University, Maastricht, the Netherlands).

\section{Animal model and study design}

All procedures were in compliance with the European directive 2010/63/EU. Study protocols were approved by local animal welfare committees at the involved institutions in Belgium (Medanex Clinic, Diest) and in the Netherlands (Maastricht University, Maastricht). Seven skeletally mature female Zwartbles sheep (age 2-4 years, weight 76-112 kg) underwent interbody fusion surgery at two non-contiguous levels (L2-L3 and L4-L5). Each sheep was assigned a PEEK cage at one level and a TT cage at the other level using block randomization.

\section{Surgical technique and postoperative course}

All surgeries were performed by an experienced spine surgeon (PW). Animals were sedated by intravenous (IV) administration of xylazine $(0.1 \mathrm{mg} / \mathrm{kg})$ and anesthesia was induced by injection of ketamine ( $4 \mathrm{mg} / \mathrm{kg}$, IV) and midazolam $(0.2 \mathrm{mg} / \mathrm{kg}$, IV). The animal was placed on the operating table in a right lateral recumbent position and a cuffed endotracheal tube was inserted to provide mechanical ventilation. General anesthesia was maintained with isoflurane (2\%). The surgical site was shaved, scrubbed with chlorhexidine gluconate, disinfected with ethanol, and sterilely draped. Then, the lower lumbar spine was retroperitoneally approached following left sided lumbotomy. The spinal column was reached after careful dissection of the iliopsoas muscle and the L2-L3 and L4-L5 disc spaces were identified using fluoroscopy. Next, discectomy was performed. Customized rasp tools that gradually increased in height up to $5 \mathrm{~mm}$ allowed the surgeon to induce revascularization of the endplates and to prepare the intervertebral disc space for proper cage impaction without requiring distraction of the vertebrae. At the caudal side of the lumbotomy incision, the iliac crest was exposed and its cortical shell was opened to harvest chips of trabecular bone. Both 
cage types were filled with the autologous iliac crest bone graft (ICBG) before impaction. As the $6 \mathrm{~mm}$ high cages were hammered into the prepared disc space and were tightly compressed by the two adjacent vertebrae, supplemental fixation could be avoided. The wound was routinely closed in layers (polyglactin 910 braided absorbable suture, size 1) after which the skin was closed (polydioxanone monofilament absorbable suture, size 2/0) and disinfected with chlortetracycline spray. Antibiotics (ceftiofur, $2.2 \mathrm{mg} / \mathrm{kg}$, IV) and analgesia (meloxicam, $0.5 \mathrm{mg} / \mathrm{kg}$, IV; buprenorphine, $6 \mu \mathrm{g} / \mathrm{kg}$, IV) were administered during surgery.

Sheep were group housed after 2 weeks, were free to move throughout the follow-up period, and had ad libitum access to hay and water. Routine welfare monitoring was performed while paying extra attention to ambulatory function. Daily administration of ceftiofur $(2.2 \mathrm{mg} / \mathrm{kg}$, IV) for antibiotic prophylaxis was continued until five days after surgery. The sheep received meloxicam $(0.5 \mathrm{mg} / \mathrm{kg} \mathrm{IV}$, once a day) for analgesia up to three days after surgery and additional analgesia was given intramuscularly (IM) with buprenorphine $(6 \mu \mathrm{g} / \mathrm{kg}$, twice a day) if deemed necessary by the veterinarian. Red $(30 \mathrm{mg} / \mathrm{kg}$ alizarin complexone, IV; Sigma \#A3882), green (10 mg/kg calcein green, IV; Sigma \#C0875), blue (30 mg/kg calcein blue, IV; Sigma \#M1255), and orange (90 mg/kg xylenol orange, IV; Sigma \#398187) fluorochrome markers were administered to the sheep at 3,6, 9 , and 12 weeks after surgery respectively. Fluorochrome solutions were freshly prepared one day before administration. Each fluorochrome powder was dissolved in $1.4 \%(\mathrm{v} / \mathrm{v})$ $\mathrm{NaHCO}_{3}, \mathrm{pH}$ adjusted, sterile filtered, and protected from light. After 13 weeks, the sheep were euthanized by administering an overdose of pentobarbital $(200 \mathrm{mg} / \mathrm{kg}, \mathrm{IV})$.

\section{Ex vivo non-destructive range of motion testing}

Immediately after euthanasia, the lumbar spine L1-L6 was resected en bloc. Excessive soft tissue and musculature were removed from the spine, while retaining ligamentous structures, vertebral bodies, intervertebral discs, and joint capsules. The spine was wrapped in saline soaked gauzes, vacuum sealed in plastic bags, and stored at $-20{ }^{\circ} \mathrm{C}$. Before testing, spines were slowly thawed to $4{ }^{\circ} \mathrm{C}$ overnight. Following insertion of wood screws at the distant endplates of the spine, both ends were embedded in Technovit 3040 (Heraeus Kulzer, Dromagen, Germany) using customized potting frames. Next, the spine was mounted on a ST21 Biomechanical Spine Test System (Applied Test Systems, Butler, PA, USA). This system is capable of applying pure moments along each of the anatomical axes of the spine simulating flexion-extension (FE), lateral bending (LB), and axial rotation (AR) [18]. In parallel, an Optotrak (Northern Digital Inc, Waterloo, ON, Canada) optoelectronic measurement device captured the 3D motion of infrared light-emitting diode markers which were rigidly attached to each single vertebral body. All test procedures were performed at room temperature and spines were regularly moistened with saline spray.

Five loading and unloading cycles of continuous moment $( \pm 6 \mathrm{Nm})$ were applied along each of the anatomical axes to simulate FE, LB, and AR. The relative vertebral rotation of each spinal motion segment was determined [19], and the rotation in the loaded direction was 
expressed versus applied moment. Data of the fourth cycle was used for biomechanical analysis. Range of motion (ROM) was defined as the difference in rotation at maximum and minimum load, neutral zone (NZ) as the difference in rotation between the unloading and loading curve at zero applied moment, and the compliances as the steepest slope of the loading and unloading curve ( $\mathrm{c}_{\text {loading }}$ and $\mathrm{c}_{\text {unloading }}$ respectively). Data analysis was performed by means of a customized MATLAB (MathWorks, Natick, MA, USA) script.

\section{Histological analysis}

Following non-destructive biomechanical testing, intervertebral segments L2-L3 and L4-L5 were isolated. Undecalcified specimens were trimmed, fixed in 10\% neutral buffered formalin, dehydrated through an ascending series of ethanol, infiltrated with methyl methacrylate, and polymerized. Two inner circular sawing microtomes (SP1600, Leica microsystems, Wetzlar, Germany and RMS-16G3, RHA-tech Engineering, Oostzaan, the Netherlands) were used to obtain one $40 \mu \mathrm{m}$ and three $20 \mu \mathrm{m}$ thick midsagittal sections per segment. The sections were approximately $300 \mu \mathrm{m}$ distance from each other as a result of the thickness of the diamond blade [20].

The $40 \mu \mathrm{m}$ thick sections were left unstained for epifluorescence microscopy (Eclipse Ti-E, Nikon, Tokyo, Japan). This system was equipped with a quadruple filter block (DAPI/FITC/TRITC/Cy5) and images were digitalized with a color camera (DS-Ri2, Nikon, Tokyo, Japan). Sections were completely digitalized at 4x magnification, and stitched to give a complete image of the histological section. Per section, the presence of each fluorochrome marker around and within the cage was registered to gain insight into the timing of new bone formation [21].

The $20 \mu \mathrm{m}$ thick sections were stained with basic fuchsin and methylene blue solutions to visualize mineralized tissue in and around the cage. A digital image of the entire intervertebral space was captured using bright light microscopy (M8, Precipoint, Freising, Germany). Following segmentation of the image in three regions (cage, bone, soft tissue), bone volume over total volume (BV/TV) and bone to implant contact (BIC) were calculated via a customized MATLAB (MathWorks, Natick, MA, USA) script. BV/TV was defined as the percentage of mineralized tissue area within the available void space of the cage. BIC was expressed as the percentage of the cage interface which was in direct contact with mineralized tissue.

\section{FE analysis}

Following segmentation of the three consecutive histological sections per spinal segment, the sections were further prepared to establish segment specific FE models. First, the three sections were aligned, cropped to a $15 \times 15 \mathrm{~mm}$ region surrounding the cage, and downscaled to a resolution of 20 microns. Second, a semi 3D mesh was generated consisting of $750 \times 750 \times 3$ brick elements, each $20 \times 20 \times 300 \mu \mathrm{m}$ in size. As the size of these elements resembled the spatial resolution of the stacked consecutive sections, segment specific 


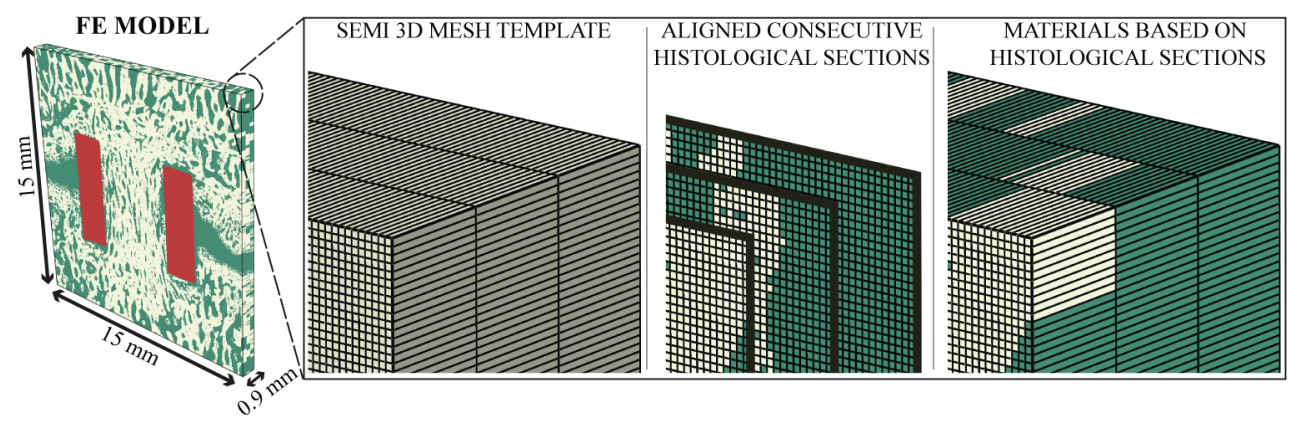

Figure 1. The FE models were $15 \times 15 \times 0.9 \mathrm{~mm}$ in size. A general semi 3D mesh template consisting of $750 \times 750 \times 3$ brick elements (each $20 \times 20 \times 300 \mu \mathrm{m}$ in size) was used. Segment specific morphologies were integrated into the model based on the histological sections.

morphologies could be integrated into the model by defining the material of each element based on the pixel values of the prepared sections (Figure 1).

Bone and soft tissue were modeled as isotropic linear elastic materials with Young's moduli of $10 \mathrm{GPa}$ and $10 \mathrm{MPa}$, respectively $[22,23]$. Poisson's ratio was set to 0.3 for both materials. The cage was implemented as rigid body and compressive axial strain boundary conditions were prescribed [24]. With these boundary conditions, a compressive displacement of $0.075 \mathrm{~mm}$ was prescribed to the top surface of the segment to induce $0.5 \%$ compressive strain in the longitudinal direction of the segment while the displacement in the other directions at the top face and in all directions at the bottom face were constrained. Models were solved using the FE solver ABAQUS/Standard (Simulia, Inc., Providence, RI, USA) version 2018. Per segment, the required stress to achieve $0.5 \%$ compressive strain was calculated as the reaction force over the total cross-sectional area of the top surface. In addition, the local maximum (in an absolute sense) principal strains and stresses were visualized in contour plots.

\section{Statistical analysis}

Paired 2-tailed $t$ tests were employed to evaluate differences between PEEK and TT segments for biomechanical parameters, bone histomorphometric parameters (BV/TV and $\mathrm{BIC}$ ), and reaction stress as predicted by the FE model. In case the difference between paired data did not follow a normal distribution, Wilcoxon signed-rank test was performed. Tests were evaluated using SPSS (IBM Corp., Armonk, NY, USA) version 25.0 and differences were considered to be significant when $p<0.05$.

\section{RESULTS}

One sheep expressed signs of paralysis postoperatively and was therefore euthanized prematurely and excluded from the study. Post-mortem micro computed tomography and tissue examination of the operated segments revealed presence of a small piece of loose bone (mm scale) in the vertebral foramen, comprising the spinal cord. Most likely, this small piece 
of bone was dislodged from the vertebral endplate and pushed forward during endplate rasping or cage impaction. The remaining six animals all completed the study according to protocol. Gross examination of the explanted lumbar spines revealed the presence of anterolateral bony bridges outside the cage at all operated segments.

The derived biomechanical parameters that resulted from non-destructive range of motion testing are displayed in Table 1. For AR loading, only the ROM was reported, as the loading and unloading curves were noisy and overlapping each other impeding reliable

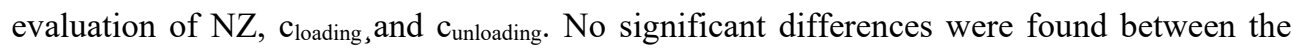
PEEK and TT segments for any of the evaluated biomechanical parameters.

The presence of fluorochrome markers is summarized in Table 2. The marker administered at 9 weeks after surgery (calcein blue) showed a diffuse signal which could not be properly distinguished from background signal. Therefore, the 9 week time point has been omitted from the analysis. All other markers were found around both cage types, while marker presence within the cages depended on timing and cage type. There was no sign of bone formation within the cages 3 weeks after surgery. At 6 weeks after surgery, bone formation was found in all PEEK cages, whereas this was found in only four out of six of the

Table 1. Biomechanical parameters derived from ex vivo non-destructive range of motion testing. Values expressed as mean \pm standard deviation. Abbreviations: PEEK, polyether ether ketone; TT, trussed titanium; ROM, range of motion; NZ, neutral zone; cx, compliance in the indicated direction $\mathrm{x}$.

\begin{tabular}{clcc}
\hline & & PEEK & TT \\
\hline Flexion Extension & $\mathrm{ROM}\left[{ }^{\circ}\right]$ & $1.3 \pm 0.5$ & $1.3 \pm 0.6$ \\
& $\mathrm{NZ}\left[^{\circ}\right]$ & $0.6 \pm 0.3$ & $0.5 \pm 0.2$ \\
& $\mathrm{c}_{\text {extension }}\left[{ }^{\circ} / \mathrm{Nm}\right]$ & $0.4 \pm 0.2$ & $0.4 \pm 0.4$ \\
& $\mathrm{c}_{\text {flexion }}\left[{ }^{\circ} / \mathrm{Nm}\right]$ & $0.3 \pm 0.1$ & $0.3 \pm 0.2$ \\
Lateral Bending & $\mathrm{ROM}\left[{ }^{\circ}\right]$ & $1.0 \pm 0.4$ & $1.2 \pm 0.6$ \\
& $\mathrm{NZ}\left[^{\circ}\right]$ & $0.4 \pm 0.2$ & $0.5 \pm 0.2$ \\
& $\mathrm{c}_{\text {left }}\left[{ }^{\circ} / \mathrm{Nm}\right]$ & $0.2 \pm 0.1$ & $0.2 \pm 0.1$ \\
& $\mathrm{c}_{\text {right }}\left[{ }^{\circ} / \mathrm{Nm}\right]$ & $0.3 \pm 0.1$ & $0.3 \pm 0.2$ \\
Axial Rotation & $\mathrm{ROM}\left[{ }^{\circ}\right]$ & $0.6 \pm 0.2$ & $0.5 \pm 0.2$
\end{tabular}

Table 2. Overview of the presence of the 3,6, and 12 week fluorochrome markers. Per cage type, the number indicates the number of fusion segments in which the marker was present around or within the cage. Abbreviations: PEEK, polyether ether ketone; TT, trussed titanium.

\begin{tabular}{cccccc}
\hline & \multicolumn{2}{c}{ PEEK $(\mathrm{n}=6)$} & & \multicolumn{2}{c}{ TT $(\mathrm{n}=6)$} \\
\cline { 2 - 3 } \cline { 5 - 6 } & Around & Within & & Around & Within \\
\hline 3w & 6 & 0 & & 6 & 0 \\
$6 \mathrm{w}$ & 6 & 6 & & 6 & 4 \\
$12 \mathrm{w}$ & 6 & 6 & & 6 & 6
\end{tabular}




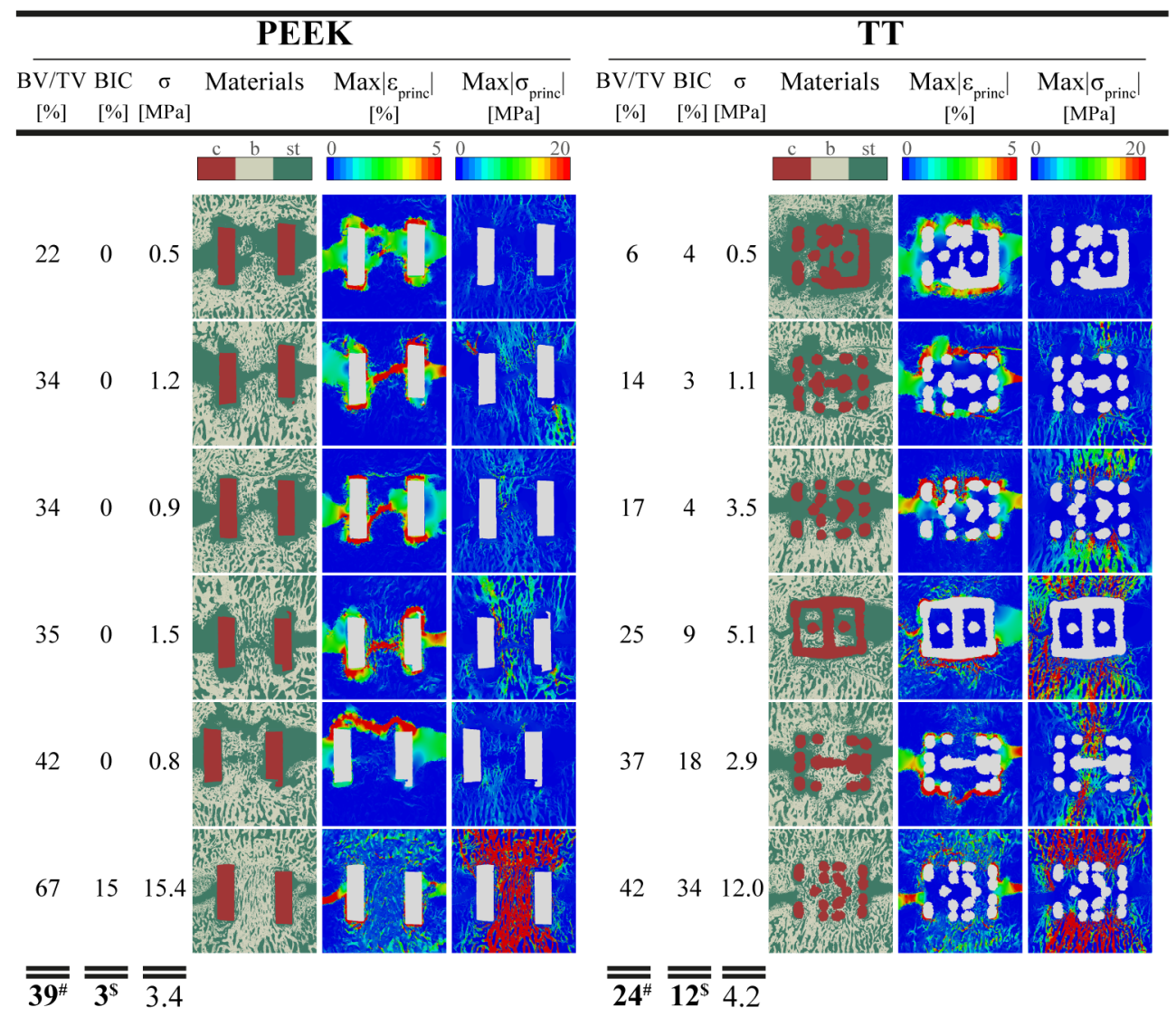

Figure 2. Polyether ether ketone (PEEK) and trussed titanium (TT) segmented histological sections (c, cage; b, bone; st, soft tissue) as well as corresponding bone volume over total volume (BV/TV) and bone to implant contact (BIC) are displayed. Additionally, the reaction stress $(\sigma)$ required for inducing a $0.5 \%$ compressive strain in the longitudinal direction of the segment is shown. Resulting local maximum absolute principal strains $\left(\operatorname{Max}\left|\varepsilon_{\text {princ }}\right|\right)$ and stresses $\left(\operatorname{Max}\left|\sigma_{\text {princ }}\right|\right)$ are visualized for each segment. Fusion segments are ordered on BV/TV within both groups. Mean values for BV/TV, BIC, and $\sigma$ can be found below the double bottom line. \# and $\$$ indicate a significant difference between the PEEK and TT group $(p<0.05)$. Orientation of sections: top, cranial; bottom, caudal; left, anterior; right, posterior.

TT cages. Active bone formation within the cage was found for all operated segments after 12 weeks, independent of cage type.

Figure 2 shows the cropped segmented histological sections for all six segments per cage type. Additionally, the calculated BV/TV and BIC are reported per segment. A significantly higher BV/TV was found for the PEEK cages whereas a significantly higher BIC value was revealed for the TT cages. As noticeable on the segmented sections, BV/TV and BIC varied widely between segments within both cage types. Despite the presence of substantial bony tissue (BV/TV 22-42\%), there was no direct bone to cage contact for five out of six PEEK segments. Only the segment with the highest BV/TV showed direct bone 
contact to the PEEK cage. In contrast, direct bone to cage contact was found for every TT segment, also for those having a low BV/TV. The relation between BIC and BV/TV is plotted in Figure 3 and labeled per cage type. Increasing BV/TV within the TT cage was accompanied by an exponential increase in BIC.

The local maximum absolute principal strains and stresses under $0.5 \%$ compressive strain are visualized for every segment in Figure 2. In addition, the longitudinal reaction stress to realize $0.5 \%$ compressive strain is presented per segment. As long as soft tissue separated bony structures from each other and from the cage in the longitudinal direction of the segment (PEEK segments on row 1-5 and TT segments on row 1-2), high local principal strains could be observed in these soft tissue areas. Consequently, the predicted reaction stress and local principal stresses were found to be low for these segments. Reaction stress and local principal stresses increased strongly for segments in which the bony structures were bridged, either directly or indirectly via the cage, in the longitudinal direction of the segment. The mean reaction stress was not significantly different between the PEEK and TT segments. In Figure 3 , the fill of the markers relates to the reaction stress as derived from the FE analysis. For PEEK segments an all-or-nothing response could be observed, whereas for TT segments a more gradual increase in segmental stability was found.

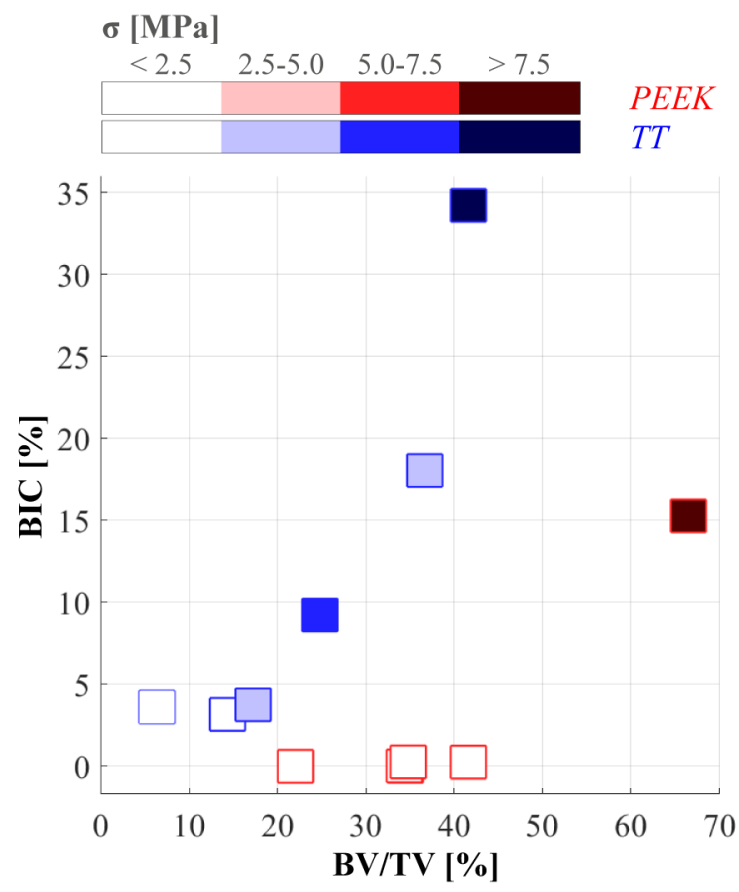

Figure 3. Bone to implant contact (BIC) versus bone volume over total volume (BV/TV) for the polyether ether ketone (PEEK) and trussed titanium (TT) segments. Color fill of the markers indicate the reaction stress $(\sigma)$ required for inducing a $0.5 \%$ compressive strain in the longitudinal direction of the segment. 


\section{DISCUSSION}

The objective of this study was to evaluate the early bone ingrowth and corresponding segmental stability during consolidation of interbody fusion in two different cage types. Differences in interbody fusion development were confirmed between conventional PEEK and newly developed TT cages as demonstrated by bone histomorphometric quantifications. Segment specific FE analysis suggested that bony structures emerging from the vertebral endplate could directly attach and integrate with the TT structure potentially providing early stability, whereas complete bony bridging was required for the PEEK cage in order to provide stability. These trends on cage level were not apparent during non-destructive range of motion testing of the complete spinal motion segment.

Consistent presence of the fluorochrome markers around the cage indicates continuous bone remodeling of the host bone [25]. Generally, several weeks are required to realize vascular ingrowth into the cage before collagen matrix is actively deposited and ossified within the cage $[26,27]$. This explains the absence of the 3 week fluorochrome marker within all cages. The difference found between PEEK and TT cages for the 6 week fluorochrome marker within the cage confirms a difference in timing of new bone formation in the cages predicting higher BV/TV within PEEK cages.

Bone histomorphometry indeed revealed that significantly more mineralized tissue was formed within the PEEK cages. This difference potentially arose from the decision to graft both cages as intended clinically, i.e. cages were manually packed with as much ICBG as possible, ignoring standardization of graft quantities. The central cuboid graft window in the PEEK cages could be completely filled with ease, whereas it was more complex to pack the TT cages with graft material throughout the cage. As a result, graft material distribution throughout the TT cages was potentially suboptimal at the onset of impaction, which might have affected the development of bone fusion [28]. The TT cage used in this research was the smallest cage commercially available from the PSTS portfolio. Difficulties concerning graft placement will doubtlessly diminish with the use of larger cages, as these contain larger open spaces. Furthermore, the expected difference in graft quantities between cages raises the question whether TT cages can reduce or even obviate the use of graft material. In fact, Wu et al. showed that bone graft could be completely eliminated using 3D printed, porous, titanium cages in the cervical spine in an ovine model [29]. Future research on the TT cage used in this study should be pursued in order to provide definite conclusions about the necessity to enrich TT cages with graft material.

Although the onset of creeping substitution within PEEK cages appeared to be sooner and led to higher BV/TV, the BIC was higher for the TT cages. Extrapolating the results, it can be suggested that even TT cages without any bone in the cage will have some BIC, i.e. bone emerging from the endplates might firmly attach to the outer interface of the cage before there is any bone present within the cage. As a consequence, early osseointegration of the TT cage at the endplates can be established without requiring full consolidation of fusion through the cage. As soon as the bone growth into the TT cages starts, BIC increases tremendously. 
On the contrary, PEEK cages only showed direct bone to implant contact in case of complete bony bridging through the cage. It is noteworthy to highlight that the BIC is expressed relatively to the total available interface of the implemented cage. The TT cages have both a larger total interface and a significantly larger BIC, meaning the absolute difference in bone to implant contact between PEEK and TT cage is even higher.

The three local consecutive histological sections, used to calculate bone morphometric parameters and to establish segment specific FE analysis of the interbody fusion region alone, were assumed to be representative for the overall bone growth throughout the entire cage. Although this assumption may have caused modest over- or underestimations of the total bone structure, there are other factors precluding a direct comparison between the stability results of the interbody fusion region alone and the stability results of the corresponding total spinal segment. The non-destructive range of motion testing presented stability characteristics of the complete motion segment involving ligamentous structures and joint capsules, whilst the segment specific FE models solely focused on the stability of the fusion region surrounding the cage. Moreover, the anterolateral bony bridges found at the operated segments obscured the potential mechanical changes in the interbody region. Although anterolateral bony bridges have been recognized before in ovine interbody fusion models [30, 31], we hypothesize that these bridges were prominently present in the current study as a consequence of the surgical rasping which was performed in order to prepare the intervertebral space for cage impaction. The rasping proceedings presumably irritated the periosteum surrounding the vertebrae, which might have elicited rapid new bone formation outside the interbody area $[32,33]$.

Therefore, this study mainly focused on the results of the FE analysis to evaluate the influence of cage type on the interbody segmental stability during consolidation of fusion. Although the mean reaction stress required for inducing a $0.5 \%$ compressive strain did not significantly differ between PEEK and TT segments, the distribution of the stress values within each group presents insight into the progression of interbody segmental stability. PEEK segments require direct fusion of the adjacent vertebrae by an uninterrupted bone bridge through the cage in order to provide increased interbody segmental stability. In contrast, TT segments can also provide increased interbody segmental stability by indirect fusion of the adjacent vertebrae, i.e. both adjacent vertebrae firmly attach to the cage without being uninterruptedly bridged through the cage. As a consequence, TT cages can provide a more gradual increase in interbody segmental stability as fusion progresses. This finding is consistent with previous preclinical and clinical literature, describing that PEEK cages require bone to grow around and through the cage to achieve successful fusion, while porous titanium cages have the benefit to accelerate consolidation of fusion by promoting direct osseointegration of the cage at the vertebral endplates [34, 35]. Results of the current study also reconfirm that higher BV/TV and BIC alone do not per definition result in higher segmental stability. In fact, proper connectivity in conjunction with decent BV/TV and BIC is essential to attain segmental stability. 
A point of improvement for the FE analysis would be the inclusion of more than three histological sections in order to comprise a larger $3 \mathrm{D}$ portion of the total fusion region. This would not only ensure higher representability of the total fusion region, but would also allow for incorporation of the exact 3D connectivity of the cages. In current models, this connectivity was implemented by assuming the cage to be a rigid body. This rigidity may construct an artificially shielded environment for the central part of the interbody fusion region in case this tissue was totally surrounded by cage material. This phenomenon is expressed in the sample on the fourth row of the TT segments (Figure 2) in which there is hardly any strain or stress observed in the center of the fusion region. Implementation of the exact 3D geometry of the cage would resolve these issues and yield more accurate FE analyses. The distance between consecutive histological sections $(300 \mu \mathrm{m})$ was considered suitable for characterizing the 3D structure of trabecular bone since it is in the same order of magnitude as the trabecular thickness and separation of bone from an interbody fusion zone $[36,37]$.

A long postoperative recovery period in an ovine interbody fusion model ( $>6$ months) results in complete fusion of all operated segments, reduces variability within experimental groups, but also conceals potential short-term differences between and within experimental groups [38]. A relatively short postoperative time period was therefore adopted in the current study in order to prevent full completion of interbody fusion in all operated segments upon termination of the experiment. Significant differences emerged between the PEEK and TT group in terms of mean BV/TV and BIC. Since considerable variability in BV/TV and BIC was observed between segments within each group, segments were ordered on BV/TV to gain more insight into the bone ingrowth and segmental stability during consolidation of fusion. Although this method is not a direct longitudinal examination of the progression of fusion within subjects, it is believed to provide reliable information on the progression of the interbody fusion over time. For future research it could be interesting to include multiple postoperative time periods in order to verify these findings.

Current study showed no differences between conventional PEEK and newly developed TT cages in terms of segmental stability of the complete spinal motion segment, but did reveal differences between cages in the mechanism of bone ingrowth and attachment. Based on the differences in development of bony fusion, we hypothesize that TT cages might facilitate increased early segmental stability by direct osseointegration of the cage at the vertebral endplates without requiring complete bony bridging through the cage. When increased stabilization of the interbody segment can be attained before achieving full consolidation of fusion, the time window that a segment is vulnerable to instability related complications might be shortened. Clinical trials involving TT cages should assess whether these local effects indeed develop, and result in lower cage related complication rates. 


\section{REFERENCES}

1. Bhalla A, Schoenfeld AJ, George J, Moghimi M, Bono CM. The influence of subgroup diagnosis on radiographic and clinical outcomes after lumbar fusion for degenerative disc disorders revisited: a systematic review of the literature. The spine journal : official journal of the North American Spine Society. 2017;17(1):143-9.

2. Seaman S, Kerezoudis P, Bydon M, Torner JC, Hitchon PW. Titanium vs. polyetheretherketone (PEEK) interbody fusion: Meta-analysis and review of the literature. Journal of clinical neuroscience : official journal of the Neurosurgical Society of Australasia. 2017;44:23-9.

3. Kassick AJ, Yerneni SS, Gottlieb E, Cartieri F, Peng Y, Mao G, . . . A Averick S. Osteoconductive Enhancement of Polyether Ether Ketone: A Mild Covalent Surface Modification Approach. ACS Applied Bio Materials. 2018;1(4):1047-55.

4. Rao PJ, Pelletier MH, Walsh WR, Mobbs RJ. Spine interbody implants: material selection and modification, functionalization and bioactivation of surfaces to improve osseointegration. Orthop Surg. 2014;6(2):81-9.

5. Weiner BK, Fraser RD. Spine update lumbar interbody cages. Spine. 1998;23(5):63440.

6. Schiffman M, Brau SA, Henderson R, Gimmestad G. Bilateral implantation of lowprofile interbody fusion cages: subsidence, lordosis, and fusion analysis. The spine journal : official journal of the North American Spine Society. 2003;3(5):377-87.

7. Vaidya R, Sethi A, Bartol S, Jacobson M, Coe C, Craig JG. Complications in the Use of rhBMP-2 in PEEK Cages for Interbody Spinal Fusions. Clinical Spine Surgery. 2008;21(8):557-62.

8. Lee JH, Jeon D-W, Lee S-J, Chang B-S, Lee C-K. Fusion Rates and Subsidence of Morselized Local Bone Grafted in Titanium Cages in Posterior Lumbar Interbody Fusion Using Quantitative Three-Dimensional Computed Tomography Scans. Spine. 2010;35(15):1460-5.

9. Slosar PJ, Josey R, Reynolds J. Accelerating lumbar fusions by combining rhBMP-2 with allograft bone: a prospective analysis of interbody fusion rates and clinical outcomes. The spine journal : official journal of the North American Spine Society. 2007;7(3):301-7.

10. Burkus JK, Gornet MF, Schuler TC, Kleeman TJ, Zdeblick TA. Six-year outcomes of anterior lumbar interbody arthrodesis with use of interbody fusion cages and recombinant human bone morphogenetic protein-2. The Journal of bone and joint surgery American volume. 2009;91(5):1181-9.

11. Benglis D, Wang MY, Levi AD. A comprehensive review of the safety profile of bone morphogenetic protein in spine surgery. Neurosurgery. 2008;62(5 Suppl 2):ONS423-31; discussion ONS31.

12. Sethi A, Craig J, Bartol S, Chen W, Jacobson M, Coe C, Vaidya R. Radiographic and $\mathrm{CT}$ evaluation of recombinant human bone morphogenetic protein-2-assisted spinal interbody fusion. AJR American journal of roentgenology. 2011;197(1):W128-33.

13. Vaidya R, Weir R, Sethi A, Meisterling S, Hakeos W, Wybo CD. Interbody fusion with allograft and rhBMP-2 leads to consistent fusion but early subsidence. The Journal of bone and joint surgery British volume. 2007;89(3):342-5.

14. Tan XP, Tan YJ, Chow CSL, Tor SB, Yeong WY. Metallic powder-bed based 3D printing of cellular scaffolds for orthopaedic implants: A state-of-the-art review on manufacturing, topological design, mechanical properties and biocompatibility. 
Materials science \& engineering C, Materials for biological applications. 2017;76:132843.

15. Pobloth A-M, Checa S, Razi H, Petersen A, Weaver JC, Schmidt-Bleek K, ..., Schwabe P. Mechanobiologically optimized 3D titanium-mesh scaffolds enhance bone regeneration in critical segmental defects in sheep. Science Translational Medicine. 2018;10(423).

16. Caffrey JP, Cory E, Wong VW, Masuda K, Chen AC, Hunt JP, . . , Sah RL. Ex vivo loading of trussed implants for spine fusion induces heterogeneous strains consistent with homeostatic bone mechanobiology. J Biomech. 2016;49(16):4090-7.

17. Caffrey JP, Alonso E, Masuda K, Hunt JP, Carmody CN, Ganey TM, Sah RL. Strains in trussed spine interbody fusion implants are modulated by load and design. Journal of the mechanical behavior of biomedical materials. 2018;80:203-8.

18. Mannen EM, Ranu SS, Villanueva AM, Friis EA. Validation of a Novel Spine Test Machine. Journal of Medical Devices. 2015;9(1).

19. Kingma I, Busscher I, van der Veen AJ, Verkerke GJ, Veldhuizen AG, Homminga J, van Dieën JH. Coupled motions in human and porcine thoracic and lumbar spines. Journal of Biomechanics. 2018;70:51-8.

20. van der Lubbe HBM, Klein CPAT, de Groot K. A simple method for preparing thin (10 $\mu \mathrm{m})$ histological sections of undecalcified plastic embedded bone with implants. Biotechnic and Histochemistry. 1988;63(3):171-6.

21. Zdeblick TA, Ghanayem AJ, Rapoff AJ, Swain C, Bassett T, Cooke ME, Markel M. Cervical Interbody Fusion Cages: An Animal Model With and Without Bone Morphogenetic Protein. Spine. 1998;23(7):758-65.

22. Rho J-Y, Tsui TY, Pharr GM. Elastic properties of human cortical and trabecular lamellar bone measured by nanoindentation. Biomaterials. 1997;18(20):1325-30.

23. Beckstein JC, Sen S, Schaer TP, Vresilovic EJ, Elliott DM. Comparison of animal discs used in disc research to human lumbar disc: axial compression mechanics and glycosaminoglycan content. Spine. 2008;33(6):E166-73.

24. Whittier DE, Boyd SK, Burghardt AJ, Paccou J, Ghasem-Zadeh A, Chapurlat R, ... , Bouxsein ML. Guidelines for the assessment of bone density and microarchitecture in vivo using high-resolution peripheral quantitative computed tomography. Osteoporosis international : a journal established as result of cooperation between the European Foundation for Osteoporosis and the National Osteoporosis Foundation of the USA. 2020;31(9):1607-27.

25. Willie BM, Bloebaum RD, Bireley WR, Bachus KN, Hofmann AA. Determining relevance of a weight-bearing ovine model for bone ingrowth assessment. Journal of biomedical materials research Part A. 2004;69(3):567-76.

26. Kalfas IH. Principles of bone healing. Neurosurgical focus. 2001;10(4):E1.

27. D'Souza M, Macdonald NA, Gendreau JL, Duddleston PJ, Feng AY, Ho AL. Graft Materials and Biologics for Spinal Interbody Fusion. Biomedicines. 2019;7(4):75.

28. Yoo JS, Min SH, Yoon SH. Fusion rate according to mixture ratio and volumes of bone graft in minimally invasive transforaminal lumbar interbody fusion: minimum 2-year follow-up. European journal of orthopaedic surgery \& traumatology : orthopedie traumatologie. 2015;25 Suppl 1:S183-9.

29. Wu SH, Li Y, Zhang YQ, Li XK, Yuan CF, Hao YL, . . ., Guo Z. Porous titanium-6 aluminum-4 vanadium cage has better osseointegration and less micromotion than a poly-ether-ether-ketone cage in sheep vertebral fusion. Artificial organs. 2013;37(12):E191-201. 
30. Sandhu HS, Toth JM, Diwan AD, Seim HB, 3rd, Kanim LE, Kabo JM, Turner AS. Histologic evaluation of the efficacy of rhBMP-2 compared with autograft bone in sheep spinal anterior interbody fusion. Spine. 2002;27(6):567-75.

31. Steffen T, Stoll T, Arvinte T, Schenk RK. Porous tricalcium phosphate and transforming growth factor used for anterior spine surgery. European spine journal : official publication of the European Spine Society, the European Spinal Deformity Society, and the European Section of the Cervical Spine Research Society. 2001;10(2):S132-S40.

32. Dwek JR. The periosteum: what is it, where is it, and what mimics it in its absence? Skeletal Radiol. 2010;39(4):319-23.

33. Wu S, Lin Z, Yamaguchi A, Kasugai S, editors. The effects of periosteum removal on the osteocytes in mouse calvaria2015.

34. McGilvray K, Easley J, Seim HB, Regan D, Berven SH, Hsu WK, . . . , Puttlitz CM. Bony ingrowth potential of 3D printed porous titanium alloy: a direct comparison of interbody cage materials in an in vivo ovine lumbar fusion model. The spine journal : official journal of the North American Spine Society. 2018.

35. Arts M, Torensma B, Wolfs J. Porous titanium cervical interbody fusion device in the treatment of degenerative cervical radiculopathy; 1-year results of a prospective controlled trial. The Spine Journal. 2020;20(7):1065-72.

36. Smit TH, Muller R, van Dijk M, Wuisman PI. Changes in bone architecture during spinal fusion: three years follow-up and the role of cage stiffness. Spine. 2003;28(16):1802-8; discussion 9.

37. Loenen ACY, Connor J, Johnson S, Davis K, Hannigan N, Barnes T, ..., van Rietbergen B. Peptide Enhanced Bone Graft Substitute Presents Improved Short-Term Increase in Bone Volume and Construct Stiffness Compared to Iliac Crest Autologous Bone in an Ovine Lumbar Interbody Fusion Model. Global Spine J. 2021:2192568220979839.

38. Lindley EM, Barton C, Blount T, Burger EL, Cain CMJ, Seim HB, . . , Patel VV. An analysis of spine fusion outcomes in sheep pre-clinical models. European Spine Journal. 2017;26(1):228-39. 




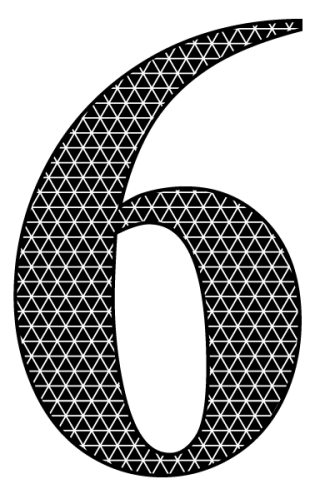

Peptide enhanced bone graft substitute presents improved short-term increase in bone volume and construct stiffness compared to iliac crest autologous bone in an ovine lumbar interbody fusion model

\author{
ACY Loenen \\ J Connor \\ S Johnson \\ K Davis \\ N Hannigan \\ T Barnes \\ JJ Arts \\ $B$ van Rietbergen
}

Global Spine Journal; Epub ahead of print https://doi.org/10.1177/2192568220979839 


\begin{abstract}
STUDY DESIGN: Preclinical ovine model

OBJECTIVE: To assess the in vivo efficacy and safety of the P-15L bone graft substitute and compare its performance to autologous iliac crest bone graft (ICBG) for lumbar interbody fusion indications.
\end{abstract}

METHODS: Thirty skeletally mature sheep underwent lumbar interbody fusion surgery. Half of the sheep received autologous ICBG and the other half the peptide enhanced bone graft substitute $(\mathrm{P}-15 \mathrm{~L})$. Following termination at one, three and, six months after surgery, the operated segments were analyzed using micro computed tomography $(\mu \mathrm{CT})$, histology, and destructive mechanical testing. Additional systemic health monitoring was performed for the P-15L group.

RESULTS: One month after surgery, there was only minor evidence of bone remodeling and residual graft material could be clearly observed within the cage. There was active bone remodeling between one and three months after surgery. At three months after surgery significantly denser and stiffer bone was found in the P-15L group, whereas at six months, P-15L and ICBG gave similar fusion results. The P-15L bone graft substitute did not have any adverse effects on systemic health.

CONCLUSIONS: The drug device combination P-15L was demonstrated to be effective and safe for lumbar interbody fusion as evidenced by this ovine model. Compared to autologous ICBG, P-15L seems to expedite bone formation and remodeling but in the longer term fusion results were similar. 


\section{INTRODUCTION}

With a lifetime prevalence of $40-80 \%$, low back pain is a major healthcare problem [1, 2]. Lumbar interbody fusion is a routine treatment to realize satisfactory pain relief when chronic back pain originates from segment instability and is refractory to conservative treatments [3-5]. The frequency of spinal fusion surgery has increased rapidly in the last two decades, partly accelerated by the development of new fixation devices and the introduction of alternative bone graft materials [6]. Despite these new innovations, autologous iliac crest bone grafting still remains the gold standard in spinal interbody fusion surgery because of its osteogenic, osteoconductive, and osteoinductive properties [7]. However, harvesting iliac crest bone graft (ICBG) is associated with donor-site morbidity [8], the amount of ICBG may be insufficient, and the ICBG quality and regenerative capacity are not uniform as they are donor-dependent.

Alternatives to ICBG have been proposed and (pre)clinically tested [9, 10]. i-FACTOR peptide enhanced bone graft (Cerapedics, Inc., Westminster, $\mathrm{CO}$ ) is one of those alternatives to autologous ICBG. i-FACTOR consists of synthetically produced 15-amino acid long polypeptides (P-15) chemically bound to anorganic bone mineral (ABM) particles, embedded in a hydrogel carrier $[11,12]$. The P-15 peptides are replicates of the cell-binding domain as naturally found on type-I collagen [13], whereas the ABM particles serve as osteoconductive three-dimensional (3D) scaffolds. The proposed mechanism of action following attachment of cells to an ABM/P-15 complex has been described in detail previously [14-17]. In short, the cell attachment is proposed to initiate a cascade of cell-signaling that modulates synthesis of extracellular matrix and growth factors to orchestrate cell proliferation, differentiation, and osteogenesis.

Sherman et al. were the first to analyze the efficacy of i-FACTOR compared to iliac crest autologous bone for lumbar interbody fusion indications by conducting a small prospective study in an ovine model [18]. In a human clinical study evaluating fusion in single and multilevel anterior lumbar interbody fusion (ALIF), Mobbs et al. found iFACTOR to be safe and effective in a cohort of 110 consecutive patients [19]. Lauweryns et al. conducted a prospective comparative analysis in which patients undergoing posterior lumbar interbody fusion (PLIF) received local autologous bone in one cage and i-FACTOR in the other enabling intra-patient control. Bony bridging was realized earlier in the cage enriched with i-FACTOR [20]. Jacobsen et al. recently concluded that i-FACTOR graft significantly increased fusion rates compared to allograft when being used as graft extender in non-instrumented lumbar posterolateral gutter fusion [21]. Additionally, the product was already proven to be non-inferior to autologous bone for single-level anterior cervical discectomy and fusion (ACDF) in a multicenter food and drug administration (FDA) investigational device exemption (IDE) study [22]. Moreover, the IDE clinical study demonstrated that i-FACTOR was statistically superior to autologous bone at both 1-year and 2-years following surgery in terms of a composite endpoint defining overall clinical success $[22,23]$. 
A new iteration of i-FACTOR, called P-15L (i-FACTOR+ Matrix), has been developed. This product incorporates $\mathrm{P}-15$ coated ABM particles within a bovine collagen carrier to offer alternate handling properties compared to the existing i-FACTOR Putty. The purpose of this study was to assess the in vivo efficacy and safety of P-15L and compare its performance to iliac crest autologous bone graft in lumbar interbody fusion. Bone remodeling was monitored in an ovine interbody fusion model using post-mortem micro computed tomography $(\mu \mathrm{CT})$, histomorphometry, histopathology, and destructive testing following termination at three different time points after surgery. In parallel, this study evaluated any impact of P-15L on systemic tissues and organs. Additionally, hematology and serum biochemistry was performed.

\section{MATERIALS AND METHODS}

\section{Animal model and study design}

All procedures were reviewed and approved by the testing facility's institutional animal care and use committee (AccelLab, Boisbriand, QC, Canada). Thirty skeletally mature, female Dorset X Rideau Arcott hybrid sheep were included (range 35-76 kg). The first cohort $(n=6)$ underwent spinal fusion at a single intervertebral level (L2-L3) while the second and third cohort ( $\mathrm{n}=12$ for both) underwent spinal fusion at two non-contiguous intervertebral levels (L2-L3 and L4-L5). All operated levels in this study were treated with a polyether ether ketone (PEEK) interbody cage $(22 \times 10 \times 7$ or $22 \times 10 \times 8 \mathrm{~mm})$. Within each cohort, half of the sheep received the cages grafted with ICBG and half received the cages grafted with P15L. The three cohorts were terminated after a period of one, three, and six months, respectively.

\section{Surgical procedure}

A retroperitoneal approach allowed access to the lumbar spine. Discectomy and distraction were completed and trial implants were used to determine the appropriate implant size. For the ICBG group, an incision was made over the iliac crest in order to harvest corticocancellous bone and the site was flushed with sterile saline and closed in layers using appropriate sutures. For the P-15L group, the putty was hydrated with saline and kneaded for approximately 30 seconds to prepare for implantation. An appropriate amount of graft material was placed to completely fill the PEEK cage in both groups. The cage was implanted into the prepared disc space and a plastic intervertebral plate was secured into place using 4 metal screws.

\section{Follow-up and termination}

Animals were group housed where hay and tap water were provided ad libitum. General welfare monitoring and observation was performed at least twice a day. At the designated time point, the animals were euthanized by a lethal injection of saturated potassium chloride. 
All animals underwent necropsy. For the P-15L group only, organ sections (heart, kidney, lung, liver, and spleen) were harvested for semi-quantitative histopathological evaluation and blood samples were withdrawn for hematology and serum biochemistry. The entire lumbar spinal column was removed en bloc and connecting soft tissue and transverse processes were removed from operative segments. Segments L4-L5 were used for mechanical testing while segments L2-L3 were used for $\mu \mathrm{CT}$ scanning and histological analysis. Scientists were blinded to the bone graft that was used, and only received the segments and their corresponding unique identifier.

\section{$\mu \mathrm{CT}$ morphology and stiffness analysis}

All L2-L3 segments were scanned at a $25 \mu \mathrm{m}$ isotropic resolution in a $\mu \mathrm{CT}$ system (Nikon XT H 225, Nikon, Tokyo, Japan). Images were converted to Scanco proprietary format and evaluated in associated software (SCANCO Medical AG, Brüttisellen, Switzerland) and downscaled to a resolution of $50 \mu \mathrm{m}$. After noise suppression by a 3D Gaussian filter $(\sigma=0.8$, support $=1$ voxel), bone tissue was segmented based on voxel reference values for air and dense cortical bone which were calculated within each image dataset separately. Since metal screws were used to constrain the plastic plate and tantalum markers were embedded in the PEEK cages, the region around the screws and a few millimeters in the central fusion region were excluded from all analyses due to metal streak artefacts (Figure 1).

Axial slices were manually contoured, segmenting the complete graft window of the cage. Slices without a complete footprint of the cage were excluded from the segmentation as these likely contain original bone structures. For the artefact-free region of the graft window, the bone volume over total volume (BV/TV), trabecular number (Tb.N), trabecular thickness (Tb.Th), trabecular separation (Tb.Sp), and connectivity density (Conn.D) were
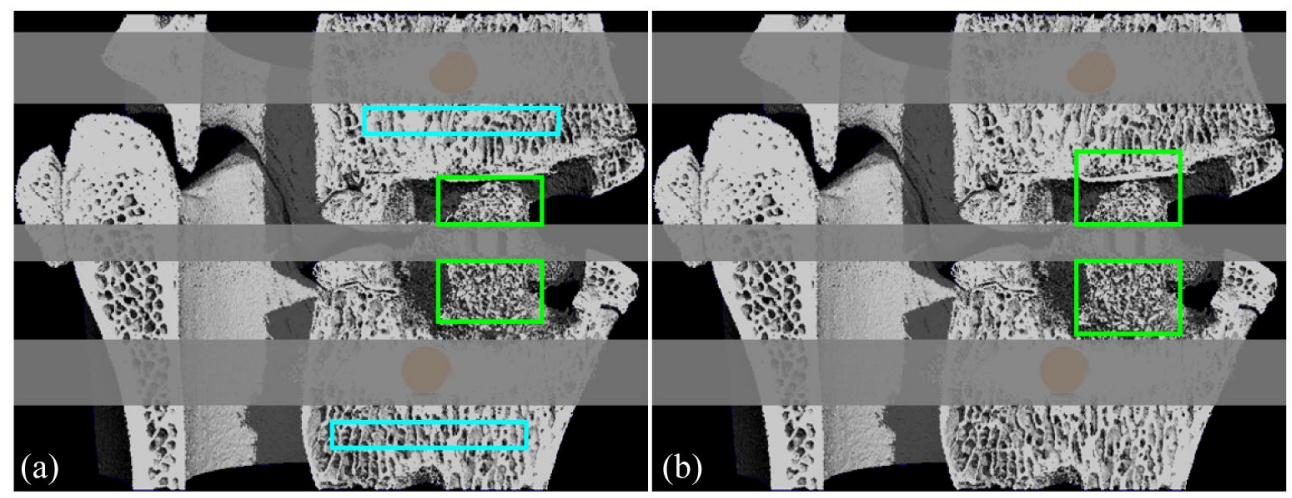

Figure 1. Sagittal cut of the 3D rendered segmentation of a representative sample of the 1 month cohort. The regions excluded due to metal artefacts are greyed out. (a) The artefact-free region of the graft window in green and the unaffected cancellous bone reference regions in cyan. (b) Both regions of the graft window were exteriorly propagated to ensure a uniform height of four millimeters for the $\mu \mathrm{FE}$ analysis. 
determined. To obtain reference values for these morphological parameters, the same parameters were calculated for unaffected cancellous bone regions in the vertebrae adjacent to the cage (Figure 1a).

For a mechanical evaluation, the regions cranial and caudal to the marker artefacts used for morphology analysis were both propagated exteriorly to realize a consistent region height of four millimeters for all datasets (Figure 1b). Inclusion of normal bone as result of these extensions was inevitable. However, inclusion of these structures will not adversely affect the eventual analysis as the stiffness of an inhomogeneous structure is primarily determined by the weakest substructure, i.e. the newly formed bone within the cage. The bone voxels within the regions were converted to $3 \mathrm{D}$ brick elements to enable micro finite element $(\mu \mathrm{FE})$ modelling. Bone was assumed to be isotropic linear elastic with a Young's modulus of 10 $\mathrm{GPa}$ and a Poisson's ratio of 0.3 . Boundary conditions applied represented a $1 \%$ compressive strain in the longitudinal direction with 'glued' interface conditions. The stiffness of both the region cranial and caudal to the artefacts were calculated as the reaction force over the applied deformation.

\section{Histological analysis}

Following $\mu \mathrm{CT}$ scanning, the undecalcified blocks were dehydrated in graded ethanol series, infiltrated with methylmethacrylate, and polymerized. A midsagittal cut extending through the graft region was obtained, microgrounded, and polished down to approximately $60 \mu \mathrm{m}$ (Exakt technologies, Inc., Oklahoma City, OK, USA). Next, the section was stained with Goldner's Trichrome for osteoid and mineralized bone differentiation. Histomorphometric analysis using Image-Pro Premier software (Media Cybernetics, Inc., Rockville, MD, USA) quantified the bone with marrow area within and normalized to the intervertebral region of interest (ROI). The ROI was defined from one endplate to the other, restricted to the width of the internal graft window of the cage.

Stained sections of the intervertebral segments were all evaluated for efficacy and safety by a certified pathologist. Sections were graded from 0 to 4 for inflammatory cell type (lymphocytes, macrophages, polymorphonuclear, and giant cells) and tissue response (neovascularization, fibrosis, fatty infiltrate, peri-implant hemorrhage, cartilage formation, and residual graft) based on ISO 10993-6 [24]. Additionally, inflammation response, bone formation and quality of bone bridging were assessed with a qualitative scale from 0 to 3 [25].

\section{Destructive tensile testing}

Spinous processes, laminas, pedicles, and plastic plates were removed from the L4-L5 segments providing the isolated interbody fusion region. The segments were anchored using stainless steel screws and secured into custom metal fixtures with potting material, ensuring horizontal and concentric alignment. The potted samples were mounted into a testing machine (ElectroPuls E3000, Instron, Norwood, MA, USA) and a uniaxial tensile load was 
applied to the upper vertebra at a constant cross-head speed of $0.5 \mathrm{~mm} / \mathrm{min}$ until failure of the implant-bone interface. Peak load and corresponding ultimate displacement were derived from the force-displacement curve which was digitally recorded at a rate of 10 Hertz.

\section{Statistical analysis}

All values are expressed as mean \pm standard deviation (SD). The two different graft groups were compared within the one, three, and six month follow-up cohort. For the $\mu \mathrm{CT}$ analysis, results from the regions cranial and caudal to the marker artefact were first averaged within the sample as they were found to be similar. Normality and equal variance tests were performed for continuous data. When both were not violated, unpaired, 2-tailed $t$ tests were applied. In case of non-normality or no equal variances, a Mann-Whitney U test was used. A Mann-Whitney rank sum test was performed in case of ordinal data. Statistical significance was set at $p<0.05$.

\section{RESULTS}

Surgical procedures were without any adverse events and all animals completed the experiment according to protocol. Necropsy and additional histopathological evaluation of systemic organs were normal and consistent with surgical intervention.

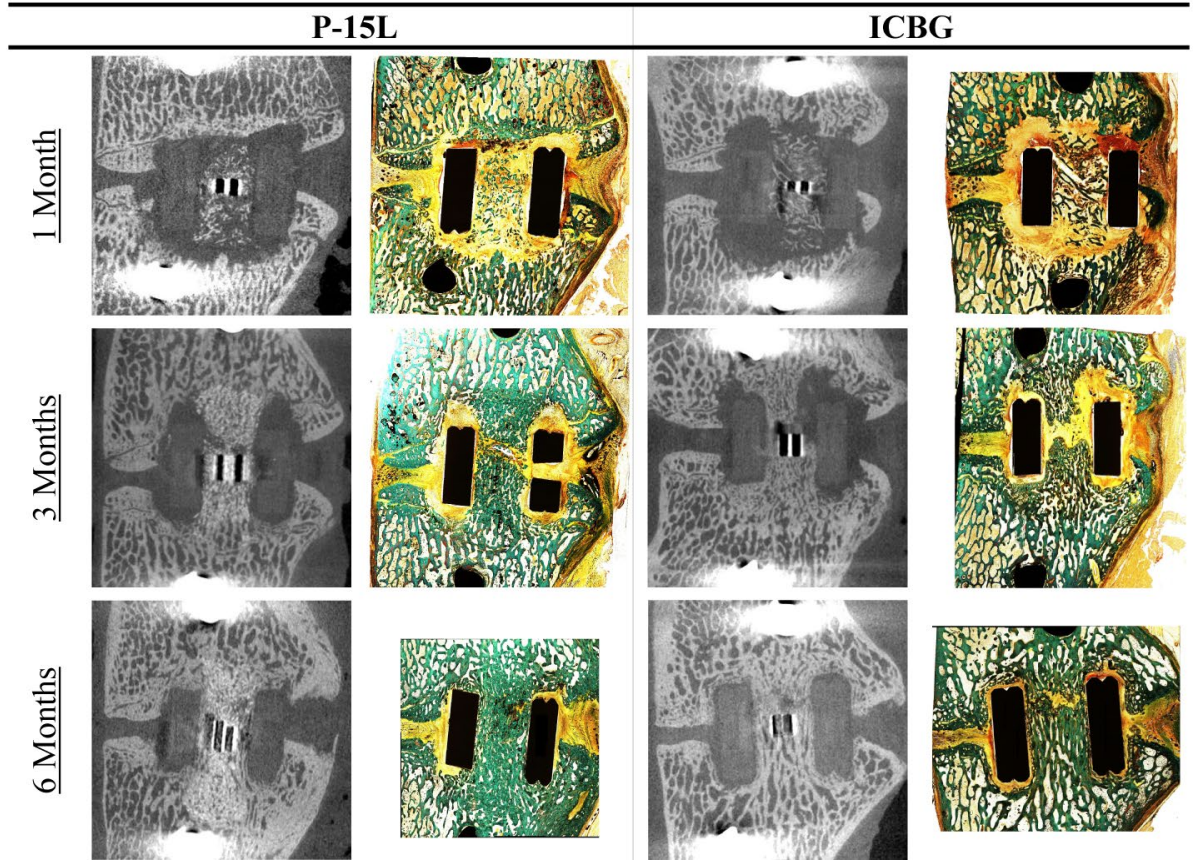

Figure 2. Sagittal $\mu \mathrm{CT}$ and histology cuts of both groups one, three, and six months after surgery. Residual P-15L graft can be recognized as hyper-opaque particles in $\mu \mathrm{CT}$ scans. For both groups, marker artefacts obscure the central region of the cage in the scans. Corresponding histological sections reveal there are no unexpected deviations in these artefact regions. 

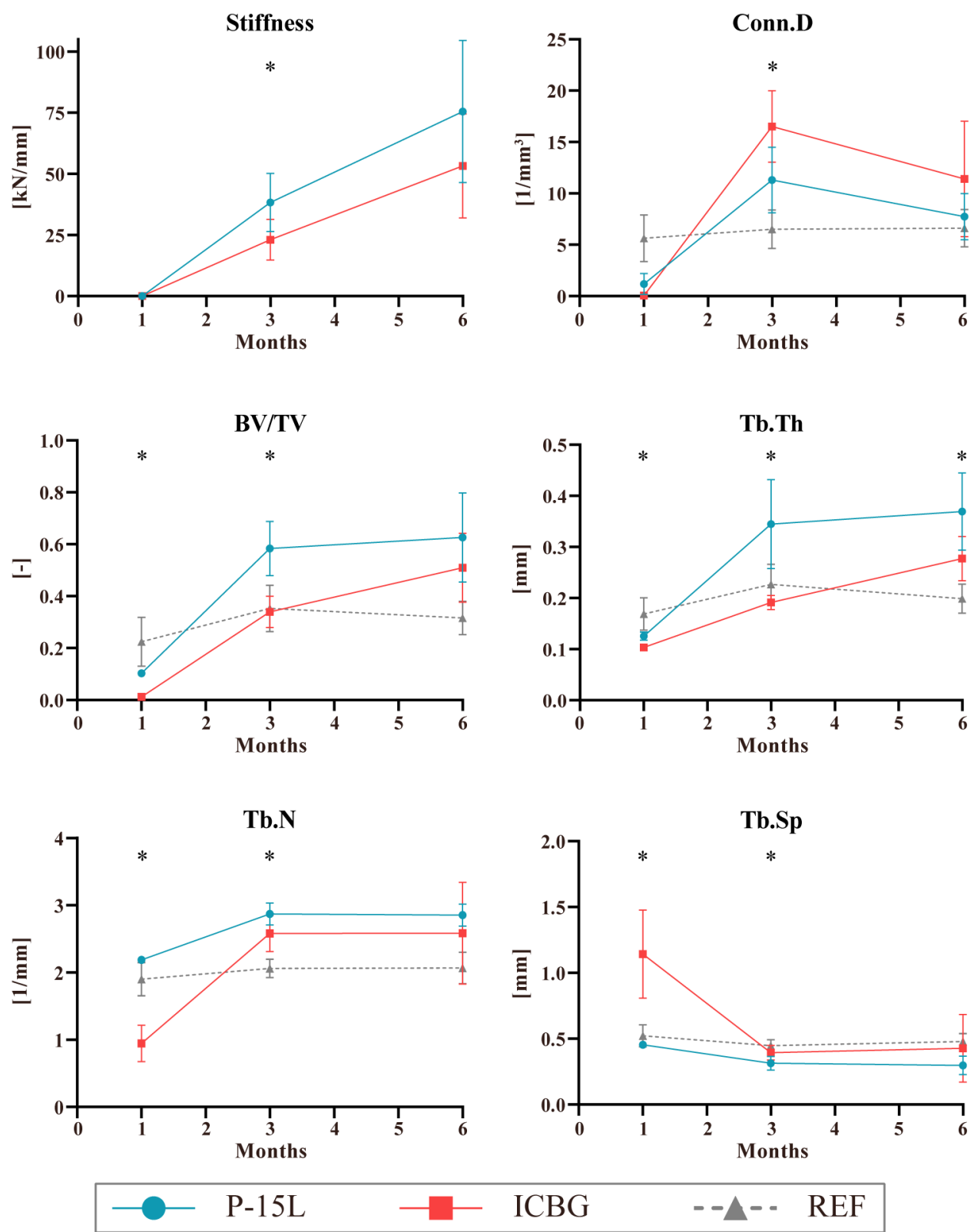

Figure 3. Changes over time in morphological parameters of the bone within the graft window and associated stiffness as determined by $\mu \mathrm{FE}$. Time points marked with a star $\left(^{*}\right)$ indicate a significant difference between the P-15L and ICBG group. Morphological parameters of unaffected cancellous bone are shown as reference (REF). Abbreviations: BV/TV, bone volume over total volume; Tb.N, trabecular number; Tb.Th, trabecular thickness; Tb.Sp, trabecular separation; Conn.D, connectivity density. 
Table 1. Overview of the bone including marrow area expressed as percentage of the intervertebral region of interest $\left(\mathrm{BM}_{\mathrm{frac}}\right)$. In addition, the peak load $\left(\mathrm{F}_{\mathrm{peak}}\right)$ and ultimate displacement $\left(\mathrm{d}_{\mathrm{ult}}\right)$ from the destructive tensile tests are displayed. No significant differences were found between the P-15L and ICBG group within the different cohorts for any of the parameters.

\begin{tabular}{|c|c|c|c|c|c|c|}
\hline & \multicolumn{2}{|c|}{1 Month } & \multicolumn{2}{|c|}{3 Months } & \multicolumn{2}{|c|}{6 Months } \\
\hline & $\begin{array}{c}\mathrm{P}-15 \mathrm{~L} \\
(\mathrm{n}=3)\end{array}$ & $\begin{array}{l}\text { ICBG } \\
(n=3)\end{array}$ & $\begin{array}{c}\mathrm{P}-15 \mathrm{~L} \\
(\mathrm{n}=6)\end{array}$ & $\begin{array}{l}\text { ICBG } \\
(\mathrm{n}=6)\end{array}$ & $\begin{array}{l}\mathrm{P}-15 \mathrm{~L} \\
(\mathrm{n}=6)\end{array}$ & $\begin{array}{l}\text { ICBG } \\
(n=6)\end{array}$ \\
\hline $\mathbf{B M}_{\text {frac }}[\%]$ & $21.5 \pm 9.2$ & $21.2 \pm 4.7$ & $66.8 \pm 12.1$ & $74.5 \pm 5.7$ & $71.8 \pm 19.7$ & $74.2 \pm 15.3$ \\
\hline $\mathbf{F}_{\text {peak }}[\mathbf{N}]$ & & & $1267 \pm 214$ & $1149 \pm 119$ & $1607 \pm 449$ & $1833 \pm 473$ \\
\hline $\mathbf{d}_{\text {ult }}[\mathbf{m m}]$ & & & $3.6 \pm 0.5$ & $3.1 \pm 0.7$ & $3.5 \pm 0.5$ & $3.6 \pm 0.5$ \\
\hline
\end{tabular}

Sagittal $\mu \mathrm{CT}$ cuts for both groups at the different evaluation points can be found in Figure 2. Note that residual graft material can be recognized in the P-15L group as hyperopaque particles. Morphometric analysis revealed higher bone volume, higher trabecular thickness, higher trabecular number and lower trabecular separation in the P-15L group compared to the ICBG group one month after surgery. Three months after surgery, these differences are more pronounced for the bone volume and trabecular thickness, and less pronounced for the trabecular number and separation. In addition, lower values for the connectivity density and higher values for the stiffness of the bone were found for the P-15L compared to the ICBG group. The stiffness and all morphological parameters but trabecular thickness were shown to eventually reach similar values for both groups after six months. A continuous increase of the stiffness of the new bone was predicted for both groups. Independent of graft group, the connectivity density increases first, after which it slightly decreases again. For the P-15L group, changes in other morphological parameters are especially observable between the one and three month time point suggestive of rapid bone formation and remodeling. Although similar trends are found in the ICBG group regarding trabecular number and separation, the bone volume and trabecular thickness seem to change more gradually over time. In contrast, the morphology parameters of the unaffected cancellous bone in the reference region do not change over time. At every time point, both graft groups differ from the reference region for at least one of the morphological parameters (Figure 3).

Sagittal sections stained with Goldner's Trichrome can be found in Figure 2 for both groups at the different evaluation points. The bone with marrow area within and expressed as percentage of the total intervertebral ROI $\left(\mathrm{BM}_{\text {frac }}\right)$ can be found in Table 1. The value strongly increases between one and three months after which it stabilizes. $\mathrm{BM}_{\mathrm{frac}}$ displays similar values for both groups at every time point. The peak load and ultimate displacement as found by destructive tensile testing are not significantly different between graft groups within both the three and six month cohort. Peak load values appear to be higher and more variable at the six months cohort.

The inflammatory cell infiltration, inflammation, neovascularization, fibrosis, cartilage formation and new bone formation were similar for both groups at all evaluation points. For 
both groups, data demonstrated no significant inflammatory responses. New bone formation increased from one to three months and remained similar at three and six months for both groups. Cartilage formation increased from one to three months and then tended to slightly decrease from three to six months. The residual graft score remained relatively similar over time in the P-15L group while the graft lost trace over time in the ICBG group. At three and six months after surgery, the resulting graft score was significantly higher for the P-15L group compared to the ICBG group.

\section{DISCUSSION}

This ovine interbody fusion model revealed the in vivo efficacy and safety of a peptide enhanced bone graft substitute (P-15L) and compared its performance as a stand-alone graft material with respect to iliac crest autologous bone. Although comparable bone morphology and stiffness were found for the P-15L bone graft substitute and the iliac crest autologous bone six months after surgery, the P-15L substitute expedites bone formation and remodeling as evidenced by superior bone morphology and stiffness three months after surgery as compared to the iliac crest autologous bone. No graft migration was observed and P-15L did not elicit any adverse local or systemic effects, demonstrating the graft substitute is safe to use for spinal interbody fusion indications.

The conclusions drawn in this study mainly rely on the $\mu \mathrm{CT}$ analyses as these accommodate a comprehensive characterization of the full 3D structure of the new bone and can predict resulting functionality in terms of mechanical stability [26, 27]. A main limitation of this study was the exclusion of the central region of the cage in $\mu \mathrm{CT}$ analyses due to marker artefacts; however, histomorphometric analyses were conducted to verify that these artefact regions did not reveal any unexpected deviations demonstrating the $\mu \mathrm{CT}$ data represents the total segment appropriately. Generally, higher bone volume ratios emerged from histomorphometry as in these analyses the bone with marrow area was quantified as opposed to the $\mu \mathrm{CT}$ analyses which did not include the marrow area. Furthermore, $\mu \mathrm{CT}$ morphometry characterized the complete 3D microstructure of the bone unraveling differences in trabecular bone development which were unnoticed by histomorphometry.

As a consequence, no differences were found between groups for bone including marrow area using histomorphometry while $\mu \mathrm{CT}$ analysis revealed denser bone in the $\mathrm{P}-15 \mathrm{~L}$ group three months after surgery. Denser bone was revealed as both more and thicker trabeculae were found in a structure having less redundant connections. Consequently, the P$15 \mathrm{~L}$ group showed lower separation between the trabeculae and a higher bone volume over total volume despite the groups having a similar bone including marrow area as determined by histomorphometry. Moreover, the bony construct in the P-15L group was found to be stiffer three months after surgery suggesting more mature remodeling. Six months after surgery, both groups showed similar bone constructs with a higher density compared to 
unaffected cancellous bone controls. Increasing bone density is a phenomenon commonly observed within the graft area of spinal cages when fusion progresses [18, 28].

Care should be taken to draw conclusions from the one month $\mu \mathrm{CT}$ and histomorphometry analyses as the bone structures at this evaluation point will consist of residual graft material and immature bone. These structures are presumably strongly inhomogeneous challenging appropriate interpretation of parameters describing the trabecular structure. In addition, the volume ratios evaluated at this time point mainly provide insight in the maximal 'background noise' generated by the graft. As the relative bone volumes at one month were low, it is plausible to attribute the differences found three months after surgery solely to ongoing bone growth and remodeling despite the presence of residual graft.

Apart from the differences in trabecular bone morphology and predicted stiffness three months after surgery, other histomorphometric and mechanical analysis yielded the same results for both groups. Destructive tensile testing provided strength characteristics of the whole segment while the $\mu \mathrm{FE}$ predicts the compression stiffness of the newly formed, artefact-free bone construct only. As a consequence, it is not possible to directly correlate these mechanical parameters. The increase in peak force and its variance between three and six months are suggested to result from the varying amount of bone bridges external to the cage. External bone bridges are commonly found in preclinical animal models as well as in clinical situations [29, 30].

A limitation of this study arose from the difference in traceability of residual P-15L and ICBG material. Corresponding to previous literature, residual P-15L was identifiable in this study up to six months after surgery in both $\mu \mathrm{CT}$ and histological slices [18]. In contrast, it was impossible to visually distinguish residual ICBG from newly formed bone in $\mu \mathrm{CT}$ slices. Histopathologically, ICBG could be recognized one month after surgery as an isolated bone structure but on the longer term, as remodeling proceeds, original ICBG lost trace, i.e. ambiguity arises whether ICGB has been resorbed and replaced or became less recognizable. Consequently, accurate distinction of remaining ICBG material is impeded. In order to avoid bias as result of difference in traceability of grafts, mineralized bone and graft tissue were analyzed as one. This method was considered legitimate as low amounts of mineralized tissue were found at the one month evaluation point. Furthermore, redundant graft structures that are not properly incorporated in the fusion mass are disregarded in $\mu \mathrm{FE}$ analysis as these loose structures do not contribute to the stiffness of the construct.

Smit et al. previously used $\mu \mathrm{CT}$ to analyze the $3 \mathrm{D}$ bone architecture within spinal cages up to three years after surgery and found trabecular bone changes comparable to those found for growing bone, i.e. development of a coarse homogenous bone architecture within the spinal cage as maturation progresses [31]. Signs of remodeling of the new bone construct in the present study were quantified using $\mu \mathrm{CT}$ analysis and compared to the change in morphological parameters of unaffected cancellous bone remote from the operative site. Specifically for the P-15L group, construct stiffness increased over time even though the 
bone volume did not increase further after three months. This indicates that extensive bone remodeling was still proceeding up to six months after surgery.

In conclusion, this study highlights the promising performance of the peptide enhanced bone graft substitute P-15L for lumbar interbody fusion indications. Clinical trials should be contemplated to evaluate the clinical outcome and cost benefit over time for P-15L as this study demonstrates superior short-term results based on observed trabecular bone development of the new bone as compared to iliac crest autologous bone.

Since P-15L exhibits similar fusion results as iliac crest autologous bone, the results of this study suggest that the introduction of $\mathrm{P}-15 \mathrm{~L}$ into the clinic as a stand-alone alternative graft material will obviate the necessity for harvesting iliac crest bone reducing the risk of donor-site morbidity and limited availability. Moreover, P-15L provides consistent material properties and does not require extensive preparation with cells or other biological agents prior to clinical use thereby reducing costs and mitigating risks associated with dosing which may be linked to adverse events including osteolysis and ectopic bone formation. These benefits may have short and long-term cost advantages which would require further evaluation within clinical studies.

\section{REFERENCES}

1. Walker BF. The prevalence of low back pain: a systematic review of the literature from 1966 to 1998. J Spinal Disord. 2000;13(3):205-17.

2. Hoy D, Bain C, Williams G, March L, Brooks P, Blyth F, . . ., Buchbinder R. A systematic review of the global prevalence of low back pain. Arthritis and rheumatism. 2012;64(6):2028-37.

3. Fritzell P, Hägg O, Wessberg P, Nordwall A. 2001 Volvo Award Winner in Clinical Studies: Lumbar fusion versus nonsurgical treatment for chronic low back pain: a multicenter randomized controlled trial from the Swedish Lumbar Spine Study Group. Spine. 2001;26(23):2521-32; discussion 32-4.

4. Kraft CN, Krauspe R. Spondylolisthesis. In: Boos N, Aebi M, eds. Spinal Disorders: Fundamentals of Diagnosis and Treatment. Berlin, Heidelberg: Springer Berlin Heidelberg; 2008. p. 733-63.

5. Bhalla A, Schoenfeld AJ, George J, Moghimi M, Bono CM. The influence of subgroup diagnosis on radiographic and clinical outcomes after lumbar fusion for degenerative disc disorders revisited: a systematic review of the literature. The spine journal : official journal of the North American Spine Society. 2017;17(1):143-9.

6. Rajaee SS, Bae HW, Kanim LE, Delamarter RB. Spinal fusion in the United States: analysis of trends from 1998 to 2008. Spine. 2012;37(1):67-76.

7. Laurencin C, Khan Y, El-Amin SF. Bone graft substitutes. Expert review of medical devices. 2006;3(1):49-57.

8. Summers BN, Eisenstein SM. Donor site pain from the ilium. A complication of lumbar spine fusion. The Journal of bone and joint surgery British volume. 1989;71(4):677-80.

9. Hsu WK, Nickoli MS, Wang JC, Lieberman JR, An HS, Yoon ST, . . , McCullough CM. Improving the Clinical Evidence of Bone Graft Substitute Technology in Lumbar Spine Surgery. Global Spine J. 2012;2(4):239-48. 
10. Duarte RM, Varanda P, Reis RL, Duarte ARC, Correia-Pinto J. Biomaterials and Bioactive Agents in Spinal Fusion. Tissue engineering Part B, Reviews. 2017;23(6):54051.

11. Sehgal D, Vijay IK. A method for the high efficiency of water-soluble carbodiimidemediated amidation. Analytical biochemistry. 1994;218(1):87-91.

12. Bhatnagar RS, Qian JJ, Wedrychowska A, Sadeghi M, Wu YM, Smith N. Design of biomimetic habitats for tissue engineering with P-15, a synthetic peptide analogue of collagen. Tissue engineering. 1999;5(1):53-65.

13. Bhatnagar RS, Qian JJ, Gough CA. The role in cell binding of a beta-bend within the triple helical region in collagen alpha 1 (I) chain: structural and biological evidence for conformational tautomerism on fiber surface. Journal of biomolecular structure \& dynamics. 1997;14(5):547-60.

14. Qian JJ, Bhatnagar RS. Enhanced cell attachment to anorganic bone mineral in the presence of a synthetic peptide related to collagen. Journal of biomedical materials research. 1996;31(4):545-54.

15. Kübler A, Neugebauer J, Oh JH, Scheer M, Zöller JE. Growth and proliferation of human osteoblasts on different bone graft substitutes: an in vitro study. Implant dentistry. 2004;13(2):171-9.

16. Yang XB, Bhatnagar RS, Li S, Oreffo RO. Biomimetic collagen scaffolds for human bone cell growth and differentiation. Tissue engineering. 2004;10(7-8):1148-59.

17. Gomar F, Orozco R, Villar JL, Arrizabalaga F. P-15 small peptide bone graft substitute in the treatment of non-unions and delayed union. A pilot clinical trial. Int Orthop. 2007;31(1):93-9.

18. Sherman BP, Lindley EM, Turner AS, Seim HB, 3rd, Benedict J, Burger EL, Patel VV. Evaluation of $\mathrm{ABM} / \mathrm{P}-15$ versus autogenous bone in an ovine lumbar interbody fusion model. European spine journal : official publication of the European Spine Society, the European Spinal Deformity Society, and the European Section of the Cervical Spine Research Society. 2010;19(12):2156-63.

19. Mobbs RJ, Maharaj M, Rao PJ. Clinical outcomes and fusion rates following anterior lumbar interbody fusion with bone graft substitute i-FACTOR, an anorganic bone matrix/P-15 composite. Journal of neurosurgery Spine. 2014;21(6):867-76.

20. Lauweryns P, Raskin Y. Prospective analysis of a new bone graft in lumbar interbody fusion: results of a 2- year prospective clinical and radiological study. Int J Spine Surg. 2015;9:2.

21. Jacobsen MK, Andresen AK, Jespersen AB, Støttrup C, Carreon LY, Overgaard S, Andersen MØ. Randomized double blind clinical trial of ABM/P-15 versus allograft in noninstrumented lumbar fusion surgery. The spine journal : official journal of the North American Spine Society. 2020;20(5):677-84.

22. Arnold PM, Sasso RC, Janssen ME, Fehlings MG, Smucker JD, Vaccaro AR, . . . , Kopjar B. Efficacy of i-Factor Bone Graft versus Autograft in Anterior Cervical Discectomy and Fusion: Results of the Prospective, Randomized, Single-blinded Food and Drug Administration Investigational Device Exemption Study. Spine. 2016;41(13):1075-83.

23. Arnold PM, Sasso RC, Janssen ME, Fehlings MG, Heary RF, Vaccaro AR, Kopjar B. iFactor $^{\mathrm{TM}}$ Bone Graft vs Autograft in Anterior Cervical Discectomy and Fusion: 2-Year Follow-up of the Randomized Single-Blinded Food and Drug Administration Investigational Device Exemption Study. Neurosurgery. 2018;83(3):377-84. 
24. ISO. Biological evaluation of medical devices. Part 6: Tests for local effects after implantation: International Standardization Organization; 2007.

25. Walsh WR, Pelletier MH, Bertollo N, Christou C, Tan C. Does PEEK/HA Enhance Bone Formation Compared With PEEK in a Sheep Cervical Fusion Model? Clinical orthopaedics and related research. 2016;474(11):2364-72.

26. Feldkamp LA, Goldstein SA, Parfitt AM, Jesion G, Kleerekoper M. The direct examination of three-dimensional bone architecture in vitro by computed tomography. Journal of bone and mineral research : the official journal of the American Society for Bone and Mineral Research. 1989;4(1):3-11.

27. van Rietbergen B, Weinans H, Huiskes R, Odgaard A. A new method to determine trabecular bone elastic properties and loading using micromechanical finite-element models. J Biomech. 1995;28(1):69-81.

28. Brantigan JW, Steffee AD. A carbon fiber implant to aid interbody lumbar fusion. Twoyear clinical results in the first 26 patients. Spine. 1993;18(14):2106-7.

29. Steffen T, Stoll T, Arvinte T, Schenk RK. Porous tricalcium phosphate and transforming growth factor used for anterior spine surgery. European spine journal : official publication of the European Spine Society, the European Spinal Deformity Society, and the European Section of the Cervical Spine Research Society. 2001;10(2):S132-S40.

30. Santos ER, Goss DG, Morcom RK, Fraser RD. Radiologic assessment of interbody fusion using carbon fiber cages. Spine. 2003;28(10):997-1001.

31. Smit TH, Muller R, van Dijk M, Wuisman PI. Changes in bone architecture during spinal fusion: three years follow-up and the role of cage stiffness. Spine. 2003;28(16):1802-8; discussion 9. 




\title{
Local bone metabolism during the consolidation process of spinal interbody \\ fusion
}

\author{
ACY Loenen \\ MJM Peters \\ R Wierts \\ RTJ Bevers \\ LW van Rhijn \\ JJ Arts \\ PC Willems
}

Journal of Bone and Mineral Metabolism; Epub ahead of print https://doi.org/10.1007/s00774-021-01281-8 


\begin{abstract}
INTRODUCTION: Although computed tomography (CT) can identify the presence of eventual bony bridges following lumbar interbody fusion (LIF) surgery, it does not provide information on the ongoing formation process of new bony structures. ${ }^{18} \mathrm{~F}$ sodium fluoride $\left({ }^{18} \mathrm{~F}-\mathrm{NaF}\right)$ positron emission tomography (PET) could be used as complementary modality to add information on the bone metabolism at the fusion site. However, it remains unknown how bone metabolism in the operated segment changes early after surgery in uncompromised situations. This study aimed to quantify the changes in local bone metabolism during consolidation of LIF.
\end{abstract}

MATERIALS AND METHODS: Six skeletally mature sheep underwent LIF surgery. ${ }^{18} \mathrm{~F}$ $\mathrm{NaF}$ PET/CT scanning was performed six and twelve weeks postoperatively to quantify the bone volume and metabolism in the operated segment. Bone metabolism was expressed as a function of bone volume.

RESULTS: Early in the fusion process, bone metabolism was increased at the endplates of the operated vertebrae. In a next phase, bone metabolism increased in the center of the interbody region, peaked, and declined to an equilibrium state. During the entire postoperative time period of twelve weeks, bone metabolism in the interbody region was higher than that of a reference site in the spinal column.

CONCLUSIONS: Following LIF surgery, there is a rapid increase in bone metabolism at the vertebral endplates that develops towards the center of the interbody region. Knowing the local bone metabolism during uncompromised consolidation of spinal interbody fusion might enable identification of impaired bone formation early after LIF surgery using ${ }^{18} \mathrm{~F}-\mathrm{NaF}$ PET/CT scanning. 


\section{INTRODUCTION}

Lumbar interbody fusion (LIF) can be used as operative treatment for a wide range of spinal disorders if conservative treatment has failed [1]. LIF aims to stabilize a painful intervertebral segment by stimulating a bony bridge between the two adjacent vertebral bodies. Following resection of the intervertebral disc and preparation of the endplates, an interbody cage filled with bone graft or bone graft substitute is inserted [2,3]. The treatment relies on bony union of the two adjacent vertebrae through the cage for long-term success [4, 5].

Meng et al. reported that up to $20 \%$ of LIFs do not result in bony union between the vertebrae of the operated segment [3]. Non-unions are not symptomatic by definition, but are generally correlated with inferior clinical outcome $[4,6]$. The symptoms secondary to a nonunion mainly emerge on mid- and long-term follow-up and may require revision surgery up to 10 years after the initial treatment [7]. It is therefore important to predict symptomatic nonunions as soon as possible. Surgical exploration is considered the gold standard to evaluate bony union, whereas computed tomography (CT) is considered as the most reliable noninvasive modality [8]. CT is typically used to classify the fusion success based on the presence of mineralized bony bridges between vertebrae throughout the disc space [9]. Although CT provides excellent details on the current presence of osseous structures at the fusion site (diagnostic information), it does not provide information on local bone remodeling activity and whether uncompromised progression of fusion is to be expected (prognostic information).

Positron emission tomography (PET) with the bone seeking tracer ${ }^{18} \mathrm{~F}$ sodium fluoride $\left({ }^{18} \mathrm{~F}-\mathrm{NaF}\right)$ has been previously proposed as a complementary modality to provide quantitative information on local bone metabolism in the operated spine [10-12]. ${ }^{18} \mathrm{~F}-\mathrm{NaF}$ tracer uptake is known to increase within skeletal tissue with increasing perfusion, vascular permeability, bone turnover, and amount of exposed mineral surface [13, 14]. Therefore, increased tracer uptake corresponds with increased bone metabolism. Persistently increased bone metabolism more than 1 year after LIF has been reported to originate from micro-instability and increased tissue stresses at the interface of the cage and has previously been identified as indicator for impaired bone graft healing and painful non-union $[11,15]$.

In operated segments in which a bony fusion is successfully consolidating, interbody bone metabolism is expected to strongly increase early after surgery because of active new bone formation in the interbody region [16]. On the longer term (years), however, interbody bone metabolism is expected to approach the bone metabolism of mature bone i.e. a bone metabolism corresponding with maintenance of bone homeostasis without any signs of under- or overloading of the bone. However, it remains elusive how the interbody bone metabolism transitions from low intensity (there is no bone metabolism in the intervertebral disc space before surgery), towards strongly increased intensity (early after surgery), towards a homeostatic intensity (long after surgery), and how these changes in metabolism relate to the status and quality of fusion of the operated segment. 
In order to properly interpret PET signals and assess their relevance in clinical research, it is important to understand the changes in local bone metabolism following LIF and how this relates to the status of fusion. Therefore, the objective of this study was to quantify the changes in local bone metabolism during the consolidation process of interbody fusion. A preclinical ovine cohort that was subjected to LIF surgery was longitudinally monitored by ${ }^{18} \mathrm{~F}-\mathrm{NaF}$ PET/CT scanning. The status of interbody fusion in the cages was quantified per scan in a standardized way using CT data, whereas local bone metabolism was quantified in the interbody and endplate regions based on normalized ${ }^{18} \mathrm{~F}-\mathrm{NaF}$ uptake values. Normalized

${ }^{18} \mathrm{~F}-\mathrm{NaF}$ uptake values were generated per scan by dividing the activity value of every voxel by the mean activity of an internal reference site in the spinal column. To evaluate the changes in local bone metabolism during the consolidation process of fusion, normalized tracer uptake was expressed as a function of fusion status.

\section{MATERIALS AND METHODS}

\section{Animal model and study design}

Six skeletally mature Zwartbles ewes (age 2-4 years, weight 76-112 kg) were included from an existing ovine cohort on LIF surgery with a scheduled postoperative time period of 13 weeks [17]. Sheep underwent LIF by insertion of a polyether ether ketone (PEEK) cage filled with autologous iliac crest bone graft (ICBG) at either level L2-L3 or L4-L5. The PEEK cages were custom designed and manufactured (Instrument Development, Engineering and Evaluation, Maastricht University, Maastricht, the Netherlands) to fit the vertebrae of the sheep. Cages were $22 \times 9 \times 6 \mathrm{~mm}^{3}$ in size, contained titanium markers, and had a central graft window of approximately $0.5 \mathrm{~mL}$. All animal protocols were conducted in accordance with the European directive 2010/63/EU and were approved by local animal welfare committees at the involved institutions in Belgium (Medanex Clinic, Diest; EC MxCl 2018-110) and the Netherlands (Maastricht University, Maastricht; AVD1070020185685).

\section{Surgical technique and postoperative course}

Surgery on the sheep was performed by an experienced spine surgeon (PW) at the Medanex Clinic (Diest, Belgium) under general anesthesia with endotracheal intubation with the animal in the right lateral decubitus position. Following a retroperitoneal approach of the designated intervertebral disc space and fluoroscopic confirmation, discectomy and endplate rasping was performed. Customized rasp tools that gradually increased in height up to $5 \mathrm{~mm}$ enabled revascularization of the endplates and preparation of the intervertebral space for cage impaction. At the caudal side of the incision, the cortical shell of the iliac crest was exposed and opened in order to harvest ICBG. The cage graft window was filled with the autologous ICBG before impaction. Additional instrumentation could be omitted because the $6 \mathrm{~mm}$ high cages were tightly compressed by the two adjacent vertebrae. The wound was closed layerby-layer using appropriate sutures. 
After complete recovery from surgery, the sheep were transported from the Medanex Clinic (Diest, Belgium) to the animal facility of Maastricht University (Maastricht, the Netherlands) for PET/CT scanning at six and twelve weeks after surgery. The sheep were group housed, were free to move throughout the follow-up period, and had ad libitum access to hay and water. After 13 weeks, the sheep were euthanized and the operated intervertebral segments were isolated for histology.

\section{PET/CT acquisition}

The sheep were scanned under general anesthesia in a Discovery MI 5 ring PET/CT system (GE Healthcare, Milwaukee, WI, USA). Thirty minutes after intravenous injection of 1.2-2.4 MBq ${ }^{18} \mathrm{~F}-\mathrm{NaF}$ tracer per kilogram body weight, a low-dose CT (120 kV, $20 \mathrm{mAs}$, slice thickness $2.5 \mathrm{~mm}$ ) was acquired, which was used for attenuation correction upon reconstruction of the positron emission signals. PET acquisition of the complete lumbar spine was performed using a single bed position with an acquisition time of ten minutes. Directly after PET acquisition, a diagnostic CT $(140 \mathrm{kV}, 300 \mathrm{mAs}$, slice thickness $1.25 \mathrm{~mm}$ with increment of $0.625 \mathrm{~mm}$ ) of the lumbar spine was made. Standard filtered back projection was performed to reconstruct CT images as 512 x 512 matrices. Attenuation-corrected PET images were reconstructed as $256 \times 256$ matrices with a block sequential regularized expectation maximization algorithm including time-of-flight and point spread functions (commercial name Q.Clear, GE Healthcare, Milwaukee, WI, USA) [18]. The penalization factor of this iterative reconstruction algorithm (termed beta) was set to 700 .

\section{Quantification of fusion based on diagnostic CT data}

The diagnostic CT images were used to quantify the status of interbody fusion of the PEEK segments for each sheep at both six and twelve weeks after surgery. Images were analyzed using medical image processing software (Mimics version 22.0, Materialise, Leuven, Belgium). For visualization purposes, the brightness and contrast settings of the grayscale were standardized across all images using the Hounsfield units (HUs). For every scan, the titanium markers of the customized PEEK cage were segmented by thresholding (HU > 1000). Then, the computer aided design file describing the PEEK cage including titanium markers and central graft window was imported into the software. To position the design file correctly within each CT scan, the cage was automatically repositioned by aligning the titanium markers of the design file with the segmented titanium markers from the scan (Figure 1). To yield a percentage of bone volume for every scan in a standardized manner, the bone was quantified $(\mathrm{HU}>500)$ within and normalized to the central graft window of the cage.

\section{Quantification of ${ }^{18}$ F-NaF uptake}

The CT and corresponding attenuation-corrected PET images were imported into dedicated research software (PMOD version 4.1, PMOD Technologies, Zürich, Switzerland) 
to quantify ${ }^{18} \mathrm{~F}-\mathrm{NaF}$ uptake. A volume of interest (VOI) with an axial height of $30 \mathrm{~mm}$, surrounding the vertebral bodies of L5 and L6, was centered on intervertebral disc L5-L6, and was thresholded for bone $(\mathrm{HU}>250)$. This resulted in a reference $\mathrm{VOI}\left(\mathrm{VOI}_{\mathrm{REF}}\right)$ per scan (Figure 2, upper row) of 15-20 mL in volume. For each scan, the mean ${ }^{18} \mathrm{~F}-\mathrm{NaF}$ uptake in the $\mathrm{VOI}_{\mathrm{REF}}$ was derived in $\mathrm{kBq} / \mathrm{mL}$ from corresponding attenuation-corrected PET images. This value was subsequently used to normalize the PET images with an internal reference value, i.e. each voxel ${ }^{18} \mathrm{~F}-\mathrm{NaF}$ uptake value (in $\mathrm{kBq} / \mathrm{mL}$ ) was divided by the mean ${ }^{18} \mathrm{~F}-\mathrm{NaF}$ uptake value of the $\mathrm{VOI}_{\mathrm{REF}}$ (in $\mathrm{kBq} / \mathrm{mL}$ ) of the scan.

On the axial slices of each CT, VOIs were manually drawn in the center of the operated interbody segment $\left(\mathrm{VOI}_{\mathrm{IB}}\right)$ and at the endplates above and below $\left(\mathrm{VOI}_{\mathrm{EP}}\right)$. These VOIs were all $3.75 \mathrm{~mm}$ in axial height and surrounded the original contours of vertebral bodies in the axial plane. $\mathrm{VOI}_{\mathrm{IB}}$ and $\mathrm{VOI}_{\mathrm{EP}}$ were $2.0-2.7$ and $1.7-2.6 \mathrm{~mL}$ in volume, respectively. To prevent any edge effects from the interface of the cage and the vertebral bodies, $\mathrm{VOI}_{\mathrm{IB}}$ and $\mathrm{VOI}_{\mathrm{EP}}$ were drawn at a distance of $3.75 \mathrm{~mm}$ from each other (Figure 2, lower row). These VOIs were transferred to the corresponding attenuation-corrected and normalized PET images to determine the mean and maximum normalized uptake values within these specific volumes. To express the relation between the normalized uptake value in $\mathrm{VOI}_{\mathrm{IB}}$ and $\mathrm{VOI}_{\mathrm{EP}}$, the $\mathrm{VOI}_{\mathrm{IB}}$ value was divided by the mean of the $\mathrm{VOI}_{\mathrm{EP}}$ values above and below. The normalized activity in $\mathrm{VOI}_{\mathrm{IB}}$ and the ratio of $\mathrm{VOI}_{\mathrm{IB}}$ to $\mathrm{VOI}_{\mathrm{EP}}$ were both plotted versus percentage of bone volume as derived from the diagnostic CT scans. A third-degree polynomial curve was fitted to the set of data points using MATLAB (MathWorks, Natick, MA, USA).

\section{Histology}

The isolated intervertebral segments were processed for undecalcified histology as described before [17]. In short, specimens were fixed in formalin, dehydrated through a series of ethanol, and polymerized with methyl methacrylate. Midsagittal sections of $20 \mu \mathrm{m}$ were obtained and stained with basic fuchsin and methylene blue solutions to visualize mineralized tissue in and around the cage. An image of the cage region was digitalized using bright light microscopy.
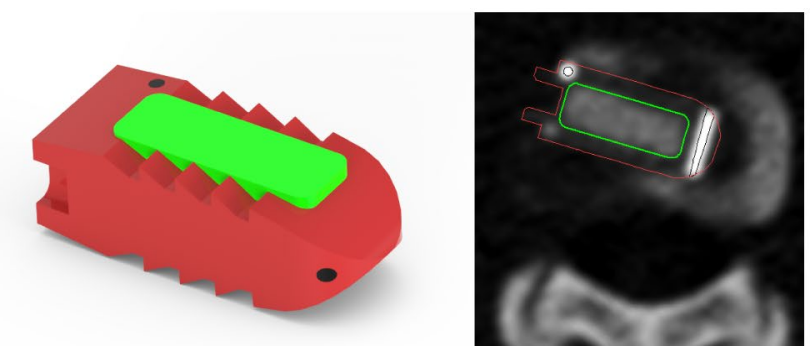

Figure 1. Three-dimensional render of the polyether ether ketone (PEEK) cage design (red) including titanium markers (black) and graft window (green). Titanium markers were used to appropriately reposition the cage into each computed tomography (CT) scan. 

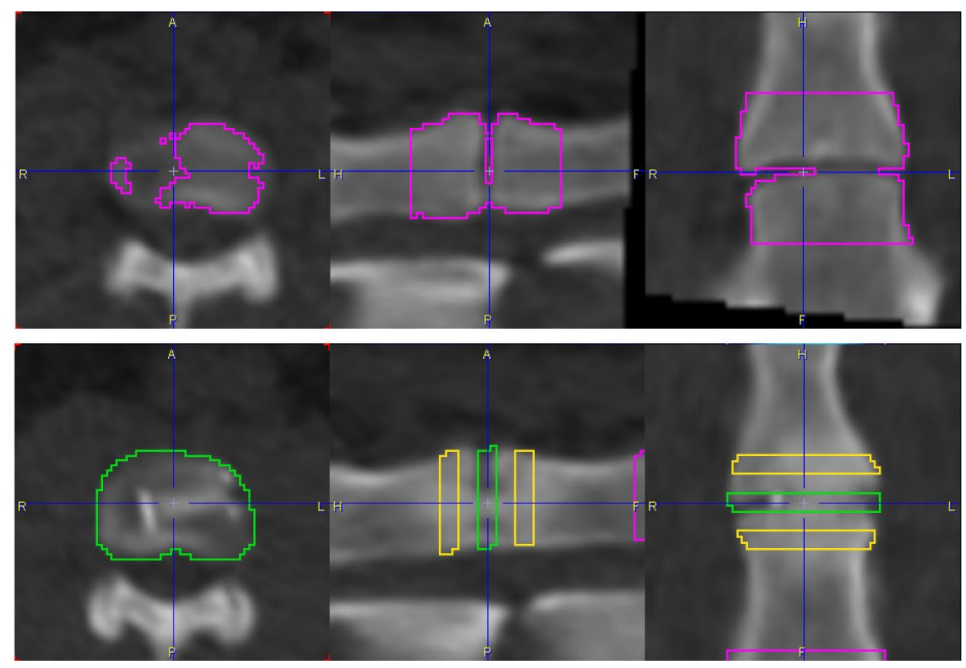

Figure 2. Upper row shows the volume of interest of the reference (VOIREF) at the unaffected segment L5-L6 in pink. Lower row displays the interbody and endplate volume of interest (VOIIB and VOIEP) at the operated segment in green and yellow, respectively.

\section{RESULTS}

All sheep were monitored according to protocol, so every sheep was scanned using PET/CT at six and twelve weeks after surgery. Figure 3 displays sagittal images of every diagnostic CT scan with a uniform grayscale across images. The bone volume inside the cage was graphically rendered and expressed as percentage below the images. Bone volumes varied largely between sheep and time points and covered nearly the whole spectrum of consolidation of interbody fusion, i.e. from hardly any bone volume ( $2 \%$ for scan a) to almost complete ossification of the graft window ( $86 \%$ for scan F). The amount of bone volume increased within every sheep between six and twelve weeks after surgery (lowercase versus uppercase letters). One of the sheep presented higher bone volume at six weeks after surgery (scan f) than all other five sheep at twelve weeks after surgery (scan A-E). In addition, the normalized attenuation-corrected ${ }^{18} \mathrm{~F}-\mathrm{NaF}$ PET sagittal images are shown in Figure 3. Colors represent the normalized uptake value and thus indicate the amount of tracer uptake in that particular voxel with respect to the mean tracer uptake in the reference volume. Within the interbody and endplate volumes of the intervertebral segment, the tracer uptake fluctuated with increasing bone volume and could increase up to ten times the reference uptake value. The further away from the surgical site, the more the normalized uptake value approached the value of one, meaning the tracer uptake in those voxels was equal to the mean tracer uptake in the reference volume. Both the $\mathrm{CT}$ and PET images revealed substantial anterolateral bone formation outside the PEEK cage in every sheep. In addition, the corresponding thirteen-week postoperative histological midsagittal sections are displayed per sheep in Figure 3. Per sheep, the bone in the histological section matches the anatomy of the bone as revealed by the twelve-week postoperative CT data. 

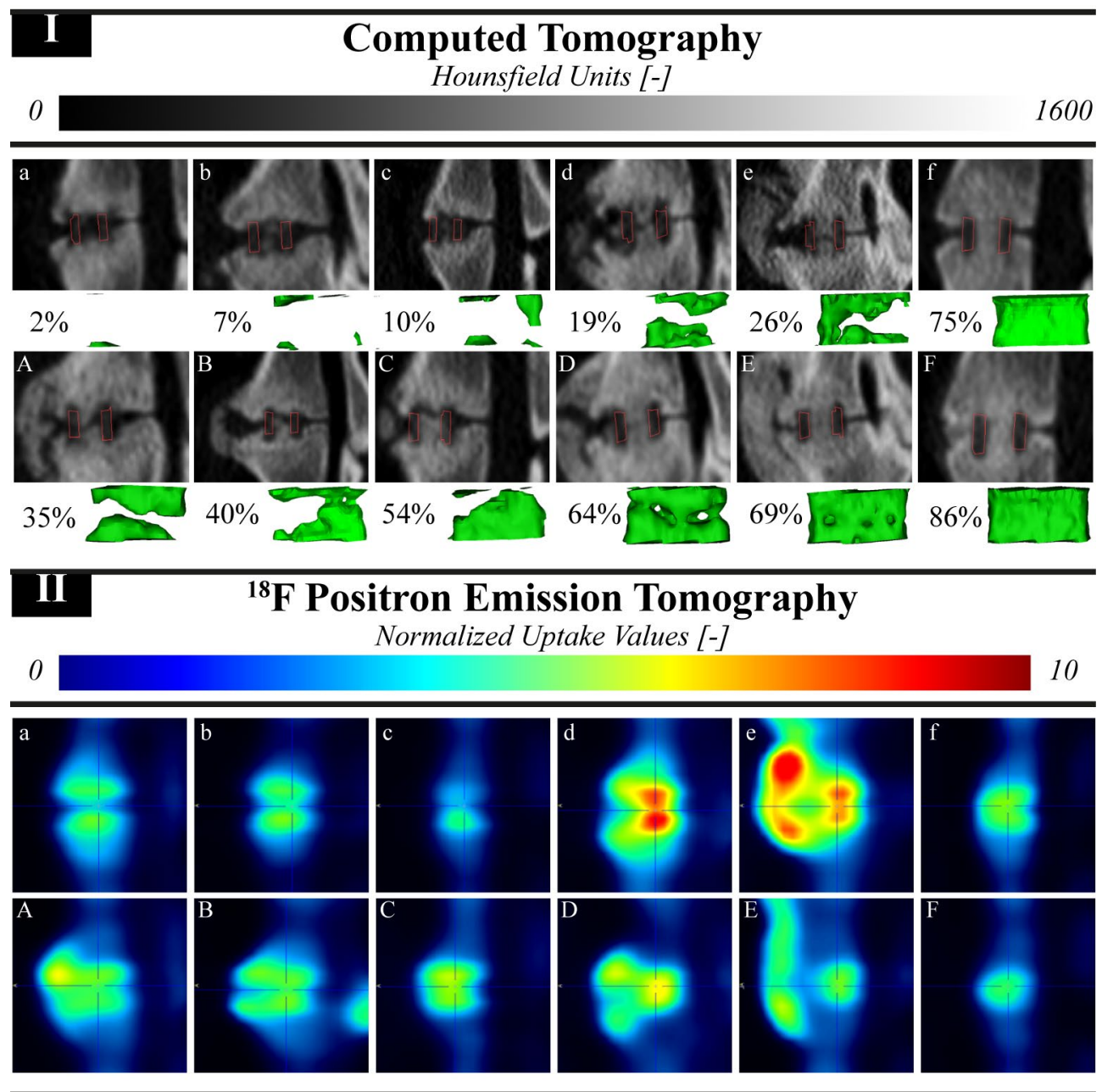

\section{Week Postoperative Histology}

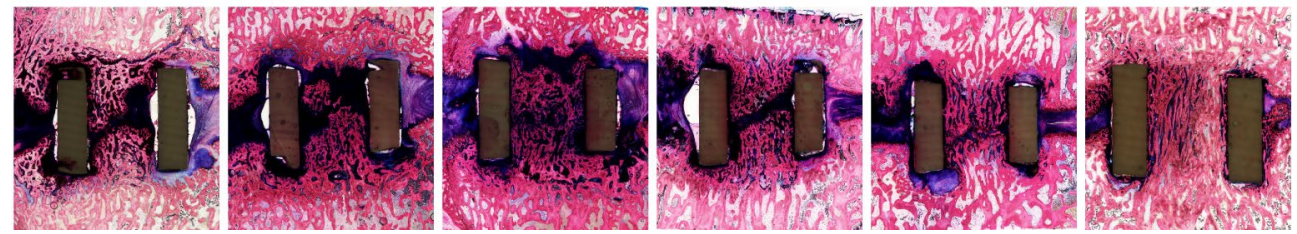

Figure 3. Diagnostic computed tomography $(\mathrm{CT})$ [panel I], ${ }^{18} \mathrm{~F}$ sodium fluoride $\left({ }^{18} \mathrm{~F}-\mathrm{NaF}\right)$ positron emission tomography (PET) [panel II] sagittal images for each sheep (a-f) at six (lowercase) and twelve (uppercase) weeks after surgery. The contours of the polyether ether ketone (PEEK) cage are visualized in red in the CT scans. Additionally, the percentage bone volume and the three-dimensional render of the bone (in green) within the graft window are displayed per CT scan. Corresponding basic fuchsin and methylene blue sections, obtained thirteen weeks postoperatively, are also displayed for each of the six sheep [panel III]. Orientation of images: top, cranial; bottom, caudal; left, anterior; right, posterior. 

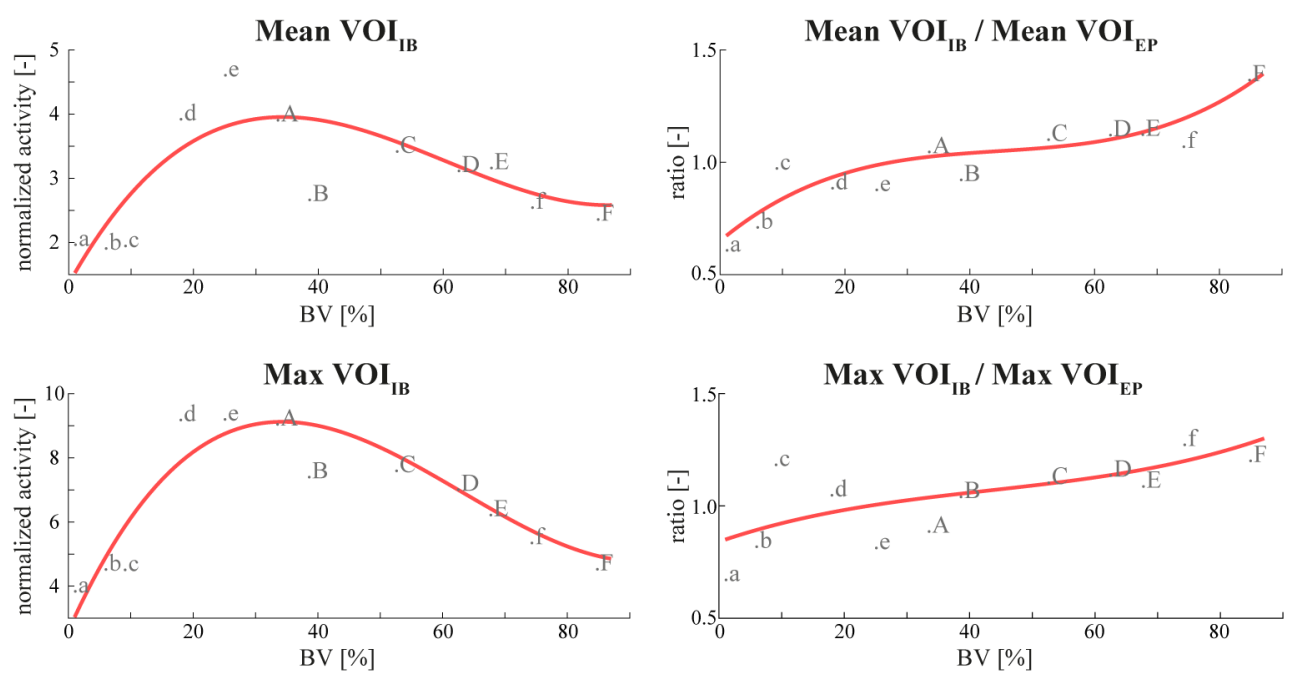

Figure 4. For every scan, the activity in the $\mathrm{VOI}_{\mathrm{IB}}$ and the ratio of the activity in the $\mathrm{VOI}_{\mathrm{IB}}$ to the activity in the VOIEP were plotted against percentage of bone volume (BV). Letters correspond to the individual scans as visualized and described in Figure 3. A third-degree polynomial curve (in red) was fitted to these data points.

Figure 4 shows the mean (upper left) and maximum (lower left) normalized activity in the $\mathrm{VOI}_{\mathrm{BB}}$ over percentage of bone within the graft window. When there was hardly any bone present within the graft window, the activity in the $\mathrm{VOI}_{\mathrm{IB}}$ was relatively low. Both mean and maximum activity peaked at $25-40 \%$ of bone volume. At higher bone volumes, the activity declined again. For all data points, mean and maximum normalized activity values were continuously exceeding the value of one, i.e. the uptake values in the $\mathrm{VOI}_{\mathrm{IB}}$ were found to be consistently higher than the mean activity of the $\mathrm{VOI}_{\text {REFF }}$. The ratio between the activity in the $\mathrm{VOI}_{\mathrm{IB}}$ and the activity in the $\mathrm{VOI}_{\mathrm{EP}}$ are shown at the right-hand side of Figure 4 . When there was a low amount of bone present within the graft window, the ratios were found to be lower than one, meaning the uptake in the $\mathrm{VOI}_{\mathrm{EP}}$ was higher than in the $\mathrm{VOI}_{\mathrm{IB}}$. With increasing bone volume, the ratio approached and exceeded the value of one, indicating higher activity in the $\mathrm{VOI}_{\mathrm{IB}}$ with respect to the activity in the $\mathrm{VOI}_{\mathrm{EP}}$.

\section{DISCUSSION}

This study aimed to evaluate the changes in local bone metabolism as measured by ${ }^{18} \mathrm{~F}$ $\mathrm{NaF}$ PET/CT during the consolidation process of LIF in a sheep model. Although the local bone metabolism in the interbody region was consistently higher than the metabolism in reference bone, it strongly varied with interbody fusion status. With increasing bone volume in the cage, the bone metabolism in the interbody region was shown to increase, peak, and decrease after which it seemed to stabilize at an activity level above that of reference bone. This trend was found for both the mean and maximum bone metabolism within the interbody region. 
In this study, a bell-shaped curve was found for the bone metabolism in the interbody region versus fusion status. The development of this characteristic curve can be related to the process of bone graft incorporation in interbody fusion, which is described to entail three distinct stages $[19,20]$. First, there is an early inflammatory stage (hours-days) in which granulation tissue is formed and vascularized. Second, there is a repair stage (weeks-months) in which the original bone graft is resorbed and simultaneously replaced by new woven bone, a process called creeping substitution [21]. Third, the woven bone mass remodels (monthsyears) into lamellar bone with a trabecular architecture which adapts to the mechanical loads experienced by the tissue [22]. Within these three distinct stages, bone metabolism is the most active during creeping substitution in the repair stage. In order to achieve creeping substitution in the center of the interbody cage, bone progenitor cells must first migrate from the vertebral endplates towards the graft window of the cage [23]. Formation of new bone and vascular tissue thus commences at the endplates before it reaches the interbody region. For this reason, the bone metabolism was found to be higher in the endplate region than in the interbody region at the onset of fusion. Additionally, the initial absence of the bone progenitor cells in the interbody region explains the delayed increase that was found in this study for the ${ }^{18} \mathrm{~F}-\mathrm{NaF}$ uptake in the middle of the interbody region during consolidation of fusion. Once new bone formation at the endplates was achieved and a vascular connection between bone marrow and interbody region was established, bone progenitor cells could enter the interbody region, differentiate, and start to actively deposit new bone in the interbody region. As a result, the bone metabolism in the interbody region peaked and exceeded the bone metabolism in the endplate region as fusion progressed. Upon complete ossification of the graft window, bone metabolism in the interbody region decreased and stabilized at an activity still higher than that of unaffected bone. Thus, the fusion mass of the segment in which the fusion was most consolidated was still actively remodeling.

The method used to quantify the fusion status of each individual CT scan in this study yielded the percentage of bone volume within the graft window of the cage. This value described the percentage of bone inside the cage without considering the microarchitecture of the segmented bone volume. As a consequence, this quantification method would not be appropriate to analyze microstructural changes of the bone in the remodeling stage of the healing process. This was of no concern in the current study, as it focused on short postoperative time periods only and aimed to monitor the bone metabolism from surgery up until the remodeling stage. It should however be acknowledged that the quantification of cage bone volume is not a standard clinical procedure as it involves relatively high radiation exposure and time-consuming manual image processing. In clinical practice, the number of bony bridges through and around the cage is often scored instead [24, 25].

Because bone remodeling activity varied considerably between sheep and did not reveal a distinct trend between six and twelve weeks after surgery, the bone remodeling activity value of each individual PET scan was interpreted as a function of bone volume. Current analysis assumed that all sheep followed the same uncompromised progression of fusion, but 
with a different speed. To confirm this assumption, all sheep should have been monitored using PET/CT at regular (shorter) time intervals up until the remodeling stage of the healing process. This was, however, unattainable as the sheep originated from an existing cohort with a short postoperative time period. Monitoring each sheep at regular time intervals up until the remodeling stage would generate activity versus bone volume plots as in Figure 4 per individual sheep, which would provide more insight in the time and subject dependency of the local bone metabolism in an operated segment.

The observed presence of anterolateral bone formation outside the PEEK cages in all animals may have resulted in inaccuracies in current analyses. First, tracer activity spillover from the anterolateral bone region outside the PEEK cage into the interbody region is expected due to limited spatial resolution in PET images [26]. Since the amount of spillover depends on the amount and distribution of activity in the anterolateral bone region, which varied across scans, it was difficult to correct for this spillover. However, it may have resulted in slight overestimations of the actual interbody tracer uptake. Second, the anterolateral bone formations may have stabilized the intervertebral segment once a complete bony bridge was developed between the two vertebrae. This stabilization might in turn have affected the formation of bone within the cage, as it has been shown before that additional stabilization of a spinal segment might increase the chances of intervertebral consolidation [27]. Anterolateral bone formation outside the cage has been reported before in ovine interbody fusion models [28]. In this study, the formation of these bony structures is, however, expected to mainly originate from the surgical rasping which preceded impaction of the cage into the disc space. Rasping might have promoted bone formation outside the interbody region as the procedure presumably stimulated the periosteum surrounding the vertebrae $[29,30]$. The rasping and cage impaction procedure was included in current surgical technique to avoid the use of pins in the vertebral bodies for distraction, which is generally required for cage insertion. Insertion of vertebral pins would have led to increased bone remodeling within the vertebrae, which was unwanted since endplate regions were also of interest in our current analyses. For future research, if solely focusing on interbody bone metabolism, it would be interesting to perform vertebral distraction to open up the disc space instead of the gradual rasping and impaction procedure. We hypothesize that implementation of a distraction step could reduce the bone formation outside the interbody region, albeit at the expense of an increased background signal at the center of the vertebrae in which the distraction pins were inserted.

This study addressed the changes in local bone metabolism following LIF surgery and proposed the underlying processes responsible in an ovine model. Since loading conditions on the ovine spine resemble those of humans and ovine models accurately approach human bone remodeling and turnover [31,32], the presented changes in local bone metabolism are believed to hold true for the human spine as well. However, the time scale of these changes might differ from the clinical situation as bony union is generally attained more rapidly in ovine models compared to human patients $[33,34]$. The bell-curved development of bone 
metabolism in well-consolidating spinal segments suggests that short-term PET quantifications for prognostic diagnosis should not be too late after surgery. In the initial phase of bone ingrowth an increased metabolic activity correlates with well-consolidating segments, whereas after this initial phase ambiguity arises as it becomes unknown whether the metabolic activity should still increase or should already decrease again. On long-term diagnostic follow-up (>years), this issue does not play part anymore as elevated bone metabolism has been recognized as a sign of micro-instability at this time scale $[11,15]$. However, it is impossible to define a clear postoperative time point after which bone metabolism should reduce to homeostatic values again. Moreover, it remains hard to predict how markedly compromised segments will differ in bone metabolism from well consolidating segments.

Previously, Foldager et al. revealed different metabolic patterns at 2, 4, and 8 weeks after surgery using PET quantifications in a porcine model in which PEEK interbody cages were enriched with autologous ICBG or osteobiologics [35]. Although their study proved that PET quantifications early after surgery could differentiate between two substantially different ossification mechanisms, changes in bone metabolism were not directly expressed in terms of progression of fusion The current study demonstrated the changes in local bone metabolism in a consolidating segment and clarified the variance in bone metabolism that may exist in well-fusing segments early after surgery. The location and intensity of the bone metabolism early after surgery provides additional information on the ongoing fusion process (prognostic) but should remain complementary to CT analysis (diagnostic) since early PET signals can be ambiguous on their own and can vary between subjects significantly. We believe it is important to take this variance into account, especially when interpreting PET signals of individual patients. Knowing the changes in local bone metabolism during uncompromised consolidation of spinal interbody fusion might enable identification of impaired bone formation early after LIF surgery using PET/CT quantifications. Early identification of impaired healing might aid in implementation of timely and efficient clinical measures potentially resulting in less non-unions. Future studies are warranted to investigate the exact timing and changes in local bone metabolism in the human spine following LIF surgery, and whether these changes may be affected by skeletal disorders (e.g. osteoporosis), by drug administration (e.g. parathyroid hormones, bone morphogenetic proteins), and by the combination of bone graft and cage material that is used.

\section{REFERENCES}

1. Mobbs RJ, Phan K, Malham G, Seex K, Rao PJ. Lumbar interbody fusion: techniques, indications and comparison of interbody fusion options including PLIF, TLIF, MI-TLIF, OLIF/ATP, LLIF and ALIF. Journal of Spine Surgery. 2015;1(1):2-18.

2. Duarte RM, Varanda P, Reis RL, Duarte ARC, Correia-Pinto J. Biomaterials and Bioactive Agents in Spinal Fusion. Tissue engineering Part B, Reviews. 2017;23(6):54051. 
3. Meng B, Bunch J, Burton D, Wang J. Lumbar interbody fusion: recent advances in surgical techniques and bone healing strategies. European Spine Journal. 2021;30(1):2233.

4. Raizman NM, O'Brien JR, Poehling-Monaghan KL, Yu WD. Pseudarthrosis of the spine. The Journal of the American Academy of Orthopaedic Surgeons. 2009;17(8):494503.

5. Chun DS, Baker KC, Hsu WK. Lumbar pseudarthrosis: a review of current diagnosis and treatment. Neurosurgical focus. 2015;39(4):E10.

6. DePalma AF, Rothman RH. The nature of pseudarthrosis. Clinical orthopaedics and related research. 1968;59:113-8.

7. Kornblum MB, Fischgrund JS, Herkowitz HN, Abraham DA, Berkower DL, Ditkoff JS. Degenerative lumbar spondylolisthesis with spinal stenosis: a prospective long-term study comparing fusion and pseudarthrosis. Spine. 2004;29(7):726-33; discussion 33-4.

8. Peters MJM, Bastiaenen CHG, Brans BT, Weijers RE, Willems PC. The diagnostic accuracy of imaging modalities to detect pseudarthrosis after spinal fusion-a systematic review and meta-analysis of the literature. Skeletal Radiol. 2019;48(10):1499-510.

9. Fogel GR, Toohey JS, Neidre A, Brantigan JW. Fusion assessment of posterior lumbar interbody fusion using radiolucent cages: X-ray films and helical computed tomography scans compared with surgical exploration of fusion. The spine journal : official journal of the North American Spine Society. 2008;8(4):570-7.

10. Hawkins RA, Choi Y, Huang SC, Hoh CK, Dahlbom M, Schiepers C, . . , Phelps ME. Evaluation of the skeletal kinetics of fluorine-18-fluoride ion with PET. Journal of nuclear medicine : official publication, Society of Nuclear Medicine. 1992;33(5):63342.

11. Fischer DR, Zweifel K, Treyer V, Hesselmann R, Johayem A, Stumpe KD, . ., Strobel $\mathrm{K}$. Assessment of successful incorporation of cages after cervical or lumbar intercorporal fusion with [(18)F]fluoride positron-emission tomography/computed tomography. European spine journal : official publication of the European Spine Society, the European Spinal Deformity Society, and the European Section of the Cervical Spine Research Society. 2011;20(4):640-8.

12. Pouldar D, Bakshian S, Matthews R, Rao V, Manzano M, Dardashti S. Utility of 18F sodium fluoride PET/CT imaging in the evaluation of postoperative pain following surgical spine fusion. Musculoskeletal surgery. 2017;101(2):159-66.

13. Genant HK, Bautovich GJ, Singh M, Lathrop KA, Harper PV. Bone-Seeking Radionuclides: An In Vivo Study of Factors Affecting Skeletal Uptake. Radiology. 1974;113(2):373-82.

14. Brenner W, Vernon C, Conrad EU, Eary JF. Assessment of the metabolic activity of bone grafts with 18F-fluoride PET. European Journal of Nuclear Medicine and Molecular Imaging. 2004;31(9):1291-8.

15. Peters M, Willems $\mathrm{P}$, Weijers R, Wierts R, Jutten L, Urbach C, . . . , Brans B. Pseudarthrosis after lumbar spinal fusion: the role of (18)F-fluoride PET/CT. European Journal of Nuclear Medicine and Molecular Imaging. 2015;42(12):1891-8.

16. Peters MJM. The diagnostic potential of $18 \mathrm{~F}$-Fluoride PET/CT in lumbar spinal fusion patients - early detection of pseudarthrosis and identification of pain generators after surgery [Doctoral Thesis]. Maastricht: Maastricht University; 2019.

17. Loenen ACY, Peters MJM, Bevers RTJ, Schaffrath C, van Haver E, Cuijpers V, . . , Arts JJ. Early bone ingrowth and segmental stability of a trussed titanium cage versus a 
polyether ether ketone cage in an ovine lumbar interbody fusion model. The spine journal : official journal of the North American Spine Society. 2021.

18. Parvizi N, Franklin JM, McGowan DR, Teoh EJ, Bradley KM, Gleeson FV. Does a novel penalized likelihood reconstruction of 18F-FDG PET-CT improve signal-tobackground in colorectal liver metastases? European Journal of Radiology. 2015;84(10):1873-8.

19. Boden SD, Schimandle JH, Hutton WC. An Experimental Lumbar Intertransverse Process Spinal Fusion Model: Radiographic, Histologic, and Biomechanical Healing Characteristics. Spine. 1995;20(4):412-20.

20. Kalfas IH. Principles of bone healing. Neurosurgical focus. 2001;10(4):E1.

21. Burchardt $\mathrm{H}$. The biology of bone graft repair. Clinical orthopaedics and related research. 1983;(174):28-42.

22. Smit TH, Muller R, van Dijk M, Wuisman PI. Changes in bone architecture during spinal fusion: three years follow-up and the role of cage stiffness. Spine. 2003;28(16):1802-8; discussion 9.

23. Craig Boatright K, Boden SD. Biology of Spine Fusion. In: Lieberman JR, Friedlaender GE, eds. Bone Regeneration and Repair: Biology and Clinical Applications. Totowa, NJ: Humana Press; 2005. p. 225-39.

24. Burkus JK, Foley K, Haid RW, LeHuec JC. Surgical Interbody Research Group-radiographic assessment of interbody fusion devices: fusion criteria for anterior lumbar interbody surgery. Neurosurgical focus. 2001;10(4):E11.

25. Ajiboye RM, Hamamoto JT, Eckardt MA, Wang JC. Clinical and radiographic outcomes of concentrated bone marrow aspirate with allograft and demineralized bone matrix for posterolateral and interbody lumbar fusion in elderly patients. European spine journal : official publication of the European Spine Society, the European Spinal Deformity Society, and the European Section of the Cervical Spine Research Society. 2015;24(11):2567-72.

26. Soret M, Bacharach SL, Buvat I. Partial-volume effect in PET tumor imaging. Journal of nuclear medicine : official publication, Society of Nuclear Medicine. 2007;48(6):93245.

27. Anjarwalla NK, Morcom RK, Fraser RD. Supplementary stabilization with anterior lumbar intervertebral fusion--a radiologic review. Spine. 2006;31(11):1281-7.

28. Steffen T, Stoll T, Arvinte T, Schenk RK. Porous tricalcium phosphate and transforming growth factor used for anterior spine surgery. European spine journal : official publication of the European Spine Society, the European Spinal Deformity Society, and the European Section of the Cervical Spine Research Society. 2001;10(2):S132-S40.

29. Dwek JR. The periosteum: what is it, where is it, and what mimics it in its absence? Skeletal Radiol. 2010;39(4):319-23.

30. Wu S, Lin Z, Yamaguchi A, Kasugai S, editors. The effects of periosteum removal on the osteocytes in mouse calvaria2015.

31. Pearce AI, Richards RG, Milz S, Schneider E, Pearce SG. Animal models for implant biomaterial research in bone: a review. European cells \& materials. 2007;13:1-10.

32. Smit TH. The use of a quadruped as an in vivo model for the study of the spine biomechanical considerations. European spine journal : official publication of the European Spine Society, the European Spinal Deformity Society, and the European Section of the Cervical Spine Research Society. 2002;11(2):137-44. 
33. Lindley EM, Barton C, Blount T, Burger EL, Cain CMJ, Seim HB, . . , Patel VV. An analysis of spine fusion outcomes in sheep pre-clinical models. European Spine Journal. 2017;26(1):228-39.

34. Schiffman M, Brau SA, Henderson R, Gimmestad G. Bilateral implantation of lowprofile interbody fusion cages: subsidence, lordosis, and fusion analysis. The spine journal : official journal of the North American Spine Society. 2003;3(5):377-87.

35. Foldager C, Bendtsen M, Zou X, Zou L, Olsen AK, Munk OL, . . ., Bunger C. ISSLS prize winner: positron emission tomography and magnetic resonance imaging for monitoring interbody fusion with equine bone protein extract, recombinant human bone morphogenetic protein-2, and autograft. Spine. 2008;33(25):2683-90. 



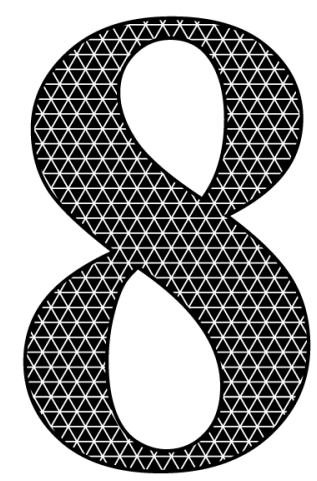

General discussion 

This thesis focused on the early phase after lumbar spinal fusion surgery both from a biomechanical and a biological perspective. First, the progression of bony bridging early after lumbar interbody fusion (LIF) has been assessed by providing a systematic overview of the longitudinal fusion rates reported in the existing literature. Second, the potential impact of technological innovations on the improvement of early fusion has been investigated with in silico and preclinical in vivo spinal fusion models. The preclinical in vivo spinal fusion model was also used to analyze local bone metabolism variations during early progression of fusion. The current chapter gives an overview of the main findings, future perspectives, and conclusion of this thesis.

\section{THE IMPORTANCE OF WELL-ALIGNED INSTRUMENTATION IN SPINAL FUSION SURGERY}

The importance of proper posterior instrument alignment (i.e. alignment of the rods within the pedicle screw heads) in fusion surgery has been demonstrated in Chapter 3. In case of misaligned instrumentation, the forces required to reduce the misalignment during the operation are in the range of those reported to cause screw pullout. This enforced correction may also result in high tissue strains in the vertebrae and intervertebral discs of not only adjacent but also downstream spinal segments, i.e. segments multiple levels distance of the operated segments. These strains were observed directly after correction, intensified during postoperative physiological movement, and indicated an increased risk for tissue damage. Proper initial instrumentation alignment thus may reduce clinical complications secondary to unfavorable biomechanics. This would be especially important in case of longsegment posterior fusions. For single level posterior fusion surgery, misalignment is of less concern as polyaxial screw heads facilitate a connection between rod and screw head within a wide range of angulations $[1,2]$. The patient-specific in silico model that was used to analyze the consequences of correcting a mismatch did not include tissue remodeling over time. Therefore, the timing and occurrence of potential complications secondary to misaligned instrumentation remains to be investigated.

To monitor the consequences of forcefully reducing misaligned instrumentation in a direct clinical fashion, it would be interesting to develop and use reduction devices with force gauges. In this way, the actual applied reduction forces during assembly of the construct can be monitored and correlated to eventual postoperative outcomes. Combining the real-world clinical outcomes with our model predictions will allow us to get more insight in which reduction forces are still acceptable and which should surely be avoided such that the onset of tissue deterioration secondary to tissue overloading can be minimized.

In Chapter 3, the focus was on misaligned posterior screw and rod constructs. However, the exact position of an interbody cage at the vertebral endplate during LIF can also be considered as correctly- or mispositioned. In Chapter $\mathbf{4}$ it was demonstrated that the exact positioning of two posterior lumbar interbody fusion (PLIF) cages affects the load on the 
cages and the stresses at the endplate interfaces. Moreover, it has been shown before that cage position influences cage migration rates [3]. For future research it would therefore be worthwhile to develop patient-specific models based on actual cage positions and to analyze whether postoperative outcomes can be explained or predicted with these models. Once these models can indeed predict postoperative outcomes and risks, the patient-specific models can be used for preoperative planning of optimal cage positions.

\section{MONITORING THE LOCAL BONE METABOLISM FOLLOWING SPINAL FUSION SURGERY}

In Chapter 7, ${ }^{18} \mathrm{~F}$ sodium fluoride $\left({ }^{18} \mathrm{~F}-\mathrm{NaF}\right)$ positron emission tomography/computed tomography (PET/CT) was used to investigate the local bone metabolism following LIF surgery in an ovine model. During progression of interbody fusion, a rapid increase in bone metabolism was found at the vertebral endplates, which gradually developed towards the center of the interbody region. The course of the local bone metabolism could be explained by progression of bony fusion via the creeping substitution process. In the current study only healthy subjects were included, thus the uncompromised situation could be analyzed and revealed. Knowing the changes in local bone metabolism during uncompromised consolidation of spinal interbody fusion may enable identification of impaired bone formation early after LIF surgery using ${ }^{18} \mathrm{~F}-\mathrm{NaF}$ PET/CT quantifications.

In the current research, ${ }^{18} \mathrm{~F}-\mathrm{NaF}$ PET/CT was used to quantify the changes in local bone metabolism during the consolidation process of LIF in an ovine model using polyether ether ketone (PEEK) cages impacted with autologous iliac crest bone graft (ICBG). How the early local bone metabolism may be affected by other cage types, or by administration of bone stimulating products, should be further investigated. In order to determine whether early ${ }^{18} \mathrm{~F}$ $\mathrm{NaF}$ PET/CT can be used to predict whether a solid fusion will eventually develop or not, the changes in local bone metabolism in case of non-union should be revealed first. With the current knowledge about ${ }^{18} \mathrm{~F}-\mathrm{NaF}$ uptake in an operated segment early after surgery, we know too little about the exact prognostic information of a single PET/CT scan. Multiple early ${ }^{18} \mathrm{~F}-$ $\mathrm{NaF}$ PET/CT scans would provide an improved understanding of the ongoing bone formation process in an operated segment, but ${ }^{18} \mathrm{~F}-\mathrm{NaF}$ PET/CT also exposes the patient to a significant radiation dose and is associated with relatively high financial costs. Future preclinical research should therefore further unveil the relation between early ${ }^{18} \mathrm{~F}-\mathrm{NaF}$ PET signals and eventual postoperative outcomes for both unsuccessful and successful fusions.

\section{THE DEVELOPMENT OF BONY FUSION FOLLOWING SPINAL FUSION SURGERY}

Generally, LIF is an effective operative treatment for a wide range of disorders if conservative treatment has failed [4]. Postoperative non-union, however, remains a major complication [5]. A systematic literature review was performed in Chapter 2 aiming to 
quantify the fusion rate over time after LIF surgery. Most of the included studies were associated with a high risk of bias and considerable variations were found in study designs, reporting, outcomes, and measures. Although the fusion rates two years postoperatively were generally high with a relatively small variation between studies (range 76-100\% with a mean of $92 \%$ ), large variations were found in early postoperative fusion rates. In fact, within six months after surgery, fusion rates varied within the whole spectrum from $0-100 \%$. Therefore, it was suggested that there is still much room for improvement for early consolidation of LIF. Because high fusion rates early after surgery seemed to be related to decreased instrument complication rates, major advantages might be gained by the introduction of new devices that focus on standardizing and enhancing short-term fusion rates. However, as fusion and complication rates are not one-to-one correlated with clinical outcomes [6], the clinical significance of enhancing early fusion rates remains to be validated. For future research, the relation between early fusion rates, late fusion rates, complications, and clinical results should be analyzed in detail to draw definite conclusions about the importance of early fusion rates. On the one hand, fundamental questions on the development of fusion rates, from early to late stage, can be investigated in preclinical animal studies with longitudinal postoperative CT analyses. On the other hand, clinical results focused on symptoms and function should be attained with human studies albeit at the expense of less radiological follow-up moments because of radiation dose considerations.

LIF surgery aims to stabilize a painful intervertebral segment by stimulating bony fusion between two vertebrae. In our opinion it should also be considered how to describe the stability of a fusion in preclinical and clinical studies. Routinely, the bony tissue through and around an interbody cage is analyzed to declare a segment fused or not [7]. However, the amount of bone (or the number of bony bridges) is not necessarily a direct measure for stability of the operated segment and could be misinterpreted due to metal artifacts or the presence of mineralized graft material (e.g. bone grafts or ceramic grafts). Moreover, the new generation of porous cages might facilitate serious stability by bony ingrowth through the interconnected pores without requiring a full bony bridge from one vertebral endplate to the other $[8,9]$. In case of metal cages, however, it is difficult to longitudinally monitor this bony growth as metal artifacts hamper detailed radiologic image analysis. Dynamic imaging (e.g. flexion-extension radiography) would in theory be able to provide more insight into the stability of an operated segment but tends to overestimate fusion rates compared to CT evaluations [10]. Additionally, metal artifacts may preclude accurate evaluation of fusion on dynamic radiographs.

None of the imaging modalities is thus able to flawlessly distinguish fusions from nonunions and we doubt whether it would be feasible to apply one standardized protocol to evaluate fusion for different interbody cage types with different design and material properties. Segmental stability seems therefore a more appropriate measure, as eventually the aim of the interbody fusion is to stabilize the treated segment anteriorly. A combination of modalities (CT, dynamic radiography, and potentially image-based computer models) will 
most likely give the best diagnosis on the attained stability of the operated segment. In case of indecisive cases, the aforementioned ${ }^{18} \mathrm{~F}-\mathrm{NaF}$ PET/CT can provide additional information to assess the state of the operated segment, i.e. it gives additional insight in the local bone metabolism. Once a segment is stabilized the bone metabolism will reduce to normal background values, so a high ${ }^{18} \mathrm{~F}-\mathrm{NaF}$ uptake is a sign of inadequate stability $[11,12]$. However, caution is warranted with these interpretations as moderately increased ${ }^{18} \mathrm{~F}-\mathrm{NaF}$ uptakes can be expected for several years as a result of ongoing bone remodeling in the new bone mass while it matures.

In addition, it remains important to consider the complete postoperative time period from surgery up until completion of remodeling when assessing the performance of new devices and graft materials. Recombinant human bone morphogenetic protein (rhBMP) for example can first produce a strong resorptive response, before stimulating bone formation [13]. In fact, Sethi et al. reported an increased incidence of cage migration and subsidence even though the overall progression of fusion was accelerated by using rhBMP [14]. So, it is not only about acceleration of the fusion process but also about maintaining segmental integrity. Besides, it has been shown before that the microarchitecture of the bone within the fusion zone keeps remodeling for multiple years as it matures [15]. In addition to a quick healing phase, the eventual mechanical integrity of the bone-implant construct thus remains critical in maintaining segmental stability after fusion surgery.

\section{ENHANCING EARLY BONY FUSION BY MECHANICAL AND/OR BIOLOGICAL TECHNOLOGIES}

Chapter 4 and Chapter 5 analyzed 3D printed trussed titanium interbody cages in in silico and in vivo models, respectively. Patient-specific finite element (FE) models of a specific subgroup revealed that patient-specific factors such as weight, bone density, degenerative state of the spine, and spinal curvature did affect local strain regimes at the surface of the trussed cages; however, the loading conditions on the spine had a much larger impact on both the size and distribution of the strain at the implant surface. We do admit that the analyzed patient group did not fully represent the broad patient population undergoing spinal fusion surgery as patients with comorbidities like previous lumbar surgery, heavy smoking, drug use or other conditions affecting bone or disc metabolism, osteoporosis, obesity, or scoliosis were not included. Within the current subgroup, strains at the implant surface were found in a range consistent with those reported to preserve bone homeostasis and stimulate bone formation. Development of preoperative patient-specific FE models would enable further design optimization of tailored implants [16]. Detailed patient anatomy and tissue state, as well as expected loading profile, can be included in the determination of the optimal patient-specific implant design. Optimizing the strains at the implant surface under physiological conditions potentially enhances early progression of fusion by means of delivering mechanobiological cues to the cells at the surface. Cells residing at the surface of 
the implant could be bone progenitor cells that migrated from the vertebral endplates towards the implant interface, or ultimately osteoblasts and osteocytes which will be present when new bony tissue is deposited at the implant interface during progression of fusion.

The preclinical in vivo model analyzed the early bone ingrowth and segmental stability of a trussed titanium cage versus a PEEK cage in an ovine study. Based on the differences in progression of fusion, it was hypothesized that trussed titanium cages might facilitate increased early segmental stability by direct osseointegration of the cage at the vertebral endplates without requiring complete bony bridging through the cage. In this way, increased stability can be realized before full fusion has been established. It might even be suggested that a full bone bridge is not essential for the trussed cages as long as the vertebral endplates tightly anchor at the outer interfaces of the cage. In contrary, as bone tissue does not firmly attach to conventional PEEK cages, these cages require bone to grow around the cage and to form a complete bone bridge between the vertebrae [8,9]. When increased stabilization of the interbody segment can indeed be attained before achieving full consolidation of fusion in case of trussed titanium cages, the time window that a segment is vulnerable to instability related complications might be shortened. Clinical trials involving trussed titanium cages should assess whether these local effects indeed develop, and result in lower cage and fusion related complication rates.

The human in silico and ovine in vivo studies addressed both a different potential benefit of the trussed titanium cages. The patient-specific computer models (Chapter 4) demonstrated the presence of a strain range on the implant surface which might provide mechanobiological cues to the adjacent cells. Since bone growth and remodeling was not simulated in these models, it merely presented the biomechanical situation directly after spinal fusion surgery. The actual in vivo relevance of these strains is thus still to be investigated in a clinical setting. The ovine in vivo results (Chapter 5) demonstrated a different development of bony fusion in trussed titanium cages compared to conventional PEEK cages, which is thought to be advantageous from a biomechanical perspective. Although the implanted cage in the ovine study was smaller than the one used in the FE models and the exact forces in the ovine spine differ from those found in the human spine [17], relevant surface strains would presumably have been present at the trussed titanium cages in the ovine model as well. However, it is difficult to conclude anything about the in vivo effect of these strains as the experimental group consisted solely of healthy sheep. In general, healthy sheep are known to develop a full fusion relatively rapidly compared to humans $[18,19]$. Independent on cage type and mechanobiological cues, the surgery provoked an inflammatory response resulting in a metabolically active environment which is in a state of healing. The mechanobiological cues, if present, are suggested to be of less importance in this initial healing phase in healthy subjects. For this reason, it would be interesting to test these trussed titanium cages in segments for which an impaired healing might be expected. Additionally, it would be interesting to analyze the long-term effect of these trussed titanium cages in the bone remodeling phase after bony union has taken place. 
Moreover, to analyze the exact effect of the surface strains in vivo, similar cage designs with various strut thicknesses should be compared with each other instead of a trussed titanium cage with a conventional PEEK cage. Patient-specific geometries consisting of the trussed titanium structure have been designed and manufactured to treat several bone defects before $[20,21]$. The application of the 3D printed trussed titanium structures thus is not limited to spinal cages only.

In the search for a stand-alone substitute for autologous ICBG, Chapter 6 demonstrated the efficacy and safety of the peptide enhanced bone graft substitute P-15L (brand name iFACTOR+Matrix) for LIF in an ovine model. As P-15L rendered similar fusion results as autologous ICBG, introduction of $\mathrm{P}-15 \mathrm{~L}$ into the clinic as a stand-alone alternative could probably obviate the need for harvesting iliac crest bone and reduce the risk of donor-site morbidity. Since P-15L is produced synthetically, donor-dependent quality and product availability are of no concern. Moreover, P-15L expedited bone formation and remodeling in the ovine LIF model compared to autologous ICBG. Accelerated bone formation after LIF surgery is believed to be advantageous. The sooner the fusion is attained, the shorter the time window that hardware complications such as instrument subsidence and failure may arise. Intuitively, postoperative recovery periods and return-to-work time might also be shortened by reducing the time to fusion. This hypothesis should be further validated in clinical studies.

Recently, the predecessor of P-15L (i-FACTOR) was shown to attain similar fusion rates as autologous bone graft with superior overall clinical outcomes in anterior cervical discectomy and fusion [22]. It was concluded that the product was highly cost-effective for this application. Further clinical trials are warranted to test the efficacy and cost-effectiveness of the new product P-15L for LIF surgeries. Although each specific graft application may require tailored modifications to obtain the optimal product, the potency of these peptide enhanced substitutes is obviously not limited to the spine only.

The efficacy of the biomechanically tailored interbody cage and biomimetic graft product in this thesis were mainly compared with the current standard of care for LIF surgery, i.e. PEEK cages impacted with autologous ICBG. This comparison revealed the potential enhancements that can be realized by the introduction of these new devices. However, the true clinical efficacy and urgency of the products remains to be explored. We suggest that the actual demand for these new products highly depends on the patient profile, in which the healing capacity of the patient is the determinant. Imagine a scale bar that describes the capacity to heal (Figure 1). At the right extreme we have a system with (almost) infinite healing capacity characterized by an axolotl, which are famous for their ability to heal and regenerate different organs. In this special case of extreme high healing capacity, it hardly matters what kind of devices would be used, it will heal anyways. Moving to the left on the scale bar, reaching lower healing capacities, we will find a first subset of patients eligible for LIF surgery (Figure 1-I). This group represents vital patients without any significant 
comorbidities, who generally obtain a high fusion rate with the standard of care devices. Because essential metabolic and biological processes will be naturally present at the fusion site, standard of care devices will result in high fusion rates even if the created biomechanical environment or implemented material type is suboptimal. Moving further to the left on the scale bar, the healing capacity further decreases and there would exist a patient group in whom essential metabolic and biological processes are present at the fusion site, albeit at a slightly impaired level (Figure 1-II). For this group, standard of care solutions might render inadequate fusion rates. As long as the local biology is still of sufficient intensity, biomechanically tailored interbody cages might improve the current fusion rates for this group by providing a biomechanically sound environment at the fusion site. The biological processes that are present will then follow the cues as delivered by the local biomechanics and result in decent fusion rates in the end. Moving even further to the left on the healing capacity scale bar, there is the patient group in which also local metabolic and biological processes are significantly compromised (Figure 1-III). It is hypothesized that, even with biomechanically tailored interbody cages, the achieved fusion rates might be too low in this group. Even though the tailored cages can provide an excellent biomechanical environment, there would be no decent fusion because of the absence of proper biological processes at the fusion site. In this patient group, there is an additional need to boost the local biology. This might be accomplished by administration of the biomimetic graft product as introduced in this thesis or with other growth factors or proteins that stimulate the formation of bone. At the left extreme of the scale bar, we have something without any healing capacity like cadaver tissue. No matter how optimized the local biomechanics at the fusion site are, and no matter what kind of promoter of bone formation has been administered, a fusion will never be achieved. The proposed scale bar is of course not linear and the main challenge for the future is to identify the exact phenotypes of the three patient groups highlighted in the concept.

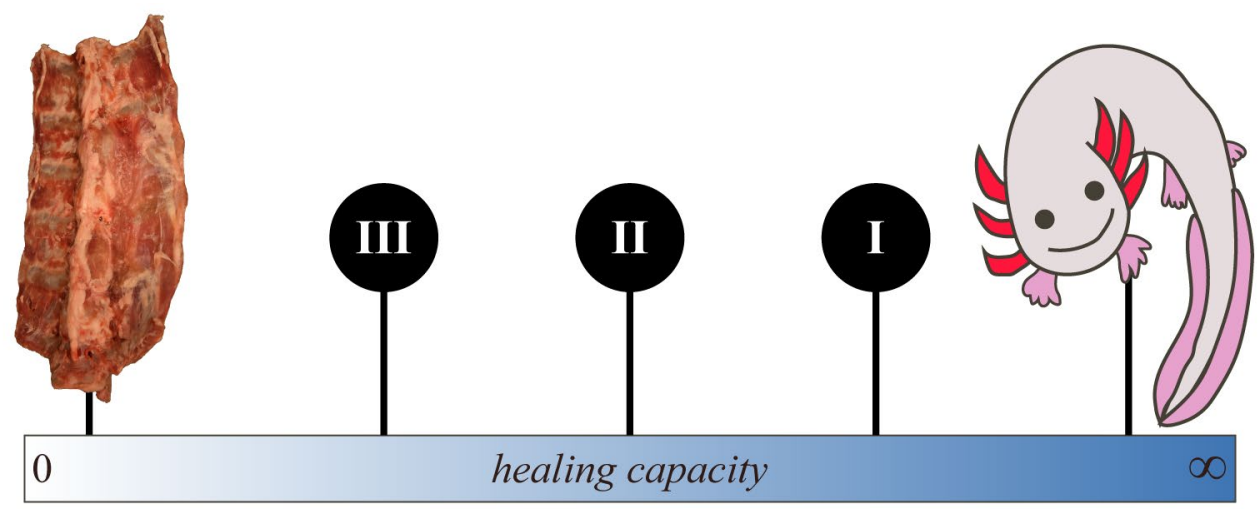

Figure 1. Scale bar describing healing capacity from zero to infinity with three proposed patient groups in between (III, II, and I). It is hypothesized that the three different patient groups require different devices to be applied in order to realize high fusion rates within these groups. 


\section{FUTURE CONSIDERATIONS}

At present, the development and use of patient-specific models is quite laborious, costs a significant amount of money, and requires expertise in image processing software as well as FE modelling software [16]. It is therefore not straightforward nor cost-effective yet, to determine patient-specific implant designs and predict performance indicators based on preoperative image and patient data. With the increase in clinical data and the emergence of machine learning techniques, it may however be well-possible that the development of patient-specific frameworks will be progressively automized [23]. Ultimately, this might overcome the current hurdles associated with preoperative patient-specific planning, modelling, and designing, and consequently enable the implementation of tailored implants in standard clinical care.

In addition to the development of new interbody cages and synthetic bone graft substitutes, innovative technologies are also continuously explored in order to minimize the impact of the surgical procedure itself. Several minimally invasive surgery (MIS) techniques to achieve LIF exist (e.g. posterior or transforaminal approaches), which have gained popularity over the last years [24]. Although there is a significant learning curve associated with mastering MIS techniques, it minimizes the damage to the surrounding tissue, reduces the amount of blood loss, and might shorten the length of hospitalization following LIF [25]. With the development of new interbody cages, it thus is recommended to also keep in mind how the cage may be manipulated during MIS.

The current thesis focused on lumbar spinal fusion surgery. However, it is also worthwhile to emphasize that this surgical intervention preferably is averted if possible. Although spinal fusion is generally effective when previous conservative treatment has failed, there is always some risk associated with the surgical intervention and fusion will inherently alter the spinal motion profile. Therefore, the use of regenerative medicine techniques within the spine (e.g. for the intervertebral disc) should also be continuously further explored and investigated [26]. Non-invasive techniques that stimulate regeneration, or at least inhibit degeneration of the tissue, are of major interest as these techniques may postpone the need for invasive surgical interventions like spinal fusion surgery.

\section{CONCLUSION}

This thesis presents new insights into the importance of the progression of fusion early after spinal interbody fusion surgery. Whereas two years postoperatively the fusion rate is relatively similar for different devices and graft materials, there is a large variation in fusion rates early after surgery at three and six months postoperatively. Introduction of innovative technologies such as biomechanically tailored interbody cages and biomimetic graft products may outclass current standard devices, thereby improving the early spinal fusion rates. Whether the use of these new technologies will indeed result in higher early fusion rates with improved clinical results and lower complications, warrants further dedicated clinical trials. 


\section{REFERENCES}

1. Shepard MF, Davies MR, Abayan A, Kabo JM, Wang JC. Effects of Polyaxial Pedicle Screws on Lumbar Construct Rigidity. Clinical Spine Surgery. 2002;15(3):233-6.

2. Fogel GR, Reitman CA, Liu W, Esses SI. Physical Characteristics of Polyaxial-Headed Pedicle Screws and Biomechanical Comparison of Load With Their Failure. Spine. 2003;28(5):470-3.

3. Abbushi A, Čabraja M, Thomale U-W, Woiciechowsky C, Kroppenstedt SN. The influence of cage positioning and cage type on cage migration and fusion rates in patients with monosegmental posterior lumbar interbody fusion and posterior fixation. European Spine Journal. 2009;18(11):1621.

4. Mobbs RJ, Phan K, Malham G, Seex K, Rao PJ. Lumbar interbody fusion: techniques, indications and comparison of interbody fusion options including PLIF, TLIF, MI-TLIF, OLIF/ATP, LLIF and ALIF. Journal of Spine Surgery. 2015;1(1):2-18.

5. Meng B, Bunch J, Burton D, Wang J. Lumbar interbody fusion: recent advances in surgical techniques and bone healing strategies. European Spine Journal. 2021;30(1):2233.

6. Park Y, Ha JW, Lee YT, Sung NY. The effect of a radiographic solid fusion on clinical outcomes after minimally invasive transforaminal lumbar interbody fusion. The spine journal : official journal of the North American Spine Society. 2011;11(3):205-12.

7. Brantigan JW, Steffee AD. A carbon fiber implant to aid interbody lumbar fusion. Twoyear clinical results in the first 26 patients. Spine. 1993;18(14):2106-7.

8. McGilvray KC, Easley J, Seim HB, Regan D, Berven SH, Hsu WK, . . , Puttlitz CM. Bony ingrowth potential of 3D-printed porous titanium alloy: a direct comparison of interbody cage materials in an in vivo ovine lumbar fusion model. The spine journal : official journal of the North American Spine Society. 2018;18(7):1250-60.

9. Arts M, Torensma B, Wolfs J. Porous titanium cervical interbody fusion device in the treatment of degenerative cervical radiculopathy; 1-year results of a prospective controlled trial. The Spine Journal. 2020;20(7):1065-72.

10. Goldstein C, Drew B. When is a spine fused? Injury. 2011;42(3):306-13.

11. Fischer DR, Zweifel K, Treyer V, Hesselmann R, Johayem A, Stumpe KD, . ., Strobel $\mathrm{K}$. Assessment of successful incorporation of cages after cervical or lumbar intercorporal fusion with [(18)F]fluoride positron-emission tomography/computed tomography. European spine journal : official publication of the European Spine Society, the European Spinal Deformity Society, and the European Section of the Cervical Spine Research Society. 2011;20(4):640-8.

12. Peters M, Willems $\mathrm{P}$, Weijers R, Wierts R, Jutten L, Urbach C, . . . Brans B. Pseudarthrosis after lumbar spinal fusion: the role of (18)F-fluoride PET/CT. European Journal of Nuclear Medicine and Molecular Imaging. 2015;42(12):1891-8.

13. Vaidya R, Sethi A, Bartol S, Jacobson M, Coe C, Craig JG. Complications in the Use of rhBMP-2 in PEEK Cages for Interbody Spinal Fusions. Clinical Spine Surgery. 2008;21(8):557-62.

14. Sethi A, Craig J, Bartol S, Chen W, Jacobson M, Coe C, Vaidya R. Radiographic and $\mathrm{CT}$ evaluation of recombinant human bone morphogenetic protein-2-assisted spinal interbody fusion. AJR American journal of roentgenology. 2011;197(1):W128-33.

15. Smit TH, Muller R, van Dijk M, Wuisman PI. Changes in bone architecture during spinal fusion: three years follow-up and the role of cage stiffness. Spine. 2003;28(16):1802-8; discussion 9. 
16. Zhang M, Pu F, Xu L, Zhang L, Liang H, Li D, . . , Fan Y. Development of an integrated CAD-FEA system for patient-specific design of spinal cages. Computer methods in biomechanics and biomedical engineering. 2017;20(4):355-64.

17. Smit TH. The use of a quadruped as an in vivo model for the study of the spine biomechanical considerations. European spine journal : official publication of the European Spine Society, the European Spinal Deformity Society, and the European Section of the Cervical Spine Research Society. 2002;11(2):137-44.

18. Lindley EM, Barton C, Blount T, Burger EL, Cain CMJ, Seim HB, . . , Patel VV. An analysis of spine fusion outcomes in sheep pre-clinical models. European Spine Journal. 2017;26(1):228-39.

19. Schiffman M, Brau SA, Henderson R, Gimmestad G. Bilateral implantation of lowprofile interbody fusion cages: subsidence, lordosis, and fusion analysis. The spine journal : official journal of the North American Spine Society. 2003;3(5):377-87.

20. Hamid KS, Parekh SG, Adams SB. Salvage of Severe Foot and Ankle Trauma With a 3D Printed Scaffold. Foot \& ankle international. 2016;37(4):433-9.

21. Tetsworth K, Block S, Glatt V. Putting 3D modelling and 3D printing into practice: virtual surgery and preoperative planning to reconstruct complex post-traumatic skeletal deformities and defects. SICOT-J. 2017;3:16.

22. Thaci B, Yee R, Kim K, Vokshoor A, Johnson JP, Ament J. Cost-Effectiveness of Peptide Enhanced Bone Graft i-Factor versus Use of Local Autologous Bone in Anterior Cervical Discectomy and Fusion Surgery. ClinicoEconomics and outcomes research : CEOR. 2021;13:681-91.

23. Memon AR, Li J, Egger J, Chen X. A review on patient-specific facial and cranial implant design using Artificial Intelligence (AI) techniques. Expert review of medical devices. 2021;18(10):985-94.

24. Joseph JR, Smith BW, La Marca F, Park P. Comparison of complication rates of minimally invasive transforaminal lumbar interbody fusion and lateral lumbar interbody fusion: a systematic review of the literature. Neurosurgical focus. 2015;39(4):E4.

25. Lee JC, Jang H-D, Shin B-J. Learning Curve and Clinical Outcomes of Minimally Invasive Transforaminal Lumbar Interbody Fusion: Our Experience in 86 Consecutive Cases. Spine. 2012;37(18):1548-57.

26. Basso M, Cavagnaro L, Zanirato A, Divano S, Formica C, Formica M, Felli L. What is the clinical evidence on regenerative medicine in intervertebral disc degeneration? Musculoskeletal surgery. 2017;101(2):93-104. 




\section{Societal impact}

Spine related disorders are commonly observed clinical problems. As the lower (lumbar) region of the spine carries more body weight than higher regions, disorders are most abundant in the lumbar spine. These disorders can ultimately result in low back pain. With a lifetime prevalence of up to $80 \%$, low back pain is the primary cause of years lived with disability. Low back pain is the main cause for work absenteeism or disablement, which makes it not only a healthcare but also a leading global economic and social problem.

Initially, low back pain patients will be treated with conservative interventions like physiotherapy, bracing, spinal injections, and pain medication. When the patient is nonresponsive to these nonsurgical interventions, spinal fusion surgery can be used as operative treatment for a wide range of spinal disorders responsible for low back pain. Over the years 2004-2015, the volume of elective lumbar spinal fusion increased 62.3\% in the United States and overall hospital costs exceeded 10 billion United States dollars in 2015.

With spinal fusion surgery the intervertebral disc between the vertebrae is often removed and replaced by an implant (also called a cage). In addition, the vertebrae of the affected segment are fixated using metal screw and rod instrumentation. The instrumentation and implant together stabilize the spinal segment, reduce compression of surrounding neural tissue, and restore the initial height of the spinal segment thereby alleviating pain and preventing motion. As time progresses, it is essential that the operated vertebrae fuse together by bony union via or around the cage in order to achieve long-term clinical success. This is because delayed fusions and non-unions can result in adverse effects that lead to inferior clinical outcome and the need for additional revision surgery, which is challenging, economically costly, and inherently comes with additional risks for the patient.

This thesis first provided an overview of current existing literature on fusion surgery and confirmed that $10 \%$ of the patients do not achieve bony fusion of the vertebrae. Early after surgery, there is a large variation in fusion rates across patient groups. Moreover, low early fusion rates were associated with higher complication rates. The importance of enhancing early fusion rates was thus highlighted in this literature review.

Then, it was shown that 3D printed, spinal cages affect the way how bony union progresses after spinal fusion surgery. With these new porous cages, stability of the operated segment can be realized sooner than with conventional cages. This is because bone can grow and integrate into the cage at the interface, and thus stabilize the vertebrae via the cage without the need to form a complete bridge from one vertebra, through the cage, to the other.

In current clinical practice, cages are packed with bone graft material to stimulate bone formation. This bone is harvested from the patient itself via an additional incision at the hip to reach the iliac crest. This thesis investigated whether the bone graft can be replaced with a synthetic material. It was shown that the synthetic material was safe and effective, and that it seemed to stimulate bone formation more extensively than patient donor bone does. When 
using this synthetic material in the clinic instead of bone of the patient itself, there is no need for a second incision and a painful harvesting procedure. This will eliminate donor-site morbidities. In contrary to the amount of patient bone that can be harvested, the amount of synthetic material will not be limited. Patients that will undergo fusion surgery will thus benefit from this product as the need for bone harvesting can be eliminated.

Both the porous, 3D printed, spinal cages and the synthetic bone graft substitute are commercially available and can enhance the fusion results early after surgery. The new cages provide increased stability to the operated segment by the way the bone integrates with the cage, and the synthetic bone graft substitute stimulates bone growth within the cage. Firstly, the use of these new products might reduce the number of non-unions amongst patients undergoing fusion surgery. Secondly, it might reduce the time from surgery to full union and stabilization in patients for which conventional techniques would already work. Reducing the number of non-unions will lead to less revision surgeries, whereas reducing the time that an operated segment is not fused yet results in less non-union related complications. Shortening the time to fusion can also potentially reduce the return-to-work time and allow a patient to resume social activities on a shorter notice. This will lead to better patient satisfaction, lower costs, and less societal burden.

Apart from evaluating specific new products, this thesis showcased how several research models (in vitro, in silico, and in vivo) are valuable in providing answers that cannot be determined directly via clinical research. These models help in product development, in decision making, and in answering fundamental questions about the progression of bone growth and how this process is affected by biomechanical and biological factors. Patientspecific finite element models of relevant subjects have the power to estimate internal forces and displacements that cannot be measured clinically. First, this information is of use to encourage or discourage certain procedures during surgery. For example, we showed that high forces on metal fusion instrumentation should be avoided. Second, these models can derive patient-specific performance indicators of implemented cages and facilitate development of tailored cages for each patient.

The preclinical animal models were not only used to assess the performance of the new cage and the bone graft substitute, but also to monitor the bone growth after surgery with clinical imaging modalities. The preclinical models enable multiple follow-up time points as well as a combination of clinical imaging and planned post-mortem microscopical analysis. This helped us to provide answers on fundamental questions about how bone growth occurs after fusion surgery and to predict the suitability of imaging modalities in the human clinic. Specifically, this research contributed to the interpretation of positron emission tomography/computed tomography (PET/CT) scans early after fusion surgery. As we revealed the changes in PET/CT scans during uncompromised early fusion, we are one step closer to be able to recognize impaired bone healing early after fusion surgery by using clinical PET/CT in patients. 




\section{List of publications}

\section{PUBLICATIONS IN SCIENTIFIC JOURNALS}

- Loenen ACY, Noailly J, Ito K, Willems PC, Arts JJ, van Rietbergen B. Patientspecific variations in local strain patterns on the surface of a trussed titanium interbody cage.

Frontiers in Bioengineering and Biotechnology 2022; 9(750246)

https://doi.org/10.3389/fbioe.2021.750246

- Loenen ACY, Peters MJM, Wierts R, Bevers RTJ, van Rhijn LW, Arts JJ, Willems PC. Local bone metabolism during the consolidation process of spinal interbody fusion.

Journal of Bone and Mineral Metabolism; Epub ahead of print

https://doi.org/10.1007/s00774-021-01281-8

- Loenen ACY, Peters MJM, Bevers RTJ, Schaffrath C, van Haver E, Cuijpers VMJ, Rademakers T, van Rietbergen B, Willems PC, Arts JJ. Early bone ingrowth and segmental stability of a trussed titanium cage versus a polyether ether ketone cage in an ovine lumbar interbody fusion model.

The Spine Journal 2022; 22(1):174-182

https://doi.org/10.1016/j.spinee.2021.07.011

- Loenen ACY, Connor J, Johnson S, Davis K, Hannigan N, Barnes T, Arts JJ, van Rietbergen B. Peptide enhanced bone graft substitute presents improved short-term increase in bone volume and construct stiffness compared to iliac crest autologous bone in an ovine lumbar interbody fusion model.

Global Spine Journal; Epub ahead of print

https://doi.org/10.1177/2192568220979839

- Loenen ACY, Noriega DC, Ruiz Wills C, Noailly J, Nunley PD, Kirchner R, Ito K, van Rietbergen B. Misaligned spinal rods can induce high internal forces consistent with those observed to cause screw pullout and disc degeneration.

The Spine Journal 2021; 21(3):528-537

https://doi.org/10.1016/j.spinee.2020.09.010 
- Caiti G, Dobbe JGG, Loenen ACY, Beerens M, Strackee SD, Strijkers GJ, Streekstra GJ. Implementation of a semiautomatic method to design patient-specific instruments for corrective osteotomy of the radius.

International Journal of Computer Assisted Radiology and Surgery 2019; 14(5):829-840.

\section{https://doi.org/10.1007/s11548-018-1896-2}

- Moerman KM, van Vijven M, Solis LR, van Haaften EE, Loenen ACY, Mushahwar VK, Oomens CWJ. On the importance of 3D, geometrically accurate, and subjectspecific finite element analysis for evaluation of in-vivo soft tissue loads.

Computer Methods in Biomechanics and Biomedical Engineering 2017; 20(5):483491

https://doi.org/10.1080/10255842.2016.1250259

\section{CONFERENCE CONTRIBUTIONS}

- Loenen ACY, Schaffrath C, Arts JJ, van Rietbergen B. Patient specific variations in local strain patterns on the surface of a trussed titanium interbody cage. Online oral presentation; Using motion analysis and musculoskeletal modeling of the spine to better understand spinal disorders and evaluate treatment effects, Virtual Symposium (12/05/2021)

- Loenen ACY, Noriega DC, Ruiz Wills C, Noailly J, Nunley PD, Kirchner R, Ito K, van Rietbergen B. Misaligned spinal rods can induce high internal forces consistent with those observed to cause screw pullout and disc degeneration.

Online poster presentation; German Spine Society (DWG), Virtual Annual Meeting (09/12/2020)

- Noriega DC, Loenen ACY, Nunley PD, Noailly J, Ito K, van Rietbergen B. Analysis of the segmental and adjacent level impacts of forcing the connection of misaligned pedicle screws and rods and subsequent unintended forces applied to the construct and spine: a finite element analysis.

Online poster presentation; North American Spine Society (NASS), Virtual Annual Meeting (06/10/2020) 
- Loenen ACY, Arts JJ, Boelen EJH. Mechanical properties and biocompatibility of 3D printed Ti-6Al-4V.

Poster presentation; Orthopedic Research Society (ORS), Annual Meeting, New Orleans, USA (10/03/2018)

Loenen ACY, Arts JJ, Boelen EJH. Mechanical properties and biocompatibility of 3D printed Ti-6Al-4V.

Oral presentation; European Orthopedic Research Society (EORS), Annual Meeting, Munich, Germany (13/09/2017) 



\section{Dankwoord}

Wat een doorzetter ben jij, je hebt het volgehouden met het lezen van mijn boekje tot aan de laatste pagina's, wat goed! ..... We weten natuurlijk allebei dat dit niet waar is en dit zo ongeveer de eerste sectie van mijn boekje is waar je naar toe gebladerd hebt. Zonde, ook alle voorgaande bladzijdes heb ik mijn ziel en zaligheid ingestopt terwijl deze laatste pagina's getypt zijn tijdens een aantal retourtjes Eindhoven-Maastricht. Dit betekent echter niet dat deze woorden onbelangrijk zijn. Integendeel, zonder de samenwerkingen en steun, zowel binnen als buiten mijn onderzoeksprojecten, zou dit boekje er nooit geweest zijn.

\section{Vandaar een grote dankjewel aan eenieder die zich aangesproken voelt!}

Leden van de beoordelingscommissie en tevens opponenten, dank voor de kritische evaluatie van mijn proefschrift en de bereidheid om hierover te komen discussiëren op mijn promotieceremonie.

Mijn promotieteam wil ik graag bedanken voor de goede begeleiding en vorming van mijn promotietraject. Beste Lodewijk, dank voor de geboden flexibiliteit en vrijheid tijdens mijn aanstelling(en) bij de afdeling orthopedie. Fijn dat we regelmatig de grote lijnen van het project samen hebben kunnen bespreken om zo de relevantie van deelprojecten duidelijk te krijgen en de haalbaarheid van de planning te waarborgen.

Beste Bert en Chris, jullie moet ik wel samen in één adem noemen in mijn woord van dank. Na, of eigenlijk nog tijdens, mijn afstudeerproject wat ik onder begeleiding van jullie uitvoerde, werd mij deze $\mathrm{PhD}$ positie aangeboden. Al moest ik er destijds nog even over twijfelen, ik heb er zeker geen spijt van gehad. Een van de redenen om de positie te accepteren was de begeleiding vanuit jullie als duo. Chris, zonder jou was het prosperos project er niet eens geweest en mijn $\mathrm{PhD}$ positie dus ook niet. Bedank voor het bieden van deze kans en de hoeveelheid aan samenwerkingspartners die je aan mij geïntroduceerd hebt. Dit maakte mijn $\mathrm{PhD}$ allesbehalve eentonig, iets wat ik zeer waardeer. Bert, voor de (technisch) inhoudelijke en academische discussie had ik in jou altijd een goede sparringpartner. Ik waardeer je pragmatische aanpak en de directheid en duidelijkheid in de communicatie, dit heeft onze academische stukken ook zeker tot een hoger level weten te brengen. Helaas hebben we met zijn drieën niet heel veel congressen mee kunnen pakken maar ook buiten de academie om hadden we een fijne omgangsvorm. Hoog tijd voor weer eens een biertje.

Keita and Paul, although you were not officially in my promotion team, for me it felt like you did. Keita, thanks for accepting me as 'guest' researcher in Eindhoven. By having regular meetings and being part of the group outings, I didn't feel like a guest at all. Paul, buiten de praktische expertise die jij geleverd hebt als uitvoerend chirurg van de dierstudies, heb ik ook heel veel gehad aan je klinische blik op mijn onderzoek en je snelle feedback. De operaties met uitzicht op alpaca's zal ik nooit vergeten. 
Also, a big thanks to all co-authors who were involved in my academic publications. A special word of thanks to Jérôme and Carlos for hosting me a couple of days in Barcelona and providing me access to and giving me tutorials on the patient specific computer models. Without you guys, the computer modeling chapters wouldn't be there. Marloes, ontzettend bedankt voor jouw hulp en expertise in de schapenstudie. Zonder jouw hulp en het voorbereidende werk wat jij al allemaal klaar had liggen was dit nooit gelukt. Ook Raymond harstikke bedankt voor alle hulp met de praktische uitvoering en het gesjouw tijdens de studie.

Over praktische uitvoering gesproken, ik wil graag al het personeel van Medanex Clinic bedanken en het in bijzonder Els voor het samen plannen en coördineren van het uitdagende pakket waar we in zaten. Het was zeer fijn samenwerken en wat een mooie faciliteit hebben jullie daar neergezet. Natuurlijk ook CPV groot hartstikke bedankt. Richard, Joyce, Saskia voor al het meedenken met de regelgevingen, Huub voor de goede zorgen, en Rachelle en Petra voor de interessante maar ook gezellige scanavonden. Ook een thanks naar alle helpende laboranten van de afdeling nucleaire geneeskunde en in het bijzonder Eefje en Amy zonder wie deze scanavonden ook onmogelijk zouden zijn. Natuurlijk ook een woord van dank aan Roel voor het helpen met het verkrijgen en analyseren van de bijbehorende data. Natasja en Vincent vanuit Radboud UMC maar natuurlijk ook de technicians van ons eigen lab, thanks voor de hulp bij de histologie. Remco, thanks voor de expertise en hulp als chef spine tester en het was mooi om als paranimf bij jou alvast af te kijken hoe het moet.

I also deeply enjoyed the collaborations with different industrial partners during my $\mathrm{PhD}$ project. It was nice to experience the role of translational research in medical product development and to directly work with products that are in use or going to be used in the clinic in the future. Kleijnen Systematic Review company, Jos, Jeremy, Kevin, thanks for the collaboration and expertise on the review project. Neo Medical, Ingrid, thanks for the fruitful collaboration with the computer models. Cerapedics, Scott, thanks for the collaboration and the interesting discussions we had on spinal fusions. 4WEB, Claus, thanks for planning and helping with the sheep studies and of course as well for having me at 4WEB for several months. It was interesting to get some more insights into working in the medical technology industry.

Natuurlijk ook een groot woord van dank aan alle directe en indirecte collegae waarmee ik samengewerkt heb, gediscussieerd heb, of simpelweg een keer in de windelgangen gesproken heb. Ik heb me overal welkom gevoeld en altijd het idee gehad dat alles verteld en besproken kon worden, dat heeft zeker bijgedragen aan een fijne en open werksfeer.

Stafleden en secretariaat van de afdeling orthopedie in het ziekenhuis en zeker ook alle mensen van het lab orthopedie in Maastricht. In het bijzonder natuurlijk mijn directe kamergenoten Alzbeta, Basmans, Deadshortie, Ellen, Jane, Mirella, Piet, Ro, Rrralph, Smiles, Tom, Ufuk. Hier was altijd wel wat te beleven of te bespreken. Daarnaast zullen ook 
zeker de Oktoberfesten, zowel in München als 'simpelweg' in Maastricht, en bezochte congressen me altijd bij blijven.

Naast Maastricht had ik ook nog het genot om in Eindhoven een tweede (of juist eerste?) thuis te hebben. Ook al was ik afwisselend een tijdelijke en/of gast onderzoeker, ik heb mij in de OPB groep op de TU/e altijd thuis gevoeld en heb ook zeker genoten van alle gezellige uitjes en drankjes, bedankt daarvoor allemaal. Dan hebben we natuurlijk ook nog office 4.14 in Eindhoven waar een goede mix van mechanical/medical engineering, jong/oud, phd/postdoc, etc. hadden. Bedankt voor de fijne werkomgeving en verschillende uitstapjes. Speciale dank naar Floor als pionier van 4.14 en naar Alicia, Meike, Rienk voor het opvangen van deze wees en het zo nu en dan bewaken van mijn stekje.

Het leven van een onderzoeker gaat niet altijd over rozen maar gelukkig heb ik gedurende mijn studie en $\mathrm{PhD}$ traject leuke en fijne mensen privé om mij heen gehad die mijn geklaag aan wilde horen, die deden alsof ze mijn geklaag aan wilde horen, die hielpen met een goede reflectie, of, mijn lievelings, verstand op nul en even niet over academische zaken met mij konden praten.

Mannen van AV, mooi om te zien wat we allemaal opgebouwd hebben sinds 2010 en fijn jullie nog regelmatig te zien. Het was een genoegen samen gestudeerd en gewoond te hebben. Jeroen en Kees, hopelijk hebben jullie er ook van genoten om aan mijn zijde te mogen flaneren tijdens de ceremonie. Bedankt hier voor.

Lieve bestuursgenoten van UPN 13-14, het is alweer lang geleden dat we tussen onze studies een jaar met elkaar opgescheept zaten. Het was een zeer leuk en leerzaam jaar en de destijds opgedane ervaringen zijn ook zeker tijdens mijn PhD project nog van pas gekomen. Mooi dat we allemaal iets totaal anders zijn gaan doen maar nog steeds regelmatig leuke diners hebben samen.

Mannen van P1, fijn dat jullie mij de kans hebben kunnen bieden dat ik niet meteen cold-turkey moest gaan vanuit mijn studentenleven. Zowel binnen als buiten het veld heb ik genoeg afleiding kunnen vinden bij jullie. Laten we dat corona-kampioenschap nog een keer vieren.

Vrienden regio Holthees, met jullie praat ik eigenlijk over van alles, maar zelden over onderzoek. Al moet ik zeggen dat de schapenstudie bij de meesten toch wel goed blijft hangen in tegenstelling tot de computerstudie. Dank voor alle gezellige momenten waarop ik mijn hoofd even helemaal leeg kan maken.

Lieve pap en mam, bedankt voor alle onvoorwaardelijke steun en toestemming die jullie mij bij elke stap of keuze geven. Alles kan en alles mag en wanneer ik iets wil doen moet ik dat maar gewoon lekker doen. Het is altijd fijn en warm thuiskomen en ook wanneer ik thuiskom laten jullie me lekker gaan als ik weer eens aan tafel de laptop opensla en de oorkleppen opzet om aan dit boekje te werken. Nou, het is niet voor niks geweest. Heel fijn 
dat jullie me gewoon mijn eigen gang laten gaan en alles met een nuchtere, open, en hopelijk trotse blik, kunnen aanschouwen.

Beste broeder, Jelco, redelijk lang heb ik jouw voetsporen een soort van kunnen volgen. Keeper bij het voetballen, technisch profiel op de middelbare school, naar de TU/e, naar dezelfde vereniging, maar de studiekeuze en wat we hiermee wilde bereiken bleek wel degelijk te verschillen tussen ons. Mooi dat we alle voorgaande dingen samen hebben kunnen delen maar onszelf toch heel anders ontwikkeld hebben en op heel andere werkgebieden terecht zijn gekomen. Gelukkig kan ik altijd bij jou terecht voor verhalen en pro bono advies over allesbehalve de academie. Ece, really nice to have you in the family as well. Good to see that Jelco found someone who is as adventurous as he is, but please do not win all games during family evenings.

Ook een bedankje naar mijn schoonouders, Theo en Marijke. Laatst zeiden jullie nog "oh is hij met zijn dankwoord bezig, dan zet ons er ook maar in". Zeker horen jullie hier ook in thuis. Altijd fijn en erg gezellig om ergens samen een hapje en een drankje te doen en de vraag te krijgen of ik niet eens klaar zou moeten zijn met 'studeren'. Jullie gedrevenheid en ondernemerschap is inspirerend om te zien en hopelijk kunnen we snel en vaak weer op een normale manier een hapje en drankje doen.

Dan nog de belangrijkste woorden van waardering die overblijven, want hier ga ik thuis waarschijnlijk nog vaker mee geconfronteerd worden. In de positieve en trotse zin van het woord natuurlijk. Lieve Valerie, inmiddels zijn we alweer 50\% van ons leven bij elkaar en dat percentage gaat natuurlijk alleen nog maar toenemen over de jaren. Ik kan me dan ook geen leven meer voorstellen zonder jou. Al die tijd samen hebben we elkaar heel veel vrijheid gegeven, elkaar een beetje opgevoed, maar vooral elkaar gewaardeerd om wie we zijn. Ook tijdens mijn studie en $\mathrm{PhD}$ heb je me alle ruimte gegeven om ergens anders te gaan wonen, meerdere keren naar het buitenland te gaan, en lange avonden te spenderen in mijn corona kantoor. Bedankt voor alle liefde en steun die je mij gegeven hebt en ik kijk nu al uit naar september 2022. Ik hou van je! 
I would like to thank the following partners for their contribution and support to the production of this thesis.

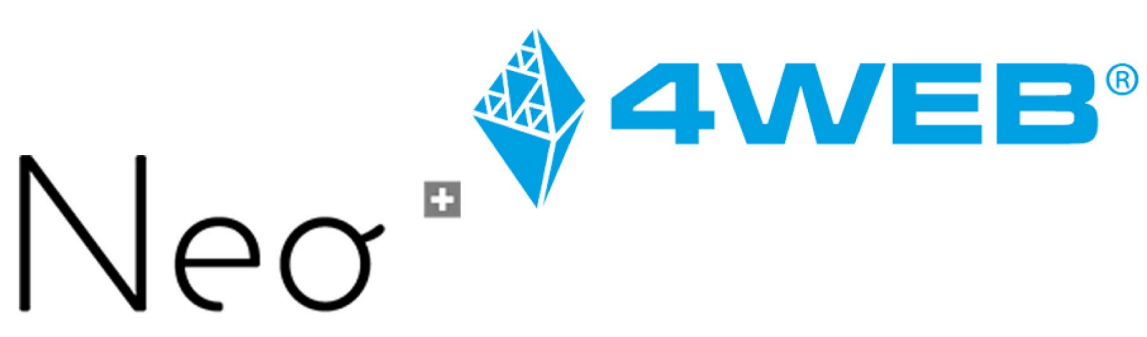

BEYOND THE EXPECTED
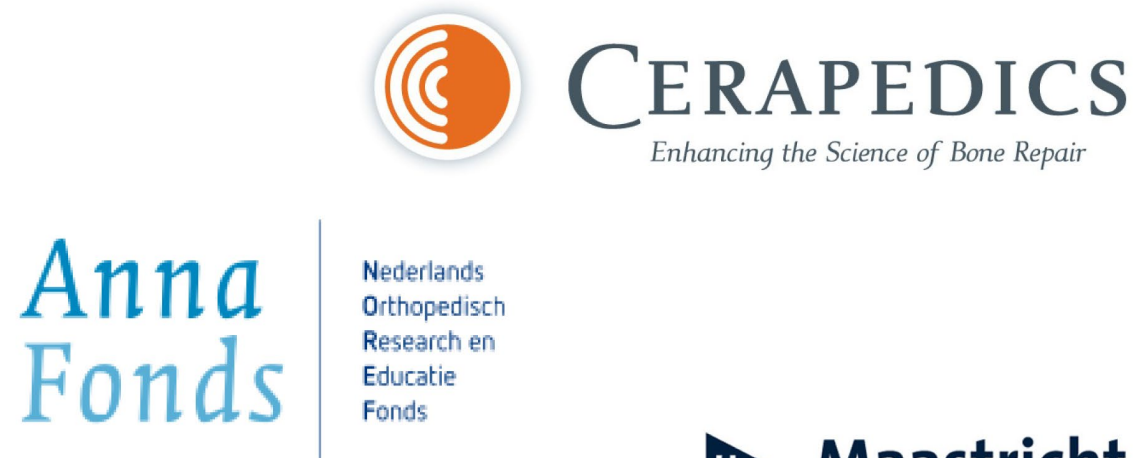

Maastricht
University

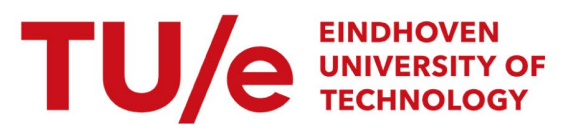

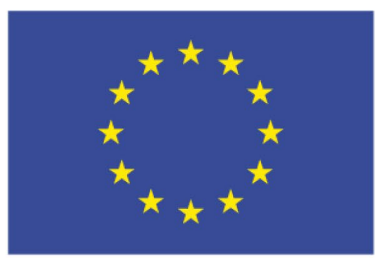

Interreg a

Vlaanderen-Nederland

Europees Fonds voor Regionale Ontwikkeling

$\ngtr$ prosperos 